Write Here, Right Now: An Interactive Introduction to Academic Writing and Research 



\title{
Write Here, Right Now: An Interactive Introduction to Academic Writing and Research
}

\author{
AARON TUCKER AND PAUL CHAFE
}

RYERSON UNIVERSITY

TORONTO 


\section{(ㄷ) (i)}

Write Here, Right Now: An Interactive Introduction to Academic Writing and Research by Ryerson University is licensed under a Creative Commons Attribution 4.0 International License, except where otherwise noted. 


\section{Contents}

Preface

$\underline{\text { Part I: Introduction }}$

Chapter r: Time is on Your Side

Chapter Overview

Introduction to Close Reading

Gathering Evidence

Reading Slowly

Example

Your Turn!

What Now?

Your Turn!

Thinking Ahead...

Chapter 2: Evidence

Chapter Overview

Drafting the Blueprint

Turning Your Lists Into Your Blueprint

Why Construct an Essay Blueprint?

Constructing Your Essay Blueprint

Constructing Your Two-Storey Opening, Part 1

Constructing Your Two-Storey Opening, Part 2

Your Turn! (Part 1)

Your Turn! (Part 2)

Watch This!

Thinking Ahead...

Chapter 3: The Full Three Storey Thesis

Chapter Overview

Revising Your Two-Storey Thesis

Self-Evaluation of Your Two-Storey Thesis 
Revising Towards A Second Draft of Your Two-Storey Thesis

Watch This!

Your Turn!

Adding the Third Storey

An Example Third Storey

Putting it all Together

Your Turn!

Returning to the text

The Full Three-Storey Thesis

Additional Practice

Thinking Ahead...

Chapter 4: From Thesis to Essay

Chapter Overview

Editing the Three-Storey Thesis

Self-Evaluation of Your Three-Storey Thesis

Watch This!

Your Turn!

Editing and Rewriting for Precise and Muscular Language

Your Turn!

The Three-Storey Thesis as a Roadmap

Introduction

First Storey

Second storey

Third Storey

100

Conclusion

101

Your Turn!

103

Watch This!

104

Thinking Ahead...

Chapter 5: Maintaining Focus and Purpose: The Body Paragraphs

Chapter Overview

109

Writing the Essay

110

Big Beefy Building Blocks: Filling Those Body Paragraphs

Keep Your Thesis Close

Body Paragraphs

Body Paragraphs 
$\begin{array}{lr}\text { Body Paragraphs } & 119\end{array}$

$\begin{array}{lr}\text { Body Paragraphs } & 120\end{array}$

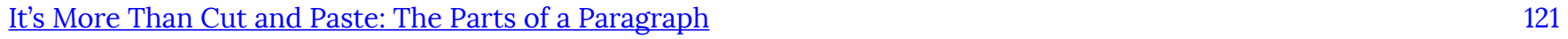

Claim, Evidence and Warrant $\quad 123$

$\begin{array}{lr}\text { Topic Sentences and Transitions } & 124\end{array}$

Incorporating Cited Passages into Your Own Writing $\quad 125$

$\begin{array}{lr}\text { The Author's Subject is Not Your Subject } & 126\end{array}$

$\begin{array}{lr}\text { Exit Strategy: Composing the Final Body Paragraphs } & 128\end{array}$

$\begin{array}{lr}\text { What Now? } & 131\end{array}$

Chapter 6: One Last Time Before You Go: The Conclusion and Final Review

$\begin{array}{lr}\text { Chapter Overview } & 135\end{array}$

You Cannot Live on Hamburger Alone: Moving Beyond the Five-Paragraph Essay Form 136

$\begin{array}{lr}\text { Top Bun } & 137\end{array}$

$\begin{array}{ll}\text { Meat Patties } & 138\end{array}$

$\begin{array}{lr}\text { Bottom Bun } & 139\end{array}$

$\begin{array}{lr}\text { Writing Your Conclusion } & 141\end{array}$

Three-Storey Thesis: Introduction $\quad 143$

$\begin{array}{lr}\text { Body Paragraphs } & 144\end{array}$

$\begin{array}{lr}\text { Your Turn! } & 146\end{array}$

$\begin{array}{lr}\text { What Now? } & 148\end{array}$

$\begin{array}{lr}\text { In Conclusion } & 149\end{array}$

$\begin{array}{lr}\text { Supporting Your Claim } & 151\end{array}$

$\begin{array}{lr}\text { Putting it All Together } & 152\end{array}$

$\begin{array}{lr}\text { What Now? } & 155\end{array}$

Chapter 7: Making Your Own Argument

$\begin{array}{lr}\text { Chapter Overview } & 159\end{array}$

$\begin{array}{lr}\text { Moving From a Close Reading to Making Your Own Argument } & 160\end{array}$

$\begin{array}{ll}\text { Try This! } & 161\end{array}$

$\begin{array}{lr}\text { Watch This! } & 162\end{array}$

Choosing and Analyzing Your Central Document 166

$\begin{array}{lr}\text { Your Turn! } & 168\end{array}$

Answers to Your Turn! 169

$\begin{array}{lr}\text { Analyzing a Central Document } & 170\end{array}$

$\begin{array}{lr}\text { Better Understanding the Medium of Your Central Document } & 171\end{array}$

Analyzing a Specific Central Document $r$

$\begin{array}{lr}\text { Watch This! } & 178\end{array}$ 
Thinking Ahead...

Chapter 8: Gathering Research and Establishing Evidence

Chapter Overview

Introduction to Research

How Information is Produced

Try This!

Types of Information

Scholarly Peer-Reviewed Sources

193

General "Popular" Sources

When to Use Popular Sources

Try This!

Evaluate What You Find With the "CRAAP Test"

Try This!

Where to Find Authoritative Research Documents

Search Strategies: Plan, Refine, and Modify

Boolean Operators

OR Operator

AND Operator

NOT Operator

Putting Together All of Your Search Concepts Using Boolean Operators AND, OR, NOT

Watch This!

Smart Searches

Understanding a Search Result

When Your Results are Limited or Inappropriate

Reviewing and Applying What You've Learned

Chapter 9: Towards the Well-Researched Paper

$\begin{array}{lr}\text { Chapter Overview } & 219\end{array}$

$\begin{array}{ll}\text { Editing Your Two-Storey Thesis } & 220\end{array}$

Complete the Essay Self-Evaluation of Your Two-Storey Thesis Below.

$\begin{array}{ll}\text { Adding a Third Storey } & 224\end{array}$

$\begin{array}{lr}\text { Watch This! } & 226\end{array}$

$\begin{array}{lr}\text { Try This! } & 228\end{array}$

The Three-Storey Thesis: The Importance of Outlining $\quad 229$ 
$\begin{array}{lr}\text { Introduction } & 230\end{array}$

$\begin{array}{lr}\text { Body } & 231\end{array}$

$\begin{array}{lr}\text { First Storey } & 232\end{array}$

Second Storey $\quad 233$

$\begin{array}{ll}\text { Third Storey } & 234\end{array}$

Conclusion 235

Full Outline $\quad 236$

$\begin{array}{lr}\text { Try This! } & 238\end{array}$

$\begin{array}{lr}\text { Watch This! } & 239\end{array}$

Research: First Steps

$\begin{array}{lr}\text { Research Types } & 241\end{array}$

Corroborate, Contrast, Contextualize $\quad 242$

Definitions 243

$\begin{array}{lr}\text { Data and Statistics } & 244\end{array}$

"Factual" Material 245

$\begin{array}{lr}\text { Analysis } & 246\end{array}$

$\begin{array}{lr}\text { Engaging With Research } & 247\end{array}$

$\begin{array}{lr}\text { The Scholarly Concept } & 248\end{array}$

Questions to Ask $\quad 249$

Application 250

Try This! $\quad 252$

Watch This! $\quad 253$

$\begin{array}{lr}\text { Looking Ahead.... } & 254\end{array}$

Chapter ro: Joining the Conversation: Primary Sources, Secondary Sources, and You

$\begin{array}{ll}\text { Chapter Overview } & 257\end{array}$

Standing on the Shoulders of Giants: Using Your Essay to Look Forward 258

Finding Our Scholarly Conversation Partners: Primary and Secondary Sources $\quad 260$

Watch This! 261

$\begin{array}{lr}\text { Scholarly Articles } & 266\end{array}$

$\begin{array}{lr}\text { Scholarly Articles } & 267\end{array}$

Scholarly Articles $\quad 269$

$\begin{array}{lr}\text { Watch This! } & 270\end{array}$

Joining the Scholarly Conversation: Using Your Primary and Secondary Evidence 272

Dominating the Conversation $\quad 273$

$\begin{array}{lr}\text { Passive Conduit } & 274\end{array}$

$\begin{array}{lr}\text { Purposeful Conversation } & 275\end{array}$

$\begin{array}{ll}\text { Watch This! } & 276\end{array}$ 
$\begin{array}{ll}\text { Your Turn! } & 277\end{array}$

Setting the Stage: Getting the Primary and Secondary Sources into Your Introduction 279

Looking Ahead...

Chapter II: Editing and Evolving the Thesis and Outline

$\begin{array}{lr}\text { Chapter Overview } & 285\end{array}$

$\begin{array}{lr}\text { Revisiting Body Paragraphs } & 286\end{array}$

$\begin{array}{ll}\text { Effectiveness of Your Sources } & 287\end{array}$

$\begin{array}{lr}\text { Article } & 289\end{array}$

$\begin{array}{lr}\text { Try This! } & 292\end{array}$

Starting a Conversation with Your Sources $\quad 293$

$\begin{array}{ll}\text { Watch This! } & 295\end{array}$

$\begin{array}{lr}\text { Try This! } & 296\end{array}$

Transitioning Between Ideas $\quad 297$

$\begin{array}{ll}\text { Watch This! } & 298\end{array}$

$\begin{array}{lr}\text { Try This! } & 299\end{array}$

$\begin{array}{lr}\text { Thinking ahead... } & 300\end{array}$

Chapter I2: What Have I Accomplished? Conclusion and Final Assessment

$\begin{array}{lr}\text { Chapter Overview } & 303\end{array}$

Revising Your Thesis and Body Paragraphs $\quad 304$

$\begin{array}{lr}\text { Potential Questions to Ask } & 305\end{array}$

$\begin{array}{lr}\text { Try This! } & 307\end{array}$

$\begin{array}{lr}\text { Watch This! } & 308\end{array}$

$\begin{array}{lr}\text { Concluding Your Argument } & 309\end{array}$

Try This! $\quad 311$

$\begin{array}{ll}\text { Watch This! } & 312\end{array}$

Revising and Editing for the Last Time $\quad 313$

$\begin{array}{lr}\text { Self-Evaluation } & 314\end{array}$

$\begin{array}{lr}\text { Try This! } & 317\end{array}$

$\begin{array}{ll}\text { The Last Edit } & 318\end{array}$

$\begin{array}{ll}\text { YOU'RE DONE! } & 319\end{array}$

Chapter I3: Works Cited

$\begin{array}{ll}\text { Chapter Overview } & 323\end{array}$

$\begin{array}{ll}\text { Introduction to Citations } & 324\end{array}$

$\begin{array}{lr}\text { Scholarship is a Conversation } & 325\end{array}$ 
$\begin{array}{lr}\text { Watch This! } & 327\end{array}$

$\begin{array}{ll}\text { What is Bibliographic Information? } & 328\end{array}$

$\begin{array}{ll}\text { Try This! } & 331\end{array}$

What is a Bibliography? $\quad 332$

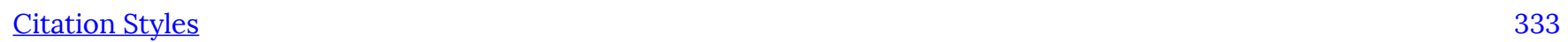

Citation Tip! $\quad 334$

$\begin{array}{ll}\text { MLA Citation Style } & 337\end{array}$

How to Cite and Reference with MLA $\quad 338$

MLA Citation for the Same Article $\quad 340$

Document Your Research As You Go! (or, How Not to Cry When Creating a Bibliography) 341

Summary $\quad 342$

Try This! $\quad 344$

$\begin{array}{ll}\text { Answers to Try This! } & 345\end{array}$

$\begin{array}{lr}\text { Try This! } & 346\end{array}$

$\begin{array}{lr}\text { Recommended Reading } & 348\end{array}$

$\underline{\text { For the Instructor }}$

Chapter 1: Time is on Your Side $\quad 351$

Chapter 2: Evidence $\quad 353$

Chapter 3: The Full Three-Storey Thesis $\quad 354$

Chapter 4: Getting From Your Thesis To Your Essay $\quad 356$

Chapter 5: Maintaining Focus and Purpose: The Body Paragraphs

Chapter 6: One Last Time Before You Go: The Conclusion and Final Review $\quad 359$

$\begin{array}{ll}\text { Chapter 7: Making Your Own Argument } & 360\end{array}$

Chapter 8: Gathering Research and Establishing Evidence 362

Chapter 9: Towards the Well-Researched Paper $\quad 363$

Chapter 10: Joining the Conversation: Primary Sources, Secondary Sources, and You 364

Chapter 11: Editing and Evolving the Thesis and Outline 366

Chapter 12: What Have I Accomplished? Conclusion and Final Assessment $\quad 367$

$\begin{array}{ll}\text { Chapter 13: Works Cited } & 368\end{array}$

Appendix: CTRL-F List $\quad 369$ 



\section{Preface}

This open access textbook was developed as a first-year university and college student writing textbook that is intended to facilitate the flipped/blended classroom. The project was supported and funded by eCampusOntario. This book is best viewed via the online, Pressbooks format. However, a pdf format is made available; the videos are also available individually on the Write Here, Right Now YouTube Playlist, opens new window.

eCampusOntario is a not-for-profit corporation funded by the Government of Ontario. It serves as a centre of excellence in online and technology-enabled learning for all publicly funded colleges and universities in Ontario and has embarked on a bold mission to widen access to post-secondary education and training in Ontario. This textbook is part of eCampusOntario's open textbook library, which provides free learning resources in a wide range of subject areas. These open textbooks can be assigned by instructors for their classes and can be downloaded by learners to electronic devices or printed. These free and open educational resources are customizable to meet a wide range of learning needs, and we invite instructors to review and adopt the resources for use in their courses.

\section{About the Authors}

Paul Chafe, PhD, MA, BA, Contract Lecturer, Ryerson University, Faculty of Arts, English Department, Toronto, ON, Canada.

Aaron Tucker, MA, BA, Contract Lecturer, Ryerson University, Faculty of Arts, English Department, Toronto, ON, Canada.

Kari Maaren, PhD, MA, BA, Contract Lecturer, Ryerson University, Faculty of Arts, English Department, Toronto, ON, Canada.

Martha Adante, PhD, MA, BA, Contract Lecturer, Ryerson University, Faculty of Arts, English Department, Toronto, ON, Canada.

Val Lem, MLS, BEd, BA, Liaison Librarian, Ryerson University, Ryerson Library, Toronto, ON, Canada.

Trina Grover, MLS, Hons. B.A., Librarian, Ryerson University Library and Archives, Toronto, ON, Canada

Kelly Dermody, MA, MISt, BA (Hons), Librarian, Ryerson University, Ryerson University Library \& Archives, Toronto, ON, Canada.

\section{Contact Person}

\section{Aaron Tucker}

atucker@ryerson.ca

350 Victoria St.

Toronto, ON, M5B 2K3

English Department

Ryerson University

Dr. Paul Chafe

pchafe@ryerson.ca 
350 Victoria St.

Toronto, ON, M5B 2K3

English Department

Ryerson University

\section{Note to Educators Using this Resource}

We encourage you to use this resource and would love to hear if you have integrated it into your curriculum. Please consider notifying Dr. Chafe or Aaron Tucker if you are using it in your course and if you are: identify the course you are using it in, which parts of the text you are using and the number of students.

\section{Content Advisory Team}

Stuart Murray, PhD, MA, M.Phil, BA (Hons), Professor, Carleton University, Faculty of Arts, English Department, Ottawa, ON, Canada.

Rachel Stuckey, MA, developmental editor.

\section{Digitization Assistants}

Jean Puthenpurayil, BA, Research Associate, Ryerson University, English Department, Toronto, ON, Canada. Andrea Davidson, MSt, BA (Hons), Research Associate, Ryerson University, Ryerson University Library \& Archives, Toronto, ON, Canada.

Andrea Lee, BA (Hons), Library Digitization Projects Assistant, Ryerson University, Human Resources, Toronto, ON, Canada.

Hafsa Misbahuddin, BEng student, Library Digitization Projects Assistant, Ryerson University, Biomedical Engineering, Toronto, ON, Canada.

\section{Video Design and Production}

Catherine Jenkins, PhD, MA, BA, Contract Lecturer, Ryerson University, Faculty of Communication and Design, School of Professional Communication, Toronto, ON, Canada.

Kari Maaren, PhD, MA, BA, Contract Lecturer, Ryerson University, Faculty of Arts, English Department, Toronto, ON, Canada.

Nada Savicevic, MA Interactive Design, MArch, BSc Eng, Instructional Designer, Office of eLearning, Ryerson University, Toronto, ON, Canada.

Negin Hematlooeian, Motion Graphics Designer, Toronto, ON, Canada.

xiv | Preface 
Ahmad Abu-kwiek, BA student, Ryerson University, Faculty of Communication and Design, RTA School of Media: Sport Media, Toronto, ON, Canada.

Aaron Hamilton, BA student, Ryerson University, Faculty of Communication and Design, RTA School of Media: Sport Media, Toronto, ON, Canada.

Jing Han, BTech student, Ryerson University, Faculty of Communication and Design, Graphic Communications Management, Toronto, ON, Canada.

Christo Luksatrio, BA student, Ryerson University, Faculty of Communication and Design, School of Professional Communication, Toronto, ON, Canada.

Andrew Tang, BTech student, Ryerson University, Faculty of Communication and Design, Graphic Communications Management, Toronto, ON, Canada.

\section{Acknowledgments}

Wendy Freeman, PhD, MSc, Director, Office of e-Learning, Associate Professor, Ryerson University, Faculty of Communication and Design, Toronto, ON, Canada.

Ann Ludbrook, MLIS, MA, BA, Copyright and Scholarly Engagement Librarian, Ryerson University, Toronto, ON, Canada. Christopher Visser, BSc, Special Projects Coordinator, Ryerson University, Office of the Provost, Toronto, ON, Canada. Sally Wilson, MLS, BA, Web Services Librarian, Ryerson University, Toronto, ON, Canada.

\section{Customization}

This textbook is licensed under a Creative Commons Attribution 4.0 International (CC-BY) license, which means that you are free to:

- SHARE - copy and redistribute the material in any medium or format

- ADAPT - remix, transform, and build upon the material for any purpose, even commercially

The licensor cannot revoke these freedoms as long as you follow the license terms.

\section{Under the Following Terms}

Attribution: You must give appropriate credit, provide a link to the license, and indicate if changes were made. You may do so in any reasonable manner, but not in any way that suggests the licensor endorses you or your use.

No additional restrictions: You may not apply legal terms or technological measures that legally restrict others from doing anything the license permits.

Notice: You do not have to comply with the license for elements of the material in the public domain or where your use is permitted by an applicable exception or limitation.

No warranties are given: The license may not give you all of the permissions necessary for your intended use. For example, other rights such as publicity, privacy, or moral rights may limit how you use the material. 
For information about what was used and/or changed in this adaptation, refer to the statement at the bottom of each page where applicable.

Content that is not taken from the above three OERs should include the following attribution statement:

Licensed under a Creative Commons Attribution 4.0 International License. Write Here, Right Now by Dr. Paul Chafe, Aaron Tucker with chapters from Dr. Kari Maaren, Dr. Martha Adante, Val Lem, Trina Grover and Kelly Dermody. Download this book for free at: https://pressbooks.library.ryerson.ca/writehere/ 


\section{PART I: INTRODUCTION}

In this introduction we will:

- Lay out the basic structure for the textbook

- Read the essay "The Plot to Privatize Common Knowledge" by David Bollier

- Write a brief essay in response to "The Plot to Privatize Common Knowledge"

- Complete a self-evaluation of your own essay

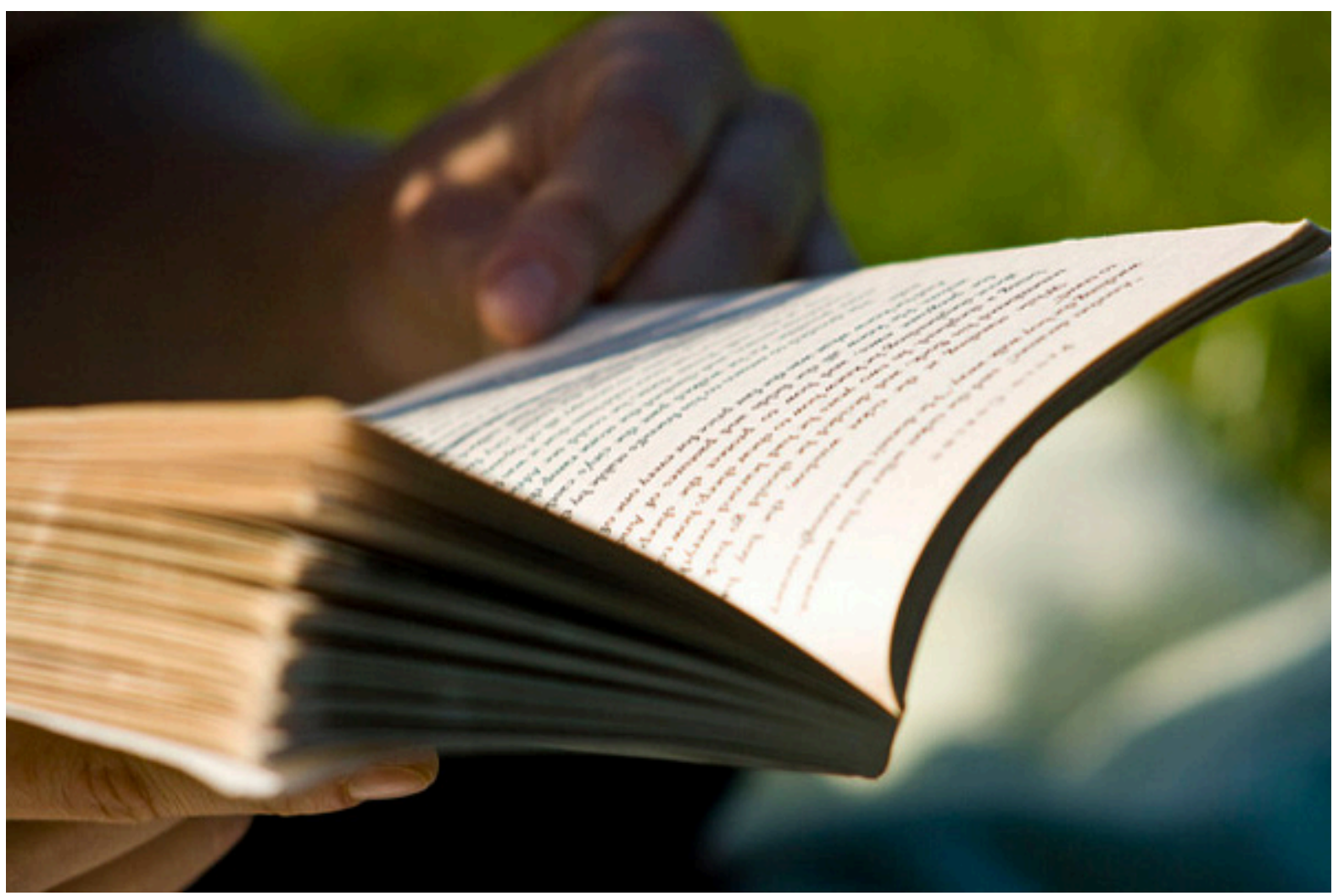

Reading (CC BY 2.0) by Sam Greenhalgh

\section{Getting Started}

This textbook is divided into two parts with each of those two parts built around outlining and completing the process of writing a single assignment. Ideally, each chapter is meant to be paired with one week of classroom time and so, the idea is that by reading a chapter a week and then practicing the tools and techniques during class time where you can get feedback from your peers and professor you will be slowly and methodically building strong reading and writing habits that will help you throughout your university career. Each chapter has three videos that will give you the opportunity to pause, rewind, and re-watch the brief lectures to ensure that you are comfortable with the terminology and techniques being taught in this textbook. 
Part I: Chapters 1 through 6 will focus on writing a close reading essay while Part II: Chapters 7-13 will focus on writing an argumentative essay in which you will make your own argument in response to an essay prompt. We will not get into too much detail about Part II for now as it relies on Chapters 1-6 to lay the foundation for the skills needed to write an argumentative essay. Instead, we will use this introduction to focus on your first assignment: writing a close reading essay.

A close reading essay is an essay that analyzes another author's complex argument. In order to write a close reading essay, however, you will need a variety of other tools and skills including:

- Reading critically with a pen in your hand, taking notes

- Analyzing a text by looking for key observations and pieces of evidence

- Focusing your analysis on key portions of a text, rather than trying to cover the whole essay

- Reconstructing the author's complex argument based on the focused evidence you identify

- Expanding out to consider the full scale of the author's complex argument

- Writing a thesis statement that proposes an analysis of the author's complex argument

- Expanding that thesis into an essay with logically constructed paragraphs

- Revising your thesis and your essay at multiple points throughout the process of completing your close reading essay

To begin acquiring and reaffirming these tools and skills, we are going to do a short writing activity that will help you evaluate your strengths and weaknesses at this point. We are deliberately not going to give you a whole lot of specific direction at this point and we want to see what skills and tools you already possess and what areas you may want to focus on as a way of improving.

\section{Try This!}

Read David Bollier's "The Plot to Privatize Common Knowledge" and once you have completed reading it, write a brief 250-word essay analyzing the author's argument. Again, we are going to use the upcoming chapters to build up a vocabulary and skill set to help you improve your writing, but the point of having you write the essay at this point is to assess what strengths and weaknesses you possess at this point.

\section{"The Plot to Privatize Common Knowledge," by David Bollier}

Over the past three decades, modern culture has become infatuated with the idea that knowledge should be owned like real estate or stock shares. The original idea, of course, is that copyrights, trademarks and patents reward people for their creative labors and thereby boosts the common good.

But this line of thinking has come to resemble a kind of Market Fundamentalism: copyrights, trademarks and patents are the only morally legitimate and practical method for managing creations of the mind. There is no middle ground. You either believe in intellectual property rights, or you support "theft" and "piracy.

This fundamentalist approach shuts down a broader discussion about how knowledge ought to circulate in our culture. To avoid any confusion, let me just say straight-up that I believe in copyrights and patents. In

2 | Part I: Introduction 
some cases, they provide significant and necessary incentives to invest in new works. But today, copyrights and patents are going far beyond their intended goals-such as the U.S. Constitution provision to "promote progress in science and the useful arts"-to become ends in themselves. Instead of carefully balancing private interests and public needs, copyrights and patents are becoming crude, anti-social instruments of control and avarice.

This is the conclusion that I came to in my book Brand Name Bullies, which is filled with dozens of stories of copyright and trademark owners bullying citizens, artists, scholars and others with ridiculous legal threats.

\section{Silent Campfires}

One of my favorite stories about the alarming expansion of copyright law involves ASCAP, the American Society of Composers, Authors and Publishers, the organization that collects performance licensing fees from public establishments where recorded music is played.

ASCAP decided that their domain should be extended to summer camps. Why shouldn't boys and girls singing around the campfire be considered a "public performance" that should pay royalties? A while back ASCAP approached the American Camping Association and said it wanted blanket performance licenses from hundreds of summer camps- something on the order of $\$ 300$ to $\$ 1,400$ per season per camp.

This caused quite a ruckus. When it was discovered that ASCAP wanted money for the Girl Scouts to sing "This Land Is Your Land" and "Puff, the Magic Dragon", the press went nuts. There were stories about camps resorting to non-copyrighted songs like "The Bow-Legged Chicken." An ASCAP official heartlessly told a reporter: "They [camps] buy paper, twine and glue for their crafts - they can pay for the music too." Eventually, after a huge public outcry, ASCAP backed down. But its claim to legal authority in charging summer camps for their "public performances" of copyrighted songs remains intact.

\section{Lawsuit Barbie}

The issue in so many of these battles is: Who shall control the "public meaning" of familiar images? Mattel is legendary in trying to protect the cultural "meaning" of Barbie. It has gone after any unauthorized uses of Barbie. It went after a series of photographs by Mark Napier called Distorted Barbie, which dared to depict Barbie as fat or as having Down's Syndrome. Even highly distorted images of Barbie that were essentially unrecognizable were deemed unacceptable by Mattel.

Mattel went after a magazine that caters to adult collectors of Barbie dolls. Mattel even pressured the Seattle publisher of a book, Adios, Barbie: Young Women Write About Body Image and Identity, to change the title. The book was reprinted as Body Outlaws. This extreme clampdown on free expression spurred culturejammers, such as the self-styled Barbie Liberation Organization, which substituted voice boxes of GI Joe with those in Barbie, so that GI Joe would say, "Let's plan our dream wedding," and Barbie would yell, "Vengeance is mine!" 
I am happy to report, a federal circuit court in the United States put a damper on Mattel's bullying litigation. The case involved Utah photographer Tom Forsythe, who made a series of 78 photos of Barbie for his Food Chain Barbie exhibit. It featured Barbie in enchiladas, stuffed into a blender and in other kitchen poses. Only a few of Forsythe's photos sold. He spent about $\$ 5,000$ to mount the exhibit, and lost money. No matter; Mattel wanted to send a message that you can't mess with Barbie. It spent years litigating the case, requiring Forsythe to find pro bono legal counsel, which spent nearly \$2 million defending him. Forsythe prevailed in the circuit court, which delivered a stinging rebuke to Mattel for bringing a "groundless and unreasonable" trademark dilution claim.

\section{Watch Your Words}

The privatization of words-language is one of the most basic form of commons- is another disturbing trend. The Japanese corporation that owns the "Godzilla" trademark has a habit of threatening all sorts of people who use the phoneme "zilla," including a website called "Davezilla" that featured a lizard-like cartoon character.

The corporate obsession with owning words is really quite extensive. McDonald's claims to own 131 words and phrases. The San Diego-based McDonald's actually claims to own the Irish prefix "Mc." It has successfully prevented restaurant from naming their businesses McVegan, McSushi and McMunchies.

Ralph Lauren, the clothing line, went after Polo magazine, run by an equestrian organization, claiming it was a trademark infringement for the U.S. Polo Association to use the word "polo" on its line of clothing! MasterCard went after Ralph Nader for using "priceless" in his campaign ads when running for President in 2000. (Nader's free speech rights ultimately prevailed.) But the gay athletes who wanted to host a series of athletic competitions in San Francisco could not use the phrase "Gay Olympics" because that phrase is owned by the U.S. Olympic Committee, who gets to decide who can use it. "Special Olympics" for disabled kids is OK, but not "Gay Olympics."

The TV demagogue Bill O'Reilly reportedly went ballistic when he learned that the comedian (and now senator) Al Franken was using the words "fair and balanced" as a subtitle in his book that mocked various right-wing pundit, including him. The federal court laughed Fox News' case out of court, and Franken won. But pity the people who can't afford to hire Floyd Abrams, a prominent First Amendment attorney, to represent them. A woman from Los Angeles dared to name her neighborhood newspaper the Beechwood Voice. She was threatened with legal action by the Village Voice, which claimed that use of the word "voice" as a newspaper name diluted its trademark.

These stories illustrate just how far Market Fundamentalism is willing to go in order to enforce its vision of the world. It wants to commodify all of culture as private property, and require people to obtain permission (and to make royalties) before embarking on any modestly derivative new creativity. This approach, not coincidentally, favors the Disneys, Time Warners and Rupert Murdochs because it protects the market value of large inventories of copyrighted and trademarked works. It directly stifles expression that is local, amateur, small-scale or non-commercial in nature-the kind of expression that almost anyone outside a powerful corporation would engage in. This amounts to a wholesale privatization of our cultural commons. 


\section{Patents Privatize Taxpayer-Funded Research}

The Market Fundamentalist worldview is even more infuriating, if that is possible, when applied to patents arising out of publicly funded research. Until 35 years ago, there had been a broad consensus that the intellectual property rights of federal research should stay in the public domain, or at least be licensed on a nonexclusive basis. That way, taxpayers could reap the full measure of value from their collective investments. In the late 1970s, however, large pharmaceutical, electronics and chemical companies mounted a bold lobbying campaign to reverse the public ownership of federal research. Since enactment of Bayh-Dole Act of 1980, authorizing universities to patent the fruits of federally funded research, we have seen a land rush to sell academic research that was once freely available to all.

Between 1980 and 2000, the number of patents secured by universities grew ten-fold, bringing in more than \$1 billion in royalties and licensing fees-a windfall enjoyed mostly by a dozen top research universities. This, in reality, is a privatization of the public's investments. Even though the public pays for the lion's share of risky basic research for new drugs, the long-term equity returns tend to go to drug companies and a handful of top research universities. In the United States, we have seen this with the cancer drug Taxol; the anti-depressant Prozac; the hypertension drug Capoten; and a number of HIV and AIDS therapies.

The upshot is that citizens often have to pay twice for pharmaceuticals and other medical treatments-first, as taxpayers who finance the research, and second, as consumers who pay monopoly prices for drugs. This is a pure giveaway because it's not even clear that companies need exclusive patent rights as an incentive to commercialize new drug research.

\section{Corporations Loot Indigenous People's Knowledge}

Multinational corporations are no longer content to simply claim ownership of commons knowledge at home. Now they scour the developing world-in a practice known as biopiracy-to claim patents on the botanical and ecological knowledge acquired by indigenous people through the centuries. They move into Madagascar, Brazil, Guatemala and other poor countries to find plants and microorganisms that might be used in making new medicines and genetically engineered crops. But as Seth Shulman writes in his book Owning the Future, "Who, if anyone, should be able to claim ownership rights to the globe's genetic and cultural inheritance?"

Sir John Sulston answers this question eloquently in his book, The Common Thread, which chronicles the race to de-code the human genome. A private startup company, Celera, was aggressively trying to put genomic sequences in one big privatized database. That way, it would have a monopoly over future use of the genomic data by licensing access to its database. Fortunately, a coalition of public-sector scientists published the data first, which is why the human genome is now in the public domain. Sulston answers, quite rightly, that the human genome must be treated as the "common heritage of humankind." 


\section{Life Itself Can Now Be Owned}

We dodged a bullet there when the publicly funded scientists won the race to decode human genome. Yet the threat of private ownership of essential knowledge for the sake of profits is not by any means over. Further attempts will by the logical culmination of a path first opened by the U.S. Supreme Court's Diamond $v$. Chakrabarty ruling in 1980, which authorized the patenting of live, genetically altered microorganisms. The patenting of living organisms opened the way for an ecologically and ethically dubious future in which the life forms that are part of the sacred web of life can be owned and treated as commodities. Knowledge is treated as private property, not as a public good.

One inevitable result of all these new ownership claims is the rise of new barriers to open sharing, collaboration and discovery among researchers and scholars. Patents are increasingly being granted for "upstream" research, which means that basic knowledge that everyone else must use for the field to advance, is becoming proprietary. Harvard, MIT and the Whitehead Institute, for example, have a patent on all drugs that inhibit something known as NF-kB cell signaling. Since this physiological process is believed to have something to do with many diseases such as cancer and osteoporosis, the patent deters anyone else from pursuing their own scientific investigations in this area.

Things were not always this way concerning valuable knowledge. Contrast these stories with Jonas Salk, the inventor of the polio vaccine. When journalist Edward R. Murrow asked him, "Who owns the patent on this vaccine?" Salk replied, "Well, the people, I would say. There is no patent. Could you patent the sun?" This story helps us remember that current notions about ownership of knowledge are not inevitable and universal; they are the result of mounting market pressures to make our scientific and cultural commons into private property.

The privatization of knowledge has only intensified as the courts-in the United States, at least-have lowered the standards for obtaining patents while broadening the scope of what is patentable. It is now possible to own mathematical algorithms embedded in software programs. The very tools needed to conduct scientific research are now private property, available only for a steep fee.

Imagine what might have happened to biotechnology and computer science if contemporary patent rules had been in place in the 1950s and 1960s. Neither the biotech nor the computer revolution would have occurred in the first place. Too much fundamental knowledge would have been off limits due to patents.

\section{Problem of the Anti-Commons}

The over-patenting of knowledge sometimes results in what is called an "anti-commons" problem, in which property rights for a given field of research are so numerous and fragmented that it becomes very difficult to conduct research. The transaction costs for obtaining rights are simply too numerous and costly. For example, there are thirty-four "patent families" for a single malarial antigen, and those rights, applying to

6 | Part I: Introduction 
different pieces of the research agenda, are owned by different parties in many different countries. One reason that a malaria vaccine has been so elusive is because the patent rights are so complicated and expensive to secure.

It is worth noting that openness, sharing and the public domain do not harm the market. Quite the contrary. They invigorate it. In 2005, I co-hosted a conference called Ready to Share: Fashion and the Ownership of Creativity. It explored the power of openness in apparel design. Precisely because no one can own the creative design of clothes-they can only own the company name and logo, as trademarks-everyone can participate in the design commons. The result is a more robust, innovative and competitive marketplace. This is exactly the effect that Linux, the open-source computer operating system, had on the software sector. It has opened up new opportunities for value-added innovation and competition in a marketplace until then dominated by the Microsoft monopoly.

Yale Professor Yochai Benkler argues in his magisterial book, The Wealth of Networks, that a great deal of knowledge production is more effectively pursued through a commons than through markets. Questions of ethics aside, why doesn't money succeed at simply "buying" the knowledge it needs? Because money tends to subvert the social dynamics that make the knowledge commons work. It can sabotage self-directed inquiry. It undermines the social trust, candor and ethics that are essential to creativity and good research.

Republished here under Attribution-ShareAlike 3.0 Unported License

\section{After You Have Finished Writing Your Essay}

Now that you have a 250-word essay in which you analyze Bollier's complex argument, you are going to do a brief selfevaluation of your work. Complete the Essay Self-Evaluation below. Each question requires a "Yes" or "No" answer. For each "Yes" response, give yourself one point. For each "No" response give yourself zero points. Your final score will be mark out of ten (ex: Seven "Yes" responses $=7 / 10$ ). Be honest with yourself. This is not for grades and is meant as an assessment tool so that you have a better sense of yourself as a writer and your strengths and weaknesses at this point.

\section{Essay Self-Evaluation}

\section{Taking Measure}

1. Do you begin your essay with a thesis focused on the purpose of the text? Remember: a thesis must be something a reader can agree or disagree with; a fact, summary or an opinion is not an argument. 


\section{$\mathrm{Y} / \mathrm{N}$}

2. Does your thesis make an interpretive claim about the text (i.e. do you make a claim about the text that is not obvious and is more than a simple summary of the text)?

$\mathrm{Y} / \mathrm{N}$

3. Do you use the author's name and the title of the essay in your argument? Hint: if you do not, you are not making an argument about the text.

$\mathrm{Y} / \mathrm{N}$

4. Does your thesis statement quote specific parts of the text as evidence? $\mathrm{Y} / \mathrm{N}$

5. Do you discuss a new aspect of the text in every paragraph (rather than repeat the same observation over and over)? Please answer "No" if your essay is only one paragraph.

$\mathrm{Y} / \mathrm{N}$

6. Do you stay focused on the assigned text and avoid irrelevant "evidence" from outside the text (ex: personal experiences, facts or opinions you have read somewhere else, vague references to history)?

$\mathrm{Y} / \mathrm{N}$

7. Do you avoid the five-paragraph essay (vague introduction, three body paragraphs for every piece of repetitive "evidence," a conclusion that repeats your introduction)?

$\mathrm{Y} / \mathrm{N}$

8. Do you cite from the text and use specific textual evidence while making your points in your body paragraphs and conclusion?

$\mathrm{Y} / \mathrm{N}$

9. Do you use the specific terms used in the text rather than generalizing terms like "people" or "society"? $\mathrm{Y} / \mathrm{N}$

10. Do you culminate rather than simply repeat your essay in your conclusion? Do you finish with a claim about what your unique reading has discovered about the text?

$\mathrm{Y} / \mathrm{N}$

BONUS: Take a moment to read aloud what you have written. Were you able to read it from start to finish without stumbling? Does it make sense?

$\mathrm{Y} / \mathrm{N}$

Total: $\quad / 10$

8| Part I: Introduction 


\section{Thinking Ahead...}

Make sure that you keep reviewing your essay and your self-evaluation over the next few weeks as we will be using it for a variety of purposes in the upcoming chapters. It is also useful to have it nearby to remind yourself of the progress you are making. If you gave yourself a score that is lower than you would like to achieve in the future, this essay will serve as a reminder and motivator in the weeks ahead. You will get better as we add more tools that will allow you better to articulate your interesting and complex thoughts and insights.

As you work through each chapter in this textbook, you will find yourself adding different tools to make your work sharper and more coherent. This is a process and it does require patience and practice. Your first task is to slow down. Chapter 1 is all about taking your time and analyzing a text before jumping to conclusions about what its "meaning" might be. In order to build an effective and complex close reading essay, you must slow down and gather the best and most compelling evidence from the author's text. In Chapter 1 we will explain and demonstrate this process and then you will practice it. 



\section{CHAPTER I: TIME IS ON YOUR SIDE}





\section{Chapter Overview}

\section{Learning Outcomes}

\section{In this chapter we will:}

- Introduce the basic principles of a textual analysis.

- Examine an essay looking for the author's complex argument and gather a list of evidence from the text that best reflects that author's argument.

- Identify a central concept that we feel best explains the core of the author's complex argument

- Focus on the specific evidence that we feel best enables us to analyze the author's complex argument.

- Make an initial exploration into a potential thesis that proposes a critical examination of the author's complex argument. 


\section{Introduction to Close Reading}

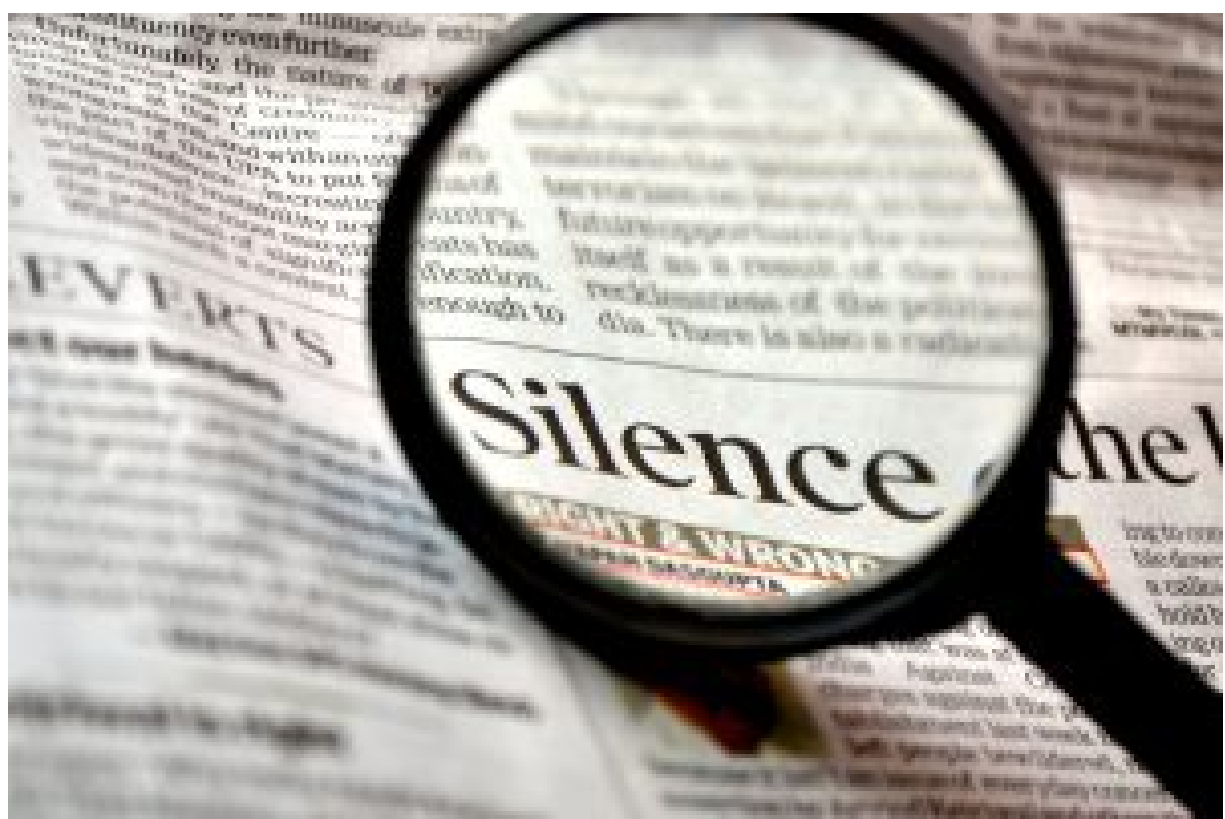

Every text has an argument, you just have to look for it. Pixabay/CC0 1.0

Writing an essay at the university level means entering an ongoing scholarly conversation. Before you select an essay subject, you should know that throughout history, scholars have addressed and articulated similar concerns and ideas; many have dedicated their lives to these problems and arguments. So, rather than worrying about generating a new idea, it would be wise to aim for active and informed participation in that conversation. This is done via the process of analysis.

Analysis is when you read a text, find specific details from that text and use those details as evidence to examine that text's argument and purpose.

In order to analyze and contribute meaningfully, you must first understand all parts of a scholarly conversation. Therefore, the ability to close read and understand others' writing is vital.

We will focus the first six chapters on producing a close reading.

A close reading first gathers specific evidence from a text and then analyzes those observations in order to provide a thorough examination of that author's complex argument. 


\section{Assignment}

For the first assignment, you will do a close reading of an essay and then write a 750-word essay analyzing an author's complex argument based on evidence from the text. 


\section{Gathering Evidence}

Every close reading relies on evidence. Without evidence, a writer is simply stating their opinion. As such, writing an essay begins well before you start writing with the process of gathering evidence. In fact, very little essay writing is actually "writing." Rather, most of the essay writing process is:

- Gathering evidence (reading the text and taking notes)

- Pre-planning and pre-writing (outlining and brainstorming)

- Research (of definitions, other scholars' concepts, statistics)

- Drafting (early attempts at thesis paragraphs and body paragraphs that will be revised as the process continues).

We will outline how to gather evidence by modeling the task of slowing down and recording all the observations that are to be had within a text. For a brief tutorial on the basics of finding evidence within a text, watch Video 1.1: Walk Through Self Evaluation, then read the subsequent text.

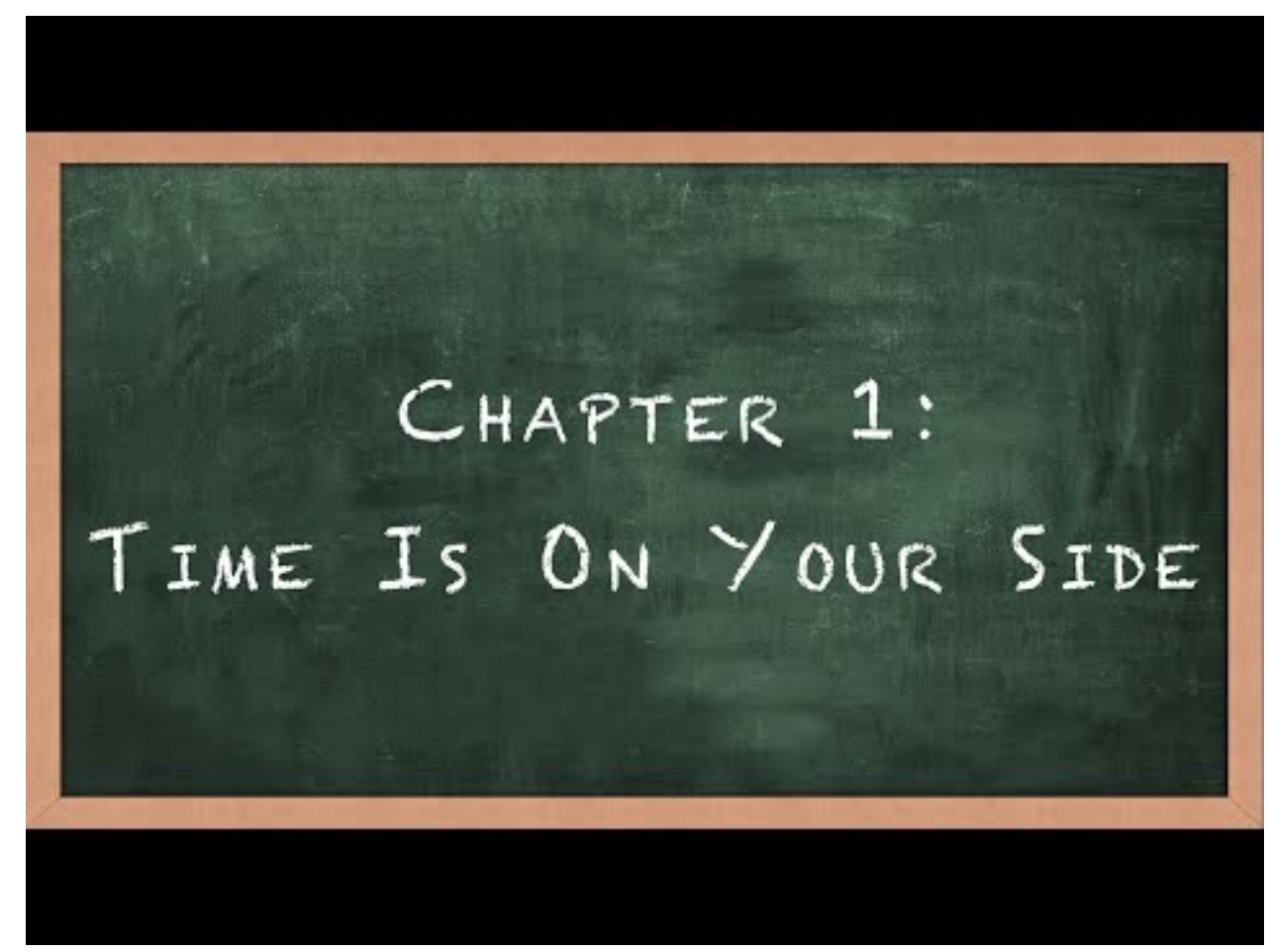

A YouTube element has been excluded from this version of the text. You can view it online here: https://pressbooks.library.ryerson.ca/writehere/?p=75 


\section{Reading Slowly}

In these early stages of a close reading, it is not necessary to find an analytical angle right away or to identify immediately the author's overall purpose. At the beginning of your close reading, your greatest asset is time; therefore, you should slow down. Analyzing a text is a multi-stage process and finding evidence from a text is the very beginning of that process. The tools we introduce in this chapter will not help you if you do not give yourself the time needed to apply them properly.

By the end of the chapter you will be asked to write a brief paragraph wherein you reconstruct what you've identified as the author's complex argument, but at this early stage of the chapter, we need to gather evidence with which we can begin that reconstruction.

You should not jump immediately to your thesis; instead, you need to gather complex evidence by reading slowly with a pen in hand. You should take this time to annotate the text you are reading with your observations and initial interpretations.

For now, it is enough to annotate what you are reading-make a note of things that are interesting, confusing, or repeated. When your task is to analyze a text, resist the need to jump in and begin drafting your thesis right away. Instead, to ensure you will eventually make an argument of adequate complexity, you should devote the time necessary to examine the text thoroughly.

To examine a text closely, you should:

1. Annotate your experience

2. Take notice

3. Be granular

\section{Annotate your experience}

You will always begin by reading with a pen in hand, writing in the margins, underlining, highlighting and otherwise marking on the text, if you own the text, or by taking notes on a separate piece of paper if you are borrowing the text. You can draw arrows in the margins to link different parts of the text as a way of following the author's logic and argument. If you are reading online, you should get in the habit of annotating your reading experience in some way. You can do this on paper, or with a digital text editor or PDF editor which allow you to highlight and make notes or comments. Hypothes.is is a free general purpose web and PDF annotator that you can use for that purpose. 


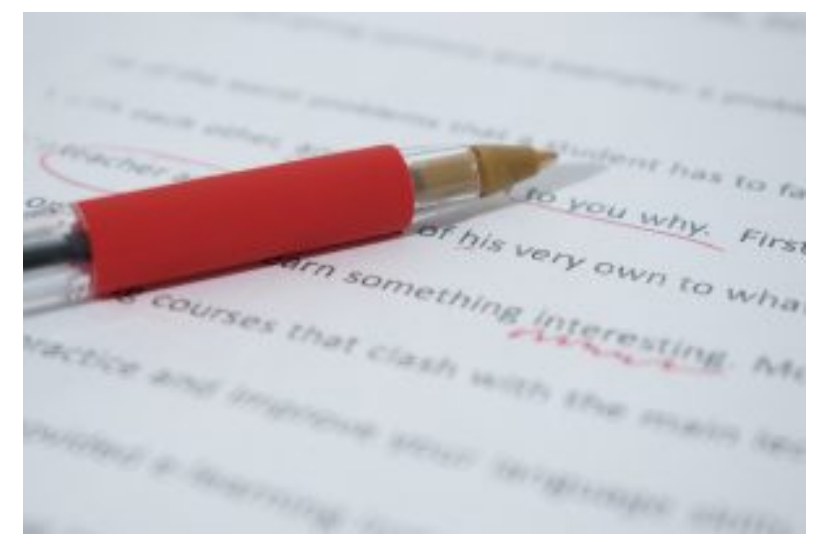

Mark down what you notice. From Pixabay/ $\underline{\mathrm{CC} 01.0}$

\section{Take notice}

During your first reading of a text, you should be looking for elements that jump out at you, that you think are interesting or puzzling, or that you think may need more attention in a second reading. Underline or highlight words you do not understand, then seek out definitions for those words. If you encounter a word that is new to you, it is likely that the word is significant to the central message or theme of the text.

\section{Be granular}

Reading critically requires being granular. It is not enough to just flag whole sentences or even whole paragraphs. You must get down to the level of the word. Begin by looking for some straightforward clues:

\section{a. What's interesting? What's strange?}

What words and phrases catch your attention in your first reading? This may take the form of repetitions; if a word or phrase is repeated, it is likely central to the author's purpose.

\section{b. What words or phrases are new to you?}

You will probably encounter words or phrases that you have never read or heard before. You may also encounter facts or concepts that you are learning for the first time. That's great! Make a note of them and then look them up, or seek out additional information.

c. What patterns are present?

What elements of the argument repeat? A common pattern is the use of synonyms or words that are similar thematically. If there are several synonyms or thematic terms, it is likely the author is focusing on a specific idea or argument that can be conveyed using these words. You might also consider larger sets of words. For example, if an author is using verbs like "flow" and "poured," nouns like "ocean" and "river" and adjectives like "wet" or "fluid," you might note that there are a lot of water-related words. Three or more words in a list of synonyms or thematicallyrelated words or phrases probably indicates a pattern.

\section{d. What contrasts or opposites are present?}

Are there words that are opposites or words understood to be contrasts of one another? The author may use these to establish the main argument by comparing points or establishing a counter argument. It may also be that the 
author is offering a more nuanced approach to a subject, so it's important to look for subtle or implied contrasts that are not as stark as good/bad, black/white. For example, an author might use the word "infantilize" and then later "adult"-while the author does not juxtapose the words side by side, the two words are opposites and may be clues about the author's larger argument.

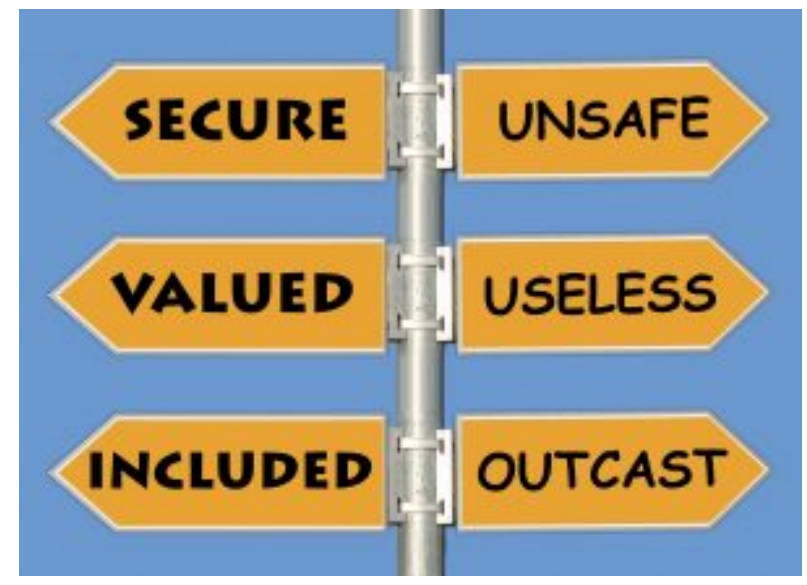

The use of contrasting language in a scholarly text is deliberate and noteworthy. From Pixabay/CCO 1.0

As you write on the text and make your notes, remember that there is no such thing as too much data at this phase. The more information you have, the more sophisticated your reading will be, and the deeper your understanding of the text. You should try to compile exhaustive lists: at least 7-10 interesting words, 7-10 definitions of new words, 7-10 lists of patterns, 7-10 contrasts.

\section{Reminder}

Remember: Do not jump into formulating an argument; you do not need to explain what anything means yet. Just gather as many observations and potential pieces of evidence as you can. 


\section{Example}

Watch Video 1.2 to see the key steps in gathering evidence from the essay "The Plot to Privatize Common Knowledge" by David Bollier. It may be useful for you to review the essay before watching the video.

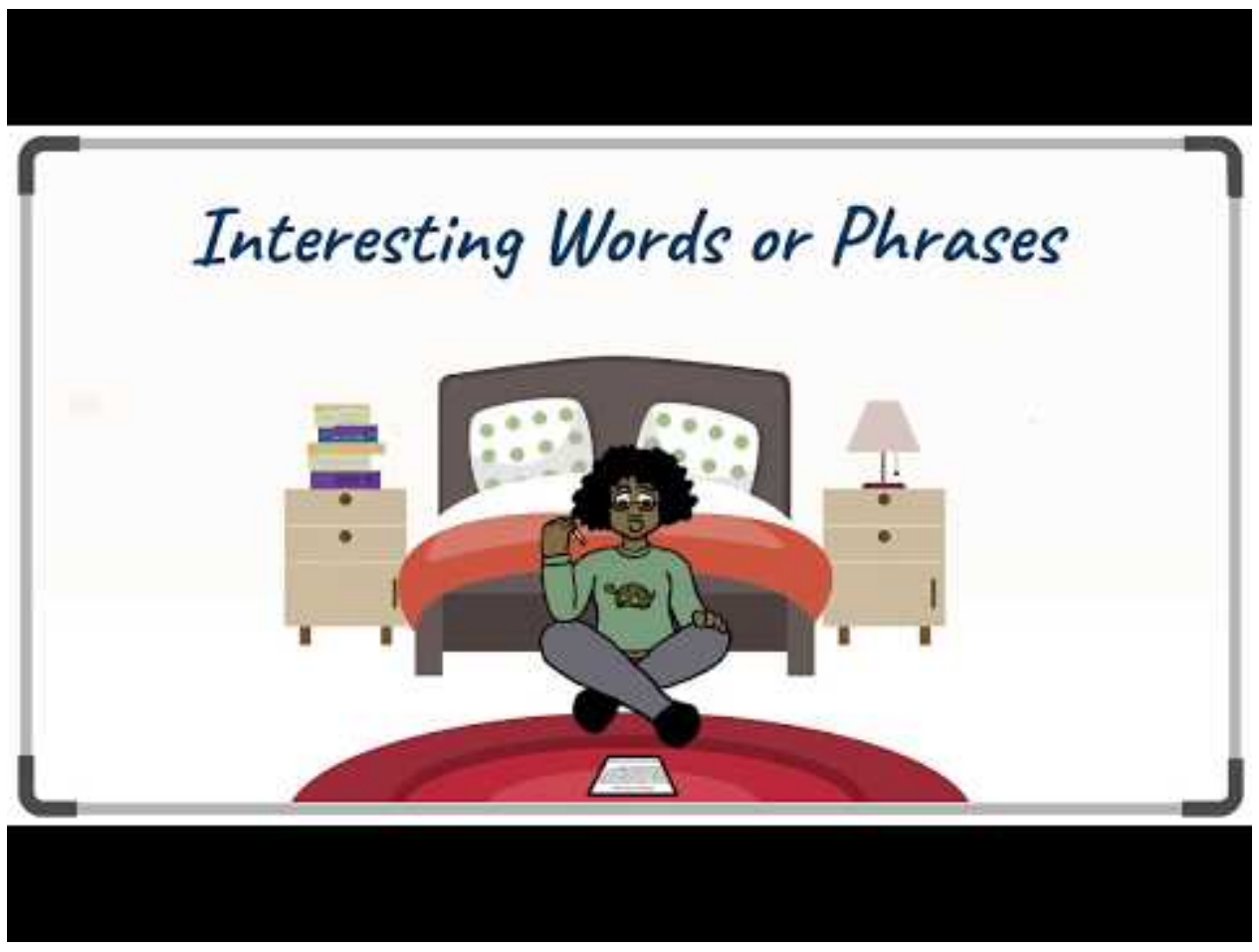

A YouTube element has been excluded from this version of the text. You can view it online here: https://pressbooks.library.ryerson.ca/writehere/? $p=48$ 
common good

managing creations of the mind

Interesting useful arts

words or $\quad \begin{array}{ll}\text { public meaning } \\ \text { cultural meaning }\end{array}$

corporate obsession

phrases ecologically and ethically dubious

fundamental knowledge

over-patenting 
market fundamentalism

ruckus

avarice

New clampdown

privatization of words

cultural commons

land rush

biopiracy

anti-commons 
Corporate control: crude, anti-social instruments of control and avarice; bullying; alarming expansion of copyright law

Patterns Creepy control: managing creations of the mind; useful arts; privatization of words

Theft: land rush; biopiracy; anti-commons

and What's at stake: modern culture; common good; fundamental knowledge

$\begin{array}{ll} & \text { Money: robust, innovative and competitive marketplace; monopoly; market } \\ \text { synonyms } & \text { Market jargon: Market Fundamentalism; trademark dilution; market value }\end{array}$

Be nice!: sharing; collaboration; public good 
intellectual property rights v. "theft" and "piracy"

useful v. useless

big business v. new voices

commercial v. non-commercial

claim v. inheritance

Contrasts barriers v. sharing

patent v. collaboration

private property $\mathrm{v}$. public good

deter v. encourage

elusive v. secure

New opportunities v. monopoly

Commons v. markets 


\section{Your Turn!}

\section{Activity}

Read the following essay and, on a separate piece of paper, identify 7-10 interesting words, 7-10 definitions of new words, 7-10 lists of synonyms, 7-10 contrasts.

\section{The Ultimate Communications App}

\section{The most amazing invention of all-time, and it belongs to all of us}

\section{Charles Justice}

\section{Source: On the Commons, The Ultimate Communications App}

I've just invented a new communication app. It can be used by almost everyone; It works anywhere and anytime, night or day; It doesn't need batteries, doesn't need to be plugged in, doesn't even need the internet; Once people start using it, it is so easy that it is almost impossible to stop using it; it becomes indispensable, and you are hooked, you cannot be without it; It can be tailored to suit any occasion; Its use facilitates an expanding network of people; It's use opens up incredible possibilities for creativity and cooperation.

There are only two things that may be problematic with it: my new app takes about four years to download. Yes, you heard correctly, not four minutes but four years. And usually, only ridiculously young kids know how to download it, but, like I said it takes about four years. During that time, the system needs constant maintenance and TLC. The other snag is that once someone starts using it, it becomes common property, available to everyone free, and so I personally, can't get rich off of it.

Are you ready to try my new free app? It's called language. OK, I lied. It's not a new app and I didn't invent it. But everything else I said about it is true, and it was invented by the first humans sometime within the last five hundred thousand years.

What is language? A method of communication that is available to virtually all humans to use. A common way for us to share information and create enduring knowledge. One of the first, but not the first commons created by human collective agreement.

Take a proto-language "Me Tarzan, you Jane". Start with naming, then add verbs to describe action and 
emotions. Once you begin to share information you are creating a common space of understanding amongst you and your fellow speakers. This common space can be called a commons.

What is a commons? A commons is a level-playing field. Everybody gets to breathe air, and we have that in common with most other species. Here in the rain forests of the Pacific Northwest, fresh water is a common resource.

We parcel up land into properties, but much land is held in common in the form of parks, trackless wilderness, public rights of way and public spaces. The sunlight that falls to earth is common to all, plants and animals on land, fish and the whales in the sea.

Before the human development of agriculture and domestication humans lived for millions of years in hunter-gatherer bands of approximately thirty to a hundred people. If the band survived and prospered, eventually, as population grew over generations, a new band would split off. As this process continued, a larger and larger area of land would need to be occupied.

Eventually groups that originally were connected, would become separated permanently by mountains or water barriers. Originally we had everything in common. Then because of our success in outgrowing our original environment we ceased to have a common place and identity.

This is probably the basis for the evolution of different languages (see "Tower of Babel") If we go back far enough in time, all of us living today have a common history, but over thousands of years different peoples occupying different places have come to conflict and cooperation with each other.

Each of us has our humanity and human origins in common with everyone else alive today. Since then, we may have got here in different ways, but we all share the present time in common. We, in fact, share this age in common with the Earth's biosphere and all its manifest diversity.

Republished here under Attribution-ShareAlike 3.0 Unported License 


\section{What Now?}

Now that you've identified 7-10 interesting words, 7-10 definitions of new words, 7-10 lists of synonyms and/or patterns, 7-10 contrasts, watch Video 1.3: The Analysis of "The Ultimate Communications App" by Charles Justice and compare your list of evidence to the ones gathered in the video.

\section{New Words}

1. Proto-language

2. Commons

3. Domestication

4. Tower of Babel

5. Biosphere
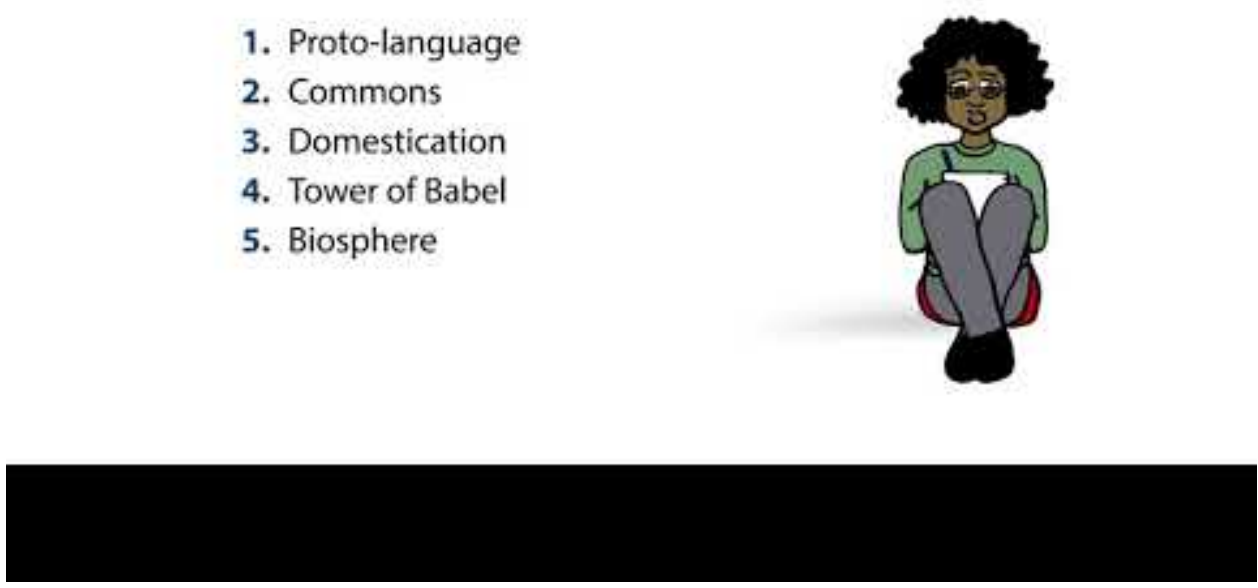

A YouTube element has been excluded from this version of the text. You can view it online here: https://pressbooks.library.ryerson.ca/writehere/? $p=57$ 


$\begin{array}{ll} & \text { Indispensable } \\ \text { Creativity } \\ \text { Interesting } \\ \text { Cooperation } \\ \text { Property } \\ \text { Process } \\ \text { Human development } \\ \text { Occupied }\end{array}$

Proto-language

Commons

New words $\begin{aligned} & \text { Domestication } \\ & \text { Tower of Babel }\end{aligned}$

Biosphere

Manifest destiny 
Battery, plugged in, download

Internet, network, app

Commons, cooperation

Synonyms/ Download

repetitions New, invented

Sunlight, fish, whales, plants, animals

Evolution, growth

Cooperation

Humanity, everyone 


$\begin{array}{ll} & \text { Property v. free } \\ & \text { New v. original } \\ & \text { Information v. language } \\ \text { Contrasts } & \text { Private v. public spaces } \\ & \text { Human v. nature } \\ & \text { Present v. past } \\ & \text { Common v. private space } \\ & \text { Collective v. individual }\end{array}$

\section{The Observational Paragraph}

The next step is to consider your list of observations carefully and narrow it down to the best two. Review the information you have collected. What's connected? Group similar observations together and think about which observations are the strongest and most interesting, and which observations are the most complex. Your small and focused pieces of evidence or observations should be something you can literally put your finger on. Your observations must then be one to three word phrases (ex. "Age of citizen"). Also consider whether your two best key observations support different elements of the author's complex argument. Evidence that is too similar will end up building a repetitive argument that likely will not develop the level of complexity that is required to write at a university level.

Your goal is to look at the long list of evidence you just gathered and choose the best two pieces. Look at your entire list of evidence and ask yourself:

- Which of these pieces of evidence points most clearly to the author's argument?

- Which of these pieces of evidence has the most interesting or complex language?

- Which of these pieces of evidence would I be interested in discussing?

- Which pieces of evidence overlap? Can I make groups out of certain pieces of evidence?

Look at your entire list of potential evidence, and, using these basic questions as your guide, focus in on two key pieces of evidence. Going back to "The Plot to Privatize Common Knowledge" by David Bollier from the introduction to this text, and the evidence we gathered in Video 1.2, we went through the list, and with the above questions in mind, decided that the two pieces of evidence we wanted to focus on were: 
1. The binary between corporations and the public because Bollier wants to establish that the corporations are being greedy in their rush to privatize knowledge of many forms, whereas the public, he argues, has a fundamental right to the "common good" of that knowledge.

2. The description of the copyrights and patterns as "anti-social instruments of control" because the author wants to ensure that the readers understand that copyrights and patents, when abused, are negative capitalist systems built around restricting, controlling and owning ideas and knowledge, and treating those ideas and that knowledge as property. 


\section{Your Turn!}

\section{Activity}

Write down what you've chosen as your two best pieces of evidence that you feel most clearly support the author's complex argument. For each of those pieces of evidence, write one sentence explaining why you chose that piece of evidence, and what portion of the author's argument that specific piece of evidence is supporting.

Now that you have two pieces of evidence and justification for why you are using those specific pieces of evidence, you are ready to move to the next stage of pre-writing and draft an observational paragraph. The goal of an observational paragraph is to

- Explain why you've chosen each piece of evidence

- Link your two pieces of evidence together

- Explain how that evidence supports a specific complex argument that the author is making within the text.

This is not your thesis, but, rather, a pre-writing activity that is meant to be an initial gathering of ideas that you will begin to shape into a more concrete close reading in the coming chapters. Do not worry about getting it all "correct" or "perfect." Just get your ideas out and be willing to edit! While this paragraph will not be your exact thesis, it will contain elements that you can use later to write a strong thesis statement that proposes your analysis of the author's complex argument.

When linking evidence into the author's complex argument you should consider:

- How does the author's specific language in the evidence I've chosen speak to the argumentative position the author is taking? In a basic way, consider whether the words that the author is choosing pointing towards a negative or positive attitude towards their general subject?

- Why has the author made the deliberate choice to use the words that you have chosen as specific evidence? What do those words mean? Why would the author choose those words and not an alternative?

- In what ways is the evidence that I have chosen a small compact example of the larger argument the author is making? In other words, how does the small specific piece of evidence chosen expand out to the author's larger complex argument?

Let's begin with an example and, after you read it, you can use it as a model to write your own observational paragraph. Here is the observational paragraph we wrote using 2 key pieces of evidence we found in our analysis of the essay given in the introduction to this textbook, David Bollier's “The Plot to Privatize Common Knowledge." 


\section{Examples}

Though he is quick to clarify that he "straight-up" believes in copyrights and patents, Bollier is also equally quick to establish his claim that contemporary corporations have converted these property rights and claims into "crude, anti-social instruments of control and avarice." He very clearly establishes a binary between these greedy corporations rushing to privatize, manage, and outright own songs, words and even prefixes, and the public who seek only to share "fundamental knowledge" for the sake of the "common good." Through continued use of this contrast, Bollier makes certain his readers cannot miss what is really at stake in this quest to manage "creations of the mind": an "over-patenting" of thought to the point where the average person can no longer access freely the accumulated wisdom of humanity.

Looking back over the list of data we gathered when examining Bollier's essay in Video 1.2, you will probably notice that this paragraph is based on the observations of the binary between corporations and the public, and the abusive use of patents by corporations being characterized as "anti-social instruments of control." Using this information, and the brief sentence description as to why we chose the evidence that we did, we were able to draft an observational paragraph in which we begin to propose what Bollier is really doing here.

\section{Your Turn!}

Go back to the list of evidence you gathered as you were reading Charles' Justice's "The Ultimate Communication App"; it may also be useful to rewatch Video 1.3. After this, write a observational paragraph of your own based on your annotation and observations of Charles Justice's "The Ultimate Communication App." Select the two pieces of evidence you believe best point to the author's complex argument and explain what makes those two pieces of evidence the strongest. From there, construct one to two sentences in which you link those two pieces of evidence to what you have identified as Justice's complex argument.

Again, you are still in the pre-writing phase and you do not need to worry about your observational paragraph being completely polished. It is important at this stage to sift through all the evidence you've collected, choose what you think are the strongest two pieces and begin to analyze the author's complex argument. We will revise this observational paragraph later, but for now, it is important to write a first draft. 


\section{Thinking Ahead...}

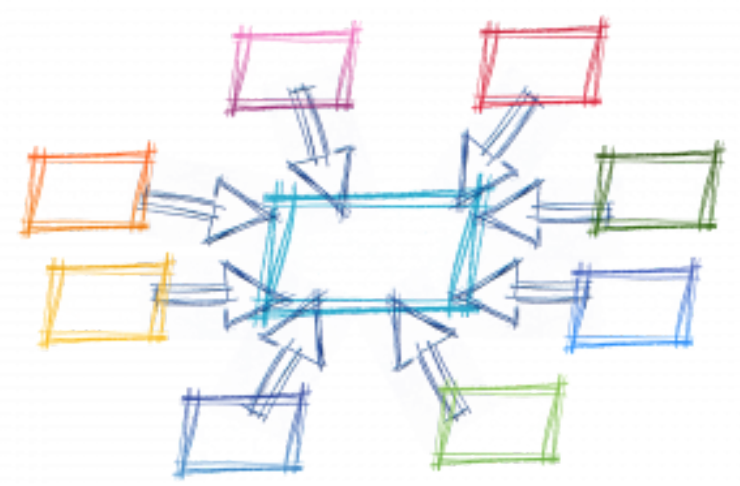

Get ready to organize your thoughts on the text. From Pixabay/ $\mathrm{CCO} 1.0$

Compare the paragraph you just wrote to your earlier essay on Charles Justice's "The Ultimate Communications App." You will likely see the improvement that gathering focused pieces of evidence brings to analyzing the author's complex argument. Now that you are comfortable with information gathering and crafting an observational paragraph, we are going to take the next step toward focusing that information into a purposeful thesis.

When you revise an observational paragraph into your unique and controversial reading of a text, you will need to capture the original text's main argument and highlight the article's main points (including any key concepts or theories) while eliminating all extraneous or minor details. Review the observational paragraph you wrote and consider how you might revise it into a purposeful thesis that analyzes the author's complex argument.

In the next chapter we will be working on revising your observational paragraph into a 2 storey thesis statement. By this we mean that you want to do a little more than summarize or simply restate what is in the text. You want your readers to understand right away that this is your reading of the text that follows from the evidence within the text that you have chosen. You are not summarizing, rather you are persuading your readers to see what they can learn about a text by reading it your way. 
CHAPTER 2: EVIDENCE 



\section{Chapter Overview}

\section{Learning Outcomes}

\section{In this chapter we will:}

- Review the information you gathered in Chapter 1 and use it to create your unique, purposeful reading.

- Reconsider some of our old habits that prevent us from creating a focused reading.

- Decide which observations will be included in your essay and create your essay blueprint.

- Create a controversial claim that will focus your essay and give it purpose.

- Develop the two-storey opening that will establish and focus your interpretive reading. 


\section{Drafting the Blueprint}

Following the information-gathering stage described in Chapter 1, the essay blueprint is the next step toward purposeful writing. The essay blueprint is NOT a summary (nor should it be confused with the essay roadmap, to be discussed in Chapter 4). Drafting an essay blueprint is an exercise that demonstrates clear understanding, meaningful citing and concise paraphrasing of the text's argument. In this sense, the essay blueprint is as much a reading comprehension exercise as it is an organizational exercise. Your thorough understanding of the text you are analyzing will determine the structure of your essay and its validity.

When drafting the blueprint, be sure the evidence you use reflects accurately the content of the original text you are analyzing. In an analytical essay you must combine different ideas, theories, and facts to construct a coherent argument. In your blueprint you should consider the purpose and lay the groundwork for the analytical essay you will be writing.

A good blueprint should distill the main points of the other writer's work and organize them in a way that best suits your analytical reading. Keep your future essay in mind as you construct your blueprint, and remember that your essay should lead your reader through the same analytical process you went through to arrive at the claim you are making.

Before we start constructing the blueprint, let's watch Video 2.1: The Blueprint. This video describes some of the habits, or "Don'ts," we want to avoid when taking an analytical approach to an article. This lecture uses David Bollier's "The Plot to Privatize Common Knowledge," so have your diagnostic essay handy.

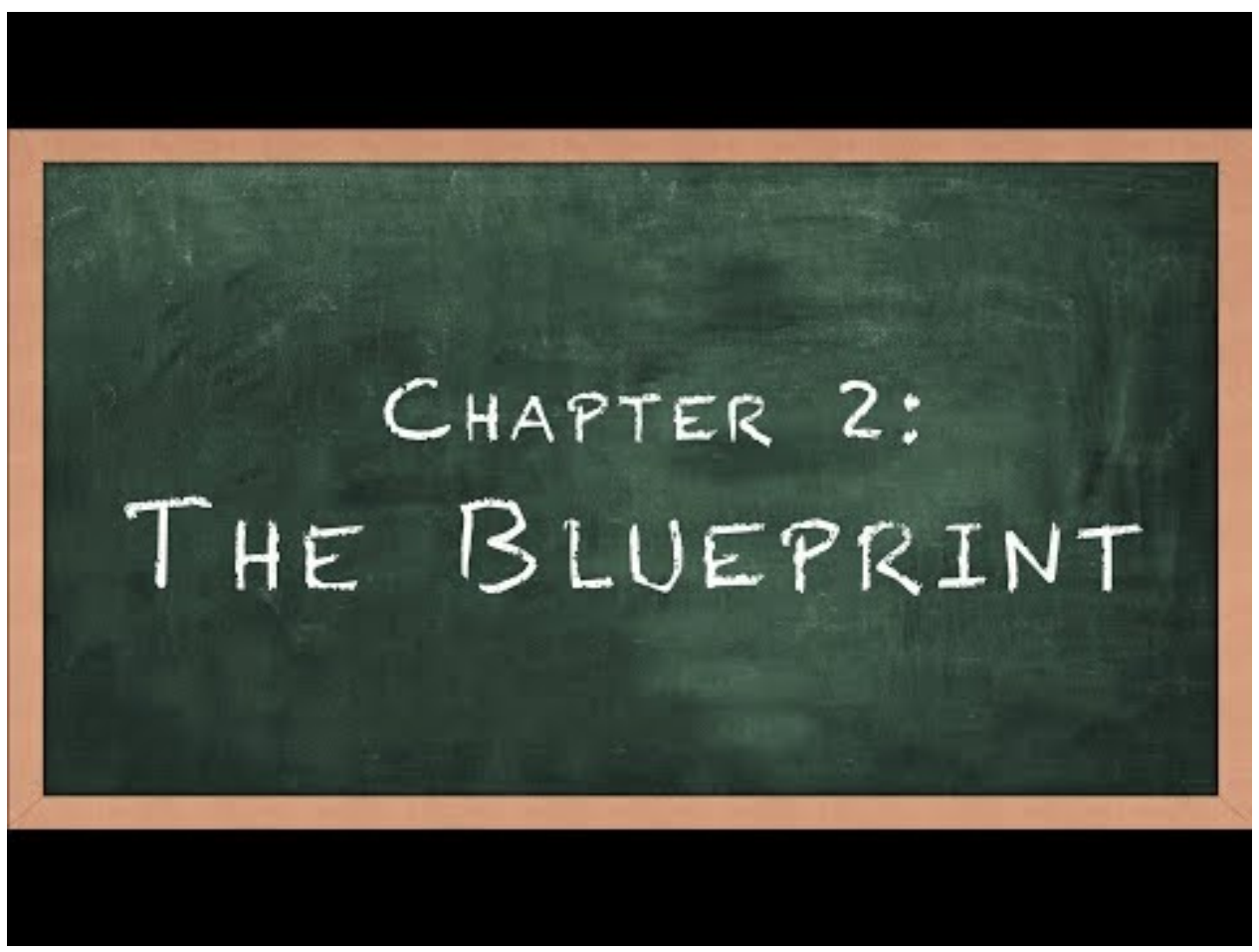

A YouTube element has been excluded from this version of the text. You can view it online here: https://pressbooks.library.ryerson.ca/writehere/? $p=345$ 


\section{Turning Your Lists Into Your Blueprint}

When preparing to write your analytical essay, make sure you have more information than you need. It is better to find yourself debating which observations to include rather than being a couple of paragraphs into your essay and realizing you have exhausted all the evidence you have gathered. In the following exercise, we'll learn how to avoid this type of situation.

Look back at the information you have gathered in your examination of Charles Justice's "The Ultimate Communication App" and then answer the following questions.

\section{Taking Measure}

Have you annotated the article you are analyzing? (i.e written in the margins and underlined interesting words and phrases; drawn connecting arrows between aspects of the text you believe work together to deliver a central message)

$\mathrm{Y} / \mathrm{N}$

Have you made a list of at least 7-10 interesting words or phrases found in the article?

$\mathrm{Y} / \mathrm{N}$

Have you made a list of at least 7-10 words or phrases that are new to you?

$\mathrm{Y} / \mathrm{N}$

Have you created at least 7-10 lists of synonyms and patterns?

$\mathrm{Y} / \mathrm{N}$

Does each of your lists of synonyms and patterns contain at least 3 different words of phrases?

$\mathrm{Y} / \mathrm{N}$

Have you created a list of 7-10 contrasts you noticed within the article?

$\mathrm{Y} / \mathrm{N}$

Have you selected 2 pieces of evidence from your data and composed an observational paragraph?

$\mathrm{Y} / \mathrm{N}$

Are these 2 pieces of evidence literal textual evidence you can put your finger on?

$\mathrm{Y} / \mathrm{N}$

Have you made your lists and your observational paragraph on a separate piece of paper ready for the next step of analysis?

$\mathrm{Y} / \mathrm{N}$

Do you have the beginnings of an idea of this article's purpose and the direction your analysis will take? $\mathrm{Y} / \mathrm{N}$ 
If you answered "No" to any questions, return to the Justice article and do the work needed to change every "No" response into a "Yes".

40 | Turning Your Lists Into Your Blueprint 


\section{Why Construct an Essay Blueprint?}

An essay blueprint is almost always written as part of an academic exercise. Although a good blueprint requires clear and concise writing, as an academic exercise, it is primarily a test of your reading comprehension skills. A blueprint demonstrates your ability to identify central arguments and key concepts and to restate theoretical concepts in your own words and around your own claims. For this reason, blueprint construction also helps to develop the reading skills you need to effectively prepare for essays and exams. 


\section{Constructing Your Essay Blueprint}

With your data and observational paragraph in front of you, read the original text again. This may seem like an exercise in redundancy, but re-reading with the seeds of your own interpretation in mind will help you to confirm or revise your reading of some passages and elements. Reading the text again may also help you find less obvious support that will strengthen and make your reading or analysis more complex. As you read, you should ask yourself, "What is the purpose of this text? What is the central argument? How does the author support the central argument?"

Draft your blueprint: Once you have extracted and compressed the essential material in the original text, it is time to begin structuring your blueprint. You do not necessarily need to present the author's ideas in the order they originally appear. You may want to begin your blueprint by stating the author's central thesis, even if it does not appear at the beginning of the original article. However, it is best to avoid a point-by-point analysis of the text as that will result inevitably in summary, which you most certainly want to avoid at this level.

You should begin your analysis with an examination of what you believe to be the most important and revealing piece (or pieces) of evidence. Was there a moment in the text or a key repetition or consistent contrast that confirmed for you what this text was really about? Begin with that. Using that strong base, you can move to your second and third strongest pieces of evidence. Continue with all your evidence, building your analysis until you reach your final points which should examine the less-than-obvious supportive aspects of the text. A close reading doesn't just rely on one or two obvious statement that prove you are "right." Imagine that you are luring your reader into your understanding of the text: "Do you agree with my reading of the first piece of evidence? The second? The third? Well, then perhaps you would like to consider what I have to say about this part of the text that you may be surprised to find in this argument."

Understand that not every essay you analyze will let you apply this formula, but the exercise of pushing your claim to consider all aspects of the text is always worthwhile.

In your blueprint, be sure to cite keywords and terms from the original text. Cite those words or phrases that you believe are pivotal to the author's delivery of his or her main message and explain why. While quoting the author is expected at this level, you never want to let these passages stand alone without analysis. So include the analysis of the selected quotations in your blueprint. While you do not want to rush to your purposeful analysis and interpretation of the text while conducting the information-gathering exercise detailed in Chapter One, it is good to start your meaningful interaction with the text in these pre-drafting stages of organization.

Review and Revise Your Essay Blueprint: Remember that a blueprint is an outline for the essay you will eventually construct. Its purpose is to organize the information or evidence you've gathered from your annotated reading of the text and to begin structuring your analysis of the author's purpose and argument. Don't just rush into your essay after you've completed your blueprint. Reread the article then review your blueprint. Have you included everything you believe will lead to your most interesting and controversial reading of the text? As you revise your blueprint, ensure that you have:

- captured the main argument presented in the original text

- highlighted the article's main points (including any key concepts or theories) and eliminated all extraneous or minor details

- presented clearly your interpretation and interaction with the text. Is it obvious that you understand the text you are analyzing? Is your interpretation of the text presented clearly? 


\section{Constructing Your Two-Storey Opening, Part I}

Now that you have created a blueprint with all the information you have gathered, it's time to develop an opening focus and claim, also known as a thesis statement. This opening will function as an analytical lens through which you will examine the details of the text. Your opening line needs to do more than simply restate what is in the text. Your opening line is your first opportunity to impose your interpretation upon the text. You want your readers to understand right away that this is your reading of the text. You are not summarizing, rather you are persuading your readers to see what they can learn about a text by reading it your way. So your opening needs to contain some sort of controversial claim.

It is helpful to think of the opening as a building with two storeys. The first storey identifies what the text you are reading is doing while the second storey identifies why that text is doing what it is doing.

The first-storey of your opening should make an observation that is factual and undeniable. By that we mean an observation that is easily proven with evidence from the text. This level or "storey" makes a statement that is not controversial and with which no reasonable person who reads the original text would disagree. A person reading such a thesis thinks immediately: "Yes, this is true."

\section{Example}

In his novel Heart of Darkness, Joseph Conrad uses the imagery of dark and light.

Joseph Conrad was an established novelist and he used many literary techniques in Heart of Darkness. There likely are other types of imagery throughout the novel. There are probably similes and metaphors. He may have even used onomatopoeia. But that does not matter, because the focus here is his use of dark and light imagery. Your opening should begin with a focus that establishes this reading as yours. You do not want to write a vague claim then grab for anything that fits. Focusing on a key textual element or concept based on evidence from the text establishes an approach that, while it may seem obvious to you, may not be the approach everyone would take.

This opening observation about Conrad's work is rather obvious. You need not have read the novel to infer that Conrad uses dark and light imagery-it's in the title: Heart of Darkness. But this level of focus is vital: you do not want say anything that is not unique to the text or your analysis of it.

The second-storey asks a question to interpret, give a point of view on, or add controversy to the facts of the first storey. "Adding controversy" means taking a position on the facts-a position with which a reasonable person could disagree. A person reading the second storey of your opening should think: "That's an interesting point of view, now prove it to me!" By controversial, we do not mean that this observation has to be absurd or idiosyncratic. Rather, we mean that it takes one position out of a number of possible positions. 


\section{Example}

In the novel Heart of Darkness, Joseph Conrad uses the imagery of dark and light to represent the contrast between civilization and savagery.

The "second storey" part of this thesis statement is well-known, but it is not undeniably true. It is plausible, but it is also debatable-it must be proven by analyzing evidence from the text. Another reader could disagree with this "second story" and use their own evidence to controvert it. That's fine. In fact this should be your goal. Debate and discussion is exactly where you want to be as a scholar and an interpretive reader. You should feel like there is something at stake here. You should feel a little uneasy. You should feel like you need to prove the validity and worth of your reading. If you are saying something that is undeniably true, then you are not moving past simply pointing at what is there. If you are saying something that requires further analysis and evidence, then you are contributing to the ongoing scholarly conversation. So, if you have found that controversial, debatable, and (most important when it comes to constructing your analytical essay) defensible claim about a text, well, CONGRATULATIONS: you are extending and expanding the scholarly conversation. You are a scholar.

You can now use your opening focus and claim to reconsider and restructure your essay blueprint. A detailed description and analysis of your evidence should follow your opening and support your focus. Let's return to our analysis of Bollier's "The Plot to Privatize Common Knowledge." In Video 2.2: Creating the Two-Storey Opening, we will review the information we have collected, the observations we have made, and the connections we have formed and use them to create a two-storey opening that will establish and guide our meaningful analysis of the text. 


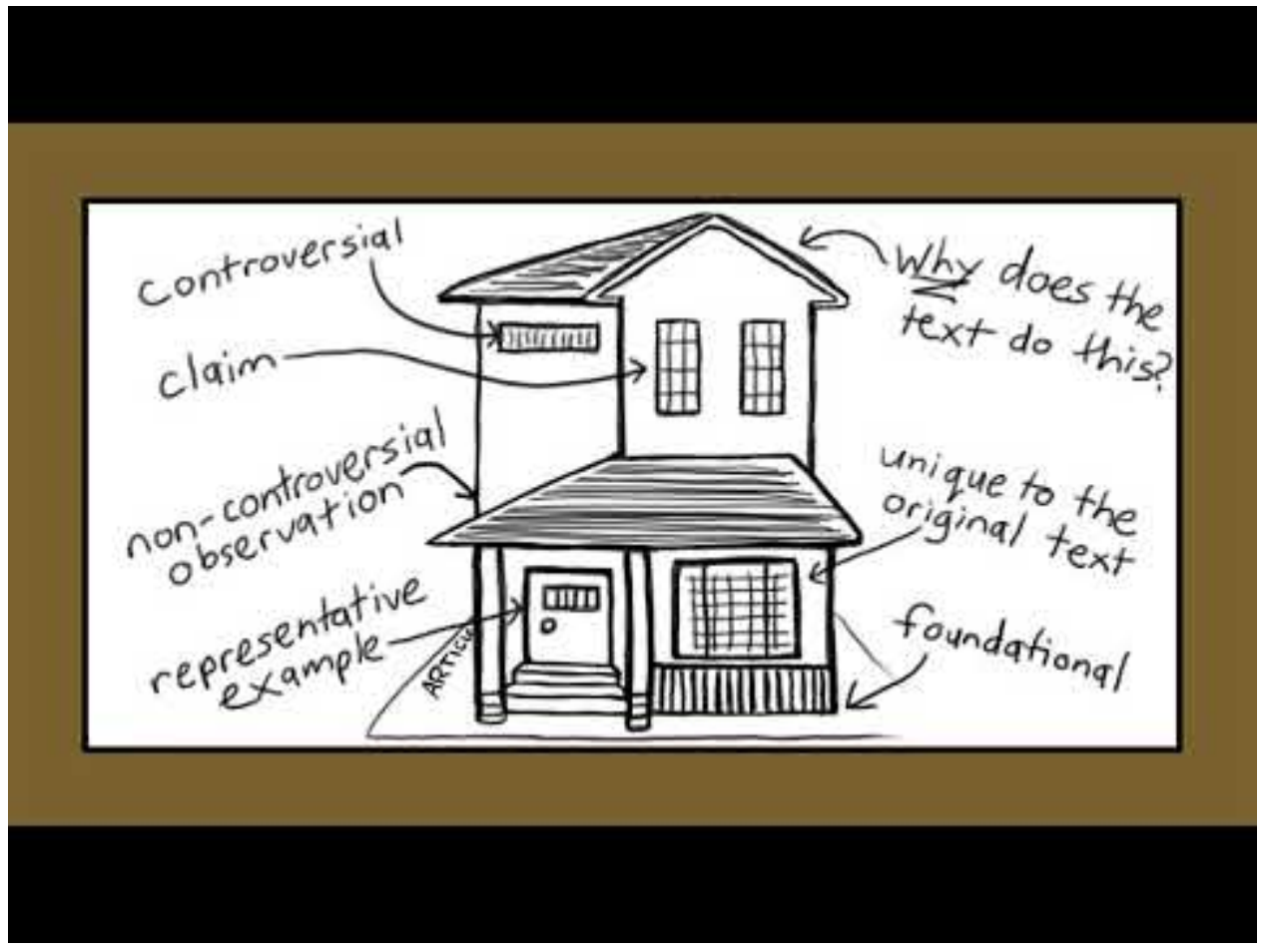

A YouTube element has been excluded from this version of the text. You can view it online here: https://pressbooks.library.ryerson.ca/writehere/? $p=361$ 


\section{Constructing Your Two-Storey Opening, Part 2}

The observational paragraph we produced at the end of Chapter 1 already contains textual evidence and the author's purpose:

\section{Example}

Though he is quick to clarify that he "straight-up" believes in copyrights and patents, Bollier is also equally quick to establish his claim that contemporary corporations have converted these property rights and claims into "crude, anti-social instruments of control and avarice." He very clearly establishes a binary between these greedy corporations rushing to privatize, manage, and outright own songs, words and even prefixes, and the public who seek only to share "fundamental knowledge" for the sake of the "common good." Through continued use of this contrast, Bollier makes certain his readers cannot miss what is really at stake in this quest to manage "creations of the mind": an "over-patenting" of thought to the point where the average person can no longer access freely the accumulated wisdom of humanity.

In our two-storey opening we present the interpretive leap we will be taking in our unique and purposeful reading of Bollier's article:

\section{Example}

In "The Plot to Privatize Common Knowledge" David Bollier examines the perceived threat to "fundamental knowledge" and the "common good" posed by contemporary corporations who are converting property rights and patenting claims into "crude, anti-social instruments of control and avarice." He uses this examination as a warning to his readers that such "over-patenting," if continued unchecked, will result in much of what has been previously considered the shared and accumulated wisdom of humanity becoming "off limits" to the average citizen. 


\section{Your Turn! (Part I)}

\section{Activity}

Now it's time for you to practice the skills we have been discussing in Chapters 1 and 2. Read the following essay: "Kids Around the World Just Want to Hang Out" by Michael Welsh and then use the granular informationgathering process we outlined in Chapter 1 to annotate or make notes as you read, highlighting interesting words (and their definitions), synonyms and related terms, and the author's use of comparisons and contrasts.

\section{Kids Around the World Just Want to Hang Out}

\section{Michael Welsh}

Between 2009 and 2010 two very different cities, Stockholm, Sweden and Keene, New Hampshire, underwent a process of community visioning and master planning. High school students in both places were asked to provide input about their preferences and visions for their cities. High school students are interesting because in many ways they are pre-political. They are clients and consumers of the public services and environmental amenities around them but with little exception they have not experienced the costs associated with their provision. Asked what they like or want, in other words, they are much less likely than adults to think about things like taxes, public sacrifice, or the restraint of private choice that might be necessary to make that outcome happen. As a result they are less likely to self-censor or consciously limit their ambitions.

Stockholm and surrounding cities boast a record of documented results from active planning, and high schoolers there predictably saw government providing public and environmental goods and services they valued for the future. High schoolers in Keene agreed that the government was a source of valued commons assets, but were hesitant to ask for more. When asked about their desired future many instead mentioned malls and amusement parks, while Swedish high schoolers wanted clean waterways, street art, and public transit. This difference, which goes beyond mere preference for environmental or cultural amenities, lies in the perceived capacity of utilizing government to provide these kinds of public goods in the future. This difference is significant and revealing, not just for the contrast it strikes between young people in these two 
cities, but also for the prospects for planning and governance as these high schoolers grow into their roles as wage earners, property owners, taxpayers, and voters.

\section{Collecting and Comparing Statements From High School Students}

In 2009 Keene city planners asked young people in high school about the features of their town that they valued and would like to protect. Meanwhile a similar effort to solicit the visions and planning objectives of students 4000 miles away in Stockholm, Sweden was already underway.

Since these two studies were not coordinated and the questions prompting all of these results were not identical, a classification system between the categories of public or social and private goods has been used to code student responses so they can be more readily compared. Private goods are items and services that can be exclusively acquired through the market. A public good, on the other hand is defined as nonexcludable, which benefits every members of a community which no one can be prevented from using,"Public goods might include a pleasing roadside garden or fireworks high above the crowd at a baseball game or benefits from government action like national defense or environmental pollution control. Public goods are of interest to the study of politics because they are, to one way of imagining it, one of the main reasons humans create and submit to government. Government is the institution that creates and sustains the provision of public goods. It has the power through taxes and other methods to coerce, if necessary, for their payment. Politics is the public debate about which of these goods will be created and how they will be paid for.

Groups in both studies were asked to describe the problems they saw around them and their source. In Sweden students overwhelmingly identified problems arising from insufficient government action or inadequate protection or provision of public goods and services: They feared a decline in green spaces. They were concerned with loss or erosion of public transit. They complained of a lack of bicycle paths or gathering spaces. In fact, of fifty one areas of concern developed in the study of Swedish high schoolers, thirty two (63\%) directly translate as declining public goods (a decline in biodiversity, for example) or a lack of government action (to stem a rise in crime, for example). Twelve percent were identified as problems resulting from a lack or decline in private goods.

American students were more focused on their town of Keene as they wrote answers that described the things they would change or problems that concerned them. Nevertheless, in their responses $62 \%$ (almost identical to those in Stockholm) identified problems arising from inadequate provision of public goods (a need for more public transportation or an improved public skate park, etc.), while $5 \%$ cited undesirable side effects of business (too many chain stores, construction leading to displacement of wildlife and natural areas). A substantial number (30\% combined) identified government actions as a problem or saw problems in their town from a lack of business or types of business.

The responses of students in both countries results are quite similar. Keene students seem to appreciate public goods, like their Stockholm counterparts, but are also more openly critical of government and desirous of private goods provided by markets.

The significant differences between Stockholm and Keene students arise in their vision of their town in the future. In the Stockholm area 53\% of high schoolers' responses sought increased public goods, with examples ranging from "a better education," to a "healthy Baltic Sea," to less crime, to free public transportation. Added 
to this were $22 \%$ of responses classifiable as the product of increased government regulation or intervention (things like "more green homes" or more renewable energy, or a "car-free inner city").

The vision that Keene students promoted of their city was more mixed. Only $36 \%$ of responses envisioned a city with access to more improved public goods. These included some of the same things Stockholm students wanted: improved public transportation, green buildings, preserved parks and green spaces, biodiesel buses, or a new skate park. However, many more of these New Hampshire students envisioned increased private goods (28\%) and hardly any (3\%) envisioned a more active or responsive government.

\section{What's Going On Here?}

One could argue that American students seem less inclined to trust government than their Swedish counterparts. Young people in Keene (one of the most liberal areas of New Hampshire, according to recent voting results) are not offended by government regulation, bloated bureaucracy, or an oppressive "nanny state." They are not Tea-Partiers alarmed at creeping socialism. Students appreciated the parks, trails, and green spaces of the town. In fact, in a question about the features of their city they value - a question not asked of Swedish students - a full 73\% of responses were government-provided or government-protected public goods. They liked the festivals and public activities as well as the fact that the town is "walkable." What they appreciated about the commercial side of their city was sometimes a specific establishment (Borders Bookstore, Dick's Sporting Goods, Brewbaker's Coffee Shop) but more often a general category: "new stores," "movies," "restaurants." Commercial establishments seemed to be appreciated because they provided "something to do" as opposed to providing goods themselves.

Thus what distinguishes American high schoolers from their Swedish counterparts is not the things they value but rather what they expect to see the future, which affects the things they feel justified in seeking and their imagination of what's possible to obtain. When asked what they like about their town, Keene students articulated a list dominated 3 to 1 by public goods. But when asked about their desired vision of a future for the town, public goods and private goods were mentioned at about the same level. Further, a majority of the envisioned private goods involve things like a mall, an arcade, or low/no cost places to "hang out." Some spelled this connection out directly: "a mall or something for teens to do," or "more places to shop and hang out." What responses like these seek is a commercial realm or market that provides them with the things that approximate a public commons - a safe, pleasant, and conducive place to be or engage with others.

But why do American teens seek these commons amenities from private sources like a mall or theme park instead of the public realm? Such places are rarely truly accessible to all (a defining feature of public goods) or even qualitatively equivalent to their public component. Gated communities feel safe but secluded and unspontaneous. Malls close before it gets too late, expect at least some spending by visitors, typically necessitate driving (or being dropped off), and employ security guards to prevent the kind of gathering that a public space invites. Knowledge of this is implied by one Keene high schooler who requested a mall "but get rid of some of the cops." With all of these shortcomings, why ask for private amenities and spaces over more public ones?

A plausible answer is that these young people no longer consider government to be the entity most able to provide them with what they want. The era of big government was declared over before they were born, perhaps eliminating the possibility of more public goods as even a possibility. During their lives current US 
high schoolers have seen the total Federal outlays as a percentage of gross domestic product track steadily downward. Tax cuts are seen as a policy tool of first choice, and privatization or charging fees for what were once public services is common everywhere from parks to police protection. New research demonstrates that young people engage in consumer choice ("political consumerism") as a means of making social change more than any other age group. Older people in America people think change comes from voting. Younger people instead practice "fair trade."

While more research is clearly called for, the upshot seems to be an ideology among American youth that appreciates the things that government makes possible in their lives and society, but that lacks imagination that these or similar things will continue to be available from government in the future. For almost a quarter of Keene students, in fact, a positive vision of the future is one that merely holds back the loss of the public goods around them. Call it an ideology of limited expectations from government. It functions as a preventative against disappointment and redirects focus to the benefits promised by the private/commercial realm.

Limited government is not embraced by everyone in America, and planners and others should not read the preferences and attitudes that might arise in surveys of young Americans as indifference to public goods. Like their counterparts in Sweden it seems likely that American young people will support things like the preservation of green and public spaces, or the expansion of mass transit. Nevertheless from within the ideology of limited government expectations explored here it makes perfect sense for a young person to place their future hopes on new stores that will not displace too much open space, even as they relax in a park playing Frisbee with friends. 


\section{Your Turn! (Part 2)}

\section{Activity}

1. Reread the essay and list the words and phrases you've highlighted-remember that at this stage, it is better to accumulate more information than you will need for your final essay.

- $\quad 7-10$ interesting words

- 7-10 definitions of new words

- $7-10$ lists of synonyms and related terms

- $\quad 7-10$ contrasts and comparisons

2. Review your lists and select the two most revealing and important pieces of information upon which to build your unique interpretation of the text. Draft an observational paragraph that uses this piece of information as the textual evidence for your interpretation.

3. Draft an essay blueprint using all the evidence that supports your interpretation.

4. Using the work completed in step 1,2, and 3, write a two-storey opening that moves from your textual evidence to a controversial claim about the author's purpose.

How did you do? Did you gather enough information and evidence from the text to come up with your own interpretive focus and claim? Your blueprint should clearly delineate how you move from the claim made in your opening, through your more obvious evidence, and into the less obvious evidence. That "less obvious" evidence appears more viable in the face of your mounting evidence. 


\section{Watch This!}

Now that you have completed the process and drafted a blueprint and opening for this essay, watch Video 2.3: Analysis of Article and Constructing the Two-Storey Opening to see what we came up with. It is important to remember that your interpretation of the text does not have to be the same as ours. There is no right or wrong interpretation of a text when that interpretation is supported by evidence from the text. Consider the argument we make in our close reading, but pay more attention to the work we put in to get to that interpretation. While your focus and claim need not be the same as ours, it should have the same level of support.

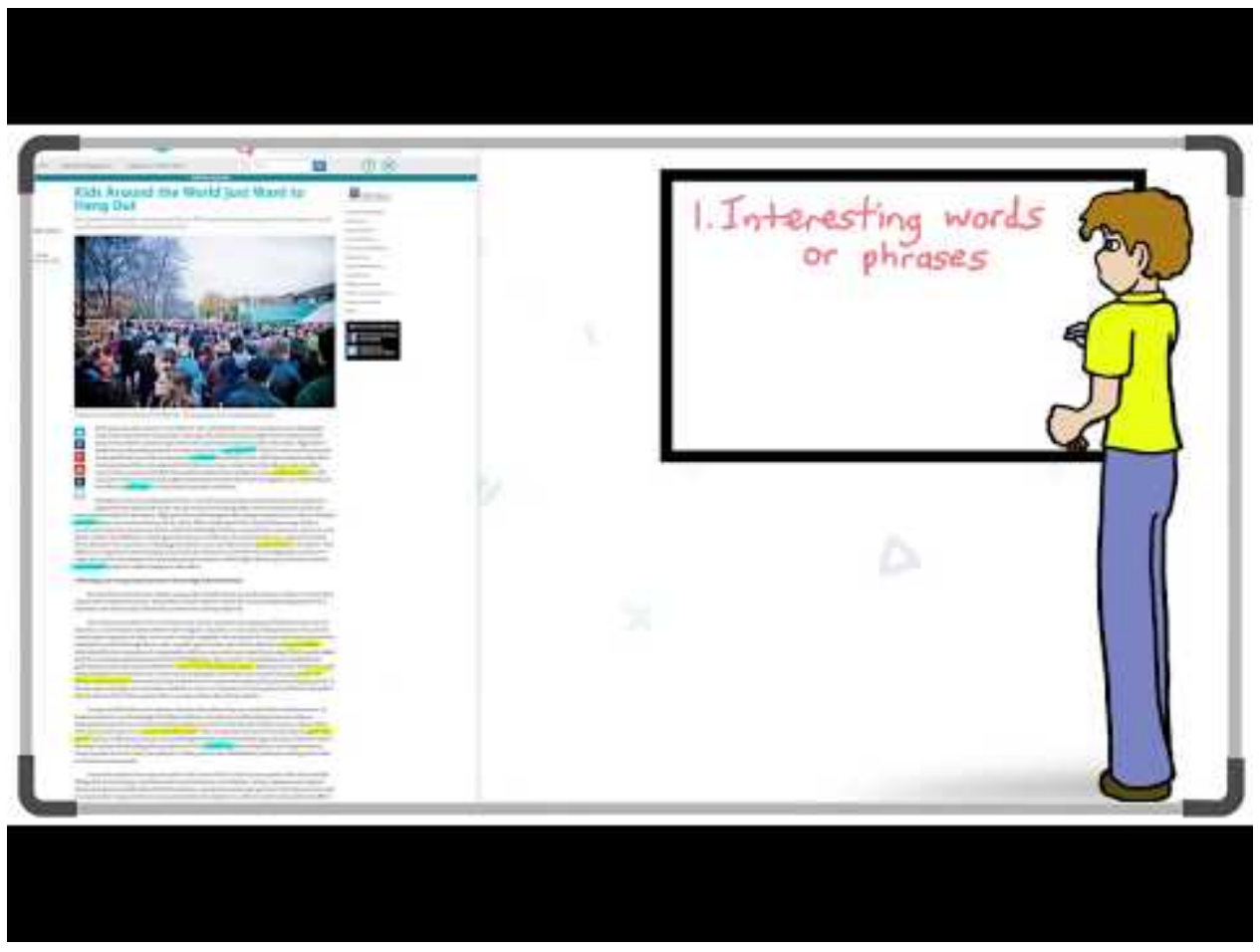

A YouTube element has been excluded from this version of the text. You can view it online here: https://pressbooks.library.ryerson.ca/writehere/? $p=374$ 
public sacrifice non-excludable

\begin{tabular}{|c|c|}
\hline $\begin{array}{l}\text { Interesting } \\
\text { words or } \\
\text { phrases }\end{array}$ & $\begin{array}{l}\text { create and submit to government } \\
\text { conducive place } \\
\text { unspontaneous } \\
\text { "fair trade" } \\
\text { public goods } \\
\text { environmental pollution control } \\
\text { erosion of public transit } \\
\text { gathering spaces }\end{array}$ \\
\hline
\end{tabular}

pre-political

self-censor

New words or commons

phrases amenities

wage earners

biodiesel

biodiversity

political consumerism 
Save the planet: walkable, car-free, green homes, biodiversity

Young People: pre-political, high school students, kids

Responsibility: taxes, public sacrifice, or the restraint of private choice

Synonyms and

Related

Terms

Making tomorrow, today!: community visioning and master planning, ambitions, desired future, young people engage

Cogs: clients and consumers, wage earners, property owners, taxpayers, and voters,

Power: submit to government; coerce; government regulation, bloated bureaucracy, or an oppressive "nanny state;" rarely t
Swedish Students' Concerns: insufficient government action, inadequate protection or provision of public goods and servic public transit, lack of bicycle paths or gathering spaces

American Students Concerns: inadequate provision of public goods, more public transportation or an improved public skat many chain stores, construction leading to displacement of wildlife and natural areas, government actions, lack of business or

Lowered Expectations?: hesitant, expect; perceived capacity; privatization or charging fees for what were once public servi protection; an ideology of limited expectations from government 
public or social v. private goods

Stockholm, Sweden v. Keene, New Hampshire

adults v. high school students

Contrasts "malls and amusement parks" v. "clean waterways, street art, and public transit"

Stockholm students' vision v. Keene students' vision

active citizenship v. "something to do"

private realm v. public realm

lack of imagination v. challenging the perceived status quo

consumerism $\mathrm{v}$. civil disobedience?

\section{Observational Paragraph}

We have chosen as our two best observations the contrast of "Stockholm students' vision v. Keene students' vision" and the list of synonyms titled "Lowered Expectations?" (It is again worth noting that the choice of these two observations as the "best" does not mean we throw away or ignore the remaining observations. Rather, we use the selected observations as a lens through which we can view, select, and organize the remaining information into our most interesting and persuasive analytical reading.)

\section{Two-Storey Opening}

In "Kids Around the World Just Want to Hang Out" Michael Welsh compares the responses given by two separate groups of high school students from Stockholm, Sweden and Keene, New Hampshire who were surveyed about "their preferences and visions for their cities." Welsh uses this comparison to convey a distressing reality he hopes his American readers will be motivated to address: while both groups of students seemed to have the same hopes and visions for a greener, cleaner future for their cities, the students of Keene displayed considerably less vision than their Stockholm counterparts, "limited expectations" of their government's ability or interested to help them attain their goals, and a worrying reliance on commercial companies to provide them the accessible, common, and entertaining spaces they desire. 


\section{Blueprint}

Point One: Analyze the similar desires Welsh identifies within the responses of both groups of students making note of how the only difference seems to be the Keene students' "lack of vision."

Point Two: Analyze how Welsh seems to point to the influence of commercialism on these students as not only a possible source of this "lack of vision" but also a source of inspiration and salvation for these hopeful but surprisingly uninspired students.

Point Three: Analyze how Welsh subtly insinuates the dangerous difference between a public commons and a corporate sponsored commons

Point Four: Analyze how Welsh discusses what is really at stake here and what is really lost. Free thought and innovation are fostered in free and open common spaces. What will happen to the future if these spaces are no longer "free" but sponsored by corporations with their own desires and agendas? 


\section{Thinking Ahead...}

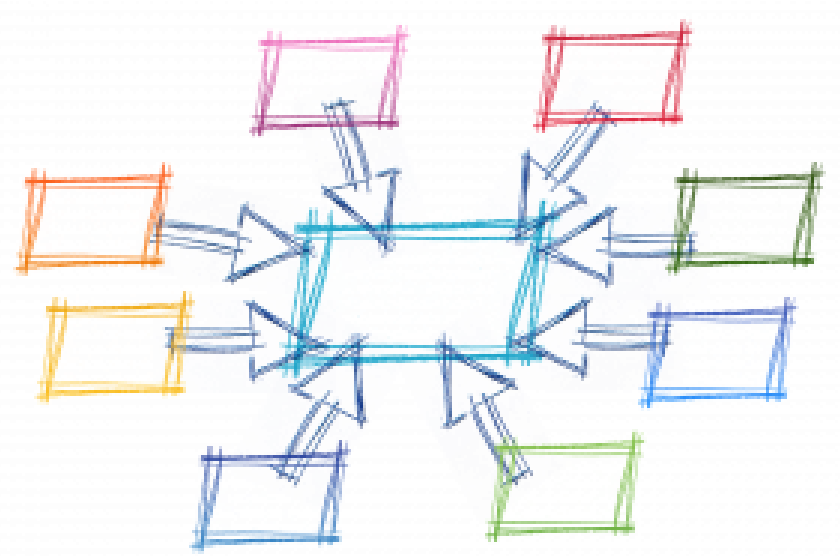

Get ready to organize your thoughts on the text.

From Pixabay/ $\underline{\mathrm{CC} 0} 1.0$.

Review the selection of essays available for your midterm. Take some time before the next class to read the selected essays. Don't choose too quickly! Try not to select automatically the shortest essay or the essay with the most interesting title. Read each essay and decide which one most interests you. For which one do you think you can gather the most information? Which one is likely to inspire you to make a unique interpretive claim for which you will have sufficient and suitable textual evidence? This should give you a clear idea of which article will work best for your midterm assignment.

After you select the article you want to analyze for your midterm, create a blueprint and write your two-storey opening. Always bring your notes and draft materials to class for feedback and further revision. 



\section{CHAPTER 3: THE FULL THREE STOREY THESIS}





\section{Chapter Overview}

\section{Learning Outcomes}

\section{In this chapter we will:}

- $\quad$ Evaluate the two-storey thesis that you wrote in Chapter 2.

- $\quad$ Edit and rewrite the two-storey thesis statement you wrote in Chapter 2.

- Add the third storey to your thesis to complete the first draft of a thesis that will lead to a universitylevel close reading. 


\section{Revising Your Two-Storey Thesis}

Your thesis statement is like a map for your readers: a reader should be able to look at your thesis statement and have a general idea of the direction your essay will take. Chapter 1 of this text focused on reading, annotating, and analyzing another author's text. Chapter 2 described how to turn your initial observations into a blueprint and then a first draft of a two-storey thesis statement that proposes a focused analysis of another author's argument. So far the text has focused on developing the habit of slowing down to read, re-read, and analyze a text. After gathering all the evidence in a text, choosing the best two pieces, writing an observational paragraph that we then transformed into an essay blueprint, we wrote an initial two-storey thesis. In this chapter we will begin the process of revising that initial thesis.

Revision is when you sharpen your ideas by condensing your language and clarifying the steps of your close reading.

Revision is not something you do once, at the very end of the writing process. Revision takes place all the way through the process of your writing on small and large scales. While later chapters will involve revising a completed close reading, this chapter will focus on writing a second draft of your two-storey thesis and then describe how to add the third storey: the scholarly concept.

But what should you look for when examining your first draft? What focus should you take as you write a second, third, or even tenth draft of your thesis? Let's begin with a self-evaluation of the two-storey thesis you wrote in the previous chapter. 


\section{Self-Evaluation of Your Two-Storey Thesis}

\section{Taking Measure}

Complete the self-evaluation of your two-storey thesis below. Your ideas are complex and therefore your thesis statement should be long enough to explain your thoughts. Eventually this thesis statement will be the introduction to your paper, so you want to make sure that it is strong before you begin writing your entire essay.

Each question requires a "Yes" or "No" answer. For each "Yes" response, give yourself one point. Your final score will be a mark out of twelve (ex: 10 "Yes" responses = 10/12).

\section{Components}

Did you identify a specific audience (Who? Where? When?)

$\mathrm{Y} / \mathrm{N}$

Did you identify two specific pieces of evidence?

$\mathrm{Y} / \mathrm{N}$

Did you identify a central paragraph or paragraphs (one or two paragraphs from which you will draw your key observations)

$\mathrm{Y} / \mathrm{N}$

Did you briefly paraphrase the AUTHOR'S argument? Is it a statement that can be agreed or disagreed with? $\mathrm{Y} / \mathrm{N}$

First Storey: Evidence/Observations

Is the first piece of evidence something you can literally point to in the text?

$\mathrm{Y} / \mathrm{N}$

Is the second piece of evidence something you can literally point to in the text?

$\mathrm{Y} / \mathrm{N}$

Does each piece of evidence have evocative connotative value?

$\mathrm{Y} / \mathrm{N}$

Second Storey: Argument 
Have you focused on the AUTHOR'S ARGUMENT? You should not be voicing your opinion on the author's topic.

$\mathrm{Y} / \mathrm{N}$

Does your proposed analysis of the author's argument follow from the evidence provided?

$\mathrm{Y} / \mathrm{N}$

Is your paraphrasing/reconstruction complex? More than half a sentence?

$\mathrm{Y} / \mathrm{N}$

$\underline{\text { Style }}$

Did you avoid the use of second or first person pronouns? (I, we, us, our etc)

$\mathrm{Y} / \mathrm{N}$

Did you avoid words from the Control-F List, opens new window? (society, technology, people, etc.)

$\mathrm{Y} / \mathrm{N}$ 


\section{Revising Towards A Second Draft of Your Two-Storey Thesis}

Congratulations! You are done the first draft of your two-storey thesis statement and are headed towards a second revision. One of the keys to revising your two-storey thesis at this stage is to remember that you are analyzing another author's complex argument. You are not being asked to voice your own opinion on the author's topic, nor make an argument that agrees or disagrees with the author's stance on the topic. Rather, you are being asked to identify the best two specific words and phrases used by the author that most clearly point to their complex argument. Those two specific pieces of evidence are the evidence that you are using to then analyze the author's complex argument in your own words. Let's walk through the evaluation together.

\section{Components}

In a two-storey thesis, it is essential to identify the author's audience (i.e the very people the author hopes will read the article) and in which genre the author is working. Identifying the author's intended audience is important because an author will use different vocabulary, sentence structure, and tone to argue to different groups of people; an author would argue differently, for example, if they were talking to a group of high school students in Toronto, Canada, than they would speaking to a group of senior citizens in Calgary, Canada. As well, knowing what type of document the author is creating, or the genre, will help you understand the conventions and discourse in which the author is participating. The same topic could be discussed in a newspaper article or a magazine editorial or an academic journal article, but the language and presentation will be markedly different across these publications.

You can then use the understanding of the author's audience and genre to focus more tightly on the author's argument. Remember: you are not reconstructing the author's entire argument. Instead, you are writing a short essay that examines what you believe to be one of the more important arguments the author makes. To this end, you should focus on the two best pieces of evidence in support of this selected argumentative path. As this level, your reader generally knows there are many different ways to interpret an author's work in an essay: your close reading should include two pieces of evidence that best support your interpretation of the author's audience and genre. Rather than looking at the whole essay, you should focus on the one or two integral elements that you think offer the best evidence for your reconstruction of one of the author's focused arguments. Your two-storey thesis statement must propose an examination of the purpose and function of the author's essay; stating your opinion of the author's subject is not the goal of a close reading. Rather, your thesis should combine the components of audience, genre, and evidence to produce your focused and unique examination of the author's particular argument.

\section{First Storey: Evidence/Observations}

This section asks you to examine the first storey of your two-storey thesis statement a bit more closely.

A strong piece of evidence in a close reading is one you can literally put your finger on.

You can not put your finger on a whole sentence or paragraph, nor can you put your finger on statements like "the author's example of..." or on general comments about the author's tone. In a close reading, your two pieces of evidence should be two or three words or phrases and you should use them as direct quotes (that is, they should have "quotation marks" around them to indicate that they are the author's words and not yours).

This section also asks you to consider the connotative value of the words and phrases that you have selected. Denotative meaning is the literal definition of a word or phrase; connotative meaning is the implied or suggested feeling 
or meaning attached to the word or phrase. Denotative and connotative are not polar opposites; both work together to expand the value of a word or phrase. For example, a rose has a very specific denotation related to the phylum of plant it belongs to; however, it has connotations of love, organic growth, and beauty. When reconstructing an author's complex argument, you want to choose words or phrases from the author's essay that have the most connotative richness that you can find.

Does each piece of your evidence add a different portion of the author's complex argument to your thesis?

\section{Second Storey: Argument}

This section examines whether your own arguments or opinions are clouding your close reading. You must make sure that the second storey proposes an analytical examination of the author's argument in your own words and is not a declaration of your opinions on the author's subject matter. This is done by ensuring your controversial claim is an analytical response to the evidence you have identified. Focusing on the evidence from the text ensures you are focused on the author's argument and not your own. You need to identify the author's argument, via your interpretation of the text, in your own words, but you need to do so in such a way that you give the author's argument enough time and space to be complex. As mentioned in Chapter 2, it will usually take more than a few words to capture the author's argument, so do not be afraid to make your thesis statement into two sentences. The author's argument is complex and therefore your proposed examination of that argument should also be complex!

\section{Style}

There are some simple checks you can do to make sure you are using university-level language to reconstruct the author's argument. The Style section of the evaluation asks you to consider your choice of words and phrases. While "I" might be an effective rhetorical device to make your own argument, it is not effective in a scholarly close reading because the focus should be on analyzing the author's argument. Phrases such as "I think..." or "I believe..." are not just unwarranted, they are redundant. There is no need to state such a fact-of course you think and believe what you wrote!

The use of "we," "our," and "us" is simply too broad in this context-the reader has no sense of who is being represented by these general pronouns. If you are struggling with this, revisit your identification of the author's potential audience, and refer to this audience by name.

We, along with our past students, compiled a list of words that are most often too broad to use in a university-level essay, named the Control-F List, opens new window. When reviewing your thesis, and your essay, you should use the "Find" function in your word processor (i.e. press Ctrl-F) and search for words like "society" and "people." Often when you use words on the Ctrl-F list, you are using the broad term when you actually mean something far more specific. Authors are rarely discussing a group as broad as "people" but are likely focused on a more specific set of individuals-like, "female first-year university students in Canada," for example. It is extremely useful to get in the habit of saying what you actually mean and using specific and precise language. Using the Ctrl-F list of broad words makes sure that you are analyzing the specific topic and argument that the author is discussing. If you are struggling with the Ctrl-F list, go back to the original text. Instead of using the generic term "society," identify the specific group of people the author is addressing or examining. Instead of using the generic term "technology," identify the specific hardware or software the author is discussing. 


\section{Watch This!}

Now that we understand what makes a thesis statement strong, the following Video 3.1 walks through the differences between a strong and weak two storey thesis using "The Plot to Privatize Common Knowledge" by David Bollier. It would be useful for you to have the two storey thesis statement you wrote for Chapter 2 beside you so that you can reconsider your own writing as you follow along.

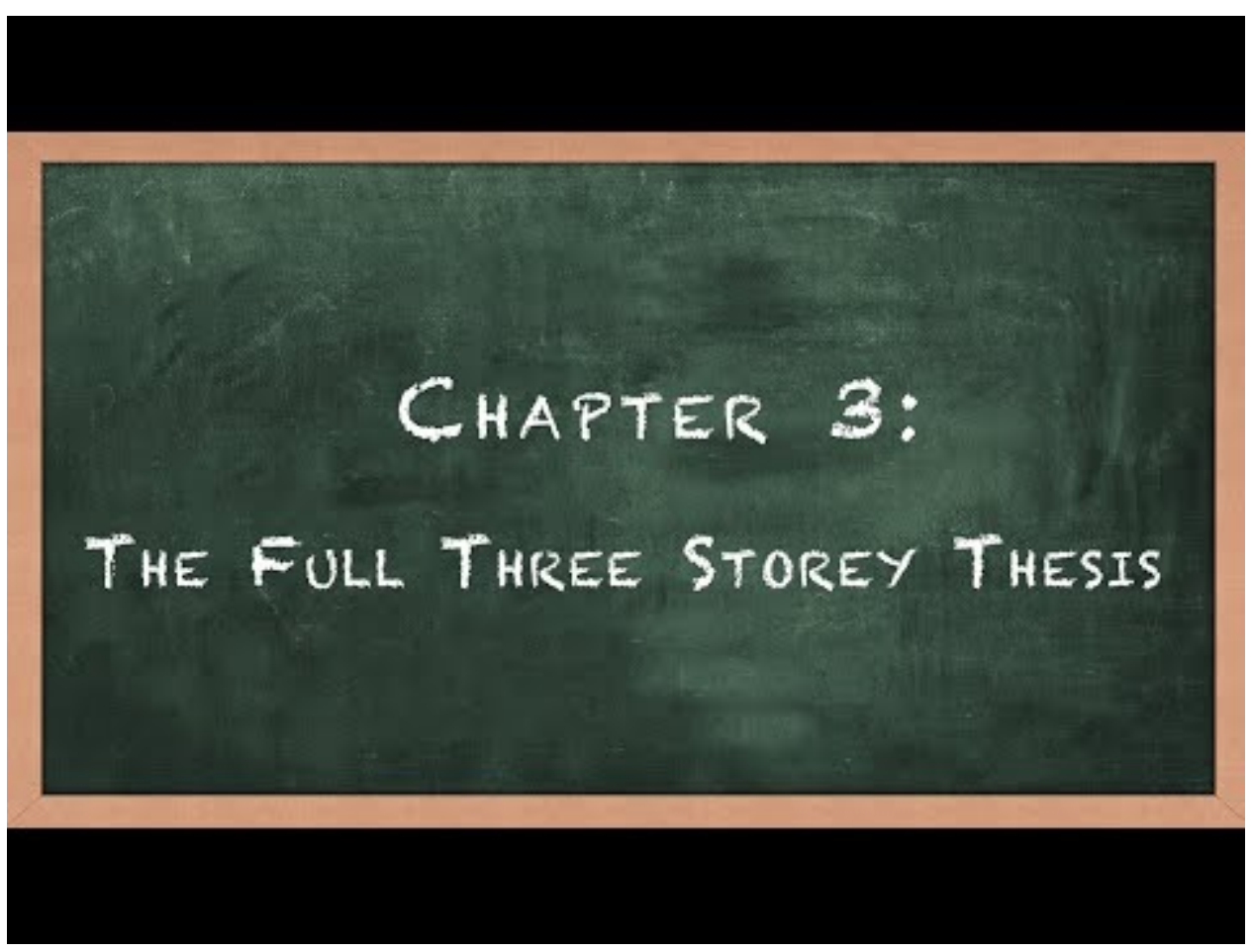

A YouTube element has been excluded from this version of the text. You can view it online here: https://pressbooks.library.ryerson.ca/writehere/?p=400

After watching the video, it's time to look more closely at your own work. Below is the two-storey opening or thesis statement we developed in Chapter 2 for Welsh's "Kids Around the World Just Want to Hang Out." How does your work compare in terms of specificity and complexity?

\section{Example}

Writing an argumentative essay aimed at university students as readers, Michael Welsh in "Kids Around the World Just Want to Hang Out" compares the responses given by two separate groups of high school students 
from Stockholm, Sweden and Keene, New Hampshire who were surveyed about "their preferences and visions for their cities." Welsh uses this comparison to convey a distressing reality he hopes his American readers will be motivated to address: while both groups of students seemed to have the same hopes and visions for a greener, cleaner future for their cities, the students of Keene displayed considerably less vision than their Stockholm counterparts, "limited expectations" of their government's ability or interested to help them attain their goals, and a worrying reliance on commercial companies to provide them the accessible, common, and entertaining spaces they desire.

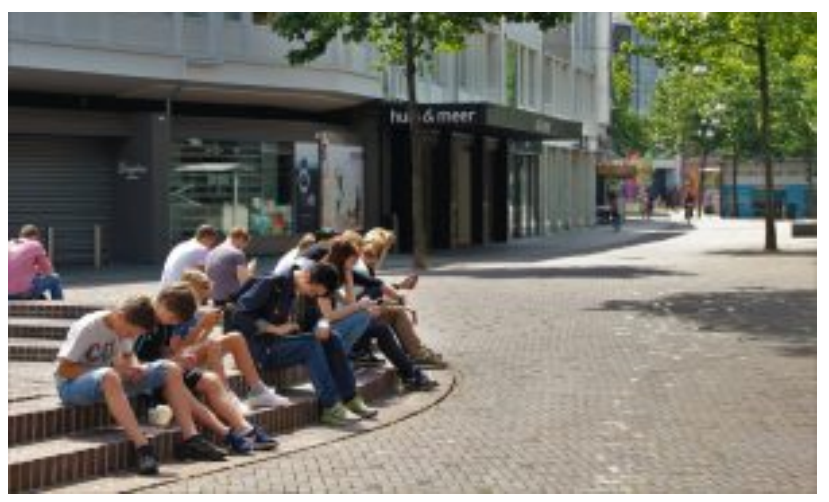




\section{Your Turn!}

\section{Activity}

Now that you have watched Video 3.1 and looked at our A-Level thesis statement, you are going to revise the thesis statement that you wrote in response to "Kids Around the World Just Want to Hang Out" in Chapter 2. Begin by writing two sentences that outline the strengths of your thesis. Follow this with two sentences explaining what you would like to improve in a second draft of this thesis. Using these reflections, return to your original thesis and rewrite the first and second storey. This is the second draft of your thesis statement.

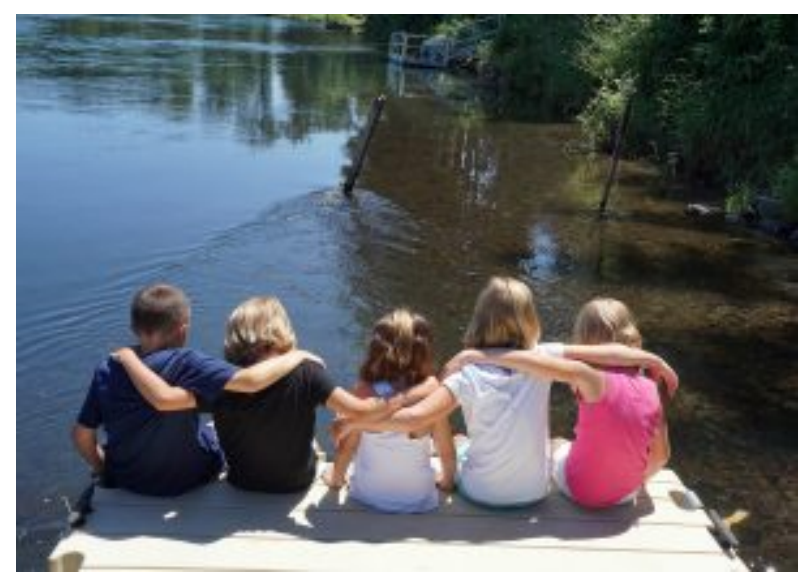




\section{Adding the Third Storey}

Now that you have built, evaluated, and revised your two-storey thesis, it time to complete your university-level close reading thesis statement by adding a third storey. If the first storey is the bedrock on which you establish the author's audience, genre, and best pieces of evidence, and the second storey is where you identify the aspects of the author's complex argument you intend to analyze, then the third storey expands the scope to consider the larger ramifications or consequences of your reading of the author's complex argument. The third storey is intended to relate the second storey to the big picture or explain its larger significance.

Remember the focus of the first two storeys. The first storey picks the best two pieces of evidence from the original text. The second storey proposes your analysis of the author's argument. The third storey should expand to consider the original text's argument as a whole and the larger world of the author's audience. Keep in mind that your thesis will likely be different than your classmate's: each of you will choose slightly different evidence and audiences, leading to different proposed analyses. Therefore, it follows that your third storey will be unique to you and your interpretation of the text. The key is that your third storey should follow logically from your first two storeys and expand the scope of your close reading to consider the breadth of the author's complex argument and the significance of your analysis. 


\section{An Example Third Storey}

\section{An Example Third Storey}

Let's revisit "The Ultimate Communications App" from Chapter 1. After careful reading of the text, and based on the evidence we gathered, we might identify the last two paragraphs as the central paragraphs to the author's complex argument:

\section{Example}

This is probably the basis for the evolution of different languages (see "Tower of Babel"). If we go back far enough in time, all of us living today have a common history, but over thousands of years different peoples occupying different places have come to conflict and cooperation with each other.

Each of us has our humanity and human origins in common with everyone else alive today. Since then, we may have got here in different ways, but we all share the present time in common. We, in fact, share this age in common with the Earth's biosphere and all its manifest diversity.

First, let's choose an audience that the author is addressing. Again, there can be more than one potential audience for a text. To make things simple here, we will look at this essay as if it were written for first-year university students based on the language used, its genre (essay on a blog) and the particular argument it is making. However, be careful: you, as a reader are not always the intended audience and when identifying an intended audience you should reflect on the tone, language and argument in the author's essay.

Then we can focus in on the contrasts of "cooperation" and "conflict" and the repetition of the word "common" as the two best pieces of evidence. When pointing to the words in the text, we remember they are not our words, so we must cite them correctly as the author's. If you need a refresher on in-text citation, you can read more in Chapter 13. We then follow with the controversial claim of our two-storey thesis statement:

\section{Example}

FIRST STOREY: In his essay "The Ultimate Communications App," Charles Justice writes for an audience of first-year university students in Canada. He uses the contrast of "cooperation" and "conflict" (para. 11) in combination with the repetition of the word "common" (para. 12) in closing his argument. 


\section{Example}

SECOND STOREY: Justice is arguing that while humans have become distanced into "occupying different places" (para. 11) by technological, agricultural and domestication evolution, it is the shared history of humanity growing from the same original roots of collective language construction that unites every modern person to their human counterparts around the globe.

When adding a third storey to this two-storey thesis, you must consider the logical extensions of this argument as they relate to the original text as a whole. In general, when developing your third storey, you might ask:

- Is the author offering a solution to a problem raised earlier in the text?

- Is the author warning of specific further consequences that will arise from a problem raised earlier in the text?

- What does the author want the reader to leave the text thinking or doing?

One danger at this stage is getting too ambitious and trying to make a broader or more general claim than you can substantiate. For example, a third storey such as "Justice therefore argues we should all get along because we all share the same human history" is a sweeping generalization and far too simplistic. Similarly, you must guard against adding a third storey such as "Justice tells us that we should destroy all technology, like apps, and go back to the old ways of communicating because they united everyone" because such a claim is not grounded in evidence from the text.

Your third storey must follow logically from your first two storeys but it cannot stray outside of the focused purpose of a close reading: analyzing the author's complex argument. You should be returning to the text itself, and perhaps making use of additional pieces of evidence, to help you explain the larger argument the author is making. While your goal is not to explain every potential argument in the text, in the third storey you should be explaining the importance of the argument that emerges from the first and second storeys of your thesis.

Watch Video 3.2: Adding a Third Storey to see how we can add third storey to the above two-storey thesis. 


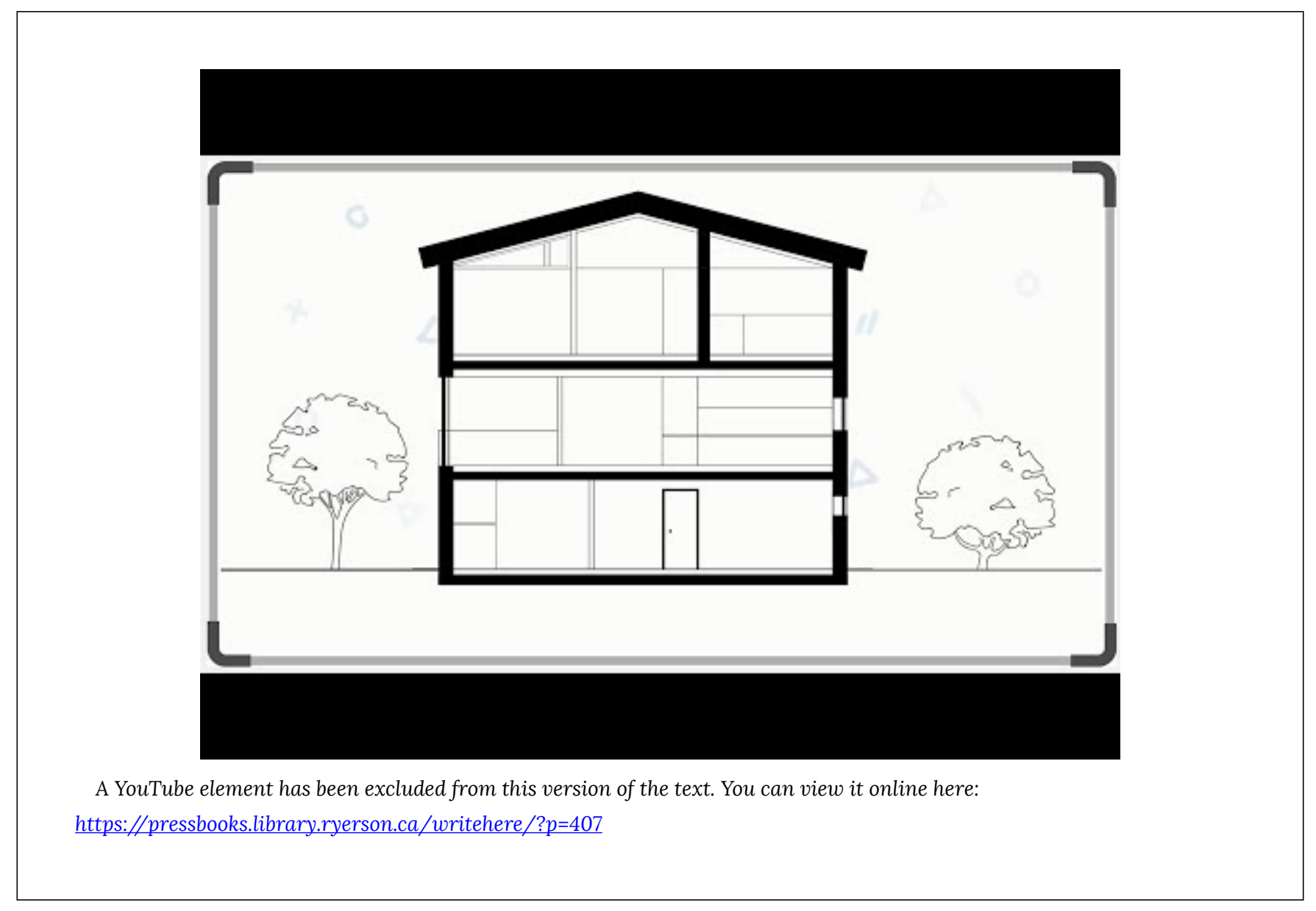




\section{Putting it all Together}

Putting it all together, we now have an effective three-storey thesis in response to "The Ultimate Communications App."

\section{Example}

FIRST STOREY: Charles Justice in his essay "The Ultimate Communications App" writes for an audience of first-year university students in Canada. He uses the contrast of "cooperation" and "conflict" (para. 11) in combination with the repetition of the word "common" (para. 12) in closing his argument.

SECOND STOREY: Justice is arguing that while humans have become distanced into "occupying different places" (para. 11) to technological, agricultural and domestication evolution, it is the shared historical fact that humanity grew from the same original roots of collective language construction that unites every modern person to their human counterparts around the globe.

THIRD STOREY: After Justice defines common as "a level-playing field" (para. 6), the author concludes with a call to arms encouraging humans to understand their ethical responsibility to each other, and to "share" (para. 12) the concerns of a globalized human population in "Earth's biosphere" (para. 12).

This full three-storey thesis expands on the second storey to identify the author's call to action-what he wishes his readers to do after reading the text- and offers further evidence from the text to support the larger concluding goal of Charles Justice's "The Ultimate Communications App." 


\section{Your Turn!}

Return to the diagnostic essay that you wrote and self-evaluated in response to "The Plot to Privatize Common Knowledge" in the introduction to this textbook.

\section{Activity}

First, following the steps detailed below, revise your diagnostic essay into a two-storey thesis focusing on the components laid out and reaffirmed throughout this chapter.

First storey: Identify author's audience and genre and point to the best two pieces of evidence from the text.

Second storey: Use the components of the first storey to focus your proposed analysis of the author's complex argument. How is the author trying to convince his audience to consider his perspective?

Now that we have built a two-storey thesis, we are ready to build a third storey. Considering what you believe to be the larger scope of the essay, answer the following questions.

- Is the author arguing that something must be done? Why?

- Is the author offering a solution to a problem raised earlier in the text?

- Is the author warning of specific further consequences that will arise from a problem raised earlier in the text?

- What does the author want the reader to think or do after reading the text?

Now add a third storey to your own thesis. Use other pieces of evidence from the text to support that third storey. Remember that your third storey should not repeat the second storey but rather add to it. The third storey expands the scope of the argument to consider the complete text and the author's larger purpose. 


\section{Returning to the text}

Re-read the essay "The Plot to Privatize Common Knowledge" to see how your thesis tracks through the essay as a whole. Re-evaluate evidence and see if your first choices are still the best choices. Think of your thesis as a proposal for the analysis you will conduct in the rest of your essay; when you re-read the original text, how well does your proposal stand up?

As an example, here is a two-storey thesis, based on our observational paragraph from Chapter 1 on "The Plot to Privatize Common Knowledge":

In "The Plot to Privatize Common Knowledge" David Bollier writes to an audience of adult readers interested in the applications of copyright law. He examines the perceived threat to "fundamental knowledge" and the "common good" posed by contemporary corporations who are converting property rights and patenting claims into "crude, anti-social instruments of control and avarice." He uses this examination as a warning to his readers that such "over-patenting," if continued unchecked, will result in much of what has been previously considered the shared and accumulated wisdom of humanity becoming "off limits" to the average citizen.

Watch Video 3.3: Three-Storey Thesis for "The Plot to Privatize Common Knowledge" to review the process of constructing a full three-storey thesis in response to David Bollier's essay. Don't worry if the content of this thesis differs from yours-recall that everyone's thesis will be different because they select different pieces of evidence and make different interpretations. What's important here is to note the level of complexity and depth required of a university-level close reading.

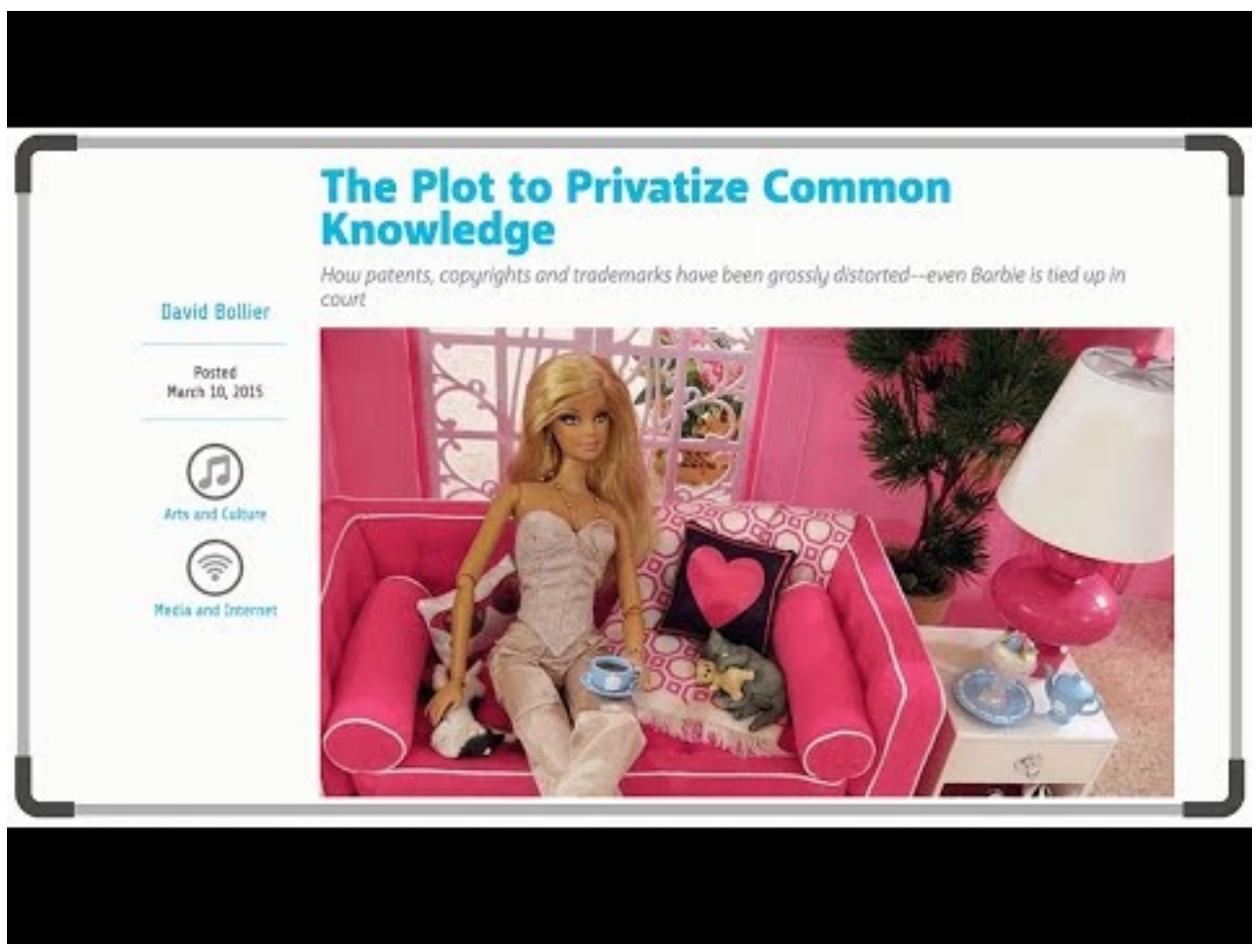

A YouTube element has been excluded from this version of the text. You can view it online here: https://pressbooks.library.ryerson.ca/writehere/? $p=415$ 


\section{The Full Three-Storey Thesis}

Here is our full three-storey thesis built upon the two-storey thesis we wrote in response to "The Plot to Privatize Common Knowledge."

FIRST STOREY:

Example

In "The Plot to Privatize Common Knowledge" David Bollier examines the perceived threat to "fundamental knowledge" and the "common good" posed by contemporary corporations who are converting property rights and patenting claims into "crude, anti-social instruments of control and avarice."

\section{SECOND STOREY:}

\section{Example}

He uses this examination as a warning to his readers that such "over-patenting," if continued unchecked, will result in much of what has been previously considered the shared and accumulated wisdom of humanity becoming "off limits" to the average citizen.

\section{THIRD STOREY:}

\section{Example}

The result of this knowledge becoming "off limits," Bollier argues, is that the lack of public "fundamental knowledge" strangles the potential leaps forward "that are essential to creativity and good research" in advancing technological or scientific fields and will ultimately greatly slow humanistic progress towards improving the lives of the global population. 


\section{Additional Practice}

You wrote and revised a two-storey thesis statement to "Kids Around the World Just Want to Hang Out" by Michael Welsh. Compare it to the sample A-level two-storey thesis below:

\section{Example}

In "Kids Around the World Just Want to Hang Out," Michael Welsh compares the responses given by two separate groups of high school students from Stockholm, Sweden, and Keene, New Hampshire, who were surveyed about "their preferences and visions for their cities." Welsh uses this comparison to convey a distressing reality he hopes his American readers will be motivated to address: while both groups of students seemed to have the same hopes and visions for a greener, cleaner future for their cities, the students of Keene displayed considerably less vision than their Stockholm counterparts, "limited expectations" of their government's ability or interested to help them attain their goals, and a worrying reliance on commercial companies to provide them the accessible, common, and entertaining spaces they desire.

Now that you have a revised two-storey thesis statement from earlier in this chapter in response to "Kids Around the World Just Want to Hang Out," re-read the essay and add a third storey. You can never practice enough! 


\section{Thinking Ahead...}

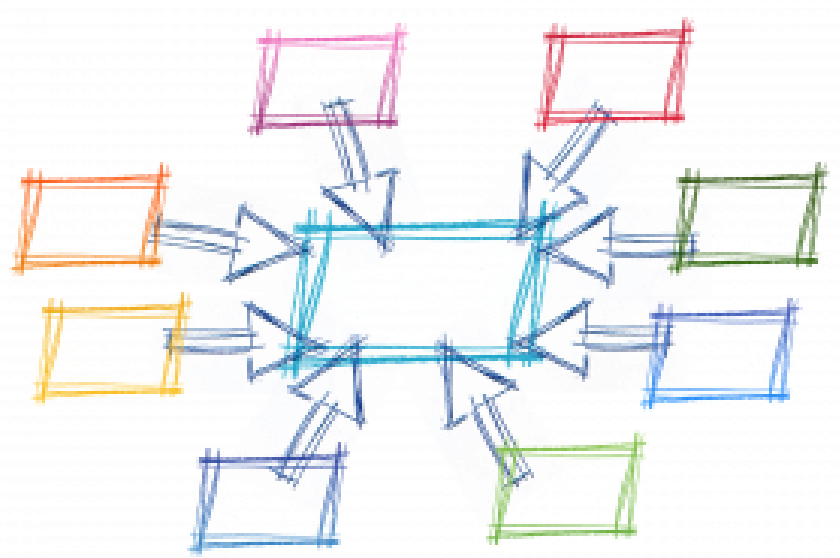

Get ready to organize your thoughts on the text

From Pixabay/ $\underline{\mathrm{CC} 01.0}$

Good news! Now that you have written a complete three-storey thesis, you can learn about the process of using your thesis to focus a draft of your complete essay. For now, be confident that in building a three-storey thesis you have drafted a roadmap for expanding on and logically connecting each component of your argument. Take the time now to revisit your three-storey thesis and the article you are analyzing to create a point-form, paragraph-by-paragraph outline for your close reading of "The Plot to Privatize Knowledge." Consider what is necessary to prove your argument. Which piece of evidence should be discussed in the first full body paragraph? Which would come second? Continue this until you have a brief essay skeleton. Remember to bring your notes and draft materials to class for feedback and further revision. 



\section{CHAPTER 4: FROM THESIS TO ESSAY}





\section{Chapter Overview}

\section{Learning Outcomes}

\section{In this chapter we will:}

- Edit the three-storey thesis generated in the previous chapter and reaffirm the principles of editing (Chapter 3).

- Establish the basic principles of constructing the skeleton of an effective university-level close reading essay.

- $\quad$ Revisit the definition of a conceptual lens and practice using it in a close reading (Chapter 3).

- $\quad$ Reaffirm the principles of the three-storey thesis.

In this chapter students will learn the basics of constructing a close reading essay and begin the early stages of turning the three-storey thesis generated in the previous chapter into an essay skeleton. This will prepare them for the next chapter, which asks them to build body paragraphs from this skeleton. 


\section{Editing the Three-Storey Thesis}

As we discussed in our previous chapter, spending the time revising your thesis statement is as crucial as writing your initial draft. The basic components of your thesis include:

- An identification of the possible intended audience of the article being analyzed,

- The specific focused portion(s) of the text you've chosen to analyze,

- The best pieces of evidence from that specific portion(s) of the text,

- A proposed analysis of the author's complex argument.

As you review the three-storey thesis you wrote at the end of Chapter 3, keep these components in mind and evaluate each piece of the argument separately. Once you have isolated and evaluated each of the components separately, then re-read your thesis to consider how well they fit together. Do not try to do everything at once. Rather, give yourself individual tasks for each revision pass and stay granular in your approach.

In this particular stage of revision, pay special attention to the third storey that we added at the end of Chapter 3, keeping in mind these specific questions:

- Is the author arguing that something must be done? Why?

- Is the author offering a solution to a problem raised earlier in the text?

- Is the author warning of specific further consequences that will arise from a problem raised earlier in the text?

- What does the author want their reader to leave the text thinking and/or doing?

Before you do the self-evaluation below, re-read your thesis and label each of your three storeys clearly in the margins. You want to see plainly which sentences and thoughts belong to which part of your argument. Now that you have read and re-read your three-storey thesis, let's do another self-evaluation. 


\section{Self-Evaluation of Your Three-Storey Thesis}

\section{Taking Measure}

Each question requires a "Yes" or "No" answer. For each "Yes" response, give yourself one point. Your final score will be mark out of twenty-three (ex: Twenty-one "Yes" responses = 21/23).

\section{Components}

Did you identify a specific audience? (Who? Where? When?)

$\mathrm{Y} / \mathrm{N}$

Did you identify two specific pieces of evidence?

$\mathrm{Y} / \mathrm{N}$

Did you identify a central aspect or element?

$\mathrm{Y} / \mathrm{N}$

Did you make YOUR claim about the AUTHOR'S purpose? Is it a statement with which one could agree or disagree?

$\mathrm{Y} / \mathrm{N}$

Is there a unique third storey that concludes your thesis? Is it different than the second storey?

$\mathrm{Y} / \mathrm{N}$

Are each of your three storeys roughly equal in length?

$\mathrm{Y} / \mathrm{N}$

\section{First Storey: Evidence/Observations}

Is the first piece of evidence something you can literally point to the text?

$\mathrm{Y} / \mathrm{N}$

Is the second piece of evidence something you can literally point to the text?

$\mathrm{Y} / \mathrm{N}$

Does each of piece of evidence add something new? Are they different from each other?

$\mathrm{Y} / \mathrm{N}$

Is your evidence rich in connotative value? Do the words potentially have multiple meanings? 
$\mathrm{Y} / \mathrm{N}$

\section{Second Storey: Argument}

Have you focused on the AUTHOR'S argument? You should not be voicing your opinion on the author's topic. $\mathrm{Y} / \mathrm{N}$

Does your proposed analysis of the author's argument follow from the evidence provided? $\mathrm{Y} / \mathrm{N}$

Is your proposed analysis complex? Does it take you more than half a sentence to describe it? $\mathrm{Y} / \mathrm{N}$

Does your proposed analysis of the author's argument utilize strong and precise language? $\mathrm{Y} / \mathrm{N}$

\section{Third Storey: A Full Complex Argument}

Does your third storey follow logically from the second storey?

$\mathrm{Y} / \mathrm{N}$

Does your third storey clarify the second storey by adding something new? $\mathrm{Y} / \mathrm{N}$

Does your third storey consider the results and consequences of the sort of analysis proposed in the second storey?

$\mathrm{Y} / \mathrm{N}$

Does your third storey use keywords or phrases from the text to add something new to the second storey? $\mathrm{Y} / \mathrm{N}$

Is your third storey still focused on the author's complex argument? You want to be sure that you have not strayed into your own unanalytical discussion of the author's subject.

$\mathrm{Y} / \mathrm{N}$

$\underline{\text { Style }}$

Did you use strong verbs throughout your thesis?

$\mathrm{Y} / \mathrm{N}$

Did the level of language reflect the tone of the author's argument? 
$\mathrm{Y} / \mathrm{N}$

Did you avoid the use of first-person pronouns? ("I," "we," "us," "our," etc.)

$\mathrm{Y} / \mathrm{N}$

Did you avoid words from the Ctrl-F list? ("society," "technology," "people," etc.)

$\mathrm{Y} / \mathrm{N}$ 


\section{Watch This!}

Follow along with Video 4.1 as we evaluate the example three-storey thesis that we generated at the end of Chapter 3.

\section{Example}

FIRST STOREY: Speaking to an audience of first year university students in Canada, Charles Justice in "The Ultimate Communications App" utilizes the contrast of "cooperation" and "conflict" (para. 11) in combination with the repetition of the word "common" (para. 12) in closing his argument.

SECOND STOREY: From this, Justice is arguing that while humans have become distanced into "occupying different places" (para. 11) through technological, agricultural and domestication evolution, it is the shared historical fact that humanity grew from the same original roots of collective language construction that unites every modern person to their human counterparts around the globe.

THIRD STOREY: Considering Justice definition of the common as "a level-playing field" (para. 6), Justice concludes with a call to arms extolling humans to grasp their ethical responsibility not only to each other but to "share" (para. 12) in the present concerns of a globalized population of humans in the entire "Earth's biosphere" (para. 12). 


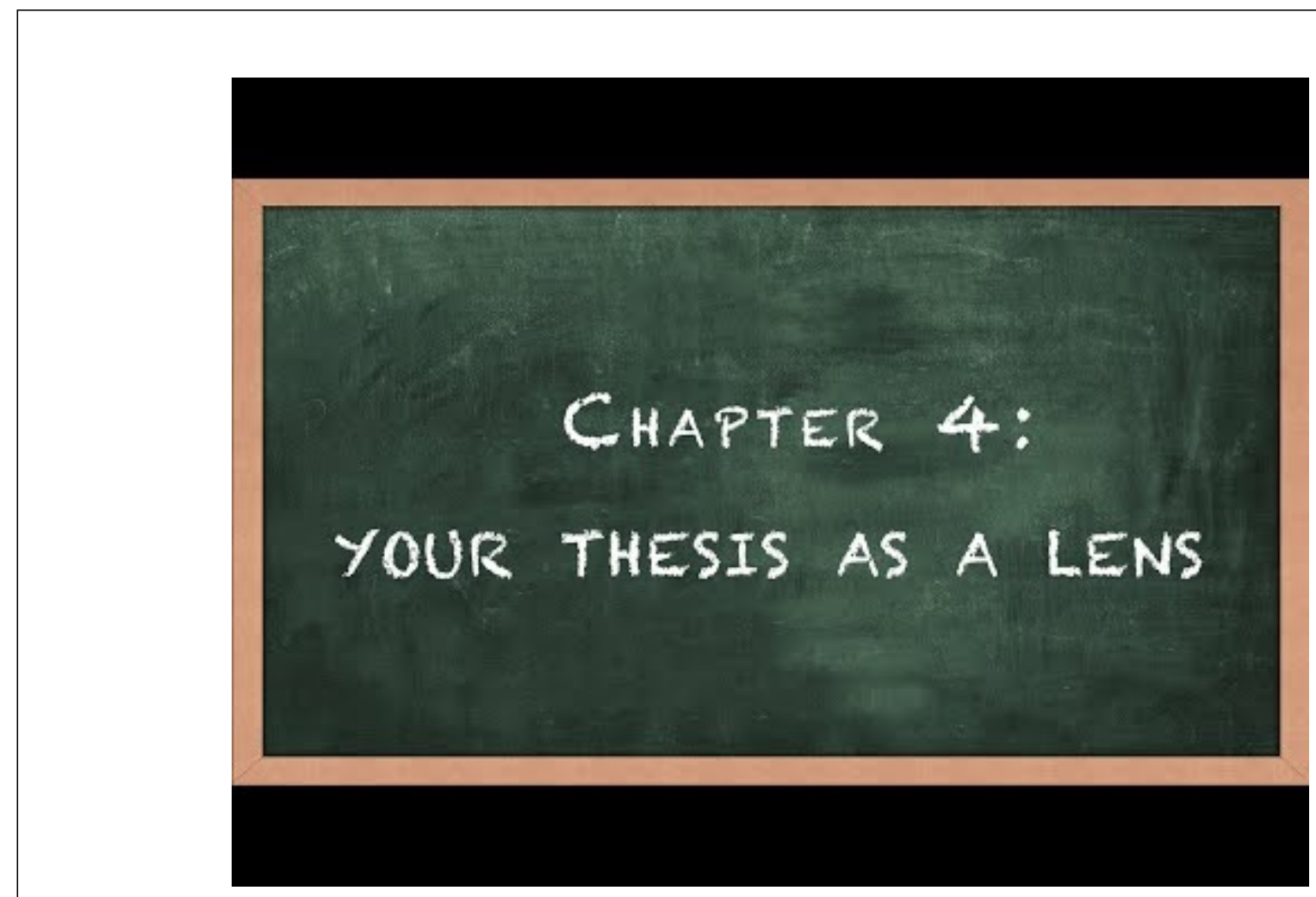

A YouTube element has been excluded from this version of the text. You can view it online here: https://pressbooks.library.ryerson.ca/writehere/? $p=443$ 


\section{Your Turn!}

\section{Activity}

Now that you have completed your self evaluation, do another revision of your three storey thesis wherein you address the issues that you have flagged thus far while also paying special attention to the compact and complex language that you should be using. After you have finished rewriting your thesis, read it aloud to check for any awkward phrasing that prohibits the logical flow of your argument.

While performing your evaluation of your three-storey thesis, you likely noticed that some of the questions were repetitions from the evaluation you did in response to your two-storey thesis in Chapter 2. That's fine! It is good to revisit what you have written, especially given that you have likely been making small changes as you read and re-write. You also likely noticed that there were a number of new questions added; in particular, there is a whole section dedicated to your third storey.

\section{Editing the Third Storey}

Now that we are getting ready to edit and rewrite our three-storey thesis, use these questions to guide your evaluation. In particular, focus on whether your third storey is adding to the complex argument established in your second storey. If the third storey repeats the second storey, it is likely due to one of two problems:

1. The second storey is not complex enough and so the writer uses the third storey to make it more complex. Instead, the second storey needs to be made more complex and then the third storey needs to be added on top.

2. The writer is not addressing the potential consequences and results of the analysis proposed in the second storey.

As you rewrite your thesis statement make sure that the third storey extends your proposed analysis of the author's argument to consider the large scope and scale of that initial argument. This will likely mean returning to the text and adding another key word or phrase to help you arrive at at the expanded scope of the author's complex argument. Return to your initial list of observations and see if there is not another piece of specific evidence that can help you better address the potential consequences and results of the analysis proposed in the second storey.

Lastly, ensure that your third storey follows and extends logically from the second storey. The third storey should not be going off in a whole new direction. Instead, think of the third storey as taking the first two storeys and opening them up to the larger examination of the author's argument. Remember that you are always analyzing the author's complex argument so the focus and purpose of the first two storeys should still be present in the last storey. 
Your Turn! | 91 


\section{Editing and Rewriting for Precise and Muscular Language}

\section{Connotative Value}

Because you have completed a number of edits, it is likely that the components of your thesis are already quite strong. Now you need to focus on being as precise as possible with your language, so that your analysis of the author's argument is as clear and sophisticated as possible.

Revisiting the evidence you've chosen in storey one is a good place to start. Ideally you want to choose words and small phrases that are rich in connotative value. That is, language that can mean multiple complex things at once which then also fit into the rich language around it. For example, identifying and focusing in on the fact that an author uses the term "Facebook" six times is not that useful as the word "Facebook" is more informational and less descriptive or argumentative and therefore does not have much in terms of connotative value. However, in "The Plot to Privatize Common Knowledge" from the first chapter, the word "common" is very rich and deserves much more attention: by definition is carries the meaning of sharing something (i.e. having something in common), as well as being meaning something that is regularly occurring. These two meanings then get added to the author's definition of what a Commons is (i.e public and shared property). Look at all the work that single word is doing! Therefore, when identifying the best pieces of evidence as the base for your analysis of the author's complex argument, look for the language that is the richest in connotative value.

\section{Ctrl-F List}

As discussed in Chapter 3, the Ctrl-F is a tool meant to help you identify broad words so that you can chose more specific vocabulary in your revision process. When applying the Control-F List, opens new window to your thesis, the intent is not to say that you should never use words like "society" or "people," but rather to say that those words are so ambiguous and general that they retain very little value. Instead, you should say what you mean! Instead of "society" or "people," you mean "2017 first year university students in Canada." Look back through your thesis and ensure that you are replacing those broad terms with language that speaks more directly to the author's audience and complex argument.

\section{Verbs}

A verb is an action word and most often the heavy lifter of any sentence you will write. As such, a strong verb will do the work of three simple words and will provide your reader with a more compact and clear version of the argument you are recreating. For example, think of the difference between the verbs "move" "run" and "gallop."

- "Move" as a verb is far too broad and simple. What part of the body is being moved? In what manner?

- "Run" is better as it implies a speed and a specific action with a body but is still generic. 
- "Gallop" is much better as it carries with it the connotations of a horse and gives the imagery of that specific locomotion. As well, using that word also brings up the connotations of animalistic movement. Instead of needing an adverb, as "move" and "run" likely would, "gallop" is a word that is doing a lot of work on its own. 


\section{Your Turn!}

\section{Activity}

To begin, go back into your thesis and literally circle all of your verbs. Once you have done this, ask yourself whether any of these verbs can be elevated to another verb that is more complex and richer in connotative value. As an example, look for the verb "use." Think of what might be meant by "using" a smartphone. "Using" a smartphone ranges from texting a friend, to playing a videogame, to browsing the Internet, to hammering a nail. All of these are "uses" for a smartphone. Instead, an author would speak to the specific activity that is taking place on that cellphone.

As you replace some of the weaker verbs, try not to think of this as a synonym-finding activity. You are not simply right-clicking and finding a longer word. Rather, you should be looking for verbs that carry more weight and point towards the argument that the author is making. You should consider, in a simple way, whether the verb you have chosen implies a negative or positive attitude. Does the negative or positive attitude implied by the verb match the negative or positive attitude that is within the author's complex argument?

Watch Video 4.2, which explains how to elevate the language of your thesis statement to make it as clear, compact and sophisticated as possible. 


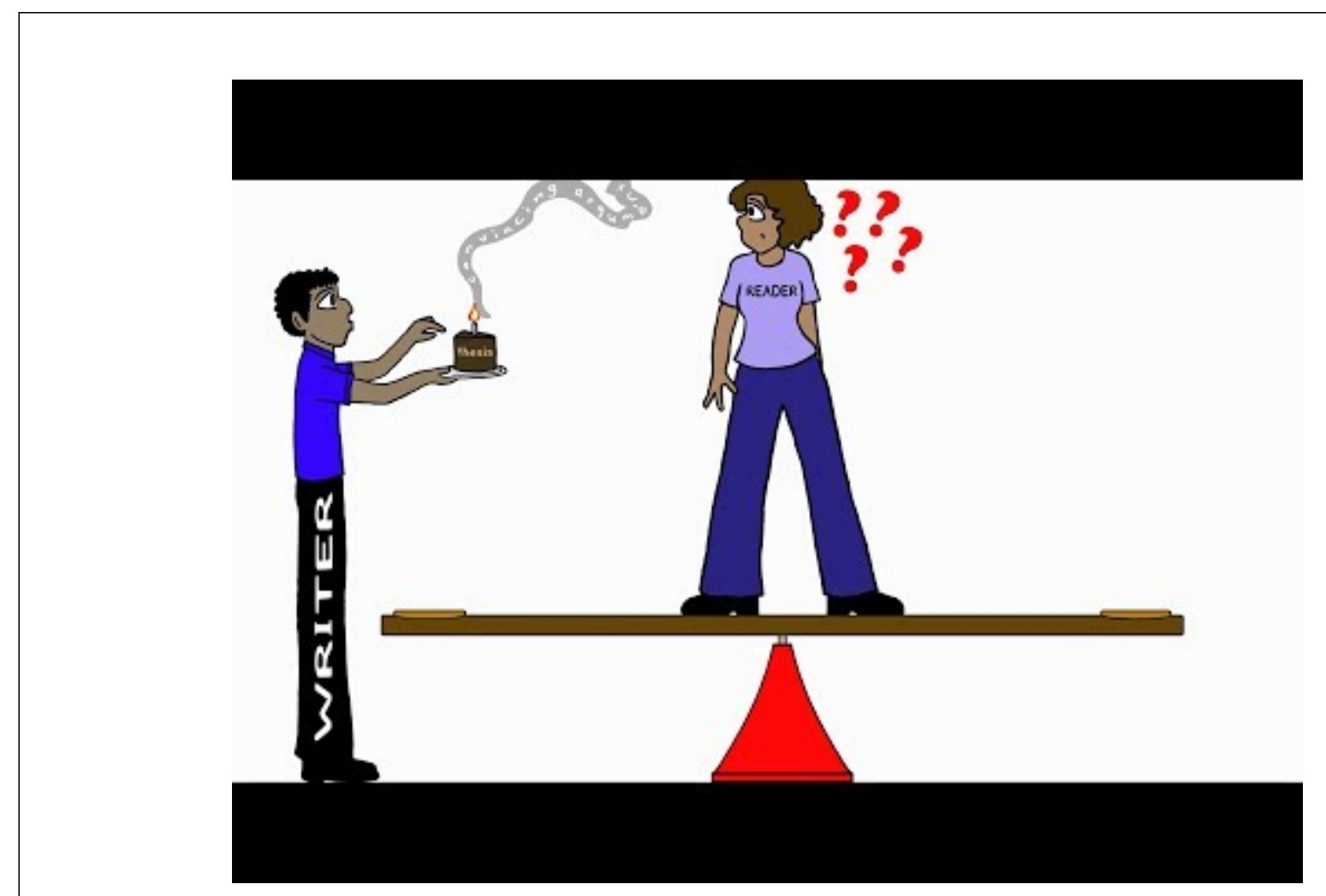

A YouTube element has been excluded from this version of the text. You can view it online here: https://pressbooks.library.ryerson.ca/writehere/? $p=449$

\section{Activity}

Now that you have evaluated your three-storey thesis statement, rewrite it so that you elevate your language and reflect the full complexity of your proposed reading of the author's argument. 


\section{The Three-Storey Thesis as a Roadmap}

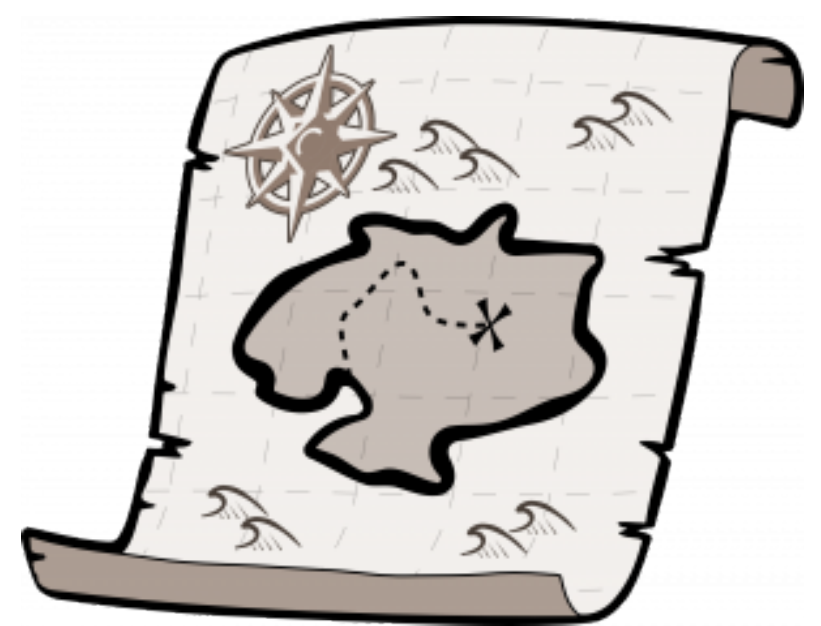

Using a "map" in essay-writing will keep you from getting lost and having to backtrack. From Pixabay.

Congratulations! Now you are ready to begin structuring your essay. Good news: you already have a logical blueprint in hand in the form of your three-storey thesis.

The next step in the pre-writing phase is creating a roadmap or outline for your essay. Taking the time to review your thesis statement and imagine paragraph-by-paragraph how your essay will flow before you start writing it will help in your revision process in that it will prevent you from writing parts of your essay and then having to delete them because they do not fit logically. You will also find that having a roadmap ahead of time will make the actual writing of your essay faster as you will know what is in each paragraph ahead of time.

A paragraph is a full and complete unit of thought within your essay. When you begin a new paragraph, you are signalling that you've completed that idea or point and are moving on to a new idea or point. The simplest way to create an essay outline is to look at your thesis statement, break it into its components, and then give each component its own paragraph by walking through each of the three storeys in sequence. Keep in mind that some components of an argument are more complex than others and may need two (or three or five) paragraphs to complete. But for now we'll keep it simple and break our thesis into its basic parts. Let's begin with our previous thesis statement, and then go storey by storey. 


\section{Introduction}

We will be discussing more complex essay introductions in Part II when we learn about writing essays about our own arguments, but for a close reading, your thesis should be as compact and clear as possible. When drafting your introduction, the key thing to remember is that you do not need to examine every aspect of the author's whole argument right away. Your introduction will be comprised of your thesis that is specific and gives your reader the basic signposts of audience, genre, evidence (first storey) and complex argument (second storey) and your proposed unique reading of the article (third storey). While a close reading introduction should include your full three-storey thesis this does not mean the validity of your argument is a given or that your argument is concluded before it even begins. Your analytical argument must be supported by logically unpacking all its components in a thoughtful process. This will force you to walk your reader through the components of your claim and the supporting evidence until it culminates in your conclusion with your final interpretive statement on the author's complex argument. 


\section{First Storey}

\section{Example}

In his essay "The Ultimate Communications App," Charles Justice writes for an audience of first-year university students in Canada. He uses the contrast of "cooperation" and "conflict" (para. 11) in combination with the repetition of the word "common" (para. 12) in closing his argument.

Our first step is to take apart our first storey and describe the evidence for our forthcoming argument.

\section{Remember: an argument without evidence is an opinion!}

Underline each element of the storey to identify how many paragraphs you will need. Let's assume that we need to dedicate a paragraph to each of our pieces of evidence.

\section{Activity}

Paragraph 1: quote and unpack the contrast of "cooperation" and "conflict" (para. 11)

Paragraph 2: quote and unpack the repetition of the word "common"

Now we have the first two paragraphs of our essay! In the next chapter, we will discuss the specifics of those paragraphs but for now, know that you need a paragraph for each of your two pieces of evidence. 


\section{Second storey}

\section{Example}

From this, Justice is arguing that while humans have become distanced into "occupying different places" (para. 11) to technological, agricultural and domestication evolution, it is the shared historical fact that humanity grew from the same original roots of collective language construction that unites every modern person to their human counterparts around the globe.

Now that you have a solid foundation of evidence, you are ready to propose our analysis of the author's complex argument. In the second storey part of our essay you want to explain how the two pieces of evidence from the first storey overlap and how that overlap produces the author's complex argument. Look again at your second storey to see the elements that deserve their own paragraph. Underline each part of the complex argument in the second storey so you know what deserves its own paragraph.

\section{Activity}

Paragraph 3: Overlap the contrast of "cooperation" and "conflict" with the repetition of the word "common" by explaining what the two pieces of evidence have to do with each other? How are they similar? How do they contrast with each other?

Paragraph 4: Explain how those two pieces of evidence lead to Justice's argument that "humans have become distanced into 'occupying different places' (para. 11) to technological, agricultural and domestication evolution"

Paragraph 5: Explain how those evolutions are offset by the fact that "it is the shared historical fact that humanity grew from the same original roots of collective language construction that unites every modern person to their human counterparts around the globe."

Now we have linked our evidence from the first storey into the complex argument that the author is making. Notice that each paragraph is rooted in the original text. Remember: the purpose of a close reading is to reconstruct the author's argument. Every paragraph must return to the author's argument and present a new complex component of that argument. 


\section{Third Storey}

\section{Example}

After Justice defines common as "a level-playing field" (para. 6), the author concludes with a call to arms encouraging humans to understand their ethical responsibility to each other, and to "share" (para. 12) the concerns of a globalized human population in "Earth's biosphere" (para. 12).

Now we are ready to add the third storey! Again, take the third storey of your thesis and give each part its own paragraph. Underline each part of the third storey so that you know what deserves its own paragraph.

\section{Activity}

Paragraph 6: Explain what Justice means by "a level-playing field" (para. 6) and how it links to " the same original roots of collective language construction that unites every modern person to their human counterparts around the globe."

Paragraph 7: Explain how this level playing field leads to "a call to arms encouraging humans to understand their ethical responsibility to each other, and to "share" (para. 12) the concerns of a globalized human population in "Earth's biosphere" (para. 12).

Again, notice how each paragraph includes specific words and phrases from Justice's work while adding something new to that thought. 


\section{Conclusion}

In Part II, we will discuss conclusions in more depth. For a close reading you must culminate the reading you proposed in your three-storey thesis. While there is a certain satisfaction that comes from analyzing the author's argument and guiding your analysis logically to the end of an essay, this does not mean that you copy and paste your thesis from the introduction into the conclusion. You cannot simply close by return at this level. You need to do more than restate your introduction in your conclusion. Your conclusion should be a reconsideration and culmination of the reading you proposed in your thesis presented for a final time in the light of the analysis you conducted in your body paragraphs. What have you and your readers learned from your analysis of the text?

Your essay outline now looks like this:

\section{Example}

Introduction: First two storeys of your three-storey thesis

Paragraph 1 (First Storey): Quote and unpack the contrast of "cooperation" and "conflict" (para. 11)

Paragraph 2 (First Storey): Quote and unpack the repetition of the word "common"

Paragraph 3 (Second Storey): Overlap the contrast of "cooperation" and "conflict" with the repetition of the word "common" by answering what the two pieces of evidence have to do with each other? How are they similar? Contrasting?

Paragraph 4 (Second Storey): Explain how those two pieces of evidence lead to Justice's argument that "humans have become distanced into "occupying different places" (para. 11) to technological, agricultural and domestication evolution"

Paragraph 5 (Second Storey): Explain how those evolutions are offset by the fact that "it is the shared historical fact that humanity grew from the same original roots of collective language construction that unites every modern person to their human counterparts around the globe."

Paragraph 6 (Third Storey): Explain what Justice means by "a level-playing field" (para. 6) and how it links to " the same original roots of collective language construction that unites every modern person to their human counterparts around the globe."

Paragraph 7 (Third Storey): Explain how this level playing field leads to "a call to arms encouraging humans to understand their ethical responsibility to each other, and to "share" (para. 12) the concerns of a globalized human population in "Earth's biosphere" (para. 12).

Conclusion: Your full three-storey thesis

Remember: While you have now completed one of the more difficult stages of writing your close reading essay, you are not done thinking about your essay. This outline is meant to be a bridge between your pre-writing and your thesis and your final essay. This outline may change as you go through the process of drafting and revising your essay. 
You are NOT beholden to this outline!

Your outline is a tool to further complicate your thesis as your write your full essay. This broad outline will provide the sturdy framework you need to start writing. 


\section{Your Turn!}

\section{Activity}

Take your edited three-storey thesis from earlier in this chapter and use it to create a paragraph-byparagraph roadmap. Identify the key individual components within your thesis statement that will need a paragraph (or two) to fully unpack in order to analyze the author's complex argument. 


\section{Watch This!}

Now watch this Video 4.3 for a walk-through of how to break up a three-storey thesis into individual paragraphs and then connect them logically from one paragraph to the next.

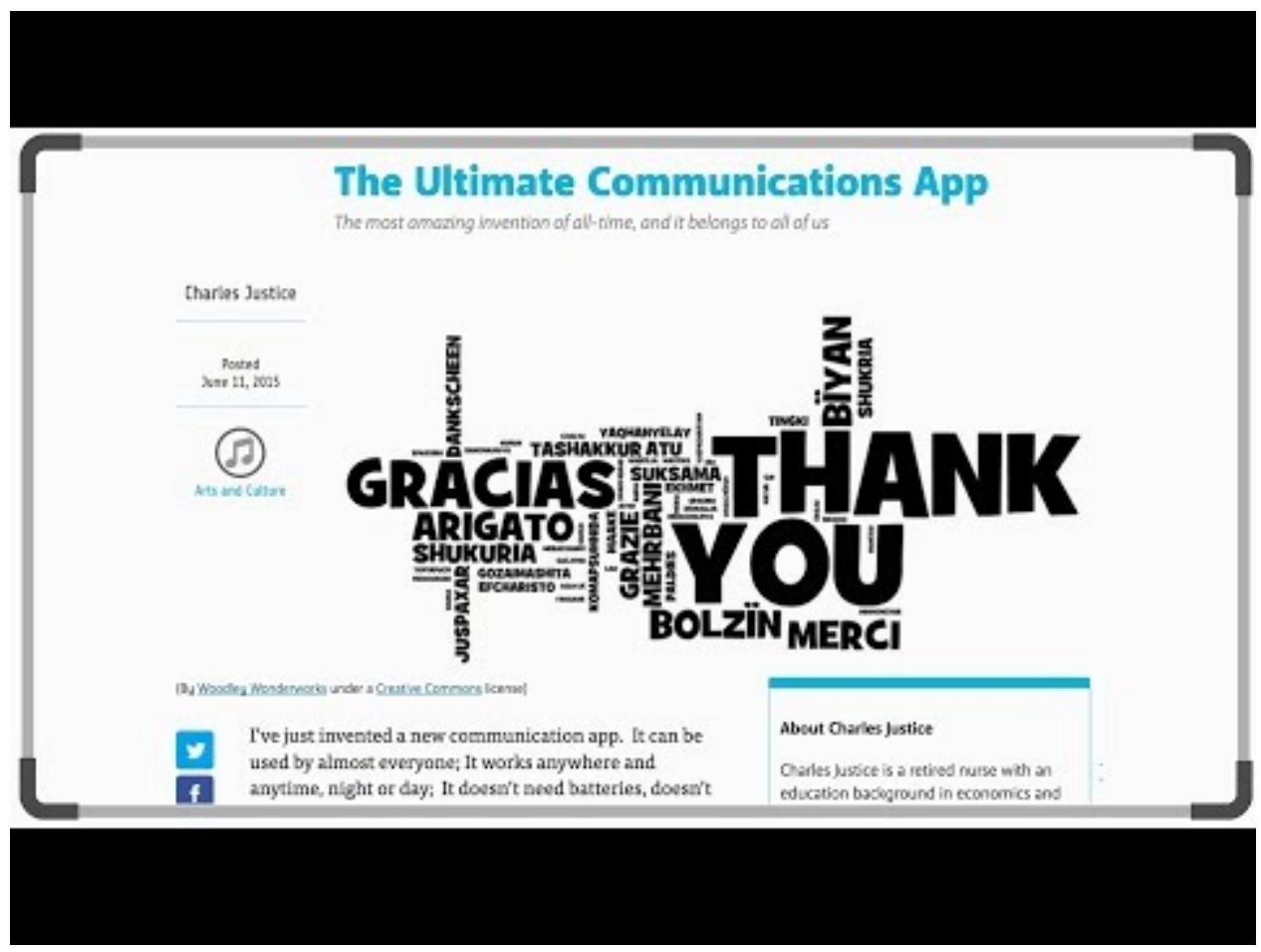

A YouTube element has been excluded from this version of the text. You can view it online here: https://pressbooks.library.ryerson.ca/writehere/? $p=466$ 


\section{Thinking Ahead...}

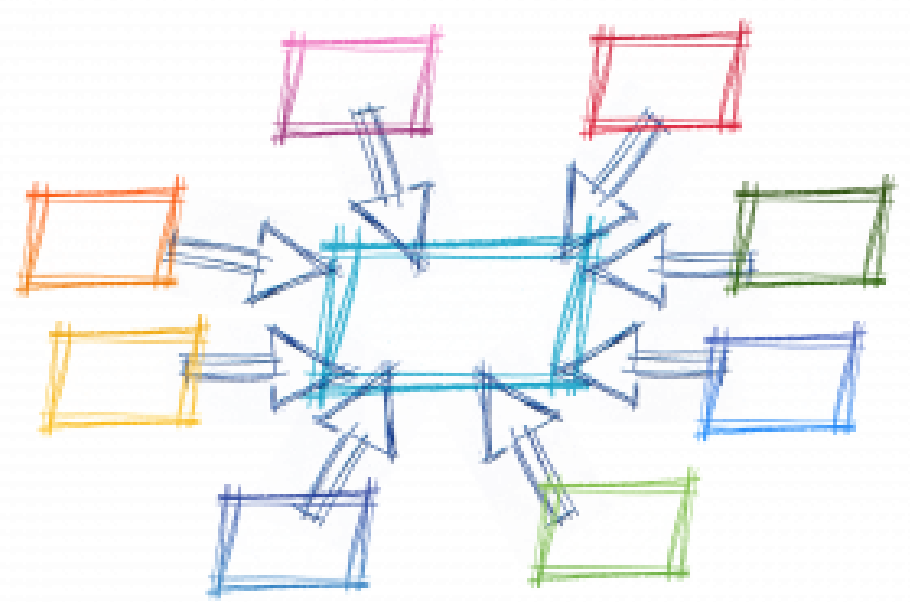

Get ready to organize your thoughts on the text.

From Pixabay/ $\underline{\mathrm{CC} 01.0}$

Now that we have a full three-storey thesis statement and a paragraph-by-paragraph roadmap, it will be much easier to write our final essay. The next chapter will expand on the roadmap to explain what needs to be done in each paragraph and discuss the basic principles of topic sentences, quoting and analyzing, and transitioning from one paragraph to the next. For now, imagine what quotations you might need for each paragraph and how you might add "muscle" to your essay "skeleton." 



\section{CHAPTER 5: MAINTAINING FOCUS AND PURPOSE: THE BODY PARAGRAPHS}





\section{Chapter Overview}

\section{Learning Outcomes}

\section{In this chapter we will:}

- Learn to draft body paragraphs that focus on specific point within our three-storey thesis and maintain a balance between claim, evidence, and warrant.

- Craft a topic sentence for each paragraph based on the textual evidence in our thesis.

- Create paragraphs that both say something new and build upon the points made in previous paragraphs.

- Create meaningful transitions between paragraphs. 


\section{Writing the Essay}

Now you have arrived, finally and purposefully, to the writing of your interpretive, analytical essay. You have read the article you are analyzing several times, you have gathered information that you have decided is interesting and relevant, you have analyzed the article's many aspects, you have crafted a thesis that encapsulates your interpretive claim and analytical purpose, and you have plotted your potential course in your essay outline.

The actual writing of the essay is challenging, but it is a task that has been made a little easier by your thorough analysis and preparation. The writing should still be a little difficult, however, as you must continue to question and interpret, even as you draft and revise the essay. It would be a mistake at this point to think the analytical process is over and you need now just plug your observations into your outlined paragraph structure. Your essay is still very much a living and evolving thing and you must remain active and engaged as you create your final product. Keeping in mind your goal to be an active analyst rather than a passive conduit, it is important to complete this checklist before you begin writing to make sure you have equipped yourself with the tools you need to complete this task:

\section{Taking Measure}

Take a survey of your immediate area as you prepare to write your essay, then answer the following questions:

Do you have a hard copy of your three-storey thesis at hand?

$\mathrm{Y} / \mathrm{N}$

Do you have a hard copy of your outline ready for easy access and alteration?

$\mathrm{Y} / \mathrm{N}$

Do you have a hard copy of the article you are analyzing, complete with your annotations and marginal comments?

$\mathrm{Y} / \mathrm{N}$

Do you still have hard copies of the lists you compiled during your initial and subsequent analyses of the article?

$\mathrm{Y} / \mathrm{N}$

Do you have a more refined list in hard copy of what you believe to be the most important and interesting moments from the text?

$\mathrm{Y} / \mathrm{N}$

If you replied "No" to any of these questions, you are not prepared to begin writing your essay. Just because you have done all this work does not mean the sentences will now just flow from your brain onto the page. It is important that you have your accumulated claims and observations at hand as you work through the final stages of producing your essay. At many times during this process you will find yourself returning to the notes and lists and claims you have made. You may even find yourself questioning your earlier work, adding to it, or revising it. This is fine. Better to be questioning what you have written than to disengage your brain and start simply plotting points on the page.

The thesis you produced through your work in the previous chapters is still in many ways a working thesis that will be 
further complicated as you bring it more closely into contact with textual evidence. For this reason, it is vital that you do not yet place your thesis into your essay. Better to have it exist for now on a piece of paper separate from your essay so you can reflect upon it as you write your body paragraphs. Through this repeated obvious contact between your thesis and the textual evidence, you will be able to produce topic sentences for each of your body paragraphs.

As for the annotated version of the original article and your lists of observations, these never lose their crucial importance to your writing process. Remember, you compiled more information than you would be able to include in your essay. Now you can select from your best ideas rather than struggle to find points and evidence as you write. The outline you have planned is an important tool, but you may need to alter your roadmap as you write your essay. You may even need to select different evidence from what you had planned on using. So, keep all your annotations, lists and notes handy. You don't want to lose creative momentum while searching for new material.

If you can now answer "Yes" to each of the questions in the checklist above, you are ready to begin writing.

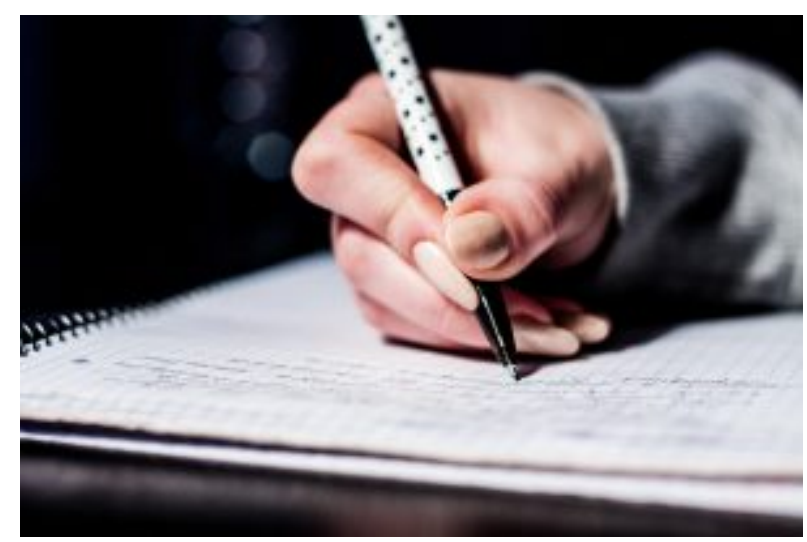

From Pixabay. 


\section{Big Beefy Building Blocks: Filling Those Body Paragraphs}

Let's first watch Video 5.1 on what body paragraphs are supposed to do.

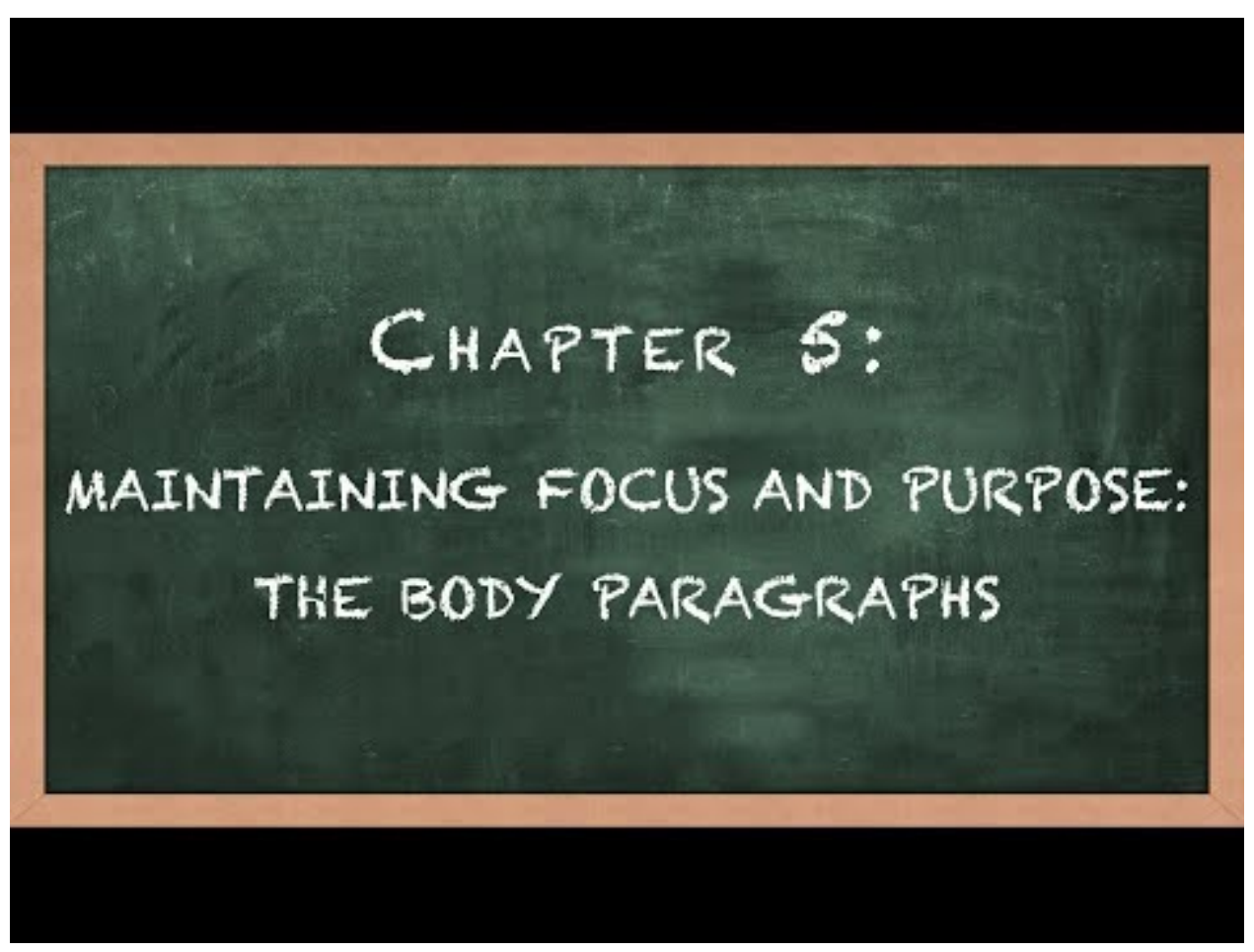

A YouTube element has been excluded from this version of the text. You can view it online here:

https://pressbooks.library.ryerson.ca/writehere/?p=486

Returning to the metaphor of the three-storey thesis, your body paragraphs are the steps you use to take your reader from the claim you make in your introduction (the first storey), through your focused analysis of textual specifics (the second storey), and into your perceived importance of your reading which you aim to culminate in your conclusion (the third storey). As such, your body paragraphs need to lead your audience through your reading of the article in a way that delineates clearly the validity of your claims and the logic of your conclusion. This is where our evolving thesis and the outline we created in Chapter 4 are so important.

For the purposes of demonstration, we will be using the thesis and outline we developed for our analysis of Charles Justice's "The Ultimate Communications App." Your task in this chapter will be to develop and use a thesis and outline for an analysis of Michael Welsh's "Kids Around the World Just Want to Hang Out." Pay attention to how we create our essay, then develop your own body paragraphs for your analysis of Welsh's article which you will bring to class. You should also be developing your thesis and outline for your midterm essay so you will be ready to workshop elements of your essay in class.

In developing our first and second storeys-our focus and claim-for our thesis on "The Ultimate Communications App," 
we built a purposeful analytical statement around the textual element we perceived to be the most important, namely, Justice's contrast of "cooperation" and "conflict" in conjunction with repetitions of "common." This contrast demonstrates that while language is the tool we often use to express our differences and dissatisfaction, it is also the manifestation of a common desire to share and connect. Here is our three-storey thesis with our first storey italicized and our second storey bolded:

\section{Example}

Speaking to an audience of first year university students in Canada, Charles Justice in "The Ultimate Communications App" utilizes the contrast of "cooperation" and "conflict" in combination with the repetition of the word "common" in closing his argument. From this, Justice is arguing that while humans have become distanced into "occupying different places" through technological, agricultural and domestication evolution, it is the shared historical fact that humanity grew from the same original roots of collective language construction that unites every modern person to their human counterparts around the globe. Considering Justice definition of the common as "a level-playing field," Justice concludes with a call to arms extolling humans to grasp their ethical responsibility not only to each other but to "share" in the present concerns of a globalized population of humans in the entire "Earth's biosphere." 


\section{Keep Your Thesis Close}

It is important to have a hardcopy of your thesis handy so that you can always remind yourself of your claim as you determine the purpose and structure of your body paragraphs. As you imagine what your first body paragraph will look like, it is worth remembering one of the central notions we discussed in Chapter 2.

\section{Example}

You should look to begin your analysis with an examination of what you believe to be the most important and revealing piece (or pieces) of evidence. Was there a moment in the text or a key repetition or consistent contrast that confirmed for you what this text was really about? Begin with that. Using that strong base you can move to your second and third strongest pieces of evidence. Continue with all your evidence, building your analysis until you reach your final points which should examine the less-than-obvious supportive aspects of the text. A close reading doesn't just rely on one or two obvious statements that prove you are "right." Imagine that you are luring your reader into your understanding of the text: "Do you agree with my reading of the first piece of evidence? The second? The third? Well, then perhaps you would like to consider what I have to say about this part of the text that you may be surprised to find in this argument."

We have identified as central to Justice's argument his examination of language as a human invention that drives debates and divisions but is more importantly developed out of a desire to connect. Our first body paragraphs will analyze aspects of the text that establish this "common" tendency to connect. This is the approach we have sketched in our essay outline.

\section{Example}

Paragraph 1 (First Storey): Quote and unpack the contrast of "cooperation" and "conflict."

Paragraph 2 (First Storey): Quote and unpack the repetition of the word "common."

Paragraph 3 (Second Storey): Overlap the contrast of "cooperation" and "conflict" with the repetition of the word "common" by answering what the two pieces of evidence have to do with each other? How are they similar? Contrasting?

Paragraph 4 (Second Storey): Explain how those two pieces of evidence lead to Justice's argument that "humans have become distanced into "occupying different places" through technological, agricultural and domestication evolution."

Paragraph 5 (Second Storey): Explain how those evolutions are offset by the fact that "it is the shared historical fact that humanity grew from the same original roots of collective language construction that unites every modern person to their human counterparts around the globe." 
Keeping your outline and three-storey thesis always in view, work through your lists and annotations to find the specific textual elements you will use in each of your purposeful, analytical paragraphs.

Watch Video 5.2 to see how we create the first five paragraphs of our analytical essay on Justice's "The Ultimate Communication App".

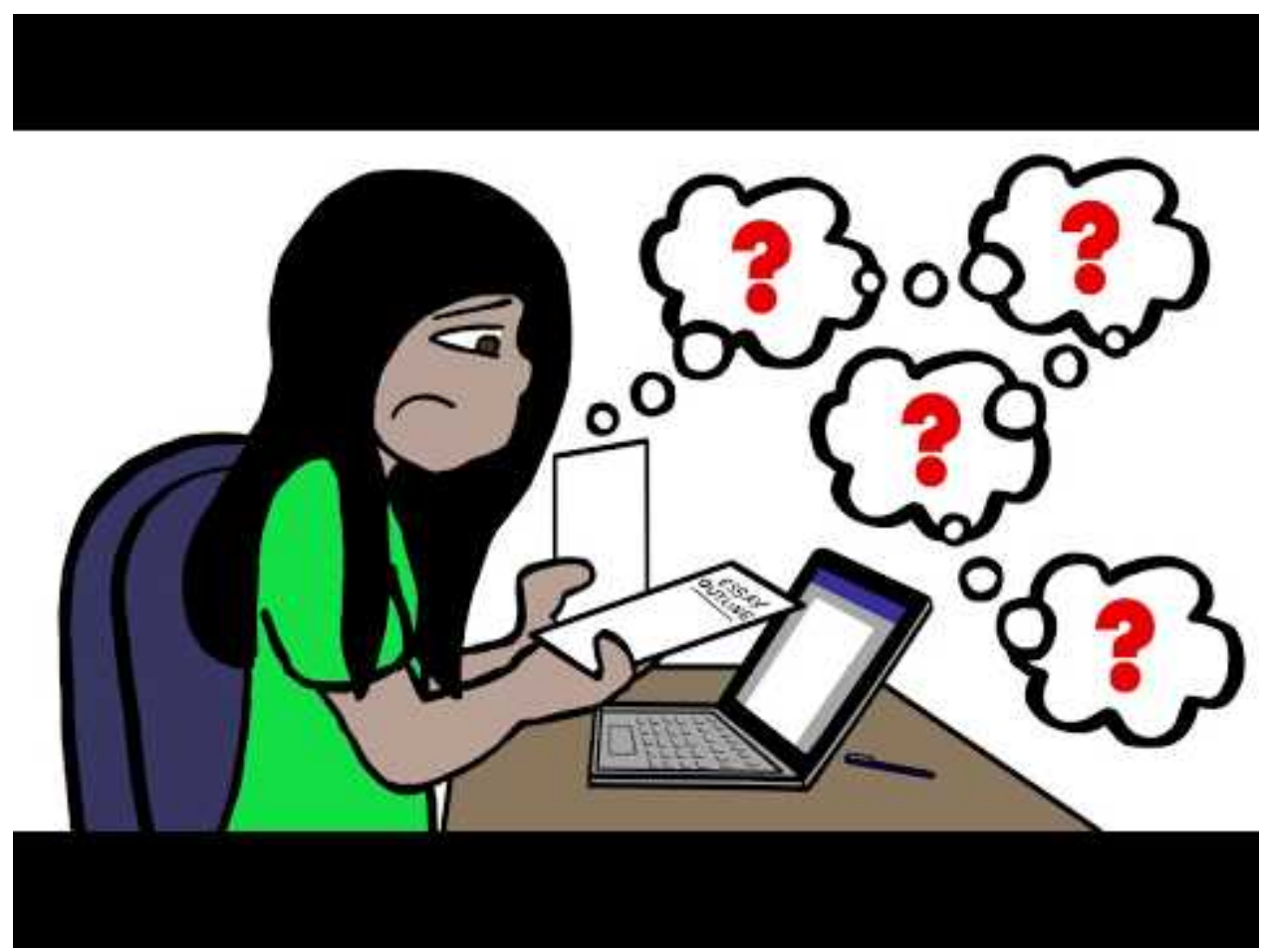

A YouTube element has been excluded from this version of the text. You can view it online here: https://pressbooks.library.ryerson.ca/writehere/?p=492 


\section{Body Paragraphs}

So, your essay-in-progress currently has five full body paragraphs. Remember, you do not want to include your thesis in the essay proper just yet. Better to keep the thesis and the body paragraphs separate for easy reference and comparison. Remember that your thesis is still evolving and may change slightly as the writing of body paragraphs forces you to confront specific aspects of the text under analysis. Here's how the essay looks so far (with some explanatory notes detailing how we arrived at each paragraph):

\section{Body Paragraph I}

\section{Example}

In his coy opening paragraphs, Justice describes the many uses of language as if they are features of a "new communications app" he "just invented." Justice notes how language use "facilitates an expanding network of people" and "opens up incredible possibilities for creativity and cooperation." Such clever itemization of language's many features enables Justice to establish language as a tool that has at its root the human desire to connect and work together. Though centuries of migration and conflict may have turned the world into a "Tower of Babel" in which populations are divided by different languages, "all of us living today have a common history" in which language was developed first and foremost to create community.

Please note: As we noted in our essay outline, a good entry point into our analysis of Justice's article is to quote and unpack the contrast of "cooperation" and "conflict." Returning to our notes and our annotated version of Justice's essay, we see how language is described as a point of conflict, a "Tower of Babel," but also, conversely, as a tool that undeniably "facilitates an expanding network of people" and encourages "creativity and cooperation." Looking toward the explication in our second paragraph of Justice's repetition of "commons," we end this first body paragraph with a transitional comment on "community." 


\section{Body Paragraphs}

\section{Body Paragraph 2}

\section{Example}

Justice stresses that such a created community is often defined by "a commons," which he defines thusly: "A commons is a level-playing field. Everybody gets to breathe air, and we have that in common with most other species." He establishes language as one of the first such commons, "available to everyone free" and a "common way for us to share information and create enduring knowledge." Thus, whether it is being used to foster cooperation or perpetuate conflict, language has always been a commons accessible to all members who wish to contribute meaningfully to their community.

Please note: To establish further our particular reading of Justice's article, we now must now quote and unpack the repetition of the word "common" and demonstrate how this repetition is connected inextricably with Justice's contrast of "cooperation" and "conflict." Looking at our annotated version of the text, we see that the word "common" or "commons" is used 18 times by Justice. Referring to our lists, we see we have listed "commons" as a "New Word"; we have paired it with "cooperation" in our lists of "Similar Words"; and we have contrasted it with "private space" in our "Contrasts." We can see through these repetitions that explaining the importance of "a commons" and then establishing language as one of the first examples of "a commons" is a driving force in Justice's argument. 


\section{Body Paragraphs}

\section{Body Paragraph 3}

\section{Example}

Justice defines language as "a method of communication that is available to virtually all humans to use"; a "common property, available to everyone free." Justice thereby establishes language as a common human right and desire-an inherent need that is obvious even in the simple naming and describing of a "proto-language" like "Me Tarzan, you Jane": "Once you begin to share information, you are creating a common space of understanding amongst you and your fellow speakers." Even if that common space is used to express difference-Tarzan is not Jane-it is still a vital tool that ensures even those who do not share opinions, backgrounds, or identities can still share ideas.

Please note: Now we have begun the analysis of the evidence upon which we developed the second storey of our three-storey thesis. Essentially, we will be justifying and enacting our claim here, analyzing evidence to demonstrate how Justice is doing what we claim he is doing. In our outline we established our goal in this paragraph to overlap the contrast of "cooperation" and "conflict" with the repetition of the word "common" by answering what the two pieces of evidence have to do with each other. We have prepared for this paragraph rather nicely with the concluding sentence in Paragraph 2 that first makes this connection. Now we can review our collected information for more evidence to analyze in this paragraph. 


\section{Body Paragraphs}

\section{Body Paragraph 4}

\section{Example}

Justice notes that sometimes such differences, even when expressed, still lead to divisions that may seem insurmountable. "We parcel up land into properties," Justice writes, marking our divisions from one another. In more extreme cases, we are "separated permanently by mountains or water barriers" which seem to end definitively any sense or hope of unity: "because of our success in outgrowing our original environment, we ceased to have a common place and identity." This insurmountable division seems an unavoidable result of human evolution and prosperity, Justice claims-as the earliest groups of humans thrived in their shared landscape, "eventually, as populations grew over generations, a new band would split off." Such splits would drive groups of humans further afield from one another, resulting in a mutual forgetting of their "common place and identity" and likely the "evolution of different languages."

Please note: You can see we have moved fully into our analysis of what this essay is really about and our argument about what is really at stake here. This paragraph is dedicated entirely to analyzing information that bolsters our claim that one of Justice's driving motives is examining how humans have become distanced into "occupying different places" through technological, agricultural and domestication evolution. It is vital here that we do not just state evidence from the essay, but that we connect all cited material directly to our interpretive claim. You should also note how the notion of bridging the distance between different groups of people is carried from the last sentence in Paragraph 3 to the first sentence in Paragraph 4. 


\section{Body Paragraphs}

\section{Body Paragraph 5}

\section{Example}

Yet, Justice claims, even as humans mark their property or separate themselves by mountains and water, it seems inherent in the human creation of place that "much land is held in common in the form of parks, trackless wilderness, public rights of way and public spaces." Justice utilizes much natural imagery when defining "a commons" like language: "The sunlight that falls to Earth is common to all, plants and animals on land, fish and the whales in the sea." Further, Justice asserts that "here in the rain forests of the Pacific Northwest, fresh water is a common resource," implying, even as he invokes the human naming of a region, that this does not override the deeper human tendency to share resources and foster a space that is mutually beneficial.

Please note: We have established as one of Justice's driving motives his desire to inspire his readers to rethink differences that may seem unavoidable, unbridgeable, and in fact fostered by seemingly natural human evolution. We now explain how those evolutions are offset by the fact that it is the shared historical fact that humanity grew from the same original roots of collective language construction that unites every modern person to their human counterparts around the globe. Justice employs a lot of natural imagery to ratify his interpretation of "a commons" like language being connected to and representative of a natural human desire to share. 


\section{It's More Than Cut and Paste: The Parts of a Paragraph}

Now that we have provided you with some examples of the sorts of paragraphs you can expect to find in an analytical essay, it is a good time to pause and reflect on the components of a successful body paragraph. You crafted an outline that evolved from the focus and claim of your thesis and in that outline you decided what you wanted each paragraph to do. As you can see, there is more to constructing a paragraph than restating your thesis and citing from the text. While your purpose will always guide the shape of your essay and your actual writing may alter the planned outline slightly, it is important to remember that there is a structure here. Each paragraph should contain a structured argument that positions it as a supported, supportive, and connected piece of your overall argument

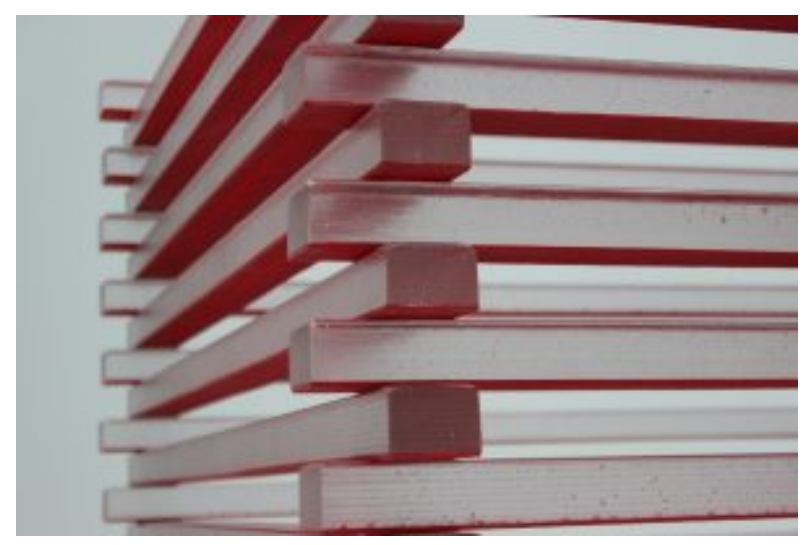

From Pixabay.

While each paragraph will look a little different and deal with a new aspect of the text, there are some elements that a paragraph must contain if it is to be a contributing part of a cohesive argument.

\section{Example}

Claim + Evidence + Warrant

When it comes to body paragraphs, especially body paragraphs in essays for introductory college and university courses, we recommend using an abridged version of the Toulmin Method. Stephen Toulmin was an English philosopher who created a model for the persuasive argument. For the purposes of this text, which is designed to introduce scholars just beginning their postsecondary careers to the act of successful analytical writing, we will consider a version of the Toulmin model that consists of Claim, Evidence, and Warrant. Each paragraph must contain an interpretive claim derived from the original claim expressed in your thesis statement. A claim is a statement you want your reader to accept or at least consider. To facilitate this acceptance you must provide textual support or evidence. This evidence will serve as a ground or basis for your claim. In a close reading such as the ones we have been conducting thus far, the evidence is something 
that is undeniably in the text you are analyzing. The warrant is an explanation of how the evidence supports the claim. The warrant may be a simplistic demonstration or it may be a larger argument, but it always proves the validity and worth of the claim as a way of reading the evidence. The warrant is a combination and interaction of the claim and the evidence that produces your interpretation of the text. Evidence-whether it is in the form of a cited passage or a paraphrase-must be irrefutably from the text you are analyzing. A warrant, however, is more controversial-it is something that is not undeniably in the text, but is rather a statement and a demonstration of what you think a text is doing. It is a directive for how you want your readers to consider the original text.

122 | It's More Than Cut and Paste: The Parts of a Paragraph 


\section{Claim, Evidence and Warrant}

Body paragraphs will often begin with a claim, then cite some evidence, then develop the warrant by reading the evidence through the claim; however, you should not regard these three elements as immovable parts of a rigid formula of $1+1+1=3$. Claim, evidence and warrant should work together more organically than that. You will rarely make a claim without connecting it immediately to evidence. Nor will you simply cite evidence without reading it through the lens of your claim. Better to keep an eye to your thesis and outline and make sure you are always reading the text the way you want your audience to consider it. To understand exactly how this works, let's compare our intended purpose for Paragraph 1 as detailed in our outline with the actual Paragraph 1 as it appears in our essay. In the final version of Paragraph 1, the evidence is bold and the

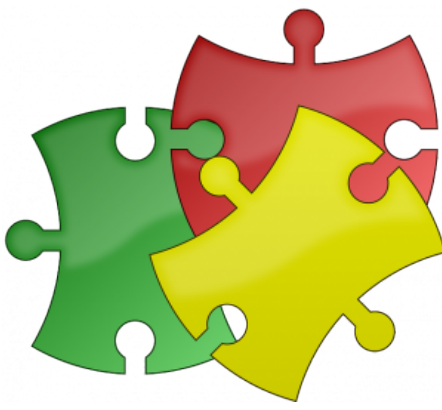

From Pixabay. claim is in italics.

Paragraph 1 (First Storey): quote and unpack the contrast of "cooperation" and "conflict"

\section{Example}

\section{Body Paragraph 1:}

In his coy opening paragraphs, Justice describes the many uses of language as if they are features of a "new communications app" he "just invented." Justice notes how language use "facilitates an expanding network of people" and "opens up incredible possibilities for creativity and cooperation." Such clever itemization of language's many features enables Justice to establish effectively language as a human tool that has at its root the human desire to connect and work together. Though centuries of migration and conflict may have turned the world into a "Tower of Babel" in which populations are divided by different languages, "all of us living today have a common history" in which language was developed first and foremost to create community.

The whole paragraph works toward our analysis that Justice is really writing about how language, so often used as a demonstration of what divides us, is really symbolic of our common desire to work together, and how if used properly, it can overcome any difference or distance. The whole paragraph is essentially the warrant, punctuated by the transitional last line that claims Justice believes "language was developed first and foremost to create community." Our choice of what evidence we use is not arbitrary and indicates our intended reading of this text. Our description of Justice's writing as "coy" and "clever" persuades our reader toward our interpretation of the text-an assertion that what is undeniably in the text is doing what we in fact claim it is doing. 


\section{Topic Sentences and Transitions}

In the end, you want your body paragraphs to build (like blocks) to your conclusion. Transitions are the glue that hold these blocks together. You should work on building topic sentences that both develop and support the thesis in a logical manner. Avoid such easy, empty transitions as "firstly," "secondly" and "finally." Your reader should be able to understand they have been moved from one aspect of your argument to another without a tell-tale "secondly" informing them that the first point is over and the second point is about to begin. Again, this is where keeping a close eye to your thesis and your outline is so important. If you know where the essay is going, you can transfer your readers smoothly from the analysis of one aspect of the text to the next with meaningful connections and statements rather than empty transitional phrases. Witness the transition from the final sentence in Paragraph 2 into the first sentence and then the topic sentence of Paragraph 3.

\section{Example}

Thus, whether it is being used to foster cooperation or perpetuate conflict, language has always been a commons accessible to all members who wish to contribute meaningfully to their community.

Justice defines language as "A method of communication that is available to virtually all humans to use;" a "common property, available to everyone free." Justice thereby establishes language as a common human right and desire-an inherent need that is obvious even in the simple naming and describing of a "proto-language" like "Me Tarzan, you Jane..."

The bolded sentence above is the topic sentence of Paragraph 3-it is what we want this paragraph to do. The final sentence of the previous paragraph and the opening sentence of the current paragraph work well to demonstrate that language, whether it is used to argue or agree, is a "commons" desired by and available to everyone. Such a connected argument solidifies our claim that Justice is establishing language as the tool that facilitates arguments but produces understanding and community through these arguments. 


\section{Incorporating Cited Passages into Your Own Writing}

We will talk more about citation in research papers in Chapter 13. For now, when dealing with a close reading of one article, keep in mind a few cardinal rules.

\section{Do not let cited passages stand alone as sentences!}

Remember that you are presenting your reading of this text, so it is not enough to simply let a cited passage speak for itself. You need to be selective in the passages you choose. Larger quotes usually do not work in short paper. You must always be interacting with the text and demonstrating how the author continues to deliver the message you identify as central, as we do in this excerpt from Paragraph 5.

\section{Example}

Justice utilizes much natural imagery when defining "a commons" like language: "The sunlight that falls to earth is common to all, plants and animals on land, fish and the whales in the sea." Further, Justice asserts that "Here in the rain forests of the Pacific Northwest, fresh water is a common resource," implying even has he invokes the human naming of a region, that this does not override the deeper human tendency to share resources and foster a space that is mutually beneficial.

Another reader may read Justice's text and NOT see what we see. It is therefore important that we not simply cite without analyzing. We must show how the text is doing what we claim it is doing, therefore it is vital that we couch cited passages within our declarative sentences. While paraphrasing is sometimes useful, it is best to cite and analyze in essays such as this one so that we do not make claims about the text that cannot be supported with evidence. It is important to remember that... 


\section{The Author's Subject is Not Your Subject}

In the process of analyzing an article there is often a tricky moment where the subject of the article threatens to become indistinguishable from the subject of the analytical essay. Remember that the author's subject is not your subject; the author's text is your subject. Maintain a critical distance and always make it clear that these are another author's claims that you are analyzing.

\section{Do not present the author's claims as if they are facts!}

Make a note of the language we use in this passage from Paragraph 4.

\section{Example}

Justice notes that sometimes such differences, even when expressed, still lead to divisions that may seem insurmountable. "We parcel up land into properties," Justice writes, marking our divisions from one another. In more extreme cases, we are "separated permanently by mountains or water barriers" which seem to end definitively any sense or hope of unity: "because of our success in outgrowing our original environment we ceased to have a common place and identity." This insurmountable division seems an unavoidable result of human evolution and prosperity, Justice implies-as the earliest groups of humans thrived in their shared landscape, "eventually, as population grew over generations, a new band would split off."

They may not seem like much, but phrases such as "Justice notes," "Justice writes," and "Justice implies" are pivotal parts of any paragraph that incorporates cited passages. It is important to continually remind your reader and yourself that you are analyzing another author's argument and not repeating irrefutable truths. Always be examining how the author's text works, and use citations to examine specific aspects of the argument, not present the argument as true. Without that angle of investigation, you will get caught summarizing an argument rather than analyzing it.

Now let's watch how we use claim, evidence, and warrant, topic sentences, and cited passages, to create our final two body paragraphs. Watch Video 5.3 on the inner workings of a body paragraph. 


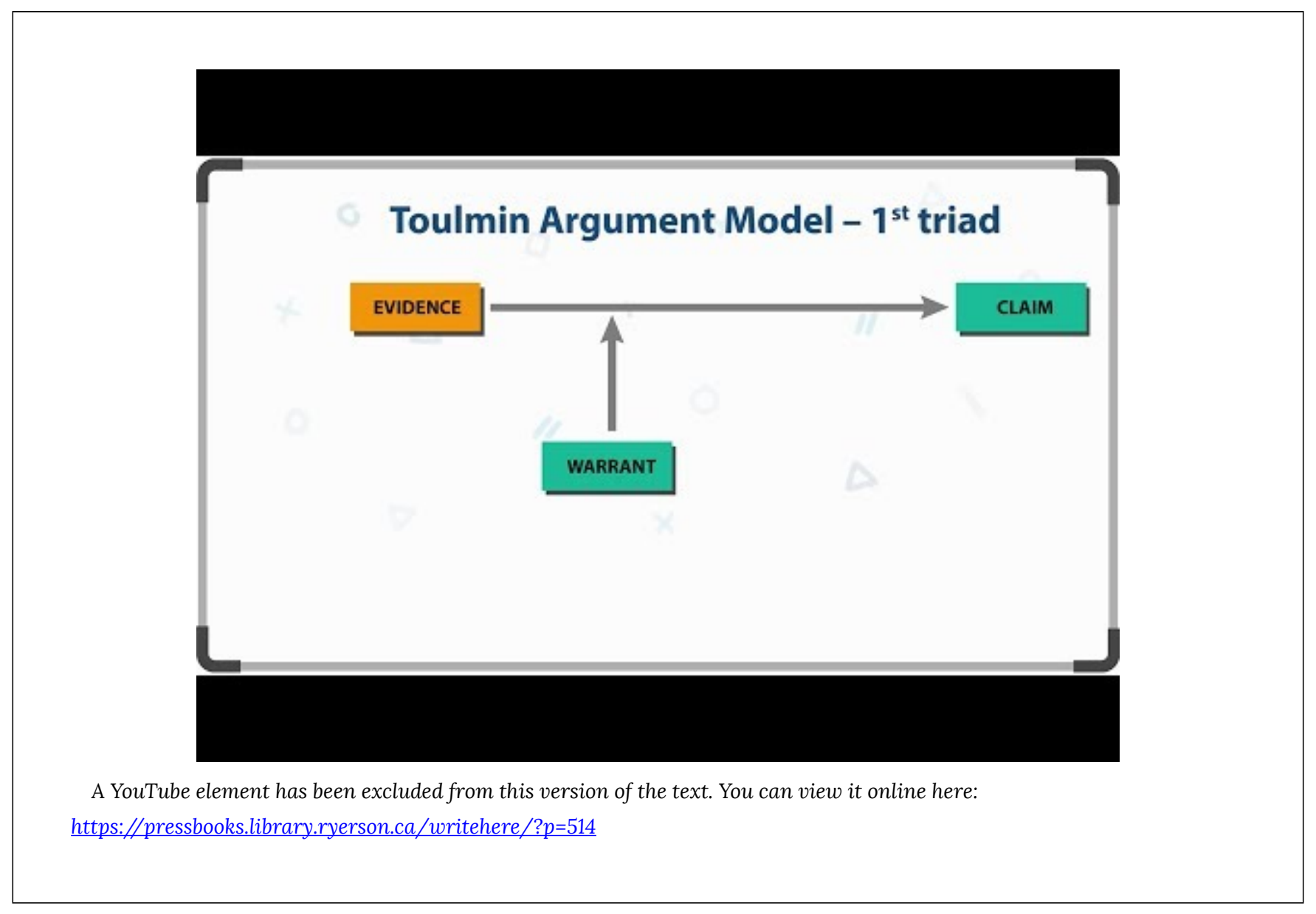




\section{Exit Strategy: Composing the Final Body Paragraphs}

We have arrived at the crux of our argument, the apex of our analysis. Best now to review once again our three-storey thesis, paying particular attention to the third storey.

\section{Example}

Speaking to an audience of first year university students in Canada, Charles Justice in "The Ultimate Communications App" utilizes the contrast of "cooperation" and "conflict" in combination with the repetition of the word "common" in closing his argument. From this, Justice is arguing that while humans have become distanced into "occupying different places" through technological, agricultural and domestication evolution, it is the shared historical fact that humanity grew from the same original roots of collective language construction that unites every modern person to their human counterparts around the globe. Reiterating his definition of the common as "a level-playing field," Justice concludes with a call to arms extolling humans to grasp their ethical responsibility not only to each other but to "share" in the present concerns of a globalized population of humans in the entire "Earth's biosphere."

It is also a good idea to remind ourselves of some of the questions we were asking when we developed this third storey in Chapter 3.

\section{Example}

When adding a third storey to this two-storey thesis, you must consider the logical extensions of this argument as they relate to the original text as a whole. In general, when developing your third storey, you might ask:

- Is the author offering a solution to a problem raised earlier in the text?

- Is the author warning of specific further consequences that will arise from a problem raised earlier in the text?

- What does the author want their reader to leave the text thinking or doing?

In the body paragraphs that flow from this third storey, we will reach a little further and make connections that solidify our reading of this text. We can make these leaps with confidence having established our analysis in the five body paragraphs leading to this. As always, it is important to have our outline close at hand so we can remind ourselves of what we need these final paragraphs to do. 


\section{Example}

Paragraph 6 (Third Storey): Explain what Justice means by "a level-playing field" (para. 6) and how it links to "the same original roots of collective language construction that unites every modern person to their human counterparts around the globe."

Paragraph 7 (Third Storey): Explain how this level playing field leads to "a call to arms extolling humans to grasp their ethical responsibility not only to each other but to "share" in the present concerns of a globalized population of humans in the entire "Earth's biosphere."

Our final sentence in Paragraph 5 facilitates nicely a transition into the claims we want to make in our final body paragraphs about Justice's identification of language as "a commons" and a "level-playing field:"

\section{Example}

Further, Justice asserts that "Here in the rain forests of the Pacific Northwest, fresh water is a common resource," implying even has he invokes the human naming of a region, that this does not override the deeper human tendency to share resources and foster a space that is mutually beneficial.

Keeping that transition in mind, here are the two paragraphs in which we strengthen and finalize our claim about why Justice was motivated to write his essay. They mark the logical extension from our granular analysis of the text to our claim about the text's purpose:

\section{Example}

\section{Body Paragraph 6:}

This mutually beneficial space is a worldwide commons manifested and made accessible by language. Despite the fact that "in outgrowing our original environment we ceased to have a common place and identity" and despite this initial "outgrowing" producing varied groups with diverse languages and varying levels of prosperity, Justice still believes that language, the one commons that is accessible to all, can be the "level-playing field" upon which all groups can interact and share. Like most successful technological innovations, this "new communications app" is intuitive and accessible, addresses a common need, and possesses the ability to perform tasks thought previously to be impossible.

\section{Body Paragraph 7:}

Justice's clever analogy of language as a "new communications app" encourages his readers to consider 
language in a new way. He want his readers to shirk off the notions of defeatism and division that often accompany discussions of language and recognize it instead as a "free" application that is linked ineluctably with the very "humanity and human origins" we have "in common with everyone else alive today." Viewed in this way, the many languages across the globe present a challenge, but they do not simply create a frustrated and disconnected "Tower of Babel." Instead, they represent a gigantic "level-playing field" that spans the entire commons that is the "Earth's biosphere." 


\section{What Now?}

We have moved successfully from our essay outline to the body of our essay. Now it is time to review what we have written thus far, account for any anomalies or missing information, create our conclusion-which is so much more than a simple summary of what we have already written-and finally add our introduction to our essay.

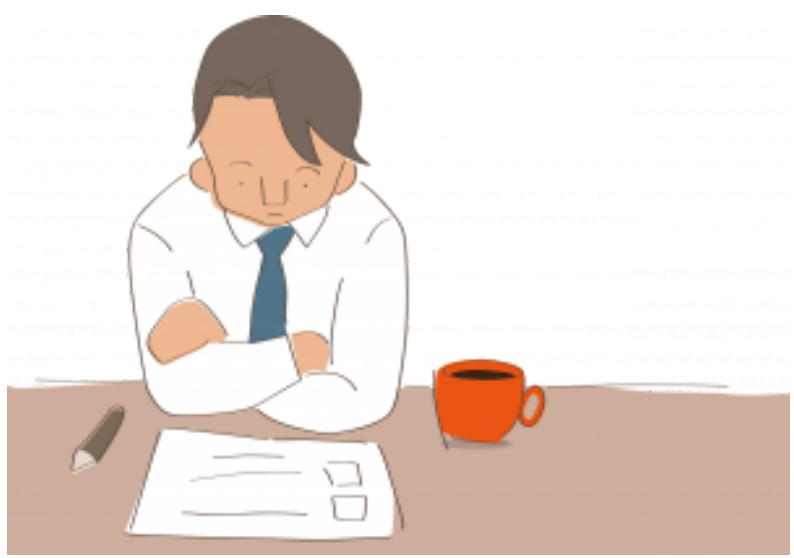

From Pixabay. 



\section{CHAPTER 6: ONE LAST TIME BEFORE YOU GO: THE CONCLUSION AND FINAL REVIEW}





\section{Chapter Overview}

\section{Learning Outcomes}

\section{In this chapter we will:}

- Review our essay-in-progress and create a conclusion that is not a repetition of what we have written but rather a final claim about the purpose of the entire text in the light of what the focused reading has revealed.

- Review our entire essay-thesis and body paragraphs-and edit for clarity and consistency.

- Demonstrate how a conclusion is not the end of analysis but rather an invitation to readers to engage in conversation.

- Demonstrate the need to say something new in the conclusion so that every aspect of the essay remains relevant to the unveiling of the analyzed article's purpose.

- Ensure that there is a logical progression from our initial claim through the body paragraphs, and into the culmination of the argument in the conclusion.

We have decided to dedicate an entire chapter to writing conclusions because, in our experience, the conclusion is the most misunderstood of all the components of the analytical essay. Most students seem to understand that a claim needs to be made in the introduction and that evidence needs to be analyzed in the body paragraphs. But these same students often share the widely held misconception that a conclusion exists simply to repeat the points already made in the essay. We think the pervasiveness and persistence of this notion has a lot to do with the five-paragraph essay form that is taught in elementary, junior high, and high school. 


\section{You Cannot Live on Hamburger Alone: Moving Beyond the Five-Paragraph Essay Form}

The major limitation the five-paragraph essay format is that it puts form before content. That presupposition creates problems at the university level: the limiting of ideas, the illusion of purposeful structure, and general repetitiveness. You may know this form it by its other name: the hamburger model. A quick examination of a "hamburger" outline for an essay on Charles Justice's "The Ultimate Communications App," will reveal many of the limitations inherent in the fiveparagraph essay, especially as it relates to the conclusion:

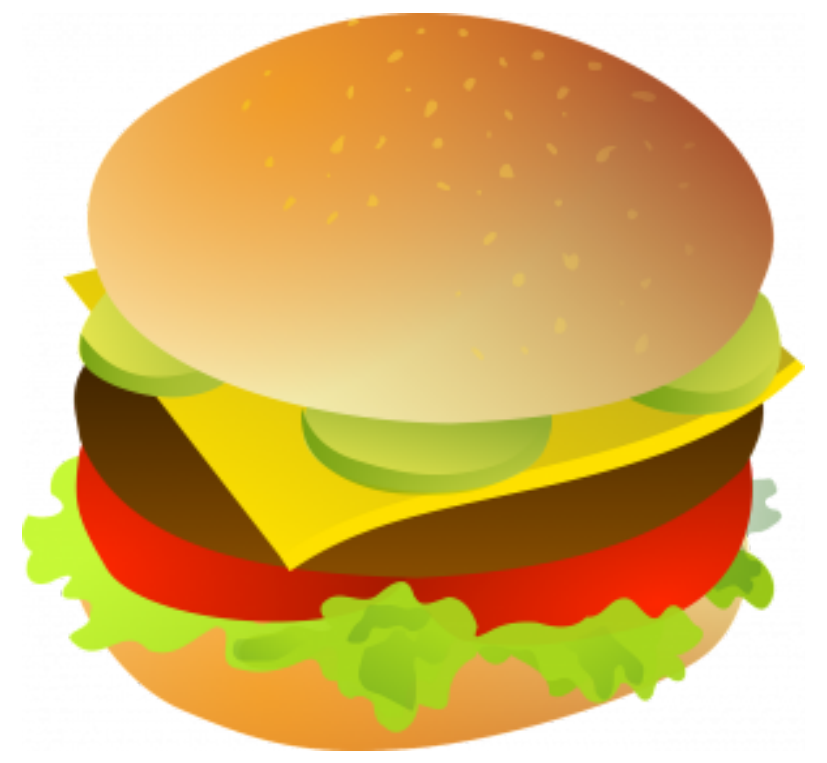

From Pixabay. 


\section{Top Bun}

\section{Introduction as Top Bun}

The main purpose of a five-paragraph essay is to prove that its writer has read the text under analysis. No position of inquiry needs to be taken, no controversial way of reading the text needs to be proposed. Like the sesame seed-adorned top bun of a hamburger, the introduction is the showiest element, covering everything that will be discussed in the remaining essay:

\section{Example}

In "The Ultimate Communications App," Charles Justice writes about the importance of language. He compares it to a "communications app," he defines it as "A common way for us to share information and create enduring knowledge," and he compares different languages to the "Tower of Babel."

While the author appears to be pointing at some of the more important moments from Justice's article, this introduction promises to do little beyond that pointing. These elements are in the text and they are part of Justice's discussion on language, but it looks as if little will be done by way of investigating how or why Justice or the author of this proposed analysis discuss these particular aspects. 


\section{Meat Patties}

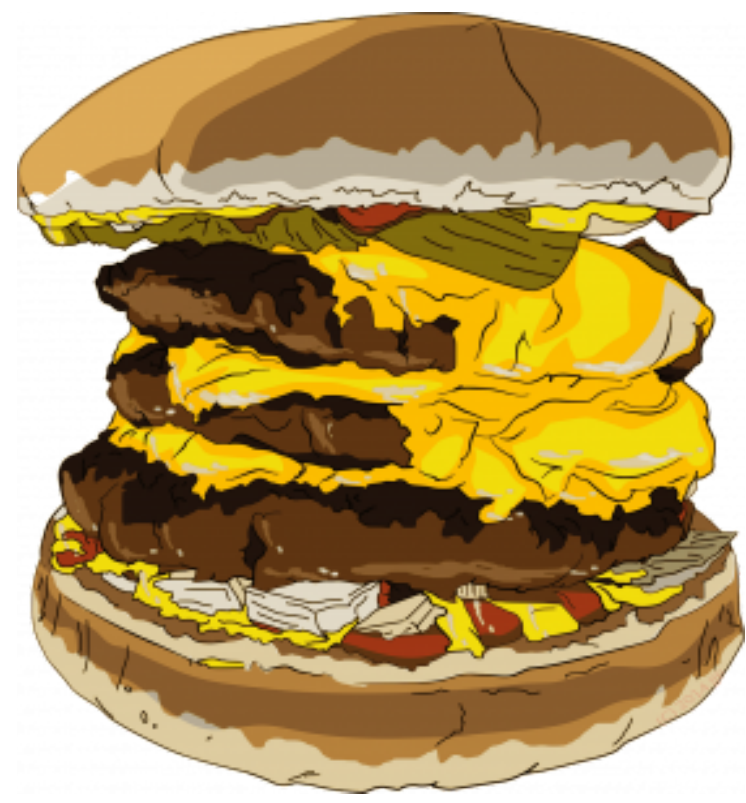

The structure of the five-paragraph essay also calls for just three body paragraphs, which means the introduction usually includes three main points. This is a serious limitation of the hamburger model: Why are there only three points? Must an analytical writer have always and only three points to discuss on any given topic? What if the author feels only two points are worth discussing? What if the author believes four points are needed for a meaningful analysis? Using this approach, the writer becomes trapped by the form and either inflates or ignores ideas to fit into a rigid structure of disconnected, observational paragraphs:

\section{Example}

\section{Body Paragraphs as Meat Patties}

Three separate points that stack one on top of the other, but do not connect:

1. Body Paragraph One on language as a "communications app"

2. Body Paragraph Two on language as "a common way"

3. Body Paragraph Three on language as a "Tower of Babel"

This is the most misleading aspect of the five-paragraph essay: the illusory notion that inserting data into the awaiting slots can create analysis. But the hamburger approach makes filling these spaces the end and only goal. When writing a five-paragraph essay, success is achieved not by connecting one's reading of specific aspects of a text but by finding three things to fill the space between the top and bottom buns. Without the evolution of an actual analysis, there is little for the conclusion to do but repeat what has been written. 


\section{Bottom Bun}

\section{Conclusion as Bottom Bun}

It is safe to say that nobody gets particularly excited about the bottom bun of a hamburger. It is a lesser version of the decorative top bun, does not add anything in the way of flavour, and functions only to give form to the burger. If you ordered a burger at a restaurant and received one with two bottom buns you would return it and demand a top bun, would you not? The bottom bun is unremarkable and unwanted. It needs to be there but it needs to do little beyond take its place.

When writing a five-paragraph essay, students use the conclusion as little more than the bottom of their essay-a paragraph that simply marks the end of the essay. If you are familiar with the five-paragraph essay, you will most likely be familiar with this scenario: after finishing the third body paragraph we go back to the introduction and copy or paraphrase the entire thing into our conclusion and add empty transitional phrases such as "To summarize...," or "In conclusion...," or, most egregious, "As I wrote in my introduction...." The progress through the essay has changed nothing and the conclusion, rather than providing a space for reflection or final judgement, does nothing but reiterate the vague claim made in the introduction and repeated through the body paragraphs. So is the purpose and the opportunity of the conclusion in analytical writing in analytical writing often missed and misinterpreted.

Now watch Video 6.1 on what conclusions can and should do.

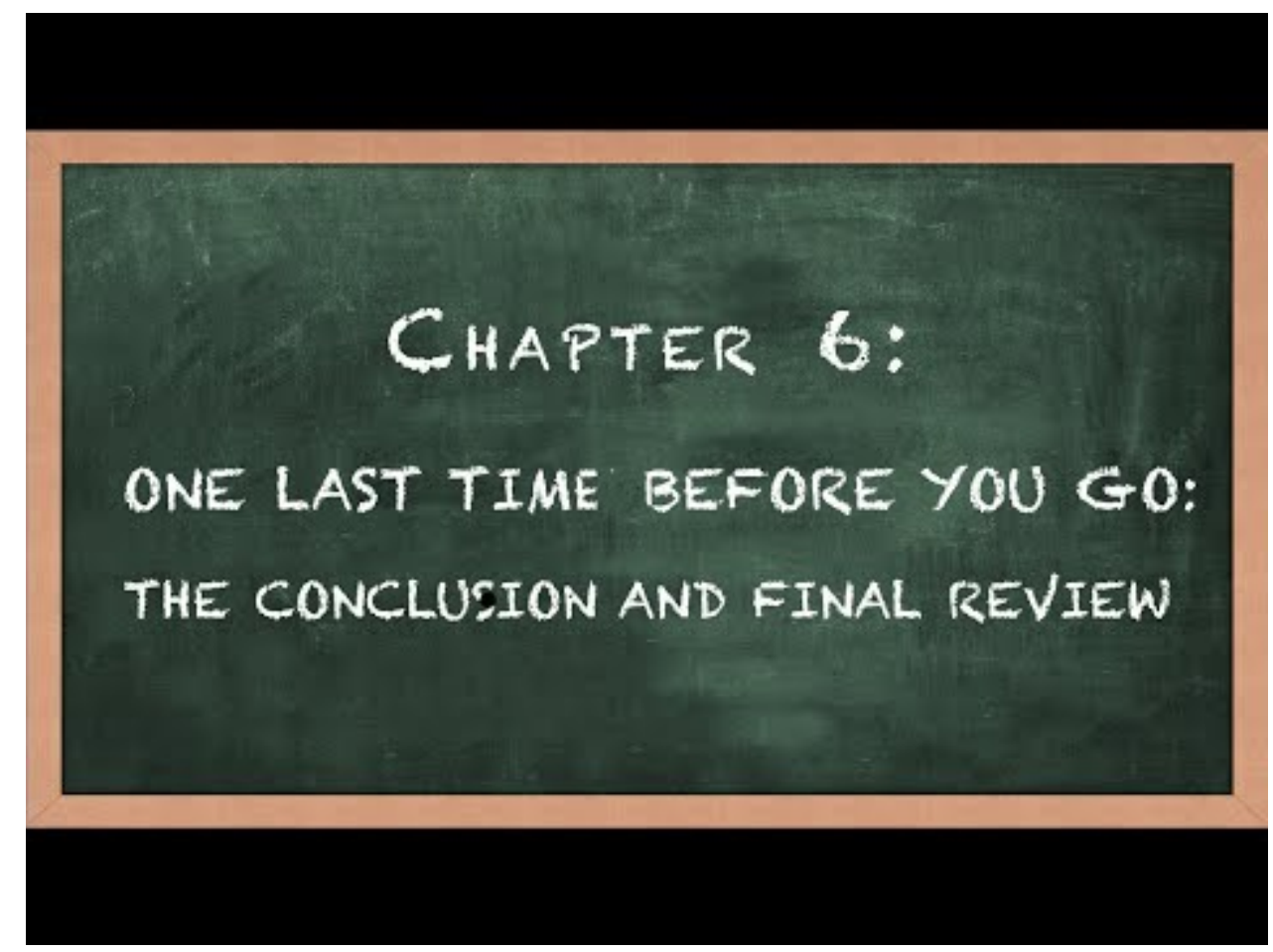


A YouTube element has been excluded from this version of the text. You can view it online here: https://pressbooks.library.ryerson.ca/writehere/? $p=531$ 


\section{Writing Your Conclusion}

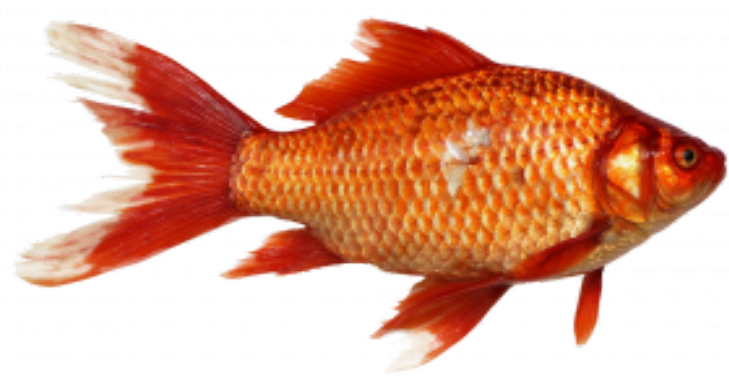

The common belief that goldfish have three-second memories is most likely a myth, but the metaphor still works for describing the problematic repetition inherent in the five-paragraph essay. It is highly unlikely you will be writing for goldfish at any point in your scholarly career, and it is equally unlikely that readers of your work will possess threesecond memories. Your readers do not need to be reminded repeatedly of your essay's focus and purpose.

The audience of your midterm essay, similar to the audience of our analysis of "The Ultimate Communications App," will certainly not need to be reminded of your thesis in your conclusion-they will not have forgotten it since reading your introduction. This type of essay simply isn't long enough for the focused reader to forget its purpose. Nor do you have the space in a short essay such as this one to repeat your thesis at the expense of examining different aspects of the text under analysis. Rather than treating your conclusion as if it is a return to your thesis, consider it as a final questioning and presentation of your thesis from the new position you have arrived at through your analysis.

Your thesis identified a focus (first storey) and built an interpretive claim (second storey) around that focus with an eye to making a final claim about what text is really doing. In your conclusion, you have arrived at the point where you can confidently make your final claim about the entire text. Essentially, your conclusion should justify your particular reading and make a final declaration on the benefit and consequence of discussing the text in the way you have. Remember that you are inviting others to discuss and debate this text with you, so your conclusion is not intended to shut down all future conversation on the essay, nor is it a final proclamation of your reading as the "right" and "only" reading of the text. While you do not want to end your essay with an arms-in-the-air disavowal of everything you have done or a pleading "What do you think?" to your readers, you do want your readers to consider the implications of your reading of this text upon their understanding of it. You want your readers to recognize your interpretation as a valuable contribution to the ongoing scholarly conversation.

In many ways, your conclusion is your own assessment of the writing you have completed to this point. You cannot write a conclusion without first reassessing your essay as it now stands. For the purposes of demonstration, let's review our analytical essay-in-progress on Justice's "The Ultimate Communications App" and determine exactly what we have left to say. 


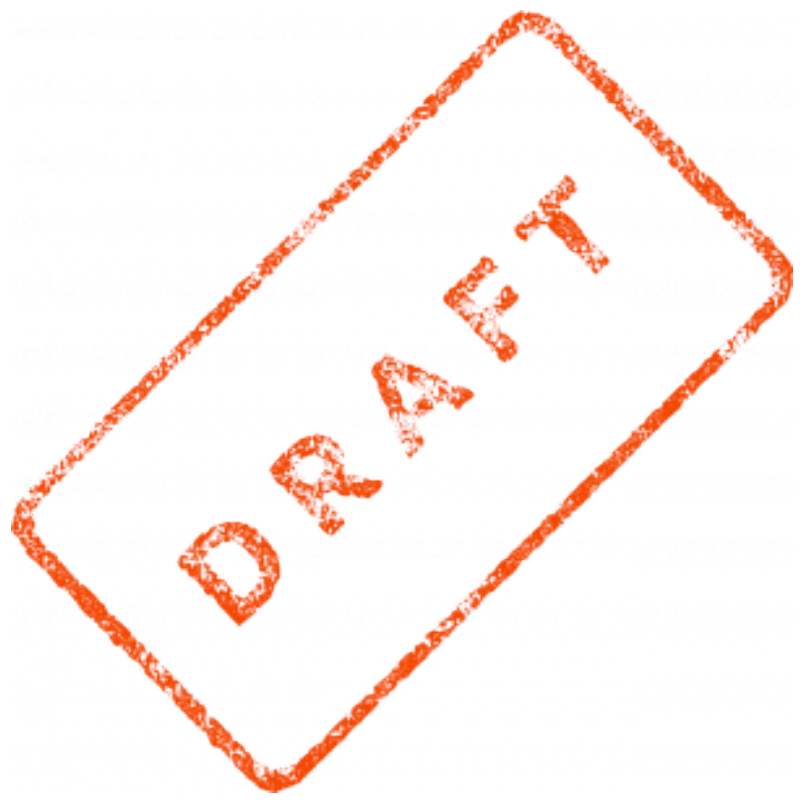

142 | Writing Your Conclusion 


\section{Three-Storey Thesis: Introduction}

Speaking to an audience of first-year university students in Canada, Charles Justice in "The Ultimate Communications App" utilizes the contrast of "cooperation" and "conflict" in combination with the repetition of the word "common" in closing his argument. From this, Justice is arguing that while humans have become distanced into "occupying different places" through technological, agricultural and domestication evolution, it is the shared historical fact that humanity grew from the same original roots of collective language construction that unites every modern person to their human counterparts around the globe. Reiterating his definition of the common as "a level-playing field," Justice concludes with a call to arms extolling humans to grasp their ethical responsibility not only to each other but to "share" in the present concerns of a globalized population of humans in the entire "Earth's biosphere." 


\section{Body Paragraphs}

In his coy opening paragraphs, Justice describes the many uses of language as if they are features of a "new communications app" he "just invented." Justice notes how language use "facilitates an expanding network of people" and "opens up incredible possibilities for creativity and cooperation." Such clever itemization of language's many features enables Justice to establish effectively language as a human tool that has at its root the human desire to connect and work together. Though centuries of migration and conflict may have turned the world into a "Tower of Babel" in which populations are divided by different languages, "all of us living today have a common history" in which language was developed first and foremost to create community.

Justice stresses that such a created community is often defined by "a commons," which he defines thusly: "A commons is a level-playing field. Everybody gets to breathe air, and we have that in common with most other species." He establishes language as one of the first such commons, "available to everyone free" and a "common way for us to share information and create enduring knowledge." Thus, whether it is being used to foster cooperation or perpetuate conflict, language has always been a commons accessible to all members who wish to contribute meaningfully to their community.

Justice defines language as "A method of communication that is available to virtually all humans to use;" a "common property, available to everyone free." Justice thereby establishes language as a common human right and desire-an inherent need that is obvious even in the simple naming and describing of a "proto-language" like "Me Tarzan, you Jane": "Once you begin to share information you are creating a common space of understanding amongst you and your fellow speakers." Even if that common space is used to express difference-Tarzan is not Jane-it is still a vital tool that can ensure that even those who do not share opinions, backgrounds, or identities can still share ideas.

Justice notes that sometimes such differences, even when expressed, still lead to divisions that may seem insurmountable. "We parcel up land into properties," Justice writes, marking our divisions from one another. In more extreme cases, we are "separated permanently by mountains or water barriers" which seem to end definitively any sense or hope of unity: "because of our success in outgrowing our original environment we ceased to have a common place and identity." This insurmountable division seems an unavoidable result of human evolution and prosperity, Justice implies-as the earliest groups of humans thrived in their shared landscape, "eventually, as population grew over generations, a new band would split off." Such splits would drive groups of humans further afield from one another, resulting in a mutual forgetting of their "common place and identity" and likely the "evolution of different languages."

Yet, Justice claims, even as humans mark their property or separate themselves by mountains and water, it seems inherent in the human creation of place that "much land is held in common in the form of parks, trackless wilderness, public rights of way and public spaces." Justice utilizes much natural imagery when defining "a commons" like language: "The sunlight that falls to earth is common to all, plants and animals on land, fish and the whales in the sea." Further, Justice asserts that "Here in the rain forests of the Pacific Northwest, fresh water is a common resource," implying even has he invokes the human naming of a region, that this does not override the deeper human tendency to share resources and foster a space that is mutually beneficial.

This mutually beneficial space is a worldwide commons manifested and made accessible by language. Despite that fact that "in outgrowing our original environment we ceased to have a common place and identity" and despite this initial "outgrowing" producing varied groups with diverse languages and varying levels of prosperity, Justice still believes that language, that one commons that is accessible to all, can be the "level-playing field" upon which all groups can interact and share. Like most successful technological innovations, this "new communications app" is intuitive and accessible, addresses a common need, and possesses the ability to perform task thought previously to be impossible.

Justice's cunning misrepresentation of language as a "new communications app" encourages his readers to consider language in a new way, to shirk off the notions of defeatism and division that often accompany discussions of language and recognize it instead as a "free" application that is linked ineluctably with the very "humanity and human origins" we 
have "in common with everyone else alive today." Viewed in this way, the many languages across the globe present a challenge, but they do not simply create a frustrated and disconnected "Tower of Babel." Instead, they represent a gigantic "level-playing field" that spans the entire commons that is the "Earth's biosphere." 


\section{Your Turn!}

Now would be a good time to revisit the Diagnostic Self-Assessment Checklist from our first class and use it to assess the introduction and body paragraphs for your close reading of Michael Welsh's "Kids Around the World Just Want to Hang Out." Read what you have written and answer the following questions. We recommend strongly that you return to this list when you reach a similar point in the writing of your midterm essay.

\section{Taking Measure}

Do you begin your essay with a thesis focused on the purpose of the text?

$\mathrm{Y} / \mathrm{N}$

Does your thesis make an interpretive claim about the text (i.e. do you make a claim about the text that is not obvious and is more than a simple summary of the text)?

$\mathrm{Y} / \mathrm{N}$

Does your thesis explain why your specific reading is worthwhile?

$\mathrm{Y} / \mathrm{N}$

Do you avoid plot summary (rather than simply repeat what the author has already said)?

$\mathrm{Y} / \mathrm{N}$

Do you discuss a new aspect of the text in every paragraph (rather than repeat the same observation over and over)?

$\mathrm{Y} / \mathrm{N}$

Do your paragraphs transition smoothly from one to the other so your analysis progresses and builds throughout your essay?

$\mathrm{Y} / \mathrm{N}$

Do you stay focused on the assigned text and avoid irrelevant "evidence" from outside the text (ex: personal experiences, facts or opinions you have read somewhere else, vague references to history)?

$\mathrm{Y} / \mathrm{N}$

Do you avoid the five-paragraph essay?

$\mathrm{Y} / \mathrm{N}$

Do you cite from the text and use specific textual evidence while making your points? $\mathrm{Y} / \mathrm{N}$

Do you use the specific terms used in the text rather than generalizing terms like "people" or "society"? $\mathrm{Y} / \mathrm{N}$

Take a moment to read aloud what you have written. Is it strong grammatically? Does it make sense? 


\section{What Now?}

You will most likely notice that you replied "Yes" more often now than you did when you evaluated your diagnostic essay. Some of these questions may even seem silly now in light of all we have worked on this term. Still, these questions may draw your attention to places where you have lost your focus momentarily, or dedicated a little too much page time to summarizing the author's argument, or committed a grammatical error or two. Remedy these situations, review your essay one more time, and begin constructing your conclusion.

Watch Video 6.2 to see how our final review of what we have written helped us develop the conclusion to our essay on "The Ultimate Communication App".

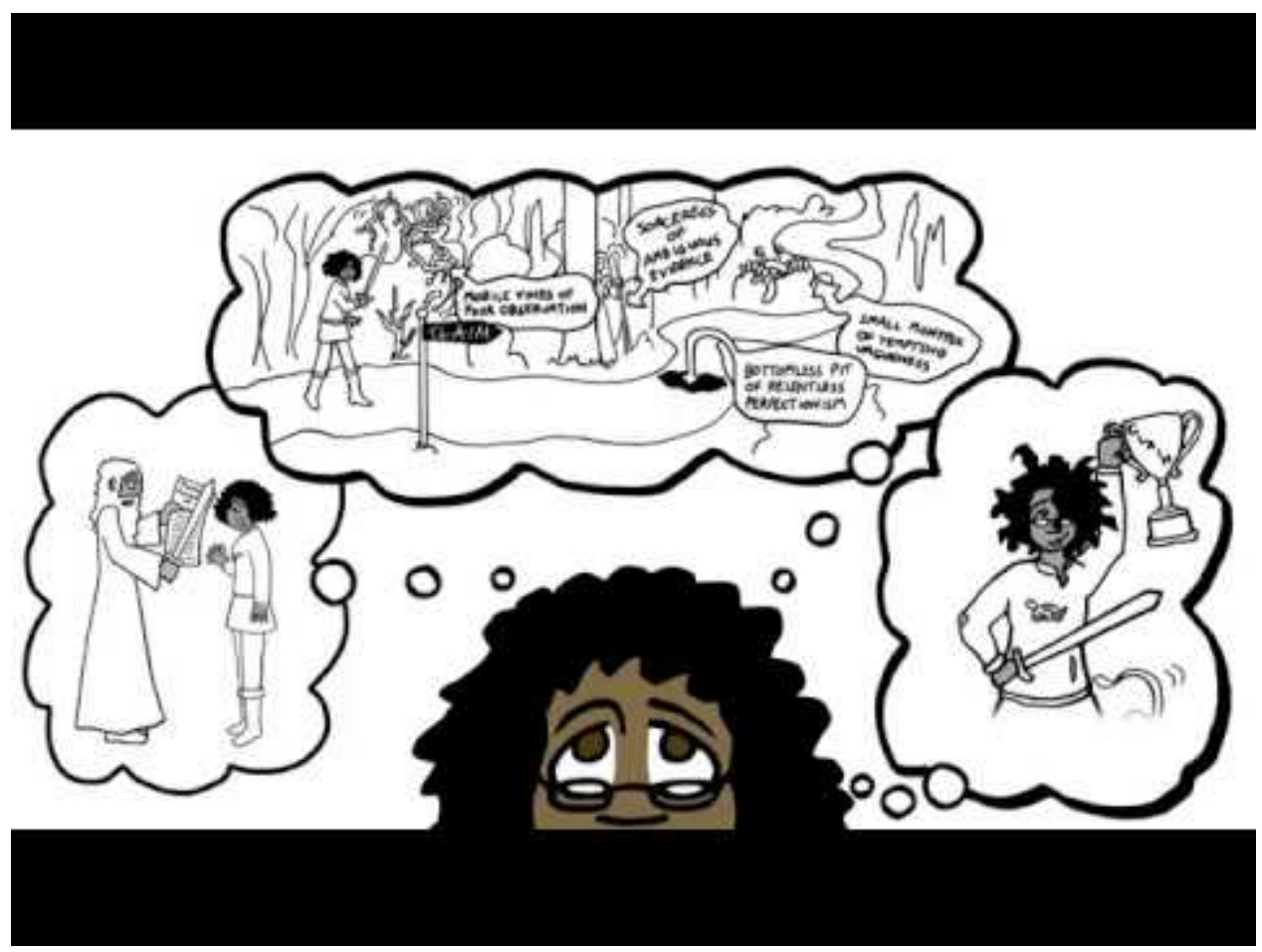

A YouTube element has been excluded from this version of the text. You can view it online here: https://pressbooks.library.ryerson.ca/writehere/?p=543 


\section{In Conclusion}

Your conclusion is as much a final assessment of your essay as it is a final commentary on the essay you are analyzing. It is vital at this point to reread the article and reread the essay you have written before writing your conclusion. Your task here has been to not just write but to justify your reading of this text. Your conclusion should constitute that final moment where you drive home what you perceive to be at stake in this text and how you believe the author best delivered that message.

Our analysis of "The Ultimate Communications App" is that Justice's concerns over a perceived misunderstanding of the power of language is what drives this text. Justice is motivated to write about this misunderstanding because it leads to a missed opportunity to unite diverse groups in a mutually beneficial conversation that could encourage them to work together to preserve the very "Earth's biosphere" that could serve as "a commons" for us all. We also appreciate Justice's use of language to convey its importance. In our conclusion then, we should make obvious how Justice proves the importance of language through a presentation of language in an innovative way that only further demonstrate how versatile and vital it is:

\section{Example}

\section{Conclusion}

Justice does well to present language as "The Ultimate Communications App," for in the technologicallydriven, always-connected world of his intended audience, access to the latest, most innovative internet and smartphone applications is almost always regarded as advantageous. The pretence of promising a new and free communications app that "can be used by almost everyone" and "works anywhere and anytime, night or day" is used by Justice to engage and enrapture his audience who presumably would be interested in an application that appears to be the manifestation of a "level-playing field" offering everyone equal access to the world's information. Though readers will eventually realize that Justice has "lied" and has not invented a new communications app, they will have likely also realized that they have already completed the "four years" required to properly "download" language and are already well-equipped to not only share but also contribute to humanity's "enduring knowledge." Justice's demonstration that the creation of an ultimate communications app would be welcomed almost universally is coupled with his eventual revelation that this "app," language, has existed for centuries and has been mastered by billions. Justice thereby inspires his audience to use their mastery of language to connect across the "manifest diversity" of their shared biosphere and foster the innate human desire for community and communication.

You will notice in our conclusion that we cite passages from "The Ultimate Communications App" that we have not cited before. This is intentional. While you do not want to begin an entirely new argument in your conclusion, you should still aim to say something new-to build upon your argument with new evidence. Review the material you have gathered in your earlier readings of the article and decide what evidence would work best with the final point in your conclusion. In our case, a rereading of our third storey reminds us of our claim that Justice's paper is really a "call to arms" to his readers. Keeping that metaphor in mind as we reviewed our notes, we were reminded of the passage in which Justice reveals to his readers that they are already sufficiently "armed" to respond meaningfully to this call: 


\section{Example}

There are only two things that may be problematic with it: my new app takes about four years to download. Yes, you heard correctly, not four minutes but four years. And usually, only ridiculously young kids know how to download it, but, like I said it takes about four years. During that time, the system needs constant maintenance and TLC. 


\section{Supporting Your Claim}

After reviewing our thesis in light of the essay that we developed from it, it seems that we have managed to stay pretty well on point. Remember, your thesis is a claim you are making about the text you are analyzing, not an itemized list of everything you are going to write about. So, while paragraphs will deal with aspects of the text not mentioned in your introduction, they should not deal with them in a way not clearly detailed in the introduction.

We notice that in our first, sixth and seventh body paragraphs, and in our conclusion as well, we make much of Justice's novel presentation of language as a new "communications app." Obviously, we regard this metaphor as a vital part of the text and a key device used by Justice to deliver his message. We should alert our readers in our thesis of the central role we believe this technique plays in Justice's essay. We need to make a few minor adjustments to our thesis before we insert it into our essay as the introduction.

Watch Video 6.3 on inserting the conclusion and introduction.

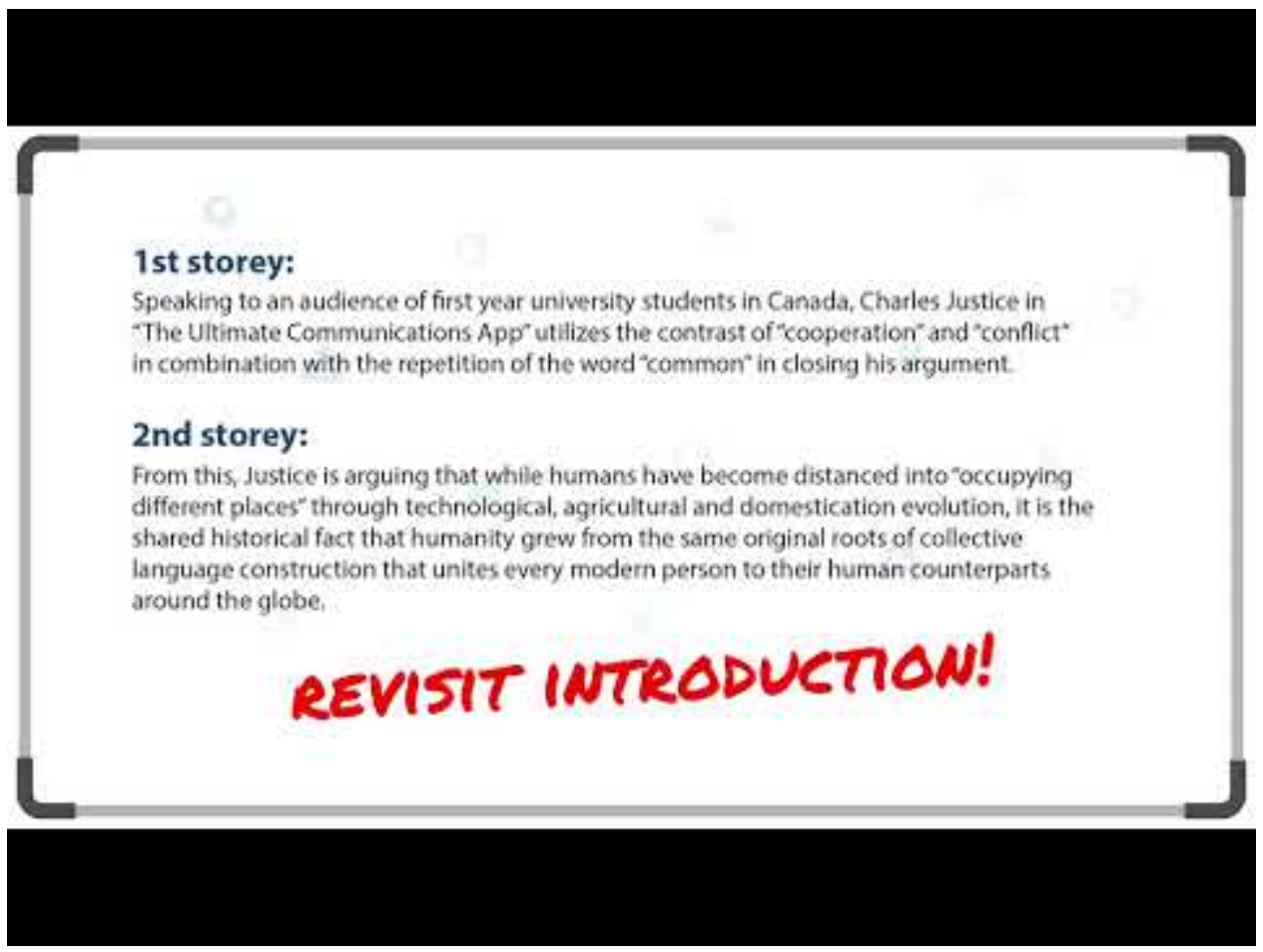

A YouTube element has been excluded from this version of the text. You can view it online here: https://pressbooks.library.ryerson.ca/writehere/?p=551 


\section{Putting it All Together}

Here, finally is our complete analytical essay of Charles Justice's "The Ultimate Communications App," with conclusion and revised introduction:

Example

Speaking to an audience of first year university students in Canada, Charles Justice in "The Ultimate Communications App" presents language as a new "communications app" that can inspire worldwide "cooperation," overcome any "conflict" and produce an equally accessible and beneficial "commons." Through this novel presentation of language, Justice argues that while humans have become distanced into "occupying different places" through technological, agricultural and domestication evolution, it is the shared historical fact that humanity grew from the same original roots of collective language construction that unites every modern person to their human counterparts around the globe. Reiterating his definition of the common as "a levelplaying field," Justice concludes with a call to arms extolling humans to use all aspects of this "new app," language, to grasp their ethical responsibility not only to each other but to "share" in the present concerns of a globalized population of humans in the entire "Earth's biosphere."

In his coy opening paragraphs, Justice describes the many uses of language as if they are features of a "new communications app" he "just invented." Justice notes how language use "facilitates an expanding network of people" and "opens up incredible possibilities for creativity and cooperation." Such clever itemization of language's many features enables Justice to establish effectively language as a human tool that has at its root the human desire to connect and work together. Though centuries of migration and conflict may have turned the world into a "Tower of Babel" in which populations are divided by different languages, "all of us living today have a common history" in which language was developed first and foremost to create community.

Justice stresses that such a created community is often defined by "a commons," which he defines thusly: "A commons is a level-playing field. Everybody gets to breathe air, and we have that in common with most other species." He establishes language as one of the first such commons, "available to everyone free" and a "common way for us to share information and create enduring knowledge." Thus, whether it is being used to foster cooperation or perpetuate conflict, language has always been a commons accessible to all members who wish to contribute meaningfully to their community.

Justice defines language as "A method of communication that is available to virtually all humans to use;" a "common property, available to everyone free." Justice thereby establishes language as a common human right and desire-an inherent need that is obvious even in the simple naming and describing of a "proto-language" like "Me Tarzan, you Jane": "Once you begin to share information you are creating a common space of understanding amongst you and your fellow speakers." Even if that common space is used to express difference-Tarzan is not Jane-it is still a vital tool that can ensure that even those who do not share opinions, backgrounds, or identities can still share ideas.

Justice notes that sometimes such differences, even when expressed, still lead to divisions that may seem insurmountable. "We parcel up land into properties," Justice writes, marking our divisions from one another. In 
more extreme cases, we are "separated permanently by mountains or water barriers" which seem to end definitively any sense or hope of unity: "because of our success in outgrowing our original environment we ceased to have a common place and identity." This insurmountable division seems an unavoidable result of human evolution and prosperity, Justice implies-as the earliest groups of humans thrived in their shared landscape, "eventually, as population grew over generations, a new band would split off." Such splits would drive groups of humans further afield from one another, resulting in a mutual forgetting of their "common place and identity" and likely the "evolution of different languages."

Yet, Justice claims, even as humans mark their property or separate themselves by mountains and water, it seems inherent in the human creation of place that "much land is held in common in the form of parks, trackless wilderness, public rights of way and public spaces." Justice utilizes much natural imagery when defining "a commons" like language: "The sunlight that falls to earth is common to all, plants and animals on land, fish and the whales in the sea." Further, Justice asserts that "Here in the rain forests of the Pacific Northwest, fresh water is a common resource," implying even has he invokes the human naming of a region, that this does not override the deeper human tendency to share resources and foster a space that is mutually beneficial.

This mutually beneficial space is a worldwide commons manifested and made accessible by language. Despite that fact that "in outgrowing our original environment we ceased to have a common place and identity" and despite this initial "outgrowing" producing varied groups with diverse languages and varying levels of prosperity, Justice still believes that language, that one commons that is accessible to all, can be the "level-playing field" upon which all groups can interact and share. Like most successful technological innovations, this "new communications app" is intuitive and accessible, addresses a common need, and possesses the ability to perform task thought previously to be impossible.

Justice's cunning misrepresentation of language as a "new communications app" encourages his readers to consider language in a new way, to shirk off the notions of defeatism and division that often accompany discussions of language and recognize it instead as a "free" application that is linked ineluctably with the very "humanity and human origins" we have "in common with everyone else alive today." Viewed in this way, the many languages across the globe present a challenge, but they do not simply create a frustrated and disconnected "Tower of Babel. Instead, they represent a gigantic "level-playing field" that spans the entire commons that is the "Earth's biosphere."

Justice does well to misrepresent language as "The Ultimate Communications App," for in the technologicallydriven, always-connected world of his intended audience, access to the latest, most innovative internet and smartphone applications is almost always regarded as advantageous. The pretence of promising a new and free communications app that "can be used by almost everyone" and "works anywhere and anytime, night or day" is used by Justice to engage and enrapture his audience who presumably would be interested in an application that appears to be the manifestation of a "level-playing field" offering everyone equal access to the world's information. Though readers will eventually realize that Justice has "lied" and has not invented a new communications app, they will have likely also realized that they have already completed the "four years" required to properly "download" language and are already well-equipped to not only share but also contribute to humanity's "enduring knowledge." Justice's demonstration that the creation of an ultimate communications app would be welcomed almost universally is coupled with his eventual revelation that this "app," language, has existed for centuries and has been mastered by billions. Justice thereby inspires his audience to use their mastery of language to connect across the "manifest diversity" of their shared biosphere and foster the innate human desire for community and communication. 
154 | Putting it All Together 


\section{What Now?}

Now it is time for you to revise, edit and proofread your final product. Reread your thesis as you reread each body paragraph and your conclusion. If possible, swap your essay with a peer and give and receive some final feedback. You have done a lot of work to get to this point, and you want to maximize your chances for success, so edit every sentence and make sure your good ideas are being expressed as clearly as possible. Congratulations, you are now ready to submit your analytical essay! 



\section{CHAPTER 7: MAKING YOUR OWN ARGUMENT}





\section{Chapter Overview}

\section{Learning Outcomes}

\section{In this chapter we will:}

- Differentiate between writing a close reading of another author's argument and creating your own argument.

- Close reading an essay prompt to identify initial potential paths and/or topics to make your own future argument.

- Identifying what document might be the most effective base for your own future argument.

- Analyzing that document to identify the strongest pieces of evidence for your own future argument.

- Building an initial two-storey thesis argument of your own. 


\section{Moving From a Close Reading to Making Your Own Argument}

Chapters 1 through 6 of this textbook focused on close reading. Those chapters walked through how to identify another author's argument and analyze it by focusing on key pieces of evidence in the first storey, linking that evidence to a specific argument within the text in the second storey, and then expanding the scope of the argument in the third storey.

However, not every assignment at the university level is a close reading. It is very common for a professor to give students an essay prompt or question (or a series of prompts or questions) and ask that students construct an argument to that question or prompt using scholarly research. In these cases, the professor is asking you to make an argument of your own. Chapters 7 through 13 of this textbook will describe how to write an effective university-level essay in which you make your own argument.

The good news is that the principles that we used to construct a three-storey close reading are exactly the same as the ones we will outline in the coming chapters. In order to make your own argument, you will:

- Begin with evidence that you acquire by analyzing a specific text in your first storey

- Combine that evidence with scholarly research to make a complex argument in your second storey

- Expand the scope of your argument in your third storey by considering the full results or consequences or solutions to the argument you raised in your second storey

As such, you will need the tools you developed in Chapters 1 through 6 as you close read other documents to get evidence for your first storey; you will also need to close read scholarly research to support your own argument in your second and third storeys.

The major difference, however, between a close reading of another work and making an argument of your own is the focus. In your close reading, you analyzed the author's complex argument. When making your own argument, you will be close reading other documents and arguments and incorporating them into your argument, but the focus is always your own argument. You will use the same tools but add further complexity and your own ideas and analysis.

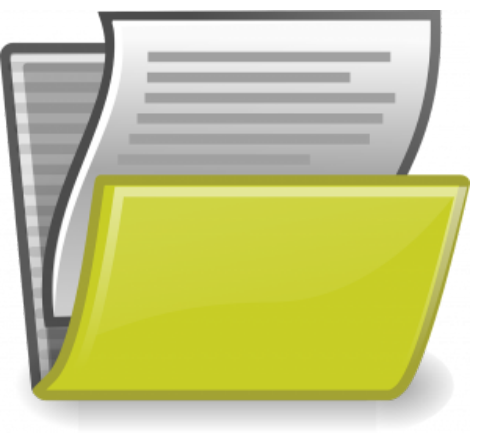

From Pixabay.

When asked to construct your own complex argument, you should first do a close reading of the essay prompt(s) and question(s), as we outlined in Chapter 1, patterns, key words, new words, and contrasts.

Forming your own argument is a slow and deliberate process and begins with the essay prompt or assignment guidelines that you are given. After you have read the assignment guidelines very carefully and asked your professor any initial questions, begin each of your assignments by identifying what you are being asked to do. 


\section{Try This!}

Using the following assignment prompt as an example, do an initial close reading of the question, make a list of any patterns, key words, new words, contrasts you find within the prompt. Notice that this prompt also includes a quote from an article; you will need to read the article to completely understand what is being asked of you.

In the case of more complex questions and prompts, it is useful for you to flag references used in the text that you may need to learn more about.

\section{Example}

In "Kosovo Attains Status (on Facebook) It Has Sought for Years," (http://www.nytimes.com/2013/12/13/ world/europe/kosovo-seeking-recognition-follows-the-crowd-to-facebook-social-media.html?mcubz=0) Dan Bilefsky reports:

"Last month, Kosovo declared victory, after its officials said Facebook approved a number of changes, including giving users registering from the diamond-shaped area on the Balkan Peninsula the option to identify themselves as citizens of Kosovo, rather than the decidedly less attractive option for many there, Serbia. They can also use the Facebook function that allows users to 'check in' on the website from locations within Kosovo, like a cinema or a bar."

Thinking about this development in the Balkans, as well as other political demonstrations, such as the Arab Spring, Black Lives Matter and Occupy Wall Street, for example, consider the role the Internet has played in protest. Choose ONE protest movement and ONE social media platform, and discuss the power dynamic created between the government and its citizens. What is the role of the Internet in affecting the balance between governments and citizens? You may consider expanding to consider movements like \#metoo and consider what power dynamics are being critiqued in on your chosen social media platform. In what ways has this technology been conducive to balancing or unbalancing these power dynamics? Has it been useful or harmful?

Activity

After you have compiled your list, complete the following simple template:

- "By using _____ [Observation One from your list]_____ and list] , this prompt is asking me to make an argument about [Observation Two from your larger discussion this prompt is asking you to join] [what you identify as the 


\section{Watch This!}

Watch Video 7.1: Making Your Own Argument, detailing a close reading of the previous assignment prompt. How does yours compare?

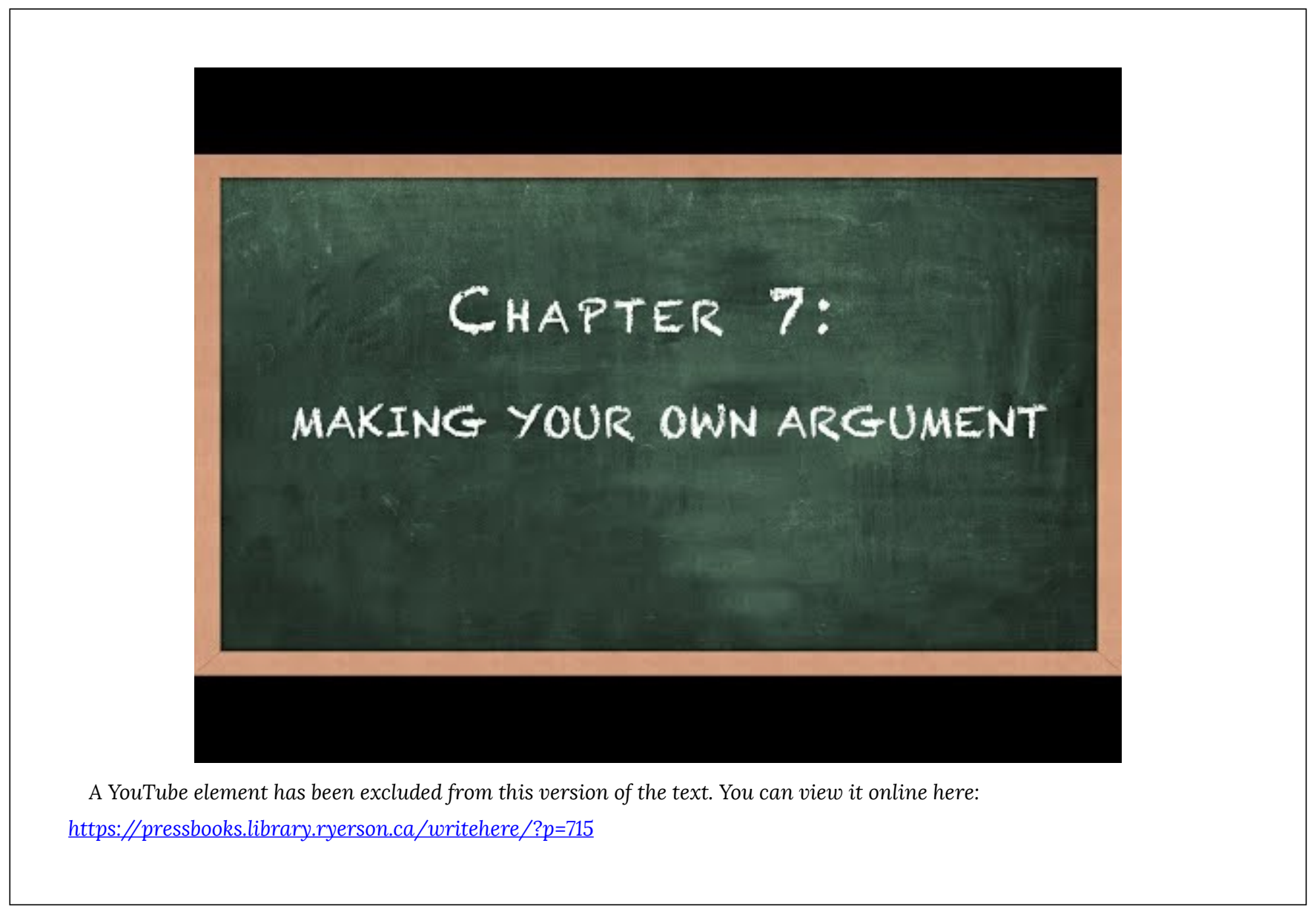

Close Reading Assignment Prompt 


\section{National identity}

$\begin{array}{ll}\text { Interesting } & \begin{array}{c}\text { Status } \\ \text { Protest }\end{array} \\ \text { words or } & \text { Balance } \\ \text { phrases } & \text { Power dynamics } \\ & \text { Internet } \\ & \text { Citizens } \\ & \text { Government } \\ \text { register }\end{array}$


Kosovo

Balkan Peninsula

"check in"

New words or phrases

Power dynamics

History of Iranian protests

Occupy Wall Street

Black Lives Matter

History of Egyptian Protests

Register and check in

Synonyms Balance of power and power dynamics

Users and citizens

Social media and Facebook

164 | Watch This! 


\section{Governments and citizens}

Contrasts Balance and unbalance

Protest and government

Useful and harmful

Best: Two

The contrast between government and citizens

Observations

Power dynamics

\section{Template:}

By using the contrast between "government" and "citizens" as well as the repetition of the phrase "power dynamics," this prompt is asking me to make an argument about the power dynamics created and/or enforced by ONE social media during ONE protest movement. 


\section{Choosing and Analyzing Your Central Document}

By now, you've probably noticed this chapter's repetition of the phrase "your own argument." The word argument is key. A professor never wants your opinion. Opinions are feelings and thoughts that cannot be proven and cannot be disagreed with. Evidence is the key difference between opinion and argument. While you may begin your essay writing process by examining our opinions, you should be ready to move them aside quickly and replace them with an argument grounded in evidence.

The first storey of your own argument should:

1. Choose a central document and explain its significance to your argument

2. Analyze that central document to focus on two key pieces of evidence

Based on your work in Chapters 1 through 6, you should be familiar with other authors' use of central documents or examples to make their arguments. For example:

Example

- In "Kids Around the World Just Want to Hang Out," Michael Welsh uses the responses given by two separate groups of high school students from Stockholm, Sweden, and Keene, New Hampshire, who were surveyed about their preferences and visions for their cities as his focused central document. Welsh argues that the students of Keene displayed considerably less vision than their Stockholm counterparts, "limited expectations" of their government's ability or interested to help them attain their goals, and a worrying reliance on commercial companies to provide them the accessible, common, and entertaining spaces they desire.

- In "The Plot to Privatize Common Knowledge," David Bollier uses the focused central document of the book Adios, Barbie: Young Women Write About Body Image and Identity, which outlines Mattel's aggressive litigation to protect its intellectual property. He uses this Barbie example to support his larger argument that "over-patenting," if continued unchecked, will result in much of what has been previously considered the shared and accumulated wisdom of humanity becoming "off limits" to the average citizen.

When choosing a central document, you want a specific document that will provide at least two focused pieces of evidence you can analyze meaningfully. Look again at the example assignment prompt from earlier in this chapter and note how that prompt explicitly identifies the central document you need when it asks for "ONE protest movement and ONE social media." Not every assignment prompt will be that overt, but, at the undergraduate level, you are expected to focus on a small number of examples-your one or two central documents-that support your focused and complex argument within the context of the assignment's guidelines. For this textbook you are only going to focus on ONE central document to create your argument.

Therefore, this central document should be short and manageable. As we do our example essay prompt about social media and protests, you will need to identify a precise central document that will provide your argument with strong supporting evidence of your argument. Imagine the scope of your essay. Let's say, for example, you are being asked to 
write an eight-page essay. It would be impossible to write an eight-page essay arguing anything about "The Internet" think how much you would have to discuss and consider; it would be everything from smartphones, to Internet-enabled appliances, to self-driving cars, and would include every app and website and function of "The Internet." That scale of argument would require a series of books! Similarly, you cannot write an eight-page essay about "Social Media." Think about all the different kinds of "social media" and all the different users of those social media and then all the different ways all those different users engage on those social media. Again, that would be a series of books. You cannot even write an eight-page essay on "Facebook." Instead, if you wanted to write an eight-page essay on "how ONE protest movement used ONE social media to balance or unbalance the power dynamics between government officials and their citizens in harmful or useful ways" from the prompt above, you would need to focus in on a specific part of Facebook (say a Facebook group) and then a specific aspect of that Facebook group (such as the photos posted, the front page, or one discussion thread). Only then are you at a level that is focused enough for an eight-page argument.

In response to the prompt above, we will chose Occupy Wall Street's Facebook page, as an example. By looking at a small slice of Occupy Wall Street's Facebook page, more specifically the comments in response to the posts on the Facebook page, you can gather two specific, focused pieces of evidence which you can then turn into a specific and focused argument in our second storey.

Remember that at the undergraduate university level, you will only ever be asked to write one focused and precise argument at a time. As such, you need to be focused and precise in limiting your scope to an appropriate central document. 


\section{Your Turn!}

\section{Activity}

This process of choosing a short, specific central document is essential to making your own university-level argument, regardless of of your discipline or faculty. Again, keeping in mind the eight-page scope, what short, specific central document might you choose if you were asked to write:

1. A psychology essay on the impact of Youtube music videos on high school students?

b. A history essay examining Canada's role in World War II?

c. A philosophy essay asking you to argue the modern applications of Plato's Republic?

d. An English essay asking you to discuss the role of gender in Shakespeare's Romeo and Juliet? 


\section{Answers to Your Turn!}

Keep in mind, these are not the only answers, but rather possible answers:
a. You would choose one specific music video on Youtube
b. You would choose a specific event within World War II, and, from there, analyze another historian's account of this event, or newspaper articles and letters about the event or period.
c. You would choose a specific part of Plato's Republic (i.e. 3-page section) and analyze it in depth.
d. You would choose a specific scene from Romeo and Juliet and analyze it in depth. 


\section{Analyzing a Central Document}

Let's pause here to acknowledge that you will often be asked to write and research about topics that have complex personal and cultural complex histories. For example, in focusing on Occupy Wall Street's Facebook page, we eventually choose to analyze a post about the Israel-Palestine relationship and Black Lives Matter. Both topics are vast and are likely to generate passionate discussion between all sides and parties involved. This is an opportunity to ask questions, to learn more about these topics if you are unfamiliar with them, to listen to those who know a bit more at this point, and to potentially discuss them further with your classmates. You are going to be asked to discuss complex and difficult topics throughout your university career and learning a wide variety of facts while also listening to a wide range of perspectives will best equip you to contribute meaningfully to these discussions.

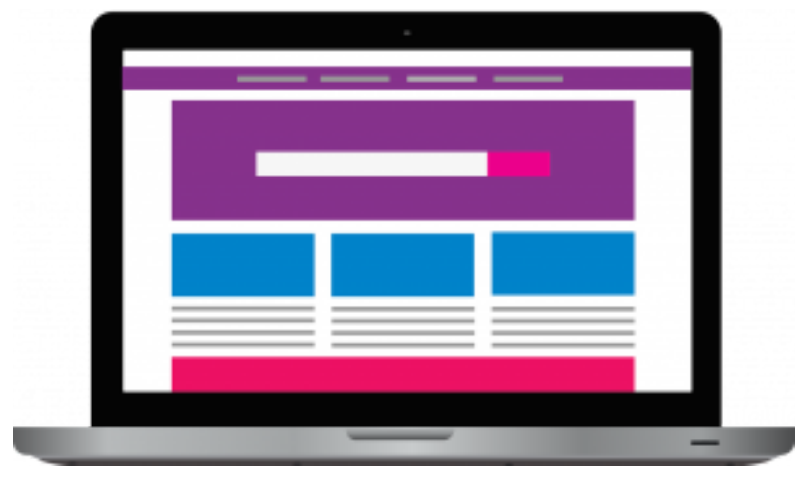

From Pixabay.

Now that we have focused on a specific part of Occupy Wall Street's Facebook page, we need to analyze the text to get the best pieces of potential evidence. This will help us make an argument about how protest pages on Facebook, like that of Occupy Wall Street, can positively or negatively affect the relationship between a specific government and its citizens.

Writing about Occupy Wall Street's Facebook page in general is not specific enough to support an argument. Instead, you will focus just on the Home page. You will then go through the Home page of Occupy Wall Street's Facebook page and begin your observations by following the same steps you introduced in Part 1 of the text textbook: make a list of patterns, key words, new words, and contrasts. These elements could be found in the words and phrases of the document, but you should also be looking for them in (if applicable) any videos, photos, or audio that are also present in your document. On a separate piece of paper, write down all of your observations in list format. It is also very helpful with ephemeral and ever-changing virtual spaces, like Occupy Wall Street's Facebook page, that you take screen grabs or save the versions of the pages and posts that you are looking at so you can some back to them later. This will help you get at observations about the content of the central document and can be potential evidence on which to base your future argument. 


\section{Better Understanding the Medium of Your Central Document}

However, we should not just restrict ourselves to the content of Occupy Wall Street's Facebook page. We should also consider the medium of Occupy Wall Street's Facebook page. By this, we mean, you should not limit yourself to just the information given on the page (images, videos, words, audio) but should also look at how the Facebook page organizes, creates, maintains and distributes information. How a document presents its information is just as important as the information it presents. Understanding how the document organizes, displays and distributes information will help you better understand its rhetorical intention and effects. This is not limited to thinking about Facebook organizational pages -you should ask this of every central document, were it a survey, a letter, a newspaper article, or some other type of document.

In order to better understand the medium you are being asked to analyze, you can begin with some basic general questions:

- What specific language is unique to the medium being used? How is your specific user using this language? ("Like" "Shares" Group")

- What mechanics are UNIQUE to your SPECIFIC central document you've focused on - i.e. a word limit, a focus on photographs, the image disappears after a set amount of time etc.

- What numbers are present on the page? What actions or documents are the numbers related to? How large are the numbers?

- What is the most common action on this page? Posting text? Posting photos? Commenting?

- How active is this page? How frequent is user activity?

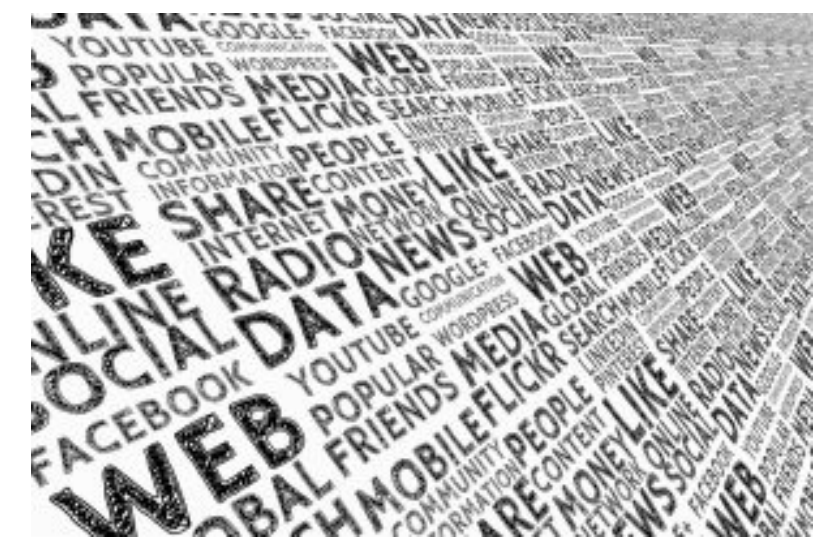

From Pixabay. 


\section{Analyzing a Specific Central Document}

While these questions are specific to analyzing Facebook groups or pages, these questions about activity, audience, and the unique structures, properties, and language of any central document will help you analyze the form of your central document, no matter the medium.

As the Occupy Wall Street Facebook group is a changing virtual document, analysis of it must be pinned to a specific time and date. In our case, we analyzed a specific comment thread on a specific post on the Occupy Wall Street Facebook page on August 6th 2016. As you narrow your focus on your Central Document, remember that the purpose is not to make an argument about the topic of the post (i.e. Israel and Palestine) but rather, the role of Facebook in protest movements. 


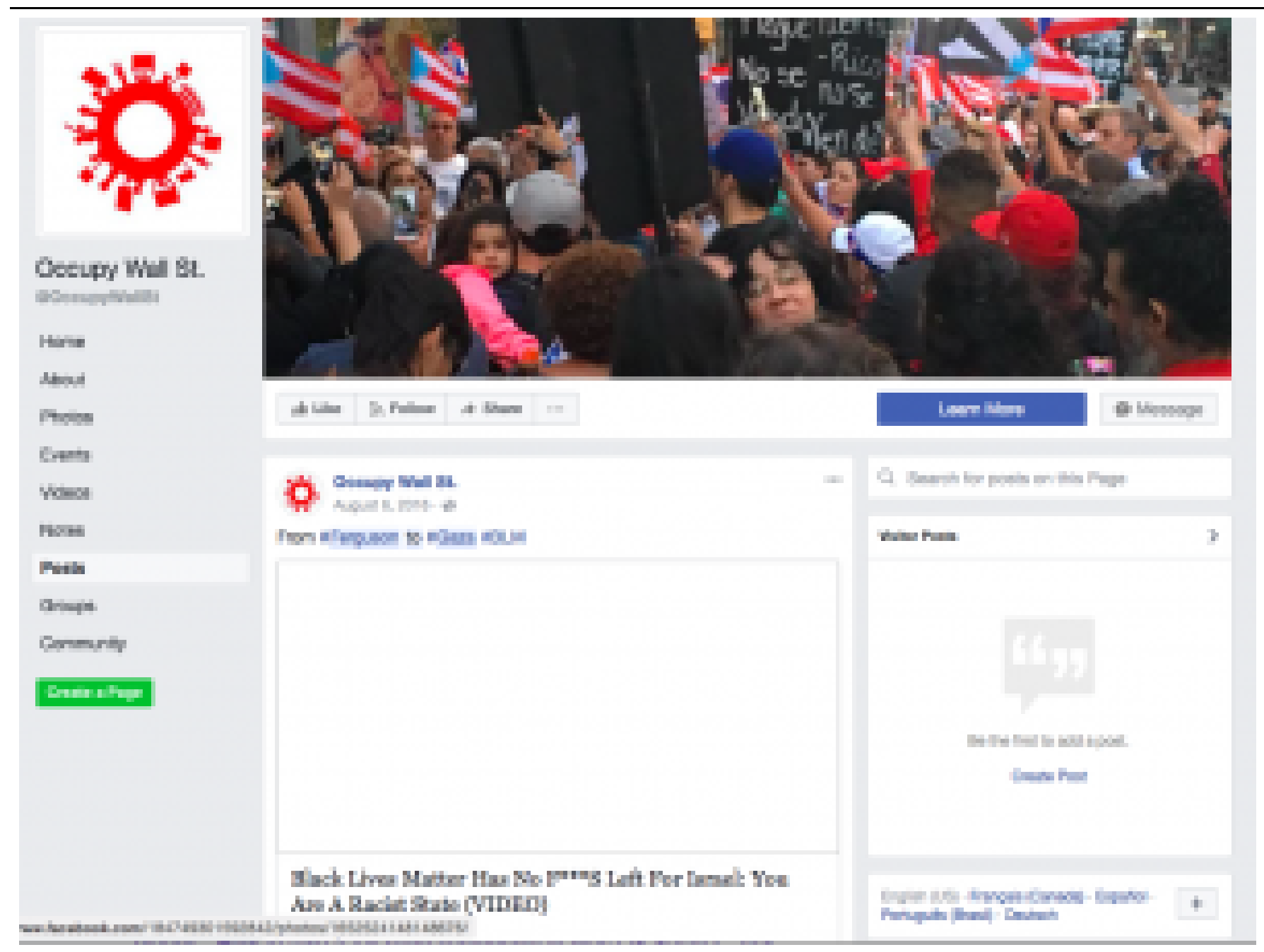




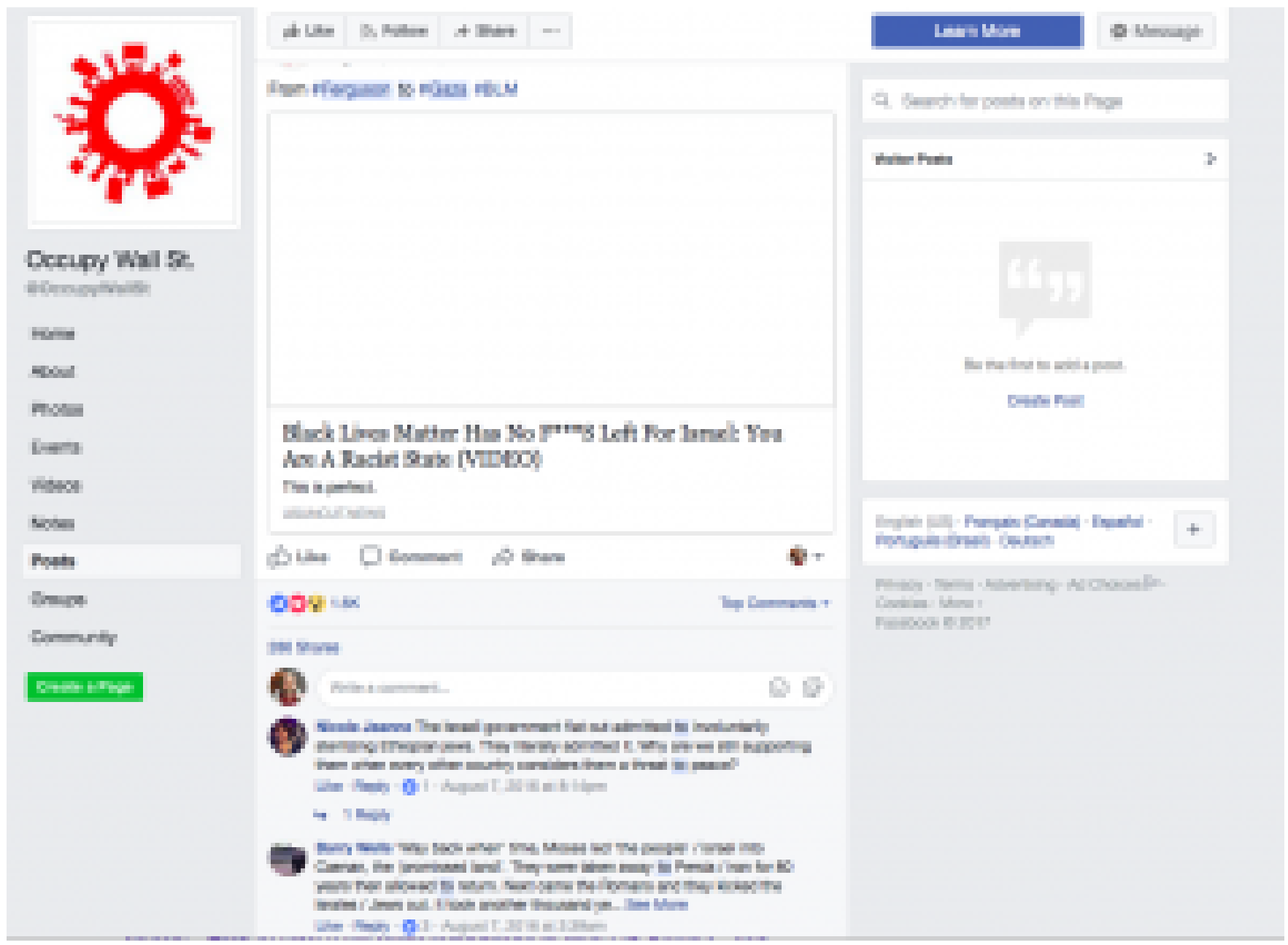

174 | Analyzing a Specific Central Document 


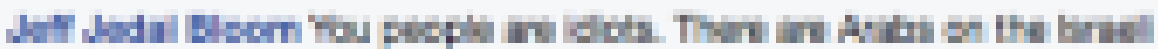

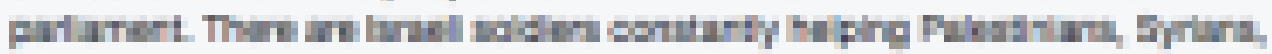

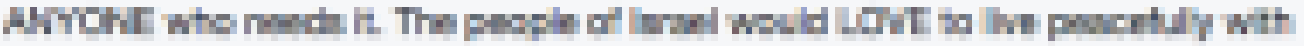

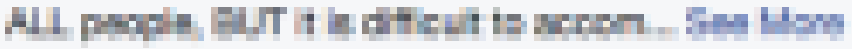

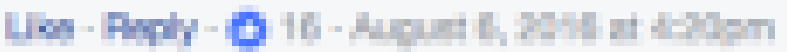

4 Mllevis

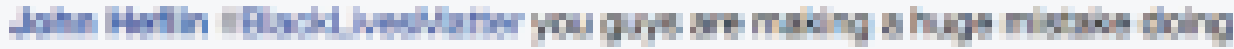

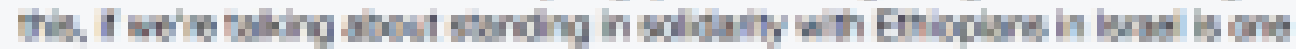

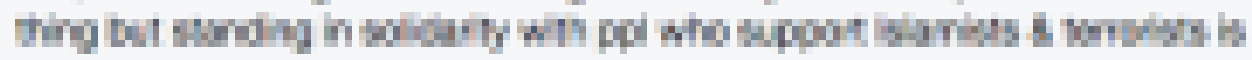
and

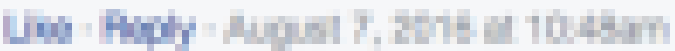

+ 1 Preily

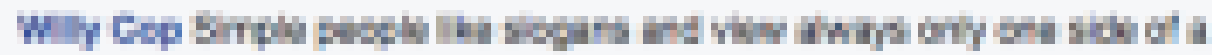

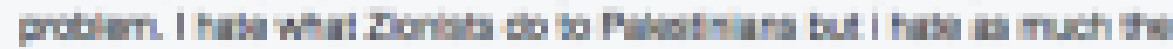

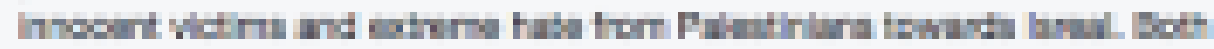

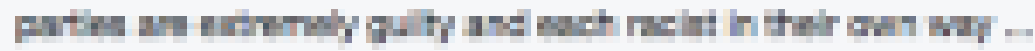

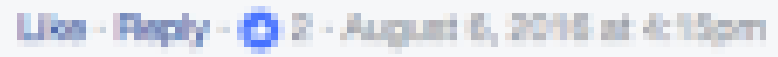

+ Hevits

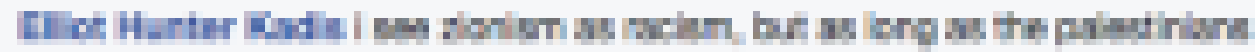

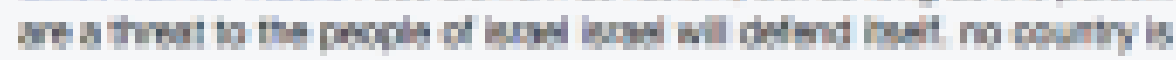

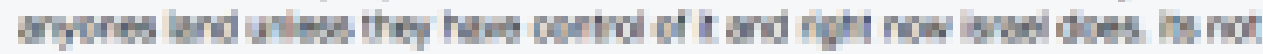

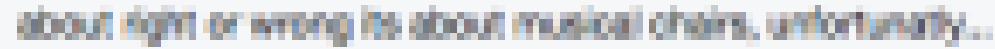

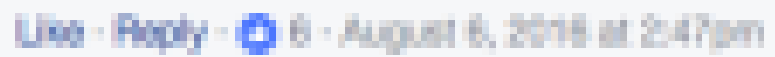

+ II Revin

E.

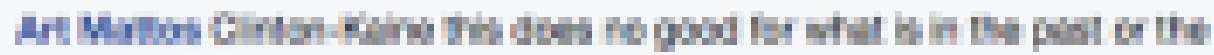

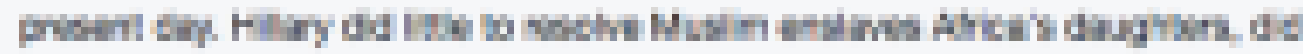

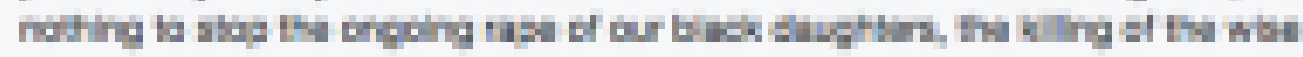

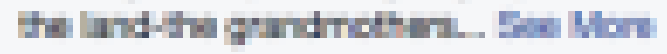

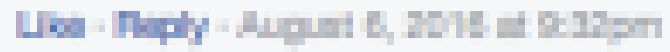

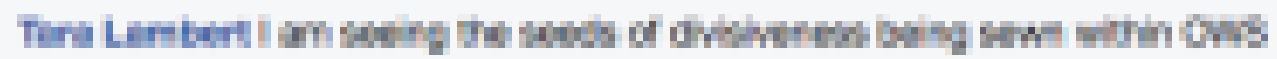

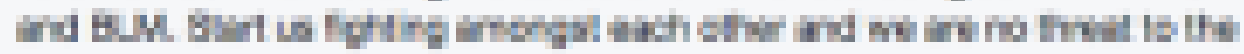

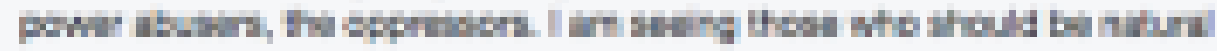

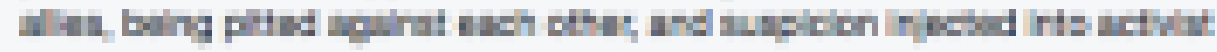

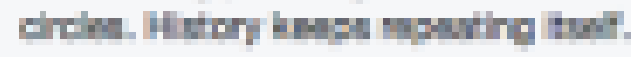

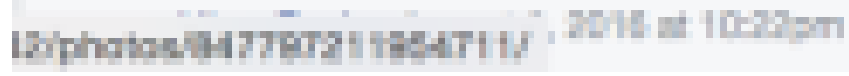




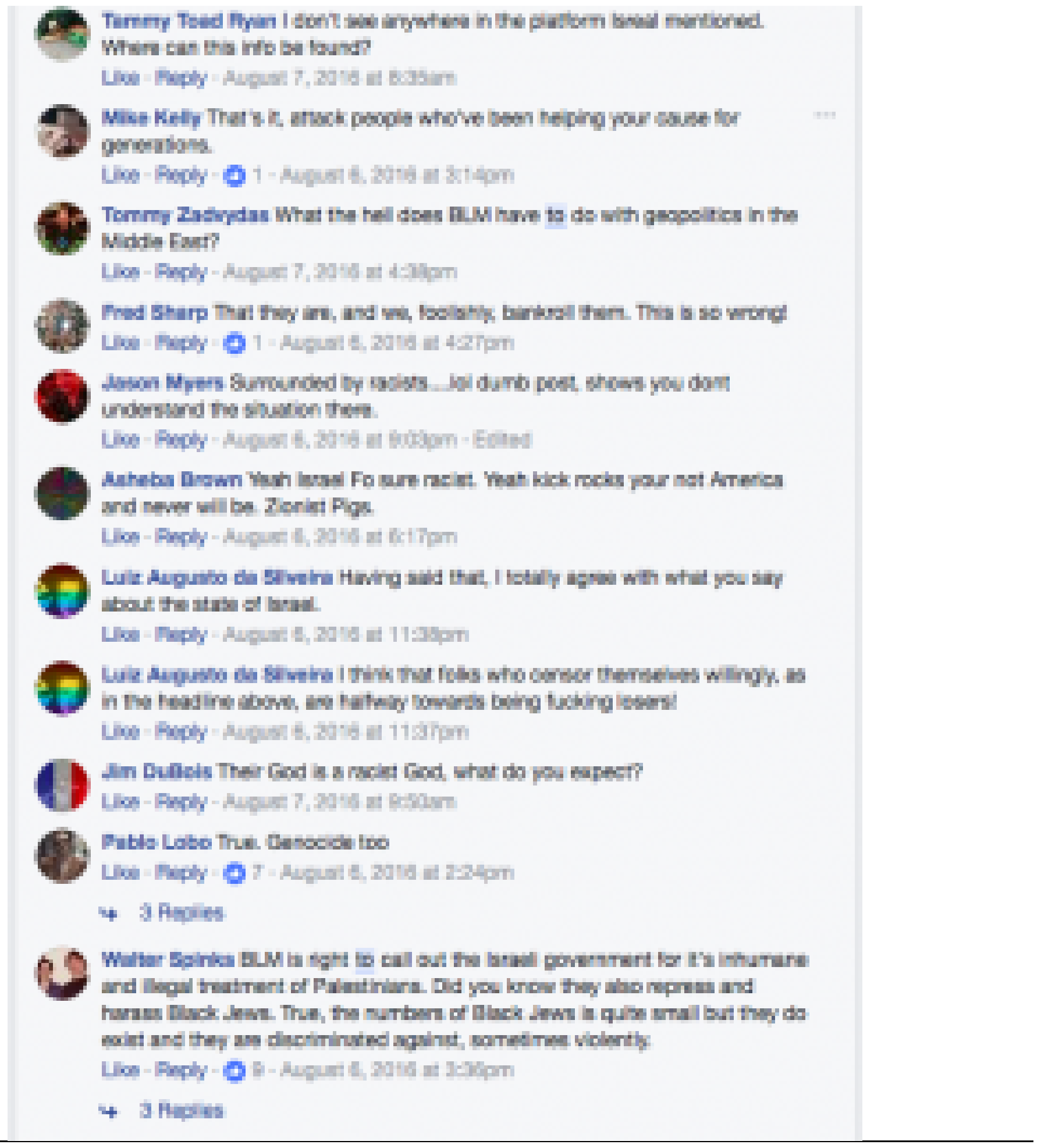

We focused on the following observations (keep in mind that the page may have changed since we made these observations):

- Repetition of raised fists in the banner photo

- Links to outside pages and events was the most common action on the home page 
- The majority of the links are to actions and event from across the globe

- The Facebook group was updated regularly (at least once a day) with consistent activity in the form of comments on each post

- In the post "From \#Ferguson to \#Gaza \#BLM," which includes a link to a video titled "Black Lives Matter has zero

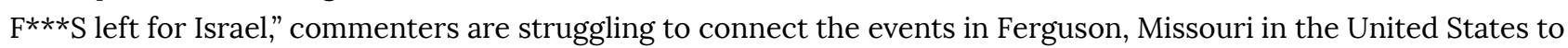
Gaza in the Middle East, as the post is prompting. Instead, people are calling each other names like "idiots" and asking questions like "What the hell does BLM have to do with geopolitics in the Middle East?"

In this brief example, you can see how we have narrowed our focus from the community page, to the timeline, to the posts on the timeline, to a specific post on the timeline, to specific comments on that post. This is the level of focus and detail that is required to write an eight-page university-level argumentative essay. With this focus, the two pieces of evidence will use are the the inflammatory name-calling and the confusion about how the two situations are related. 


\section{Watch This!}

Watch Video 7.2: Close Reading a Central Document demonstrating how to close read, as an example, a Facebook group in order to extract evidence from the form and content of your central document.

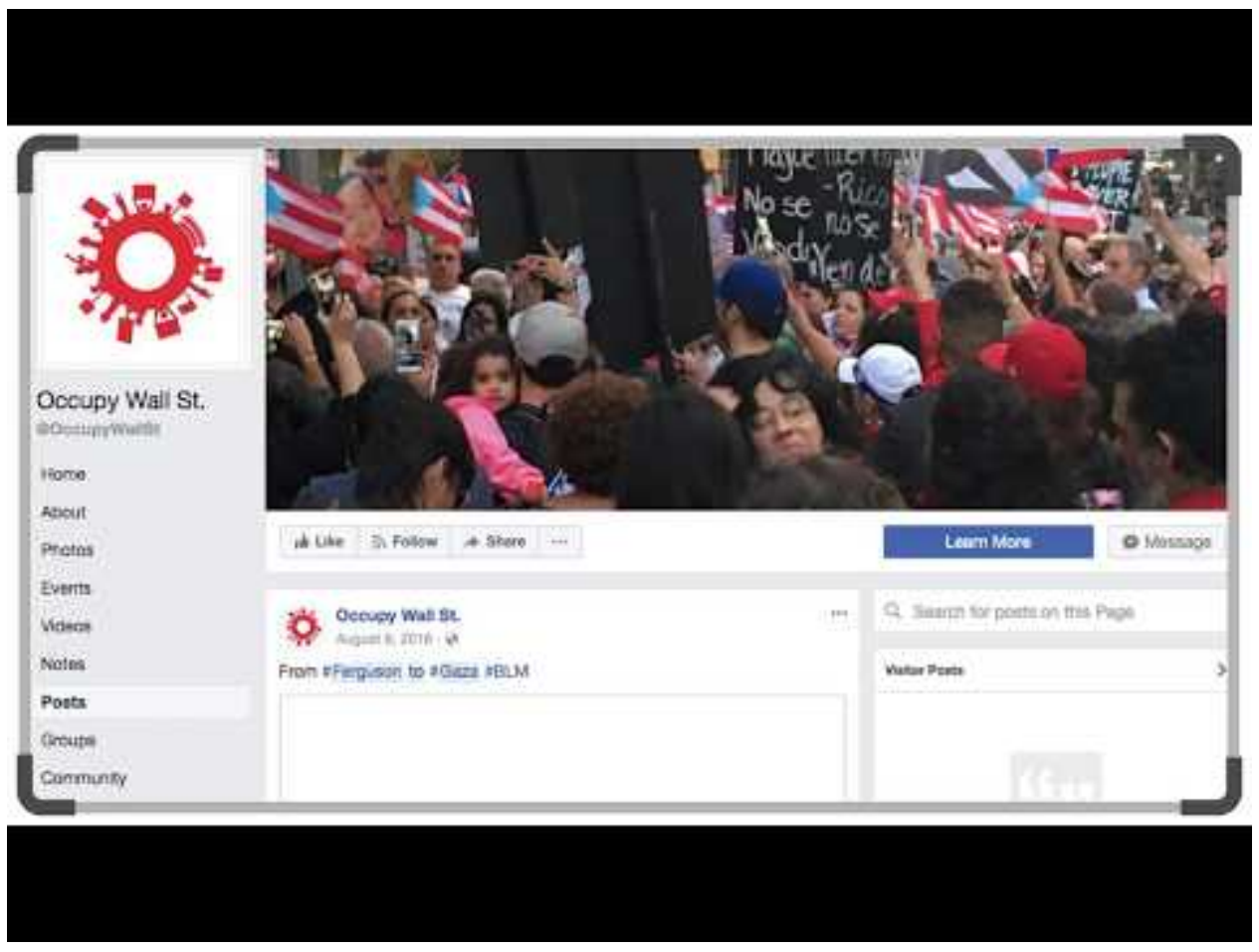

A YouTube element has been excluded from this version of the text. You can view it online here: https://pressbooks.library.ryerson.ca/writehere/? $p=729$ 


\section{Your Turn!}

\section{Activity}

Now that you've watched the video, go to Occupy Wall Street's Facebook page and do a close reading of the page and select another post with active comments. Gather a list of as many patterns, key words, new words, or contrasts you can identify. You should also answer the following questions to gather observations about the medium of the Facebook page:

- What specific language is unique to the medium being used? How is your specific user using this language? ("Like," "Shares," "Group")

- What mechanics are UNIQUE to the SPECIFIC central document - i.e. a word limit, a focus on photographs, the image disappears after a set amount of time etc.

- What numbers are present on the page? What actions of documents are the numbers related to? How large are the numbers?

- What is the most common action on this page? Posting text? Posting photos? Commenting?

- How active is this page? How frequent is user activity? 


\section{Building an Initial Two-Storey Thesis for Your Own Argument}

Now that you have gathered evidence, you have built the foundation for the first storey of your complex argument. That first storey will look a lot like the first storey you built for your close readings: you are pointing to the best one or two pieces of evidence on which you are going to base your argument.

Obviously, you can't discuss everything in your central document, so you need narrow your focus, like you did with your close readings, to the two best pieces of evidence. You can do this by looking at the list of evidence you gathered when close reading your central document and asking:

- Which pieces of evidence are the most interesting?

- Which pieces of evidence are the most important?

- Do your pieces of evidence address both the content and the medium of your central document?

- Are there two pieces of evidence that are similar and might combine to make an effective argument?

- Does each piece of evidence add something different to your potential argument? (You do not want two pieces of evidence repeating the same idea.)

For example, look through your list of evidence from Occupy Wall St.'s Facebook page. After thinking through all of the questions above, you may chose to focus on the comments on one post and from there, focus in on the repetition of commenters linking to their own local projects as the first piece of evidence and the repetition of commenters mentioning their local cities in their posts. Therefore, your first storey might look something like this:

Occupy Wall Street's Facebook page showcases that users of the page have a difficult and often frustrating time linking global events to local events and concerns that are more personal to them. This is demonstrated by the comments under the post "From \#Ferguson to \#Gaza \#BLM," wherein discussion of the event leads to participants calling each other names like "idiots" and angry confusion over how the Black Lives Matter is related to the Middle East (ex. The post "What the hell does BLM have to do with geopolitics in the Middle East?").

As you can see, not only do we state our two selected pieces of evidence, we also identify the central document (The Occupy Wall Street Facebook page) and the specific aspects of the central document we will be examining (a post and its comments thread).

Now we are ready to move onto the second storey. This is where we begin making your argument about our central document. We want to remain focused just on our central document for now. For example, our second storey, using the example from the Occupy Wall Street Facebook page, would be about only the specific page, or perhaps Facebook groups and pages used for protest movements, but not Facebook as a whole. Remember too that an argument is a statement that can be agreed or disagreed with. Therefore, look at your two pieces of evidence and ask:

- What is the significance of the evidence that you have chosen?

- What argument about the specific document can you make based on the evidence you have chosen? (Remember to stay focused at this point and not expand beyond that central document.)

- In what ways do the pieces of evidence overlap? What argument might be derived from that overlap?

- What are the benefits for the user/reader arise when interacting with your central document and how do those benefits relate to the evidence you've chosen?

- What problems for the user/reader arise when interacting with your central document and how do those problems relate to the evidence you've chosen? 
As you move into your second storey and begin making your argument, answering these questions will help you connect your argument to the evidence you've chosen.

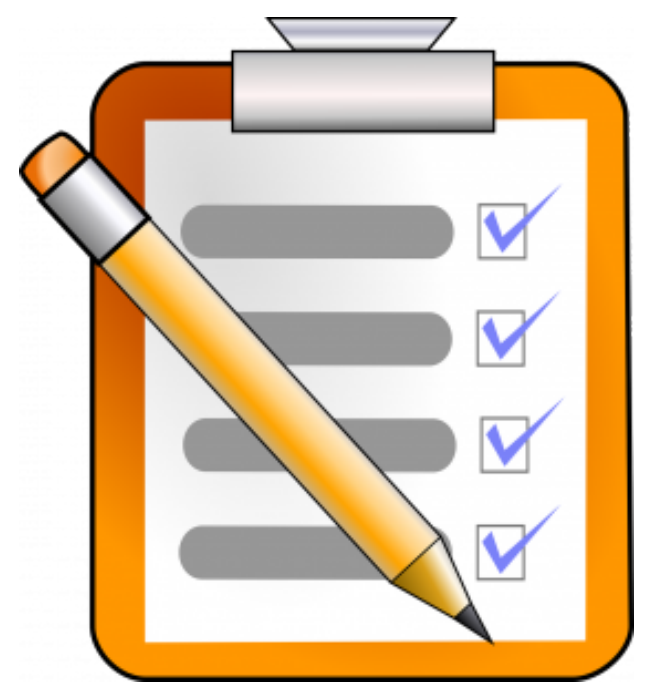

From Pixabay.

Do not be too precise in drafting your thesis at this point. Try to make it specific and complex but don't limit yourself by thinking that you have to get it exactly right at this stage. You will be doing more research and revising, so your thesis will change and sharpen over the process of writing your essay. At this stage, aim for one or two sentences that make an argument about your central document using the evidence you've selected. 


\section{Watch This!}

The following video walks through how to create a two-storey thesis statement using the Occupy Wall St. Facebook group page. Watch Video 7.3: Creating an Initial Two-Storey Thesis to see the drafting of an A-level example.

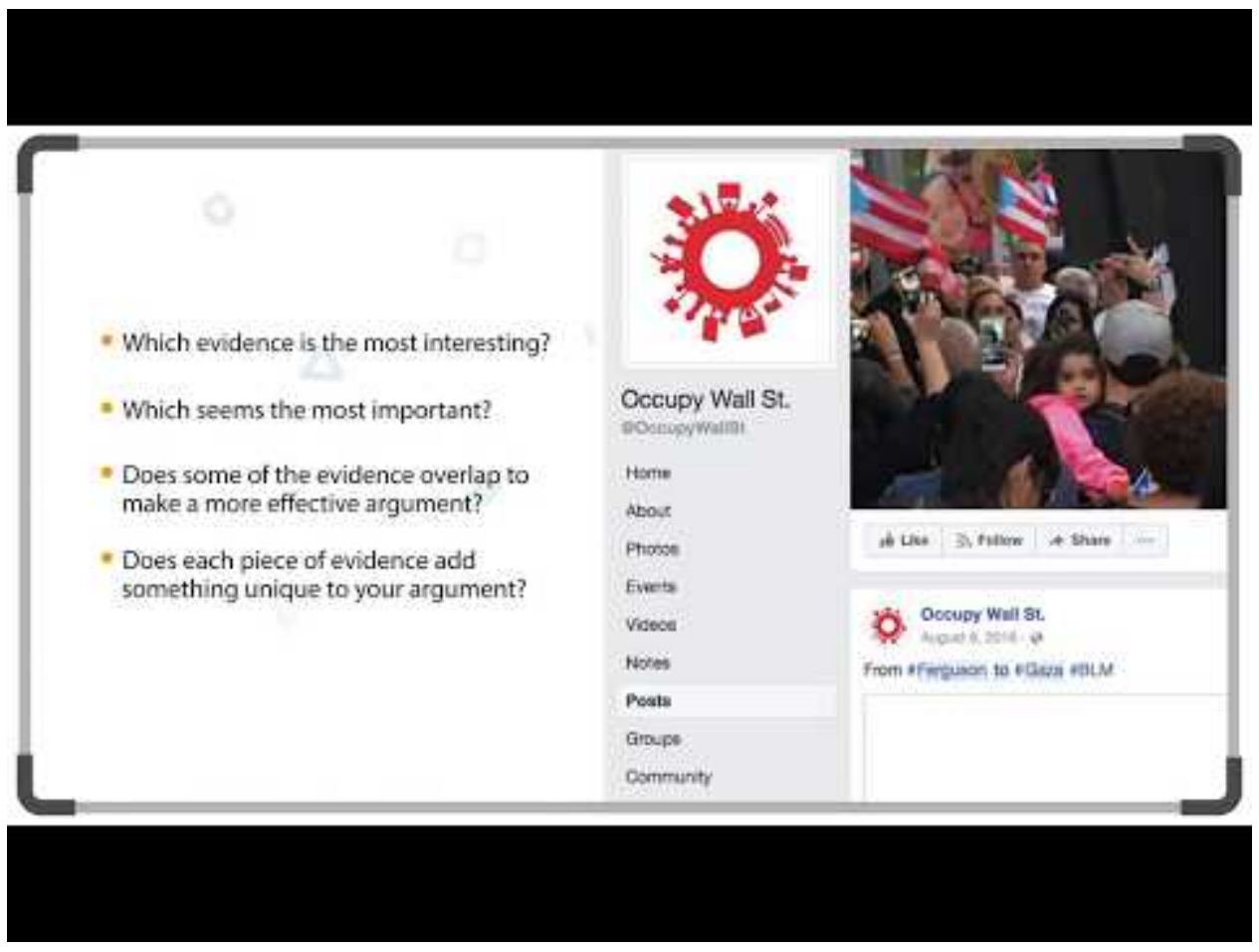

A YouTube element has been excluded from this version of the text. You can view it online here: https://pressbooks.library.ryerson.ca/writehere/? $p=735$

Example

FIRST STOREY: Occupy Wall St.'s Facebook page showcases that users of the page have a difficult and often frustrating time discussing, and perhaps linking, global events to events and concerns that are more local, and perhaps personal, to them. This is demonstrated by the comments under the post "From \#Ferguson to \#Gaza \#BLM," wherein discussion of the event leads to participants calling each other names like "idiots" and angry confusion over how the Black Lives Matters is related to the Middle East (ex. The post "What the hell does BLM have to do with geopolitics in the Middle East?").

SECOND STOREY: Such interaction on the page demonstrates that while Facebook pages do provide a useful 
tool for distributing information and bringing large communities together, users often end up using inflammatory, escalating or insulting language that stunts potential deeper discussions of the complex topics posted. 


\section{Thinking Ahead...}

Now that you have a two-storey thesis and an initial argument, you are ready to move onto the next stage: research and incorporating outside voices. Notice that you didn't begin with research. This is key because the argumentative essay you are writing must be based on your argument. You do not want to begin with research and then simply replicate someone else's argument-you want to make your own argument supported by others' research and ideas!

As you move on to the next chapter, it is useful to begin asking some questions before you head to the library or the library's website:

- What words or phrases in my thesis might need further scholarly definitions?

- What types of statistics might be useful to support my argument?

- Within what discipline am I writing? Who are the experts within that discipline?

- Are there other terms or words that might be useful search terms when looking for scholarly research about my argument?

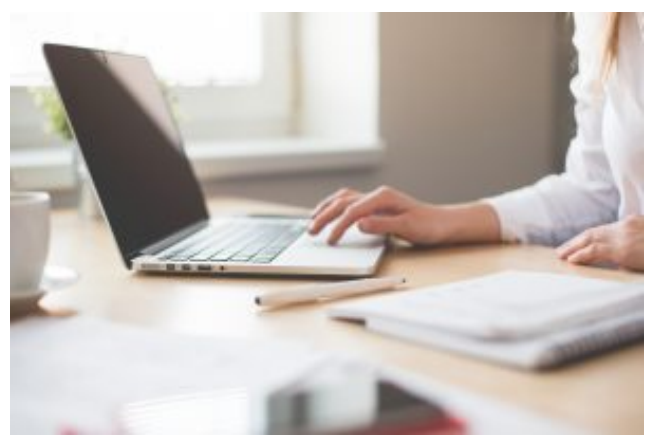

From Pexels.

When you go to the library with specific questions and goals in mind, you will find your research will go faster and be more relevant! 


\section{CHAPTER 8: GATHERING RESEARCH AND ESTABLISHING EVIDENCE}





\section{Chapter Overview}

\section{Learning Outcomes}

\section{In this chapter we will:}

- Analyze how information is created in different formats.

- Identify what makes a source scholarly or popular.

- Evaluate our sources to determine their authority and that they are credible

- Understand where scholarly information is found and the different search tools used to locate it.

- Determine keywords and develop a search strategy for your research.

- Locate two pieces of scholarly research for your paper. 


\section{Introduction to Research}

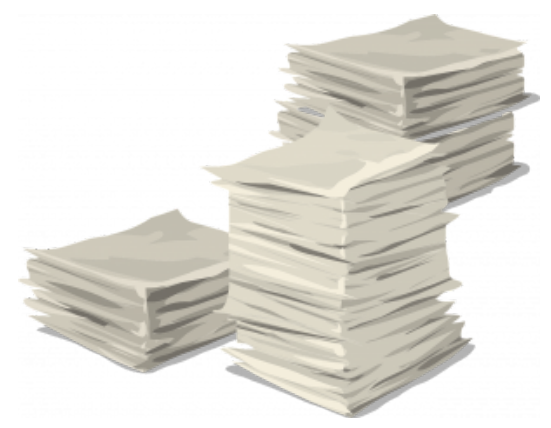

From Pixabay.

Now that you have a thesis statement, you need to find evidence that supports your arguments. Think about a conversation you've had with your friends when you wanted them to agree with you. Whether it's picking a restaurant or a movie on Netflix, you had to argue for why your choice was the best. While you probably started with your own personal belief that Restaurant A is the best place in town, or Movie B is the greatest masterpiece of all time, you might have moved towards evidence outside of your own personal beliefs. You may have pointed out the restaurant had amazing ratings or tweets from celebrities who ate there. In short, you had outside evidence that supported your argument. Sound familiar?

As you can see from the scenario above, you already know how to gather evidence. Every time you use Google to look up reviews for restaurants and movies, you are doing research. Academic research is more intensive than your typical daily Google research. It can take hours to collect your evidence. You will have to figure out your search strategy, what types of evidence you need (scholarly articles, statistics, books, news reports), and use different types of search engines and databases to find them. Ultimately, you will have to evaluate what you find. One of the main things to remember from this chapter is that not all information is reliable. There is a lot of non-credible information out there, especially on the internet where anyone can publish. Putting the keywords of your thesis into Google and hitting enter will just not cut it. You are beginning your journey as a researcher, so give yourself time to find legitimate sources; when you get frustrated, seek help from your friendly librarian;

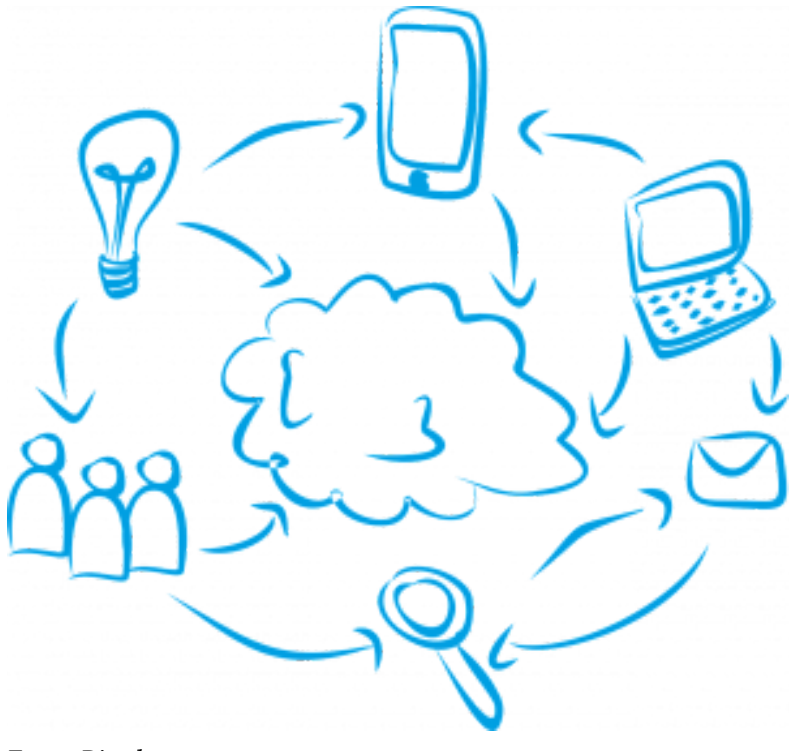

From Pixabay. and above all, work on developing a critical mind when reading your sources.

\section{Assignment}

This chapter is designed to walk you through finding and evaluating the evidence you need to support your argument and to start you on your way to becoming a researcher. By the end of this chapter, you will have chosen two supporting pieces of evidence that you have evaluated to be scholarly and appropriate in supporting your argument. 


\section{How Information is Produced}

Thanks to the internet, all kinds of information is available to us $24 / 7$. We can find out what's going on instantly on social media or with a quick Google search. However, this quick and easy access to information creates the false belief that the information we find is accurate and that all information is free. Scholarly and evidence-based information is not free. In fact, university libraries pay millions of dollars each year to subscribe to academic journals and databases and to purchase scholarly books for your research needs. Remember, as a student you have a unique privilege to access expensive information to which the general public does not have easy access. Moreover, scholarly and other types of information that contain extensive research take time to produce, as evidence must be gathered, analyzed, and reviewed by experts.

When considering different types of information for your paper, it's important to recognize how creation process influences that information. Some information sources go through reviews and editing that make it more credible for your research. This list below represents how the progression of information is connected to information sources:

Watch Video 8.1 on the creation of information following an event and then read the following text.

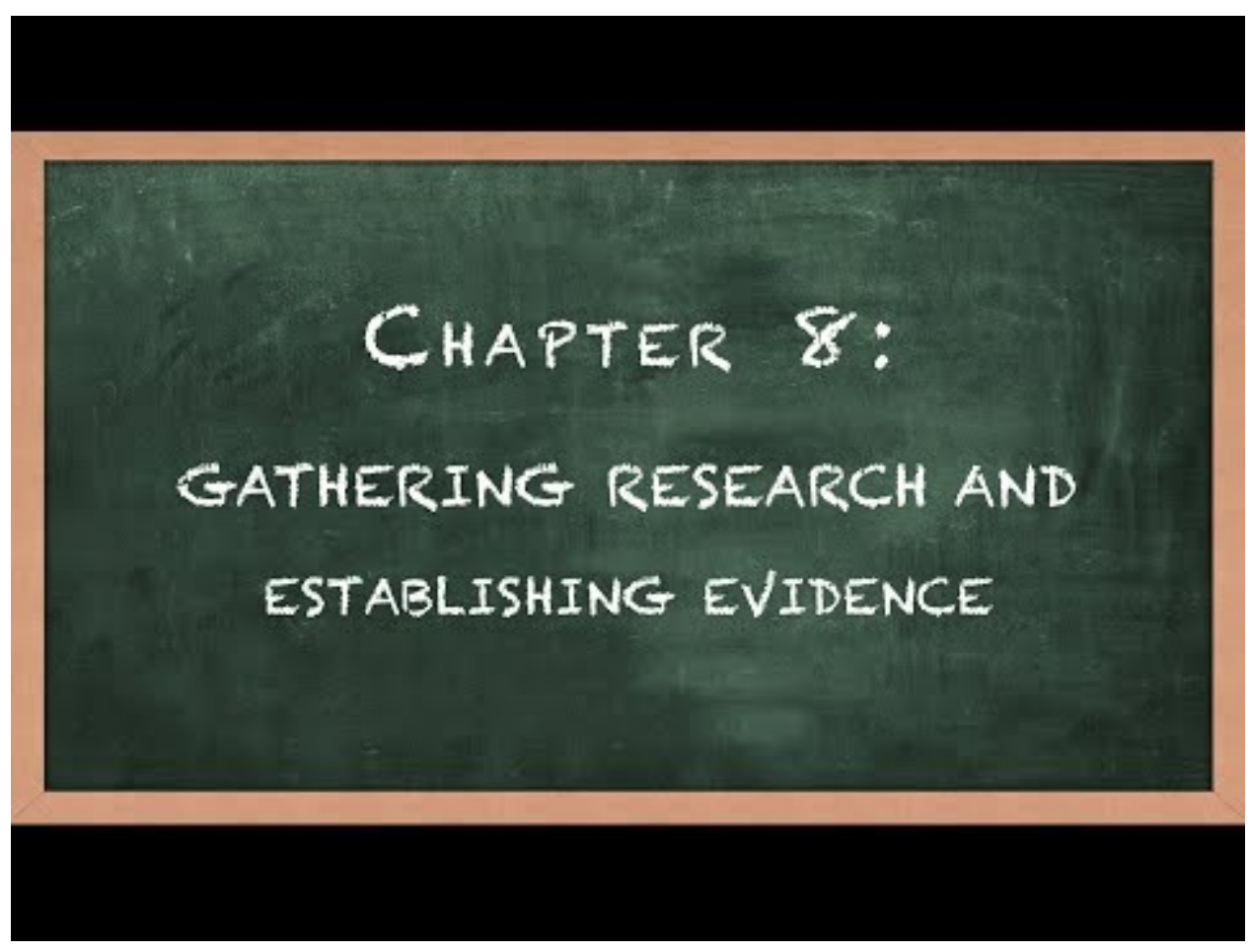

A YouTube element has been excluded from this version of the text. You can view it online here: https://pressbooks.library.ryerson.ca/writehere/? $p=748$

[\#blacklivesmatter]

- The event happens:

- Social Media gives us instant access to what's happening, but it is often emotional and biased. It might contain 
little to no analysis or verification of what is actually happening.

- The next day

- News media gives us a breakdown of the event and verification from authorities of what happened. While there may be some analysis, there is no in-depth, big picture analysis yet.

- The following weeks

- Popular sources like magazines and news documentaries publish their reports. While there is more analysis of why it happened, popular sources likes these do not contain evidence-based research.

- Months later

- Scholars are starting to research the event using their subject area's lens.

- It will be months before a study is published because of the amount of time it takes to conduct extensive research, write the paper, and submit it to an academic journal, where it must be reviewed by peers who may recommend the article be revised before it can be published.

- Articles written by scholars offer the most in-depth analysis of the event and the information is doublechecked for bias and error.

- More than one year later

- Books are written on the topic.

- Such books can vary from

- firsthand accounts by those affected, to

- easy-to-read and sensational books for the general public, and finally, to

- academic books where a professor might take her scholarly article and expand it into a book. 


\section{Try This!}

\section{Activity}

Writing about something current, like a controversial tweet from a celebrity?

- What type of information would you use to find the main details of the tweet?

- What will you do if there is no scholarly article on this topic since it happened last month?

- What is the larger issue or subject matter of the tweet? Self-esteem and women? Social media and politics?

- What is the larger issue? Can you find scholarly articles on the larger issue that will help you to analyze the tweet? 


\section{Types of Information}

\section{Finding Credible Information}

For your academic assignments, you will be asked to consult credible sources like academic books and peer-reviewed journal articles. Different writing assignments can also require other sources of information like government statistics or personal interviews.

As a researcher you want to use sources that are credible. Credible sources provide information that is factual and can be verified. You also need to be aware of bias in your sources. Bias refers to a source's intent or purpose. It is possible for credible sources to have some bias as they might learn towards one particular research methodology or viewpoint, but they will still use sources to support their argument. What to watch out for is sources that have extreme bias. These sources are overtly one-sided, lack factual information or provide little to no evidence to back up their arguments.

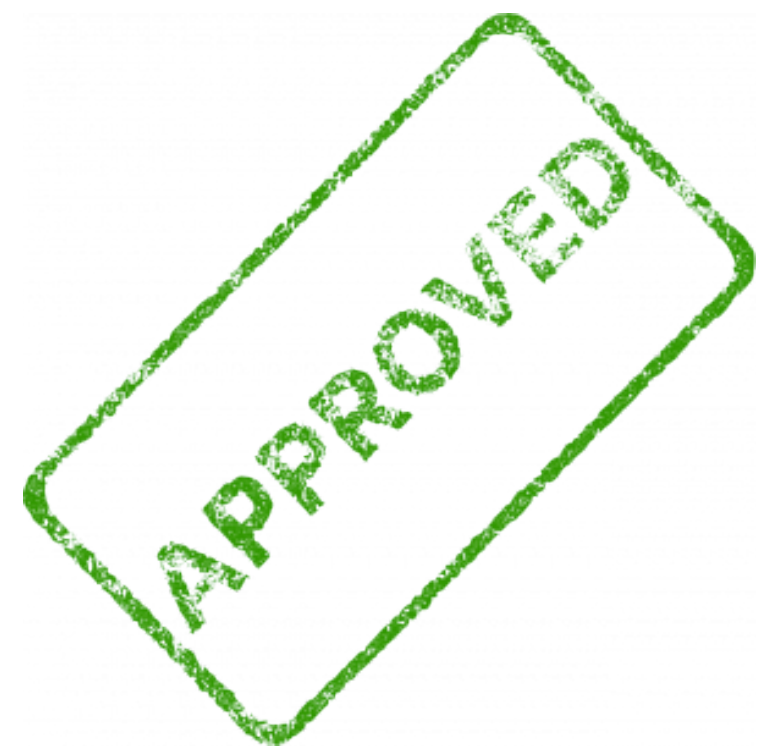

From Pixabay. 


\section{Scholarly Peer-Reviewed Sources}

We've talked a lot so far about how the standard source in university-level research is scholarly peer-reviewed articles. Peer-reviewed articles are the agreed-upon method of disseminating original research conducted by professors, scientists and other experts. In fact, when writing your own papers in your subject area, you should model their style and prose.

\section{The Peer Review Process}

A journal is a scholarly publication containing articles, letters to the editors and book reviews written by researchers, professors and other experts. Journals focus on a specific discipline or field of study and are published on a regular basis (monthly, quarterly, etc.). The intended reading audience is other experts and not the general public. The authors are considered experts because they have PhDs and have specialized in-depth knowledge of current and past theories and years of training in research and analysis.

When a professor writes a research article, she will submit it to a peer-reviewed journal to be published. However, before the journal will accept the article, it will be reviewed by experts in the same area of study, hence, her peers. If her peers deem her research lacking validity, she will be asked to make changes or her article might be outright rejected. This is why assignments ask you to use articles published in peer-reviewed journals as they contain rigorous research and use a critical lens when picking what gets published.

It is also important to keep in mind that there are many theories or schools of thought within a discipline, and professors chose to conduct her research through one particular theory. An economics professor, for example, could write her article through a Marxist or a Neoliberal lens. You need to develop an awareness of the different theories in your subject area as this will help you identify what lens the author is using to conduct their research. This is also important if an assignment requires sources from different theories or if you must support your thesis with sources from one particular theory.

Experts like professors often publish their evidence-based research in non-peer-reviewed sources like books and newspapers. These sources are still considered authoritative and contain expert research and are often reviewed by editors for accuracy, but they do not count as peer-reviewed sources. It is important to know the difference if your professor specifically requests that you use articles from peer-reviewed journals. Not to worry, library databases are designed to help you locate peer-reviewed articles. We will go over how to find peer-reviewed journals in the section below called "Where to Find Authoritative Research Documents".

\section{The Need to Remain Critical}

The peer review process is the agreed-upon method for checking credibility in the academic world but it is not without its flaws. Articles with inaccurate research methods and, therefore, flawed conclusions have been published. However, thanks to the work of journalists and other diligent experts, these papers have been retracted and the research removed from the Journal. The work of researchers can also be funded by outside corporations and many journals insist that authors state their conflict of interest within their paper. If you come across an admission of conflict when reading an 
article, it will be up to you to evaluate whether or not you feel the research was influenced by the corporation's own agenda.

You also need to be vigilant when using Google to find peer-reviewed journals as there are non-credible journals parading themselves as peer-reviewed. Your library provides you with access to databases that contain authorized peer reviewed journals and filters out the non-credible ones. Overall, even though the peer review process works to evaluate research, you as the reader need to remain critical and conduct your own evaluation of what you are reading. 


\section{General "Popular" Sources}

"Scholarly" and "popular" are terms used to describe a source's content, purpose, audience and more. Popular sources are intended for a more general audience and they can range from entertainment magazines to well researched investigative articles from the New York Times. With most scholarly sources we can rely on the peer review process to evaluate the authority and credibility of the research presented to us. With popular sources, it is up to you to determine whether the source is appropriate for your own research.

So what are Popular Sources?

- Magazines,

- newspapers (from your local daily news to the New York Times),

- books (online and in print),

- websites, social media, blogs and wikis etc., and

- media (including podcasts, movies and award-winning documentaries).
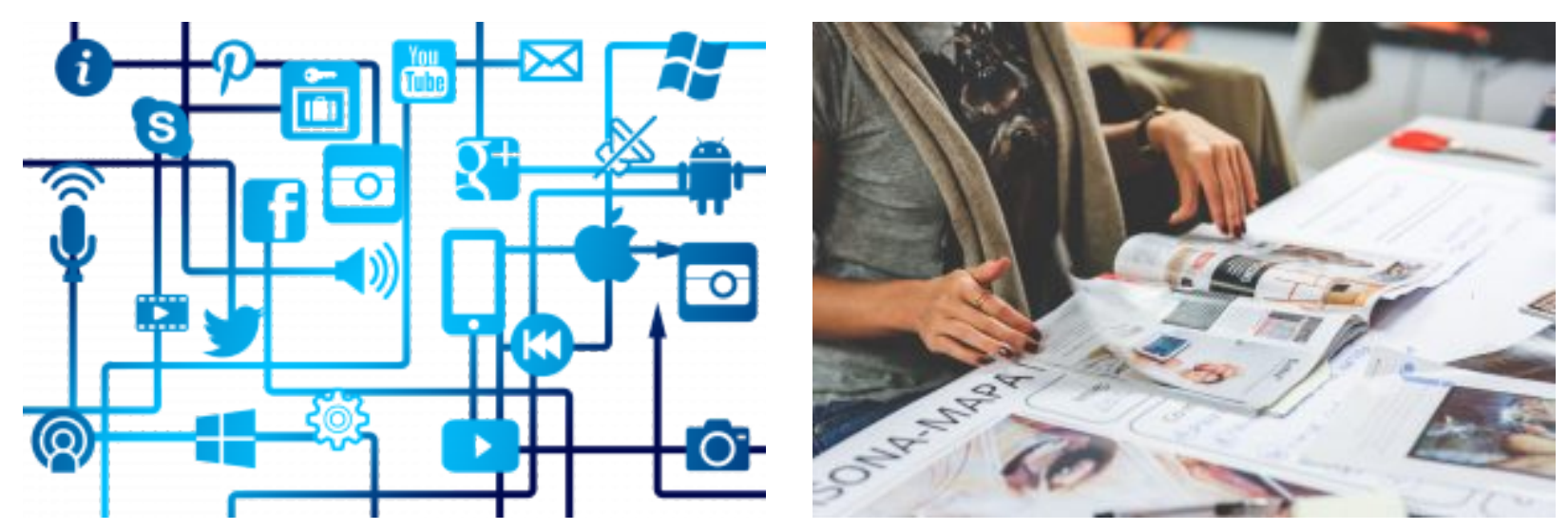


\section{When to Use Popular Sources}

This depends on your assignment, but if you are permitted to use popular sources, there are excellent sources like newspapers, personal interviews and government reports that will help you advance your own argument. Sources, such as magazines and newspapers, are very useful for current commentary on a topic or issue. Governments and organizations such as large non-profit charities, release reports and data on a regular basis. The Canadian Census is one great example of the type of information you can access for free from government websites. Investigative journalist reports and organizations, like the YMCA, often release in-depth pieces on current issues such as poverty levels in large cities and provide data and analysis. All of these types of documents can be excellent sources of information with upto-date statistics and analysis. However, you must also be aware that some newspapers, blogs and non-government organizations, such as policy think-tanks, have specific political viewpoints that you will have to be aware of. It is up to you to evaluate whether or not to use a popular source in your assignment. 


\section{Try This!}

\section{Tour a Scholarly Source}

\section{Activity}

Take a look at this Scholarly article:

The Hands of Donald Trump

Now answer these questions:

- Who is the author?

- Where do they work?

- What is the name of the journal?

- Do they cite others in the body?

- How many sources are cited at the end?

- How many pages?

- $\quad$ Is it written in formal language or informal language?

- $\quad$ Are you sure it's peer reviewed? Check out the About Journal of Ethnographic Theory. 


\section{Evaluate What You Find With the "CRAAP Test"}

Watch Video 8.2 on how to apply the CRAAP test and then read the text below.

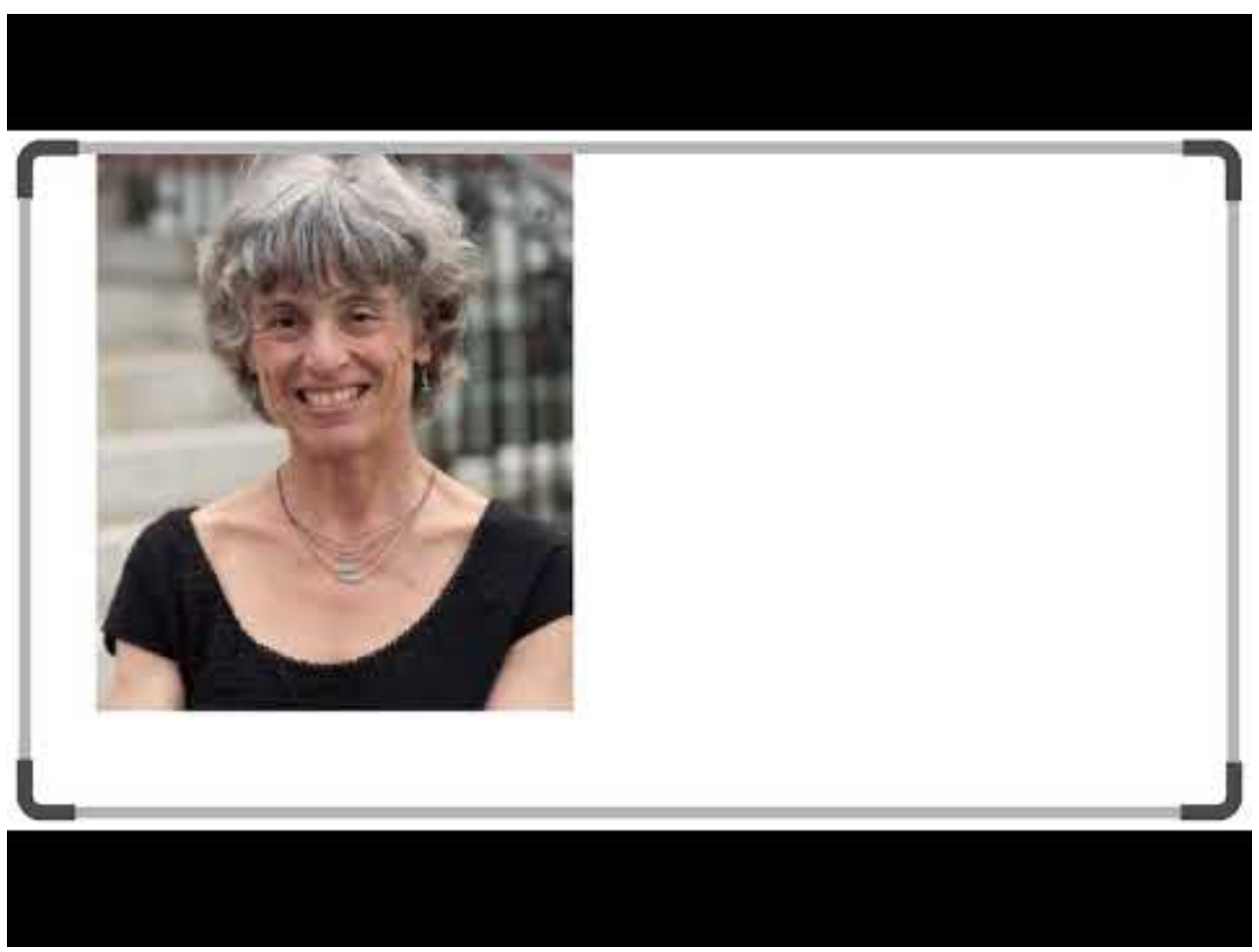

A YouTube element has been excluded from this version of the text. You can view it online here: https://pressbooks.library.ryerson.ca/writehere/? $p=763$

Sources to evaluate in the Video:

- Wikipedia onOnline Social Movements

- Discuss that it's a good starting point, and to look at the sources below

- Blog written by a professor: Role of Social Media in Social Movements (Egyptian Revolution and Occupy Wall Street)

- Click on About Author etc

- Discuss why it's not peer-reviewed

- Peer Reviewed (Open Source): The Digital Evolution of Occupy Wall Street

- Discuss why it's peer-reviewed

- Look at the conflict of interest note at the beginning

Evaluating your sources is critical to the process of academic research. The CRAAP test allows you analyze your sources and determine if they are appropriate for your research or just plain crap! The CRAAP test uses a series of questions that address specific evaluation criteria like the authority and purpose of the source. This test should be used for all your 
sources and it is not intended to make you exclude your sources, but to help you to analyze how you intend to use them to support your own arguments.

$\mathbf{C}=$ Currency: The timeliness of the information.

- When was the information published or posted?

- Has the information been revised or updated?

- Does your topic require current information, or will older sources work as well?

$\mathbf{R}=$ Relevance: The importance of the information for your needs

- Does the information relate to your topic or answer your question?

- Who is the intended audience?

- Is the information at an appropriate level (i.e. not too elementary or advanced for your needs)?

- Have you looked at a variety of sources before determining this is one you will use?

- Would you be comfortable citing this source in your research paper?

A = Authority: The source of the information.

- What are the author's credentials or organizational affiliations?

- Is the author qualified to write on the topic? Do you trust the author?

- Is there contact information, such as a publisher or email address?

- Does the URL reveal anything about the author or source? examples: .com .edu .gov .org .net

A= Accuracy: The reliability, truthfulness and correctness of the content.

- Where does the information come from?

- Is the information supported by evidence?

- Has the information been reviewed or refereed?

- Can you verify any of the information in another source or from personal knowledge?

- Does the language or tone seem unbiased and free of emotion?

- Are there spelling, grammar or typographical errors?

$\mathbf{P}=$ Purpose: The reason the information exists.

- What is the purpose of the information? Is it to inform, teach, sell, entertain or persuade?

- Do the authors/sponsors make their intentions or purpose clear?

- Is the information fact, opinion or propaganda?

- Does the point of view appear objective and impartial?

- Are there political, ideological, cultural, religious, institutional or personal biases? 


\section{Try This!}

Read this article and apply the CRAAP Test.

*Remember to be critical

Sorry Cat Haters, Science isn't on your side

\section{Key Takeaways}

$\mathbf{C}=$ Is it current?

$\mathrm{Y} / \mathrm{N}$

$\mathbf{R}=$ Could you use this information in a University-level essay?

$\mathrm{Y} / \mathrm{N}$

A = Did a professional/professor write it?

$\mathrm{Y} / \mathrm{N}$

A = Did the author cite their sources?

$\mathrm{Y} / \mathrm{N}$

$\mathbf{P}=$ Is it written as a research paper?

$\mathrm{Y} / \mathrm{N}$

**Bonus: Why you always need to be critical of Cat Articles 


\section{Where to Find Authoritative Research Documents}

Your textbook and course readings may be good starting points to help you understand your research topic. However, you'll need to do more in-depth research to find sources that support your thesis.

The creation of information-publishing in electronic or print formats-and describing and indexing information so that it can be easily found are very expensive endeavors. The information business is a multi-billion dollar global enterprise. While you can find some research for free on the internet, it remains true that much of the academic or scholarly content written by authoritative researchers is kept behind paywalls. That is where your libraries come in.

Your academic library in particular, and to some extent your public library, subscribe to huge collections of scholarly articles found in databases, to individual journals in electronic and/or print formats, and to books and e-books with scholarly content that can support the arguments you make in your research papers. Libraries also subscribe to indexing and abstracting services that help to make information easier to find. Libraries may even have powerful search engines on their websites that look like Google and search for all types of resources, from scholarly journals to trade magazines and newspapers, books and e-books, DVDs and streamed videos, and possibly even websites and visual images including photographs.

Many libraries use discovery layers or services such as Summon from ProQuest, Primo from Ex Libris, or Ebsco Discovery Service. These services may be rebranded by your library as in the case of Ryerson University Library and Archives that calls its installation of Summon "Search Everything" and Athabasca University Library that calls its installation of Ebsco Discovery Service simply "Discover." These products bring together in one search data from the traditional library catalogue of books and audio-visual resources plus journal articles, newspaper articles and other resources from databases to which the library subscribes as well as out of print and open access resources in large digital depositories. Look for a search box on the library's home page and near it you'll hopefully see an Advanced Search option. Using the advanced option helps you, the researcher, think about how information is organized, indexed and made findable in a database's search engine.

Libraries also have specialized encyclopedias, dictionaries and other reference works, in print and/or electronic formats that can provide a quick background on a topic new to you. If your professor specifies that they want you to use scholarly articles, you would not be allowed to cite these reference works as a source. However, these works are important for finding quick facts, definitions, or brief background information that may be helpful in verifying information from another source. Scholarly reference works may even include the names of the authors and cite other resources on the topic.

Two digital reference collections that are commonly available in university and college libraries in Ontario are Gale Virtual Reference Library (GVRL) and Oxford Reference. Both contain brief articles about a wide variety of subjects. Lengthier articles are often signed and include bibliographical references.

Librarians create and maintain subject-specific research guides that can usually be found on library websites. These guides can help you navigate the best possible resources in your subject area. For example, a guide on History of Canada or a History of the Caribbean may point you to databases such as America History and Life, Historical Abstracts, and Worldwide Political Science Abstracts. The subject research guides are often referred to by librarians as research guides, resource guides, course guides, pathfinders, or LibGuides (the name of a specific publishing tool for guides). If your institution does not have a helpful research guide for your discipline, you may want to consult a guide from another academic institution.

Databases on offer will vary from institution to institution. A database may contain a large collection of full-text articles from many different journals, or it may contain full-text articles from some journals and also bibliographical citations with or without abstracts (summaries) of additional articles that are not available in full-text format. MLA International Bibliography is one database that used to contain only citations but now includes links to some full-text content that 
the company hosting the bibliography provides to the subscribing library. Access to databases will normally be restricted to members of a research community, since these are licensed products that a university pays for on behalf of its own students, faculty, and staff. Some public libraries make databases available online to library card holders or to anyone at computers inside the library. Specialized databases often have search features that are unique to the discipline. For example, historical databases normally allow a researcher to limit a search to the historical time period when an event happened. Do not confuse this with the date of publication of an article or book.

[possible image, example of the Western libraries guide for American studies, open at the Articles section. http://guides.lib.uwo.ca/american_studies/articles]

This type of research is new for most post-secondary students. Many students face challenges when trying to understand, access and use these new types of resources. The next part of this chapter will emphasize how to find scholarly journal articles and other credible sources that you can use to inform and support your research paper.

Your Turn!

\section{Activity}

Use your library website to identify two databases containing links to full-text articles that are appropriate for your area of study. Try to choose at least one general or multipurpose database and one that is more targeted to your discipline of study. 


\section{Search Strategies: Plan, Refine, and Modify}

Search engines such as Google allow you to use ordinary or natural language. You can type a fully formed question and you will likely get some relevant results. The research databases that libraries provide work differently. For best results, you should break down your research question into main concepts that can be expressed as a keyword or a short phrase. You will also want to identify related terms for your concepts, including synonyms that mean the same thing or almost the same thing (e.g. corn OR maize) and variant spellings (e.g. jewelry OR jewellery; color OR colour). Failure to consider variant spellings and terms in use in different regions of the world could cause you to miss out on important research by scholars who are accustomed to using a variant word for the concept. Your keywords and phrases become your search terms. You can connect your terms with special words called Boolean operators. This will be explained more fully shortly.

Let us use this hypothetical research question:

\section{Are comics a good way to teach William Shakespeare's plays to high school students?}

Concept 1: comics OR graphic novels OR manga

Concept 2: teaching OR study OR learning

Concept 3: secondary school OR high school

Concept 4: Shakespeare

Concept 5: drama OR plays OR theatre OR theater

What are some ways that you might measure success in the study of a play? A student must understand what they have read. This points to the topic of reading comprehension. Another possible measure is memory retention. These ideas could be expressed in additional concepts:

Concept 6: reading comprehension

Concept 7: memory retention

In this case, there are probably too many concepts broken out. You may want to reorganize your list and prioritize three or four concepts to search at the start. If you search for too many concepts, you may get no results.

After exploring your research question and finding some supporting articles, you might develop a thesis statement along the following lines:

Comics and graphic novels are important tools for teaching secondary school students Shakespearean drama. Their use of visual narratives bring enhanced meaning to the late sixteenth and early seventeenth-century English language and improve both reading comprehension and memory retention.

Your Turn!

\section{Activity}

What is your research question?

What are your key concepts? 


\section{Boolean Operators}

Databases and search engines use Boolean logic. Named after mathematician George Boole (1815-1864), Boolean logic is the key to successful database searching. By using the Boolean operators AND, OR, and NOT (sometimes expressed as ANDNOT) between search words, a researcher can focus or broaden a search query to create sets of results. The operators are normally expressed in uppercase letters so as not to confuse them with the words used as non-operators.

When you see a simple search box and type in words, the search engine generally inserts the AND operator between every word. By using an advanced search option, you are encouraged to think about the way you want to focus your search.

Watch Video 8.3 to learn more.

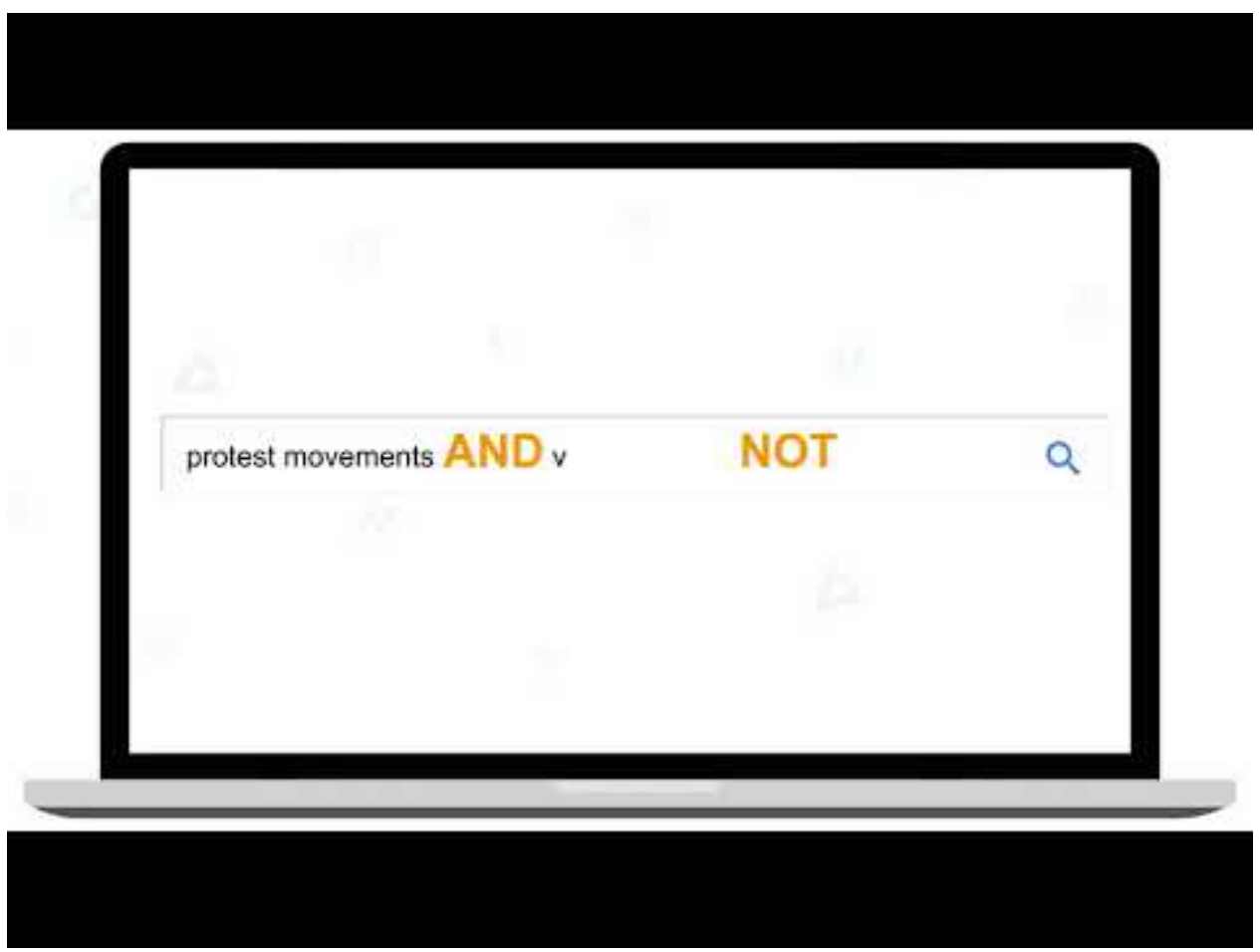

A YouTube element has been excluded from this version of the text. You can view it online here: https://pressbooks.library.ryerson.ca/writehere/? $p=774$ 


\section{OR Operator}

The operator OR is used to broaden a search by combining two or more variables into one set. The operator OR is used to combine synonyms and variant spellings (e.g. theatre OR theater) of a word into one search. Any one of the search terms must be present. More than one can be present.

A Venn diagram (also known as a set diagram) can visually display how a database's search engine handles search terms and the Boolean operators. Each term is searched separately and all of the relevant hits (articles, books etcetera identified in the database as containing that term) are grouped into separate sets, one set per term as represented by each circle. In the diagram that follows, three different related terms are being searched: comics shown by the circle in the upper left, graphic novels shown by the circle in the upper right, with manga shown by the circle at the bottom of the diagram. Some of the hits also contain one or both of the other search terms and this is represented by the overlapping of the circles. In the example, since the OR operator is being used, the search finds all of the hits containing any of terms and combines them all into one large pool of results. Because all of the results in all three sets are included, they are all represented using the same blue colour.

To reiterate, by broadening a search using the OR operator, the results of a search can be much larger and more comprehensive than a set of results from a search that does not make use of related terms, synonyms, and, variant spellings joined with the OR operator.

Example Venn diagram using the OR operator: comics OR graphic novels OR manga

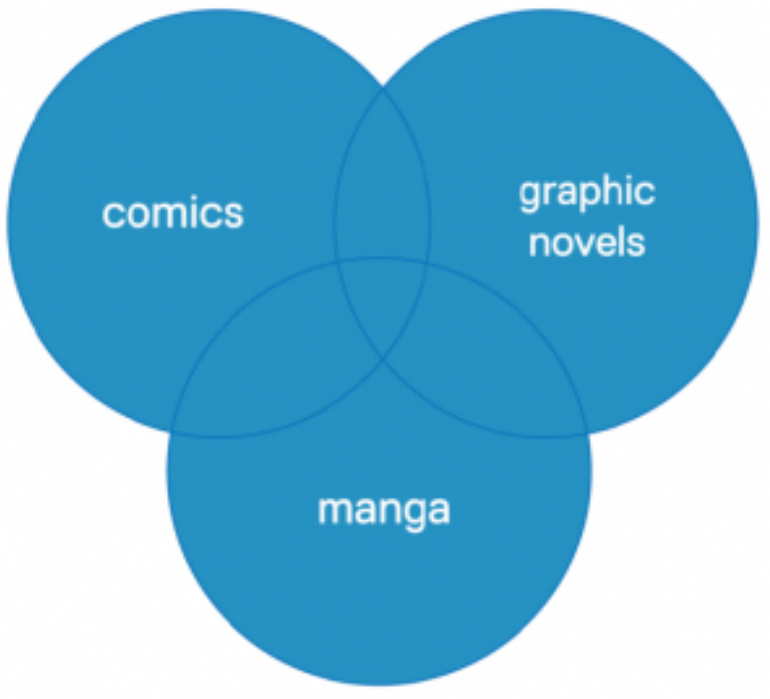




\section{AND Operator}

The operator AND is used to narrow or focus a search by finding a subset of results containing all of the keywords or search terms. For simplicity, the example depicted by the Venn diagram that follows contains only two key concepts and no synonyms or related terms. On the left, the pinkish-coloured circle labelled graphic novels represents the hits (articles, books etcetera in the database) that contain the words graphic novels. A second, yellowish-coloured circle on the right, represents all of the hits that contain the word teaching. The two sets of searches overlap since a small number of the hits contain both graphic novels AND teaching. This subset is shown in the diagram in the orange portion where the two circles or sets overlap. It is labelled AND because it represents the portion of the hits from the two concepts that contain both the first AND the second concept. The AND operator is the most commonly used Boolean operator.

Example Venn diagram using the AND operator: graphic novels AND teaching

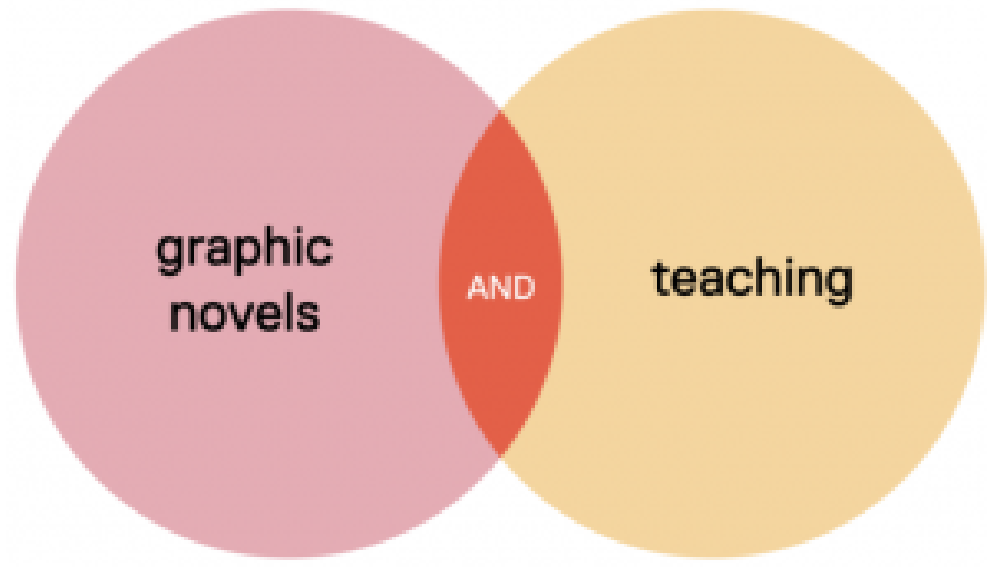

If you decide that you still have too many results when you searched for only two concepts, you can refine your search by adding a third distinct concept. This will narrow your results considerably because it is more precise. The following Venn diagram demonstrates what happens when you modify the search used in the previous example by adding a third keyword: Shakespeare. [Note that most databases allow both upper and lower case when searching for proper names.] In this example the set of hits dealing with Shakespeare are represented by the blue-coloured circle shown beneath the pinkish circle representing graphic novels and the yellowish circle representing teaching. All three circles overlap to some extent since one, two, or all three keywords may be applied to the same articles, books etcetera in the database. In this example, the small, almost triangular-shaped orange patch labelled AND in the centre of the diagram represents the relatively small subset of hits that contain all three concepts: graphic novels AND teaching AND shakespeare.

Example of a Venn diagram using the AND operator and three distinct concepts: graphic novels AND teaching AND shakespeare 


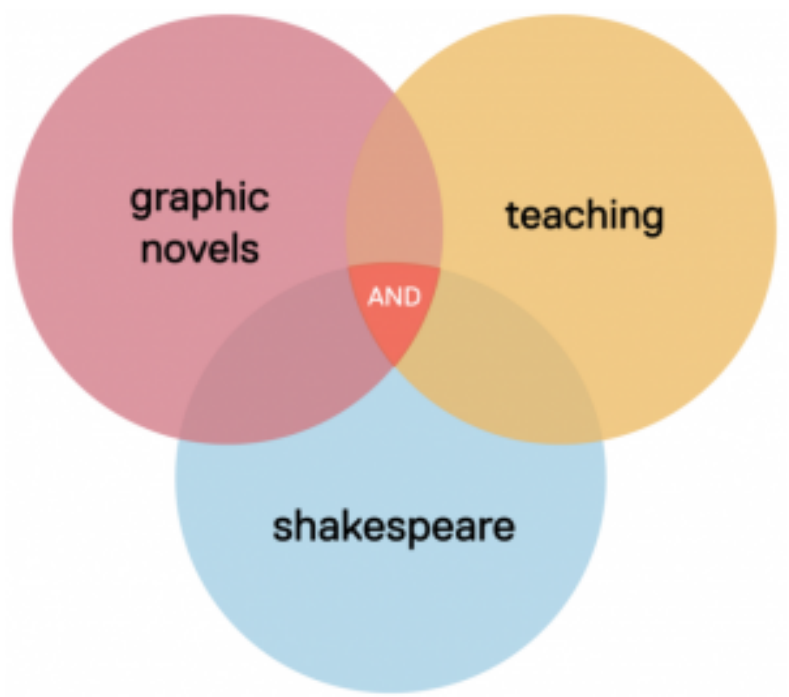




\section{NOT Operator}

The operator NOT is used when you want to search for the first term and to exclude items that contain the second term. Teaching is a very broad term that is often qualified by broad levels such as primary, elementary, intermediate, secondary, higher, or, post-secondary. While you may want to specify a level that you want to look for by trying a search such as teaching AND secondary, you could decide to qualify or narrow the search by excluding a level that you are not interested in by using the NOT operator. The following Venn diagram illustrates the concept teaching as shown by the circle in green on the left. The concept post-secondary is shown by the light grey-coloured circle on the right.. While there is some overlap with both concepts shared by some articles and books, when you use the NOT operator in the example of teaching NOT post-secondary, you exclude those hits that had both teaching AND post-secondary (not shown). That is why the desired set on teaching resembles a circle with a piece removed. [Remember that the NOT operator is sometimes called ANDNOT. The Help information in a database will give you directions if you can simply use NOT or have to use ANDNOT as your Boolean operator.]

Example of a Venn diagram using the NOT operator: teaching NOT post-secondary

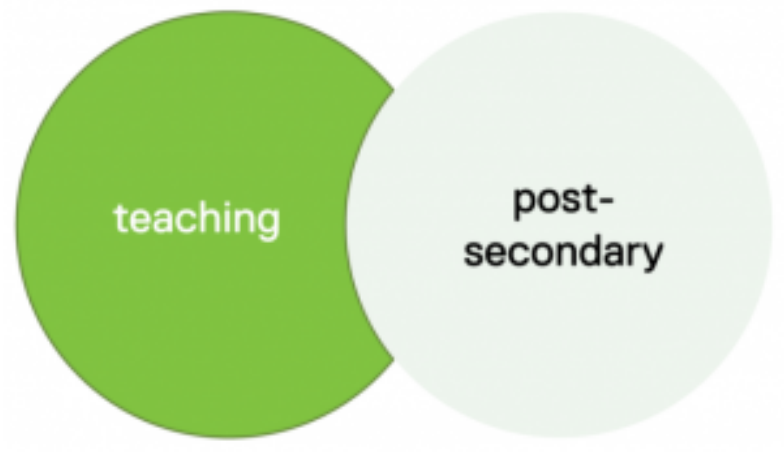




\section{Putting Together All of Your Search Concepts Using Boolean Operators AND, OR, NOT}

Remember our original research question?

\section{Are comics a good way to teach William Shakespeare's plays to high school students?}

We can express this question using the following three key concepts that are shown on separate lines Concept 1: comics OR graphic novels OR manga

AND

Concept 2: shakespeare

AND

Concept 3: teaching NOT (post-secondary OR university OR college)

Using the Advanced Search features of a database reminds you that the Boolean Operators are key to good searching. Here is a screenshot showing what this search might look like using the advanced search options of a database.

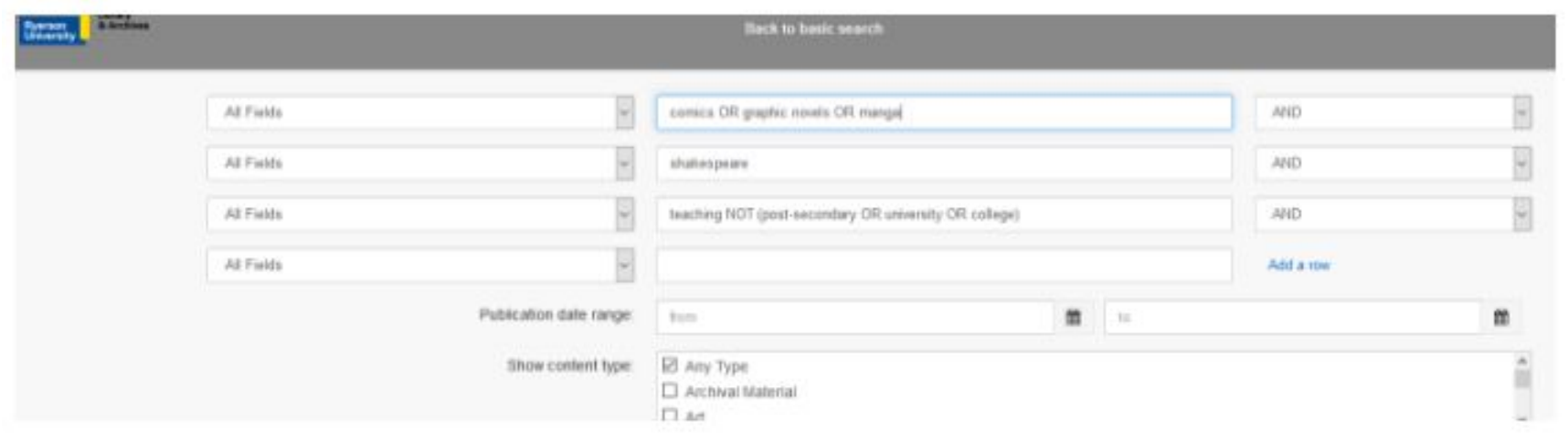

In this example of an advanced search, you, the researcher, are given options on how the search is conducted. There are three main columns and multiple rows.

The columns on the left are by default labelled All Fields and have a drop down box that allows you to specify if you want to restrict your search to specific fields such as Author fields or Title fields or Subject fields. Think of fields as subsets of data that are indexed in the computer to allow more precision in searching. For our purposes, we will use the default All Fields.

The middle column is where you input your search terms, keeping each key concept on a separate line or row. Our first concept comics OR graphic novels OR manga is typed into the middle search box with the Boolean operator OR typed in capital letters so that the computer knows we want to use the operator to expand our search for this one concept to include the related terms that we identified.

The third column of the Advanced Search screen shows by default the AND operator with a drop down box allowing you to change it to one of the other operators, OR, or NOT.

In this example, we want to search for the first concept AND also the concept of Shakespeare. Continuing down to the second row, we will use the default All Fields setting in the first column, then type our concept search term shakespeare in the middle column. Although Shakespeare is a proper name and is capitalized in the English language, databases normally ignore initial capitals in a name so you do not have to capitalize Shakespeare. In the third column, we again want to use the AND operator because we want to add a third key concept that deals with teaching on the next row.

The third row uses a slightly more complex expression of the concept than we looked at when examining the use the NOT operator. We want to find articles and books that discuss the teaching of the earlier concepts, but exclude works 
that discuss teaching at the post-secondary level. We can express this limitation using the words in the example: teaching NOT (post-secondary OR university OR college). We can include some related terms that also indicate the concept postsecondary. In the example, the words university and college are deemed very similar or related to post-secondary so all the words are grouped using the OR operator and nested within parentheses or round brackets. A researcher who is more familiar with terminology used in the field of education may include a fourth term, higher education, as a key way of expressing the concept of post-secondary teaching. Looking at the Advanced Research screenshot, the third row read from left to right has in the first column the All Fields default, the concept, i.e. teaching NOT (post-secondary OR university OR college), that we want to search in the middle column and on the right, the operator column can be ignored since we will not be going on to fill in a fourth row. We will leave the fourth row empty.

The Advanced Search screen includes many additional options to limit or refine your search. These are displayed lower on the page beneath the columns and rows that we used to input our search terms. The example screenshot has an option to set a Publication date range with two boxes that you can use to indicate a start and an end to the date range that you want to specify. For our purposes, we will leave this option blank.

Additionally, the screenshot shows at the bottom the option to choose one or more categories beside the label Show content type, The default is Any type. There is a drop down menu that allows you to choose one or more of many categories of content, for example, Archival material, Art, Article, Artifact. We can run our search without using any of these additional options.

Although we constructed our search strategy using an Advanced Search screen interface, once the search is run the computer may express the search in one single line:

(comics OR graphic novels OR manga) AND (shakespeare) AND (teaching) NOT (post-secondary OR university OR college)

In this instance, parentheses nest the synonyms separated by the OR operator, indicating that the operation within the parentheses must be done first to treat the synonyms as one concept. Databases apply algebraic logic to the processing of your request. Recall from elementary mathematics that items in brackets are done first, division is done before multiplication, and later in the order of completing a calculation come addition and finally subtraction. You may have known this sequence as BEDMAS. Similarly, there is a sequence of operations when Boolean operators are used in database searching. This controls the hierarchy of completing steps. Items in brackets or parentheses are solved or searched first. When brackets or parentheses are absent, the hierarchical sequence of operations begins with AND, followed by NOT and finally OR. By keeping your concepts on separate rows in an Advanced Search screen, you are more likely to use the Boolean operators correctly and the database will insert parentheses around your separate concepts. After you are skilled at the use of the parentheses and the Boolean operators, you may be able to input all of your search terms correctly using a single search box.

\section{Activity}

Experiment with proper and improper use of parentheses. Compare your results when you use the following two search strategies:

(graphic novels OR comics) AND shakespeare

versus

graphic novels OR comics AND shakespeare 


\section{Watch This!}

Here is a short video that recaps the principles of Boolean searching.

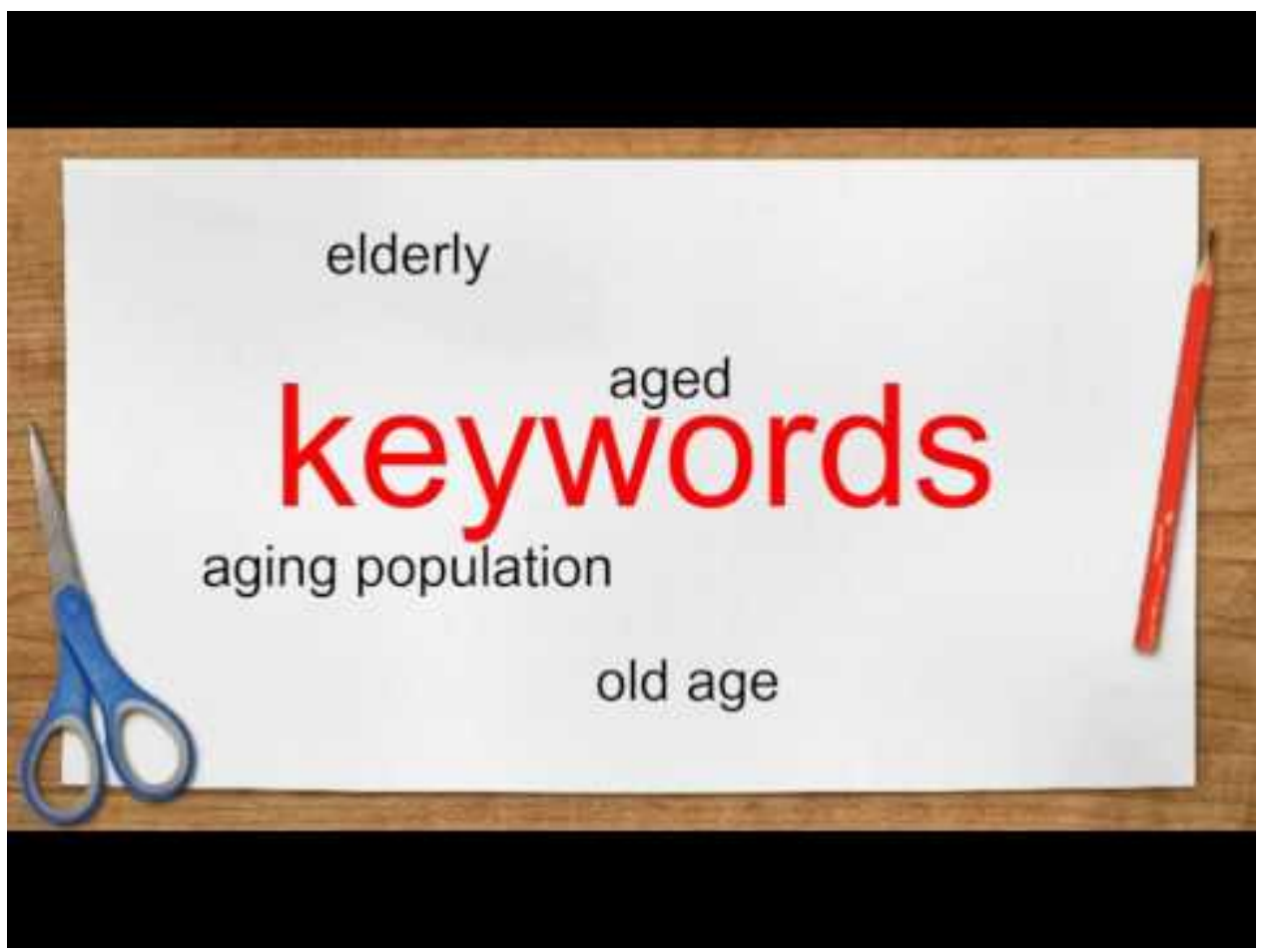

A YouTube element has been excluded from this version of the text. You can view it online here: https://pressbooks.library.ryerson.ca/writehere/? $p=837$

\section{Your Turn!}

Activity

Revise your key concepts using AND and OR Boolean operators. Nest synonyms within parentheses. 


\section{Smart Searches}

While the use of Boolean operators is key to searching, there are a couple of additional search tips that can help you construct a smart search strategy.

\section{Truncation}

In an effort to maximize the power of a search engine, you may want to make use of a handy shortcut called truncation, which is usually represented by the asterisk symbol.

For example, if you wanted to know how teaching is conducted in Canada or by Canadians, you might use the OR operator and search: canada OR canadians OR canadian.

But it is simpler to start with the common root of all of these words, canad and then place an asterisk after it (i.e.,

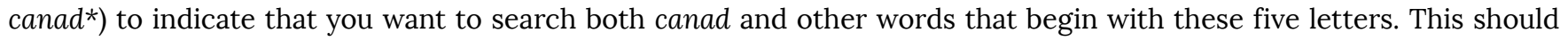
search all of the following words: canad, canada, canada's, canadian, canadians, canadiens, canadiensis. Most databases recognize the asterisk as a truncation symbol. In some instances, a database may make use of the question mark ? or another symbol-this will be explained in the database's help pages. Many databases do search automatically for singular and plural spellings of a word at the same time, but if in doubt, try using the truncation symbol.

\section{Exact Phrase Searching}

If you want to search an exact phrase consisting of two or more words, place them all within quotation marks. Searching for "reading comprehension" is more specific than just using reading comprehension, which a search engine will treat as: reading AND comprehension.

In a sample search, "reading comprehension" found one-fifth as many results as the broader search, reading comprehension, but the smaller result set is more relevant to the intended purpose.

\section{Refining and Modifying A Search}

If you are using a robust search engine, you will frequently find results across multiple formats. The search results may include links to information about books, e-books, journal articles, magazine articles, book reviews, and newspaper articles. You can make use of the options available in the search engine to refine your search.

Depending on the nature of your research, you may only want to see the scholarly articles that are written by experts in the field of study and include features such as extensive references. Professors often direct students to make use of scholarly and specifically peer-reviewed articles from scholarly journals. If you select the scholarly option in the search engine, it will exclude links to information about books, non-scholarly magazines, newspaper articles, etc. Letters to the editor, opinion pieces by an editor, and book reviews are other kinds of non-scholarly writing that may appear in a scholarly journal. If you want only journal articles, you may be able to limit your results by content type such as journal articles, thereby excluding the non-scholarly articles and book reviews that are normally not peer-reviewed.

Some databases or search engines will allow you to refine a search by other elements such as date of publication, discipline, subject term, language of publication and other options.

If you have a limited time for your research, you can try to limit your search to articles that are available in full-text format online or in print at your local library. If you have time for a more comprehensive search, you can expand your search beyond full-text articles to include locally available print resources and articles that are not available locally except through an interlibrary loan service.

You can make use of the information available in your search results to help you select the most appropriate articles for your research. There may be abstracts or summaries of the articles displayed, or you may be able to look into more information about an article and discover things like subject terms or descriptors used to describe the article. These words may help you uncover synonyms for search terms that you had not previously considered. You can modify you search strategy by applying new words. 


\section{Understanding a Search Result}

The following is a sample search result for an article in an online journal:

\section{Example}

How graphic novels support reading comprehension strategy development in children

by Brenna, Beverley

Literacy, 07/2013, Volume 47, Issue 2

.... The primary research questions related to children's applications of metacognitive reading comprehension strategies as well as the potential for graphic novels to support the students...

Journal Article: Full Text Online

More Information

Related Articles

- The first element is the title of the article, "How graphic novels ... in children"

- The second element is the name of the author in inverted order (last name, first name)

- The third element is the source, in this case a journal called Literacy. More specifically, it is volume 47 , issue 2 , of the journal that was published in July 2013. When you cite a source like this, you must include some or possibly all of the information about the source, depending upon the requirements of the citation style that you are using in your paper (MLA, APA, Chicago).

- The fourth element is a brief excerpt from the content of the text, such as part of the abstract or a summary of what the article is about.

- The fifth element tells you the type of source, in this case a journal article that is available in full text online.

- If you have a More information element, it may show you more information about the resource, including page numbers, DOI (Digital Object Identifier-like a URL that is unique for this article, but more permanent), and keywords used to describe the content of the article.

The next sample search result is for a book published in electronic format:

\section{Example}

Graphic novels and comics in the classroom: essays on the educational power of sequential art by Syma, Carrye Kay; Weiner, Robert G; Smith, Robert V; More...

2013 
1. I. Significance of graphic novels and comics: then and now. Using comics to teach the language arts in the 1940s and 1950s / Carol L...

eBook: Full Text Online

- The first element is the title of the book, including both the title proper, and following the colon, the subtitle of the book.

- The second element is a complete list of authors or creators displayed by last name, first name and middle initial, with individual creators separated by semi-colons. The presence of the More option indicates that one or more names are omitted from the display. (Note that it is unclear what roles these creators played. Are they editors, contributing editors, authors of a part of the book, or illustrators? Viewing the cover image or possibly the title page and table of contents may be necessary to clarify the roles of the named creators. It may not be necessary to name all of them depending on your chosen citation style.)

- The third element is the year of publication, 2013.

- The fourth element is a note about the book that in this case contains the beginnings of the list of contents, starting with part 1.

- The fifth element tells you the format i.e. this is an ebook that is available in full-text online.

In order to cite this work properly, you may need more information than what is shown. For example, the name of the publisher is required by most citation styles. If your search engine includes a citation tool, you may find suggested ways to cite this work. Remember that the suggested citation may contain errors and you should carefully verify the information that it provides. 


\section{When Your Results are Limited or Inappropriate}

1. Check your spelling. You may have misspelled the terms. Consider also your use of hyphens or open and closed compound words. Have you included alternate spellings or accounted for differences in Canadian, British, or American spelling?

2. Try the search without using quotations around exact phrases, in case the search engine that you are using does not consistently support this level of searching.

3. Consider better terms to describe your concept. If you are unhappy with the search results for a term like postsecondary, try using an alternate such as higher education, or, try searching using the OR operator: post-secondary OR higher education.

4. If you used a geographic term such as the name of a country or geographic region in your search, re-try it without the geographic name. This should broaden your search and return more citations. If you have limited your results to Canada, you may find there is little published with a Canadian context-there may be a fair amount of articles about the topic in other countries like the United States or the United Kingdom (Great Britain), where the populations are larger.

5. If your thesis topic is very narrow or very current, there may not be very much published in scholarly journals at this time. You may want to consider revising your topic.

For very current topics, the types of publications that will be first to report on it are likely to be newspapers, social media posts, and personal weblogs. Scholarly journal articles may appear months or even two years after they are submitted to the editor of a journal. Books generally take even longer to write and get published. Therefore, you may not find any scholarly articles that relate directly to your topic. In such circumstances, if peer-reviewed journal articles are a requirement for the assignment, you may need to step back and look at a broader view of the topic to find other research that you can apply to your own research topic.

If you do a search for the thesis example from earlier in this chapter, you would probably find articles about the use of graphic novels to teach reading comprehension in general, but not specifically for teaching graphic adaptations of the dramatic works written by Shakespeare. You may be able to apply some of this general research to your own thesis. Or, the research results may be about reading comprehension at the elementary level, not the secondary level. Again, you may be able to apply these findings to your argument. You may find an article or book chapter that discusses the use of graphic novels in teaching Renaissance literature in general but not specifically Shakespeare. Because Shakespeare is generally considered to belong to the the Renaissance period, it may be safe to apply such findings about reading comprehension of Renaissance literature toward William Shakespeare. 


\section{Reviewing and Applying What You've Learned}

- You have identified databases appropriate for your subject area using your library homepage or subject specific database guide

- You have a research question or a tentative thesis statement

- You have broken your research topic into two or three key concepts or keywords

- You have thought up some synonyms for your concepts that can be used with the OR Boolean operator

- You have decided to search for multiple concepts using the AND Boolean operator

\section{Activity}

Now, run your search.

Use the limiting filters of your database search tool to narrow your results.

Choose two articles that are relevant to your research topic. Not every article presented in the search results will be appropriate. Read the titles, abstracts, and, if necessary, skim the contents of the articles to determine if they are truly relevant to your topic.

If present, use the citation tools embedded in the database to help you cite the articles.

Briefly (in one or two paragraphs) explain how each article will be useful in supporting your thesis statement. 


\section{CHAPTER 9: TOWARDS THE WELL-RESEARCHED PAPER}





\section{Chapter Overview}

\section{Learning Outcomes}

\section{In this chapter we will:}

- $\quad$ Revisit and edit the two-storey thesis we built in Chapter 7.

- Learn what a third storey is and experiment with adding it to our two-storey thesis.

- Work with our new three-storey thesis and expand it into an essay outline.

- $\quad$ Examine some of the ways research might be used in an essay. 


\section{Editing Your Two-Storey Thesis}

In Chapter 7, we began the process of building an initial two-storey thesis statement based on our own argument. We will revisit this thesis in a moment, but you may remember that it already seemed quite long and complex. However, we are not yet done. We have chosen our key pieces of evidence, and we have formulated an analytical argument based on our interpretation of this evidence. Now we need to move on to the third and most essential step: stating the significance of this interpretation.

First, however, let's review what we've got so far. If you recall, our prompt asks us to focus on ONE protest movement and ONE social media as we consider how the Internet affects power dynamics between governments and citizens. We have been asked to consider certain questions:

1. What power dynamics does the Internet create between governments and citizens?

2. What is the role of the Internet in affecting the balance between governments and citizens?

3. In what ways are these technologies conducive to balancing or unbalancing these power dynamics?

4. Are these technologies useful or harmful?

As a comprehensive answer to these questions would probably involve thousands of pages of writing, we have narrowed the prompt down and, as it asks us to do, focused on a single protest movement (Occupy Wall Street) and its use of a single form of social media (Facebook). However, Occupy Wall Street's Facebook page contains a lot of information. We have thus narrowed our focus down further by choosing one day (August 6th, 2016) and examining the activity on the page pertaining to that day's post.

Our exploration of the evidence we have found via this examination has allowed us to come up with the following working two-storey thesis:

\section{Example}

First storey: Occupy Wall Street's Facebook page showcases that users of the page have a difficult and often frustrating time discussing, and perhaps linking, global events to events and concerns that are more local, and perhaps personal, to them. This is demonstrated by the comments under the post "From \#Ferguson to \#Gaza \#BLM," wherein discussion of the event leads to participants calling each other names like "idiots" and angry confusion over how the Black Lives Matters is related to the Middle East (ex. The post "What the hell does BLM have to do with geopolitics in the Middle East?").

Second storey: Such interaction on the page demonstrates that while Facebook pages do provide a useful tool for distributing information and bringing large communities together, users often end up using inflammatory, escalating or insulting language that stunts potential deeper discussions of the complex topics posted.

What we have so far is as follows:

1. First storey: In our specific examination of the Facebook page, we have noticed something interesting about the way people are using the page. We have focused on the comments of one particular post that is fairly typical of the posts on this page: a post we can use to represent something larger than itself, as other posts (and comments) on 
the page operate in similar ways. We have therefore given ourselves access to specific evidence that we will eventually use to develop conclusions with a wider application. We are going to answer the questions in the prompt, but if we jump to broad answers too soon, we risk ignoring the evidence at hand in favour of vague opinions or assumptions. We are instead focusing on the narrow evidence of our central example. It's worth noting that this narrow evidence doesn't speak directly to the issue raised by our prompt; therefore, leaping immediately to "This says X about government/citizen power dynamics" would be premature and leave our readers confused.

2. Second storey: The evidence alone is not a thesis. It is interesting, but why is it interesting? What does it tell us? In our second storey, we take our specific evidence and interpret it. It is important to note that not everyone who gathers this evidence will interpret it in the same way. Others might see other aspects of the evidence as more important or decide that it has a different meaning. However, these others will still be focusing closely on the evidence.

This will not be our essay's final thesis. We are, at this stage, just beginning our examination of the evidence. As we continue to think about it and to incorporate secondary research, which we will discuss below, our thesis will develop and become more complex.

At this stage, we should pause for a moment and evaluate what we have so far. As we have discussed, editing must take place throughout the essay-writing process, not simply at the end. 


\section{Complete the Essay Self-Evaluation of Your Two-Storey Thesis Below.}

\section{Taking Measure}

Please complete this self-evaluation of the two-storey thesis you wrote in Chapter 7.

Each question requires a "Yes" or "No" answer. For each "Yes" response, give yourself one point. Your final score will be a mark out of eleven (eg.: ten "Yes" responses $=10 / 11)$.

\section{Components}

Did you narrow your approach from the general prompt to a specific, concrete focus?

$\mathrm{Y} / \mathrm{N}$

Did you identify two specific pieces of evidence?

$\mathrm{Y} / \mathrm{N}$

Did you concentrate in both storeys on your central document and its concrete elements?

$\mathrm{Y} / \mathrm{N}$

\section{First Storey: Evidence/Observations}

Is the first piece of evidence something you can literally point to in the document?

$\mathrm{Y} / \mathrm{N}$

Is the second piece of evidence something you can literally point to in the document?

$\mathrm{Y} / \mathrm{N}$

Does each piece of evidence add something new?

$\mathrm{Y} / \mathrm{N}$

\section{Second Storey: Argument}

Have you provided a specific interpretation of the concrete evidence in your first storey?

$\mathrm{Y} / \mathrm{N}$

Are you still concentrating on the evidence itself, instead of overlooking it in favour of a more general discussion?

$\mathrm{Y} / \mathrm{N}$

Is your argument controversial? Is it possible for the reader to disagree with it? 
$\mathrm{Y} / \mathrm{N}$

$\underline{\text { Style }}$

Did you avoid the use of first- or second-person pronouns? (I, we, us, our, etc.)

$\mathrm{Y} / \mathrm{N}$

Did you avoid words from the Ctrl-F list? (society, technology, people, etc.)

$\mathrm{Y} / \mathrm{N}$ 


\section{Adding a Third Storey}

Now that we have our central evidence (first storey) and our initial interpretation of that evidence (second storey), it is time to move on to the third storey. As you know from your close reading, the third storey can be tricky. In a nutshell, the third storey deals with the significance of our first and second storeys. We have identified some key evidence and presented an interpretation of that evidence, but to tie everything together, we need to explain why our interpretation is important.

In order to do so, we need to connect our interpretation of specific evidence to the larger implications of that interpretation. The impulse to go broad, not narrow, will be satisfied in the third storey, with one caveat: the fact that we're dealing with larger implications doesn't mean we can forget about our evidence. The third storey needs to be connected firmly to the first and second.

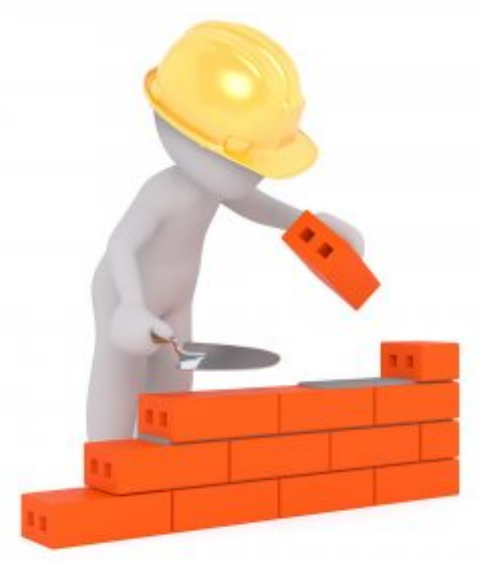

From Pixabay.

In this type of essay, the content of the third storey will necessarily vary depending on the kind of approach the writer has taken to the evidence. Perhaps the third storey will provide the solution to a problem raised in the second storey, or an observation that this problem has no solution (and why). Perhaps the argument in the second storey will lead to a surprising realization about the meaning of the evidence in relation to the larger issue it represents. The third storey should, in a way, be satisfying: not broad and simple, but a revelation that will demonstrate that the thinking we have done in this essay provides insight into the issue we are exploring.

To move towards the third storey, look at the second storey and ask:

- What is the significance of the conclusions you have drawn from the evidence?

- Why does your second storey matter? Why is it important that you have interpreted the evidence in this way?

- How do the specific observations and argument you have made connect to the larger issue you are discussing?

- What does your second storey reveal?

If we look back at the second storey about Occupy Wall St.'s Facebook page, we can begin formulating possible answers to these questions. It's important to note that the third storey we come up with at this point will not be the final version. We have not yet taken our secondary research into account, and we have a lot more work to do with our primary evidence as well. As we work at analyzing our evidence and applying secondary ideas to it, the thesis will inevitably change, becoming 
more complex and specific. However, even at this early stage, it's important that we not take refuge in generalities. Our new third storey will be as complex and specific as we can make it. 


\section{Watch This!}

The following video walks through how to create a three-storey thesis statement using the Occupy Wall Street Facebook page. Watch Video 9.1: Creating an Initial 3-storey Thesis to see an A-level example being drafted.

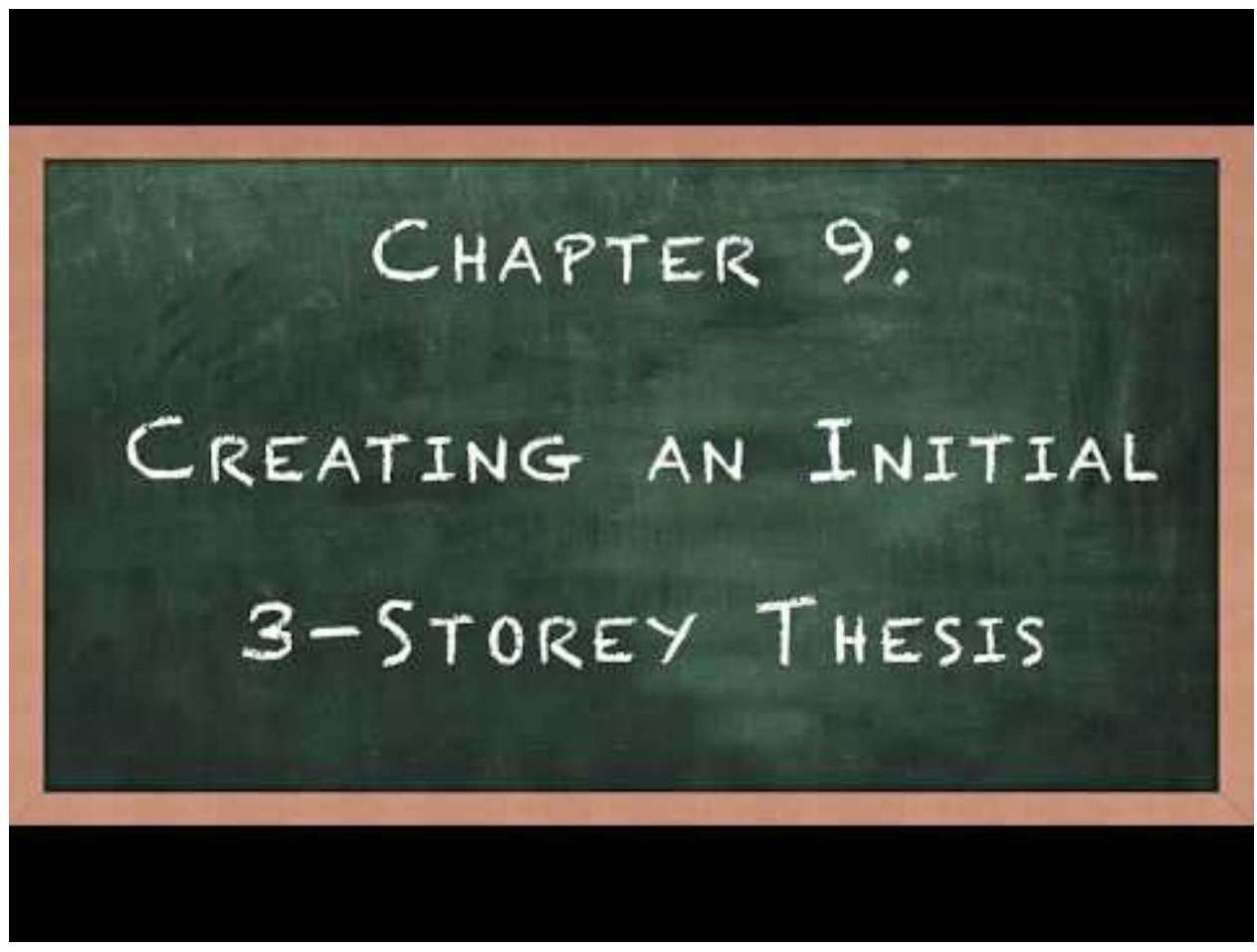

A YouTube element has been excluded from this version of the text. You can view it online here: https://pressbooks.library.ryerson.ca/writehere/? $p=1008$

\section{Example}

FIRST STOREY: Occupy Wall Street's Facebook page showcases that users of the page have a difficult and often frustrating time discussing, and perhaps linking, global events to events and concerns that are more local, and perhaps personal, to them. This is demonstrated by the comments under the post "From \#Ferguson to \#Gaza \#BLM," wherein discussion of the event leads to participants calling each other names like "idiots" and angry confusion over how the Black Lives Matters is related to the Middle East (ex. The post "What the hell does BLM have to do with geopolitics in the Middle East?"). 
SECOND STOREY: Such interaction on the page demonstrates that while Facebook pages do provide a useful tool for distributing information and bringing large communities together, users often end up using inflammatory, escalating or insulting language that stunts potential deeper discussions of the complex topics posted.

THIRD STOREY: The Occupy Wall Street Facebook page's tendency to strengthen local connections while potentially simplifying and weakening links to larger social and political contexts with inflammatory language acts as an indicator that despite the increased reach of an online community, the divisive discussions among its users are likely to affect its ability to influence governmental policy and provide a base for civilian power. Users who wish to turn the Internet into an effective tool for providing a counterpoint to corrupt, dictatorial, or simply misguided governments will need to address this simplification and attempt to ensure that the broad reach of the social-media platform does not replace the broadness in scope of the movement itself.

Notice that this third storey does not lose sight of the first and second storeys that precede it. It deals with more than just the Occupy Wall Street Facebook page but is ultimately rooted in your observations about that page. This particular third storey acknowledges the problem identified in the first storey and analyzed in the second storey, then explains what this problem means in the context of the broader issue. 


\section{Try This!}

\section{Activity}

Take your own two-storey thesis and come up with a potential third storey. Remember that your third storey may, at this point, be a little less specific than you would like it to be, though that doesn't mean you shouldn't try for as much specificity as possible.

Ask yourself the following questions:

1. Look back at the questions posed in your prompt. Have you answered some of them? All of them? If you haven't answered some of them, why are these answers missing? Can you revise your third storey to address them?

2. Are you having a hard time coming up with a third storey? If so, you may need to look back at your first and second storeys. Are they specific enough? Does your second storey provide you with a genuine argument? Is a certain vagueness in your approach making it difficult to identify the meaning of your argument?

3. Does your three-storey thesis give you something concrete to discuss? Can you imagine the discussion going on for eight double-spaced pages? Can you imagine concentrating on your central document on every one of those pages instead of quickly abandoning it and moving towards a more general and opinion-based discussion?

By the end of this exercise, you should have an initial three-storey thesis. It will not be perfect. It will, and must, change as you continue to work on the essay. However, it will give you a starting point, a sort of base camp from which to venture out as you continue to explore. 


\section{The Three-Storey Thesis: The Importance of Outlining}

\section{The Outline: Basics}

The third question in the previous section asked whether you could imagine your discussion of your central document continuing throughout your paper. If you answered "yes" to that question, you can test your assertion by drafting an outline.

In Chapter 4, we spent some time writing a detailed outline of our close reading. As that chapter explains, an outline will save you time later in the essay-writing process because it acts as your roadmap. Picturing the outline as a map can be useful. Just as a map will provide you with an overview of many possible routes to your destination, allowing you to work out which ones to avoid and which ones will get you most quickly and effectively to your destination, an outline will highlight potential roadblocks (tangents, ideas without evidence behind them, ideas that go nowhere, undeveloped points, weak points that rely on opinion, etc.) while also revealing promising connections. The outline allows you to see where you're going and decide on the best way to get there. If you eventually decide the approach in your outline is flawed, you can modify it later.

In the case of a research essay, the outline has another function as well: it will demonstrate which aspects of your argument currently lack secondary evidence. You have spent some time with your primary document, but you have not incorporated your research. We'll begin discussing research and how to work with it in our next section. For now, just keep it in mind as you move through the outline.

Chapter 4 includes the suggestion that your essay's outline follow the trajectory of your three-storey thesis. This remains a good method of organization. Keep in mind, however, that there is no one cookie-cutter method for structuring an essay. If your impulse is to look at the sample outlines in these chapters and follow them exactly, you are relying too strongly on the idea that an essay should follow a formula. An essay does not have a set number of paragraphs, and sometimes, taking a structure-based risk-for instance, spending some time on what appears to be a tangent, but turns out to provide an essential part of your argument-can be very effective.

As we move through the outline, we'll begin to acknowledge an element that did not turn up in Chapter 4's outlining exercise: research. We'll be discussing research in more detail in the next section, where we'll also go more deeply into how you might incorporate it into your essay. For now, as we go over an outline based on the threestorey thesis we constructed above, we will simply acknowledge the potential for

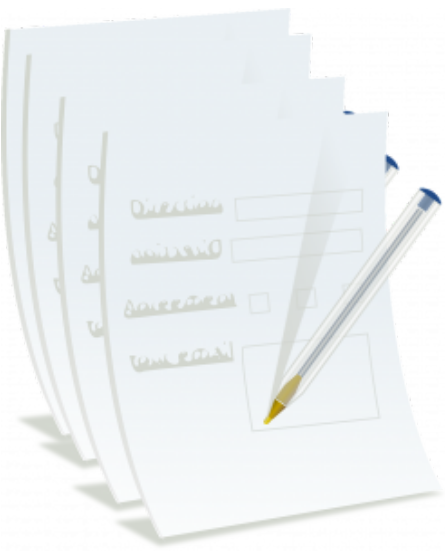

From Pixabay. research. When a point seems as if it might need some research, we'll make note of it. Don't worry: we'll revisit these notes in the next section. As you read, try to think about why the essay may need secondary support in particular paragraphs. 


\section{Introduction}

The introduction of a research essay has the same basic purpose as the introduction of a close reading: to explain your initial argument as specifically and with as much complexity as possible, on the understanding that it will be even more complex and nuanced by the essay's conclusion. However, it is also in your introduction that you will first have a chance to incorporate the most important of your secondary sources: the ones that are key to your argument.

As you outline your introduction, consider the same questions that likely arose when you wrote your close reading:

- Do you get to your argument relatively quickly? You'll have more room in this essay than you did in your shorter close reading, but perhaps not as much as you think. It may be tempting to start very expansively, with two introductory paragraphs:one in which you discuss the problem behind the essay in detail, another in which you offer the solution to that problem. However, if you do so, you risk beginning with a paragraph in which, argumentwise, nothing happens. Your introduction is a good opportunity to lay the foundations for your argument, quickly taking the reader to a place in which the argument can be complex and specific.

- Do you introduce your argument's main subject as well as its context? The temptation here is often to start extremely broadly ("Since the dawn of time, humans have communicated with each other"; "Throughout human history, people have formed social groups"). This sort of "universal opener" may feel like a way of putting your argument in context, but it tends to be far too broad. If you are analysing one post on one Facebook page, it is not necessary to begin at the dawn of time.

- On the other hand, contextualizing your argument is a good idea. Begin, perhaps, with the larger problem you are discussing, then move swiftly to your specific body of evidence. Remember that your third storey will acknowledge the connection of your body of evidence to the larger issue it represents. An acknowledgement of the larger issue in your introduction will give you something to circle back to.

- Have you explained the essentials of your complex, specific argument? You will be fleshing out this argument in the body of your essay, and it will appear in its complete form in your conclusion. It may be tempting to begin by "hiding" your argument, saving it for a revelation in your conclusion. However, a clear argument will itself provide a roadmap for the rest of your essay. It won't tell the reader the exact twists and turns of the discussion, but it will give you something concrete to develop into an even more interesting thesis.

- Research-Related Considerations: Have you incorporated your secondary research into your thesis in such a way that it provides an insight into your unique argument? We'll return to this concept later on. 


\section{Body}

You may recall that in Chapter 4, our outline mimicked the shape of the three-storey thesis itself, with early paragraphs dealing in detail with the specific evidence we were examining, paragraphs in the middle of the paper leaning further into interpreting that evidence, and the final body paragraphs providing the revelation of the second storey's ultimate significance. A similar structure will work here as well, though again, be aware that when you become more comfortable with essay structure, you may choose to play around with it for the sake of your argument's efficiency and effect.

For now, we'll be starting with the same basic trajectory as Chapter 4. Note, however, that because this essay is longer, we will be using more paragraphs. It is worth noting that you need not stick with the number of paragraphs you come up with in your outline. Your approach may shift over time as you research and draft your essay. 


\section{First Storey}

\section{Example}

FIRST STOREY: Occupy Wall Street's Facebook page showcases that users of the page have a difficult and often frustrating time discussing, and perhaps linking, global events to events and concerns that are more local, and perhaps personal, to them. This is demonstrated by the comments under the post "From \#Ferguson to \#Gaza \#BLM," wherein discussion of the event leads to participants calling each other names like "idiots" and angry confusion over how the Black Lives Matters is related to the Middle East (ex. The post "What the hell does BLM have to do with geopolitics in the Middle East?").

Our first storey has provided us with the key evidence we will be examining in our argumentative essay. As in the close reading, our essay should be evidence-based, which means we must examine this material as closely as we did the article we analyzed earlier in the course. Dedicate some paragraphs to exploring the evidence closely. The beginning of our essay's body might look something like this:

Paragraph 1: Examine and discuss the comments in terms of their statistical make-up (i.e., what proportion of the comments are dedicated to local problems, and what might that tell us?).

Paragraphs 2 \& 3: Examine and discuss particular key comments (those related, in this case, to the name calling or questions/confusion linking Black Lives Matter to the Middle East) in terms of their specific content and phrasing.

Paragraph 4: In contrast to the comments discussed above, examine the elements in the comments section that break away-or appear to try to break away-from local concerns in order to deal with larger implications.

Research-Related Considerations: Examine and discuss the evidence above in terms of external research on the larger problem you are exploring.

When we return to the concept of research in the next section, we will discuss some of the things we might do with it. Maybe it will get a dedicated paragraph of its own. Maybe it will be spread throughout the three paragraphs. However, for now, remember that we must ultimately look at our evidence in terms of supporting material. This material will not pull us away from our examination of our evidence; it will give us insight into the evidence we are discussing. 


\section{Second Storey}

Example

SECOND STOREY: Such interaction on the page demonstrates that while Facebook pages do provide a useful tool for distributing information and bringing large communities together, users often end up using inflammatory, escalating or insulting language that stunts potential deeper discussions of the complex topics posted.

We have looked closely at our evidence. Now we need to move a step further in our interpretation of it. If we go through our second storey carefully, we can see which aspects of it offer concrete ideas that can be discussed further in relation to the evidence; we can also arrange these aspects into an order conducive to moving our argument forward. For instance, we might consider arranging the next few paragraphs as follows:

Paragraph 5: Discuss the function of this particular post as an information distributor and community unifier by concentrating on the identities (where apparent) and/or stated aims of the commenters. Are they treating it primarily as a source of information? A place where a wider community can come together? Something else?

Paragraph 6: Explain the patterns you have found in the comments as an effect of the social space itself. If many of the comments seem insular, why might they be so? If the broader community seems disunified, what in the post and/or the comment section is allowing the insularity of the sub-communities within the larger community to remain?

Paragraph 7: Draw in elements that seem not to fit. Not all the comments are insular. How are those that are not insular treated by the group? Are they ignored? Do they contribute to the conversation? Do they ever come from the same people who post the insular comments, or do they originate from a distinct sub-community?

Paragraph 8: Discuss the effect of the online community's structure in light of the idea of the Facebook page's purpose. Do the patterns you have found confirm or deny the "usefulness" of the page? What, in this context, does "usefulness" mean? Is the word itself becoming inadequate (i.e., too vague and general) for your purposes?

Research-Related Considerations: Apply broader secondary perspectives to this specific example in order to gain insight into what it demonstrates.

Notice that while we are still working with the evidence introduced in our first storey, we are now asking more specific questions about it. How does it work? Why does it do X? What is its effect? How do the different puzzle pieces you have collected fit together? We are also introducing a few nudges towards our third storey. We have not quite asked what the ultimate significance of our observations is yet, but we're getting there. 


\section{Third Storey}

Example

THIRD STOREY: The Occupy Wall Street Facebook page's tendency to strengthen local connections while potentially simplifying and weakening links to larger social and political contexts with inflammatory language acts as an indicator that despite the increased reach of an online community, the divisive discussions among its users are likely to affect its ability to influence governmental policy and provide a base for civilian power. Users who wish to turn the Internet into an effective tool for providing a counterpoint to corrupt, dictatorial, or simply misguided governments will need to address this simplification and attempt to ensure that the broad reach of the social-media platform does not replace the broadness in scope of the movement itself.

Our second storey digs deeply into the material at hand and examines some of the effects of how it works. Our third storey is what we get when we then ask, "And...?" All of this information is interesting, but if we stop with our second storey, we're asking our readers to draw conclusions from our observations. Instead, we must move towards some understanding of what our observations mean.

Paragraph 9: Draw conclusions from your evidence as it relates to the page itself. Moving on from the idea of "usefulness" in paragraph 8, discuss what "use" the comments have (they allow users to connect over local issues) and what "use" they fail to have (they de-emphasize larger issues, which are obscured by the localization of user concerns).

Paragraph 10: In light of this concept, return to the idea of social media as an influencer of government policy. Is there a disconnect? What does it mean? Does this disconnect seem rooted in the structure of the page, the identities of the users, the culture that has formed around this particular form of social media, or something else? How do you know? And...?

Paragraph 11: Zoom in on a possible reason for the disconnect: the tendency of social media's reach to reveal the rhetoric being used within in-groups. Turn this, potentially, into a call to action regarding future use of social media in social and political activism.

Research-Related Considerations: While it's unlikely you will introduce new research at this point, you may use this section to return to some of the research you have cited previously to emphasize its significance or repeat it in light of the more complex conclusions you have reached.

Here we have circled back to the larger question without losing sight of our specific evidence. We have also uncovered some unexpected issues along the way, including the seemingly contradictory observation that broad reach does not necessarily equal broad effect. As we move through our second and third storeys, we need to delve beneath the surface instead of latching onto the first easy answer and repeating it in every paragraph. 


\section{Conclusion}

Your conclusion is where you bring everything together in a way that would not have been possible in your introduction. As you know, you should not simply repeat the points you have already made. The reader has just finished reading those points; if you make them again more concisely immediately after you have made them in depth, the reader will see only repetition, not development. However, you can, in your conclusion, provide a "This is where it all comes together" moment. This is where the completed puzzle appears in all its glory, and you state its implications succinctly.

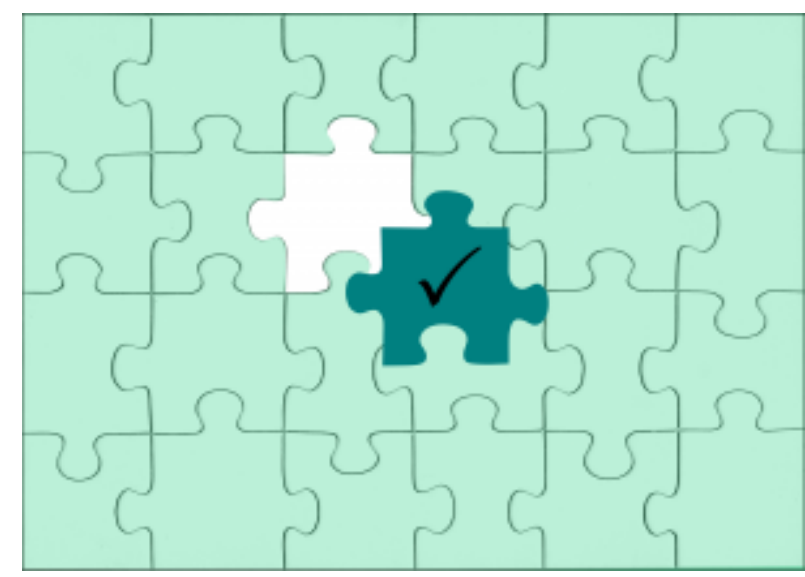

From Pixabay. 


\section{Full Outline}

Now take a look at our outline all at once. This is what we've got:

Introduction: Present and contextualize the initial complex thesis.

Paragraph 1 (First Storey): Examine and discuss the comments in terms of their statistical make-up (i.e., what proportion of the comments are dedicated to local problems, and what might that tell us?).

Paragraphs 2 \& 3 (First Storey): Examine and discuss particular key comments (those related, in this case, to the name calling or questions/confusion linking Black Lives Matter to the Middle East) in terms of their specific content and phrasing.

Paragraph 4 (First Storey): In contrast to the comments discussed above, examine the elements in the comments section that break away-or appear to try to break away-from local concerns in order to deal with larger implication.

[Research-Related Considerations: Examine and discuss the evidence above in terms of external research on the larger problem you are exploring.]

Paragraph 5 (Second Storey): Discuss the function of this particular post as an information distributor and community unifier by concentrating on the identities (where apparent) and/or stated aims of the commenters. Are they treating it primarily as a source of information? A place where a wider community can come together? Something else?

Paragraph 6 (Second Storey): Explain the patterns you have found in the comments as an effect of the social space itself. If many of the comments seem insular, why might they be so? If the broader community seems disunified, what in the post and/or the comment section is allowing the insularity of the sub-communities within the larger community to remain?

Paragraph 7 (Second Storey): Draw in elements that seem not to fit. Not all the comments are insular. How are those that are not insular treated by the group? Are they ignored? Do they contribute to the conversation? Do they ever come from the same people who post the insular comments, or do they originate from a distinct subcommunity?

Paragraph 8 (Second Storey): Discuss the effect of the online community's structure in light of the idea of the Facebook page's purpose. Do the patterns you have found confirm or deny the "usefulness" of the page? What, in this context, does "usefulness" mean? Is the word itself becoming inadequate (i.e., too vague and general) for your purposes?

[Research-Related Considerations: Apply broader secondary perspectives to this specific example in order to gain insight into what it demonstrates.]

Paragraph 9 (Third Storey): Draw conclusions from your evidence as it relates to the page itself. Moving on from the idea of "usefulness" in paragraph 8, discuss what "use" the comments have (they allow users to connect over local issues) and what "use" they fail to have (they de-emphasize larger issues, which are obscured by the localization of user concerns).

Paragraph 10 (Third Storey): In light of this concept, return to the idea of social media as an influencer of government policy. Is there a disconnect? What does it mean? Does this disconnect seem rooted in the structure of the page, the identities of the users, the culture that has formed around this particular form of social media, or something else? How do you know? And...?

Paragraph 11 (Third Storey): Zoom in on a possible reason for the disconnect: the tendency of social media's reach to reveal the rhetoric being used within in-groups. Turn this, potentially, into a call to action regarding future use of social media in social and political activism.

[Research-Related Considerations: While it's unlikely you will introduce new research at this point, you may use 
this section to return to some of the research you have cited previously to emphasize its significance or repeat it in light of the more complex conclusions you have reached.]

Conclusion: Bring the elements of your argument together in such a way that you can present their implications. As we move from the development of our initial three-storey thesis to the drafting of our essay, the outline can, as Chapter 4 points out, serve as a bridge between the two stages. However, it can also show us areas of our argument that currently seem vague or repetitive: areas that may need more support and development. In the next section, we will be discussing what the outline can mean in terms of the incorporation of research into your paper. 


\section{Try This!}

\section{Activity}

Take the three-storey thesis you developed earlier in this chapter and create an outline based on it. Remember that this outline is not final or binding; it is like a test, a way of discovering whether your current argument has the depth necessary to fill out a six-to-eight-page essay. Don't worry about research at the moment, but keep it in mind by creating "research-related considerations" placeholders like those in the sample outline. 


\section{Watch This!}

Now watch Video 9.2: Creating an Outline Based on the 3-storey Thesis in which our sample three-storey thesis is expanded, step by step, into an outline.

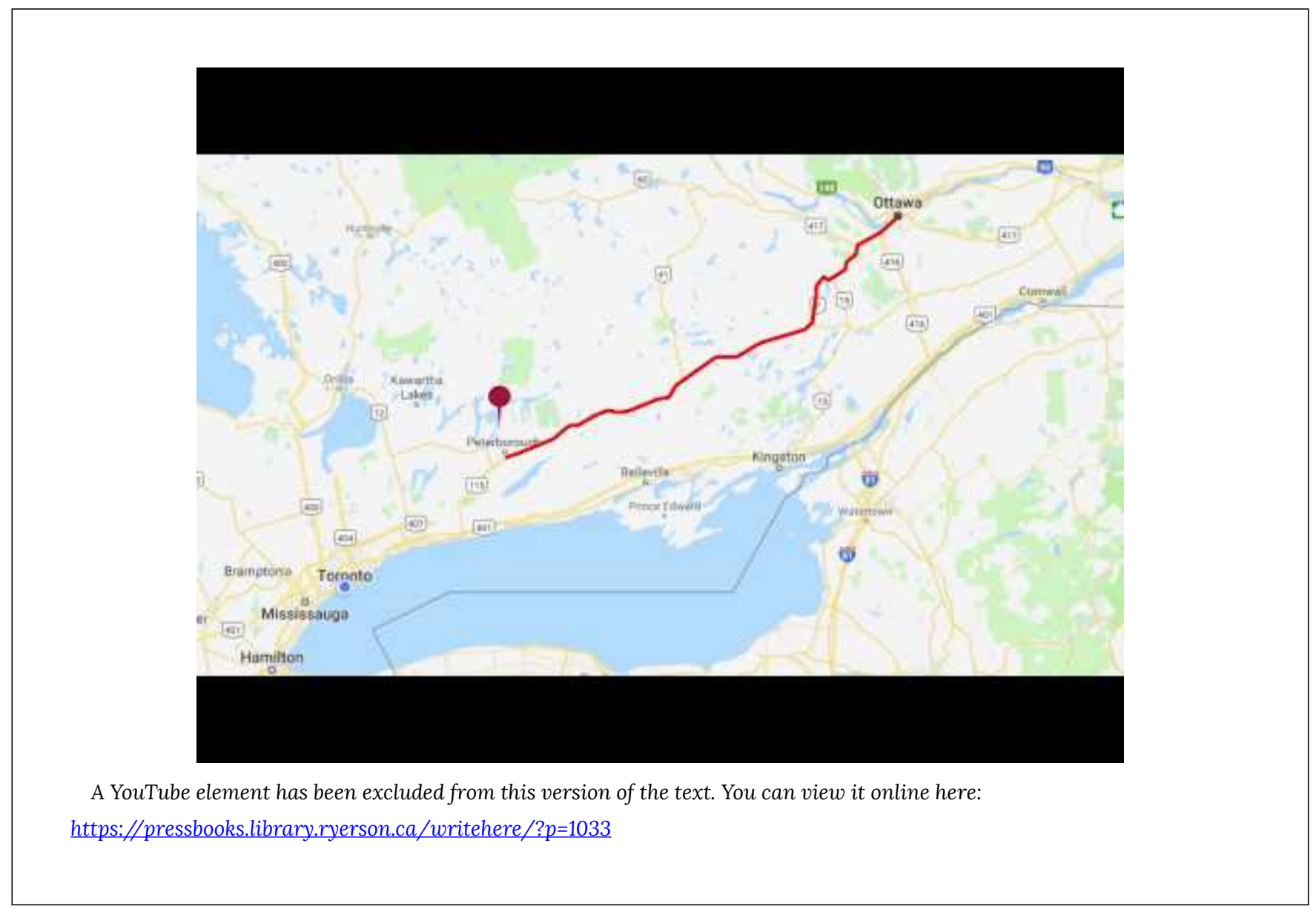




\section{Research: First Steps}

\section{The Research Essay}

When we hear the words "research essay" or "research assignment," our first impulse may be to think of a work that that takes other people's ideas and sews them together into a single document: a sort of patchwork quilt. However, a good research essay operates rather differently. "Research" is not an excuse to coast on the knowledge of others but an opportunity to use that knowledge to support and add complexity to our own original ideas.

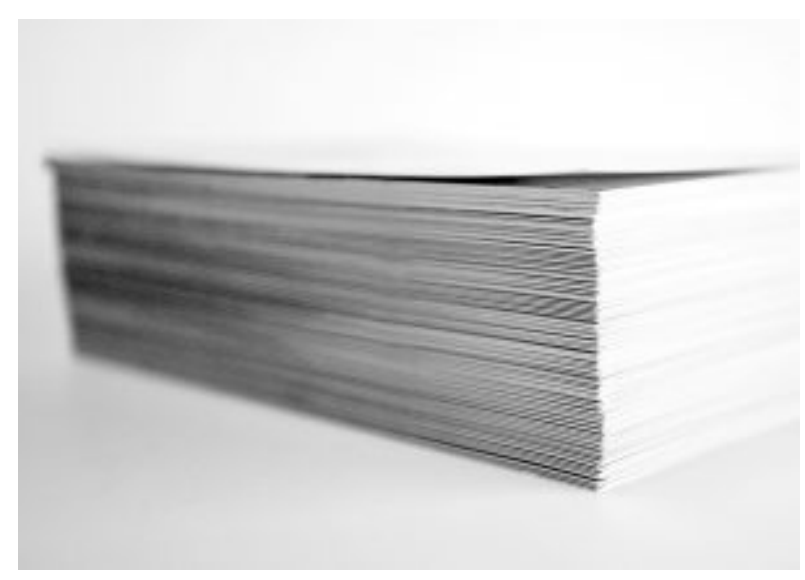

Photo by Ron Dyar on Unsplash

The word "support" is often used in conjunction with research, and it is a good place to start. Let's unpack the word a little. What does it mean to "support" an argument?

We've already seen some examples of support happening earlier in this text. An argument is not complete without evidence to back it up. However, as you will notice as you move through these chapters, using evidence in support of an argument is not as simple as just presenting it, then standing back and letting the reader figure out what it means. Supporting evidence must be developed. Support is more than the evidence itself. It consists of the evidence and the interpretation of that evidence. If you make an assertion on its own, you have an argument without evidence: an opinion. If you make an assertion and follow it with a list of evidence, you have an argument without development: an observation. If you make an assertion and follow it with a detailed discussion of how and why the evidence demonstrates its validity, you have an argument with support: a thesis.

In a research essay, you must expand your consideration of evidence beyond your own close reading. Therefore, you must also expand your understanding of "support" to include not just an interpretation of your primary work but an interpretation of secondary works that you will apply to your primary work. These secondary sources are not the primary focus of your investigation, but they can be used to give you insight into this investigation: insight you would not gain with a simple close reading.

Let's take a look at a few common types of evidence and how they might be used in a research essay. 


\section{Research Types}

The opposite of a patchwork research paper-a paper in which the writer sews together other people's ideas to create a single work-is what we might call a "nominal research paper": a paper in which secondary sources are shoehorned in, that is, used superficially because research is a requirement, not because they have been incorporated into the writer's argument. To avoid both the patchwork error and the shoehorn error, you must understand how you are using your research. It is therefore useful to think of research in terms of types.

Think back to our project on Occupy Wall St.'s Facebook page. We already have our primary source: the post and comments we are examining closely in the essay. We have noticed a lot of things by close reading this source, and we have come up with a potentially solid thesis and a detailed outline. Are there any kinds of external information that might help us make our thesis even better?

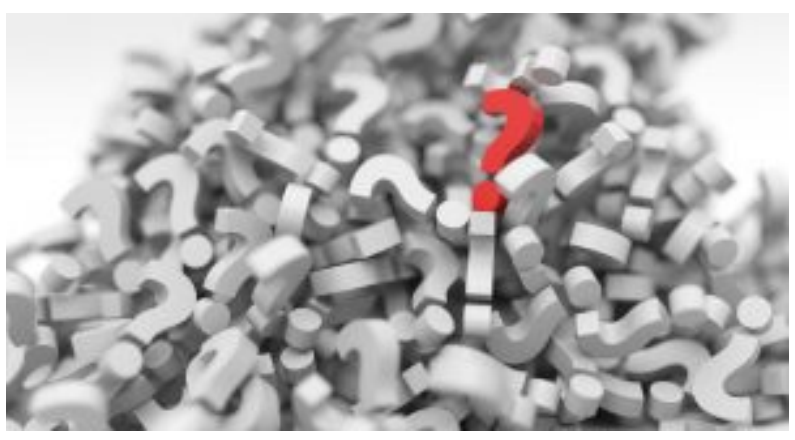

From Pixabay. 


\section{Corroborate, Contrast, Contextualize}

When you are searching for sources to help you support your argument, resist the impulse to look only for documents that pertain to your exact subject matter. Sometimes, students will be frustrated because they have searched exact terms, such as "Occupy Wall Street" AND "Facebook," and have come up with nothing. However, remember that you are creating your own unique argument. Trying to find papers that have made exactly the same argument you want to make will nudge you towards the "patchwork" model and away from the opportunity to put together something new and interesting of your own.

Instead, look for papers on similar subjects or on the broader categories into which your specific discussion fits. Other writers interested in social media and its use in protest movements will have produced papers on the subject. Exploration of this material can be very profitable for you.

You may find material that corroborates yours. If Author A's paper on some other protest movement's use of social media has come to conclusions that seem to confirm your own (when you consider both papers in light of the broader subject), you might present some of Author A's research and compare it closely to your own.

You may find material that contrasts with yours. This material is just as valuable as the corroborating material. Perhaps you can use it to explore the differences between the contexts of the two discussions (is Author B examining a different type of social media or a different variety of protest movement? Did the users approach the social media in a different way? Did the protest movement originate from a different social context or cultural background? Is Author B herself working from assumptions that are fundamentally different from yours, or does Author B's paper genuinely offer a complication you will have to take into consideration as you revise and refine your thesis?).

You may find material that contextualizes yours. Perhaps Author $\mathrm{C}$ has written a paper on the history of protest movements, or on the way communities seem to work online, or on social upheaval and the Internet, or on Occupy Wall Street's origins and modus operandi. All four of these subjects are relevant to your paper, but they are also broader in scope. It is often very helpful to look at secondary research on the categories to which your primary document belongs. You will, for instance, be able to discuss the Occupy Wall Street Facebook page more knowledgeably if you know something about Occupy Wall Street.

Corroboration, contrast, and contextualization will all give you ways of approaching your subject matter that would remain inaccessible to you if you limited yourself to a close reading. The secondary works you consult will provide factual information you would not otherwise have, as well as analytical ideas that come from perspectives that might not otherwise have occurred to you. You do need to be careful that you are engaging with these works instead of merely replicating them, but we'll discuss this issue in more detail below.

Our three "c" terms are still rather broad. Let's break them down a little and look at some more specific types of information you will find in your sources.

242 | Corroborate, Contrast, Contextualize 


\section{Definitions}

We'll be discussing the Facebook page in the context of some larger questions about protest movements and social media, and therefore, we'll probably need to use some specialized vocabulary: vocabulary that doesn't count as common knowledge. We may find it helpful to define our terms.

In the age of the Internet, definitions may seem easy to come by, but we need to be careful. It's a little too easy to do a Google search on a key term and scoop up the first definition we find. Dictionary definitions are rarely used in academic papers, simply because they are usually very general and brief. If we are using a term specialized enough that it needs a definition, a dictionary definition will be far too broad for our purposes. Like all types of research, definitions should appear in a paper for a reason, not simply to take up space.

More specific definitions can be found in scholarly works that deal in detail with the broader subject matter we are applying to our primary example. In this case, perhaps our library research has turned up a paper by Author D on the use of social media during the Arab Spring, and the paper's author has written of something she calls "social resistance." You realize when you read the paper that though the author is speaking of an entirely different movement using the Internet in a different way, we have been discussing the concept of "social resistance" as applied to the Occupy Wall Street movement. We would thus take our definition (properly cited) from the paper on the Arab Spring. Our definition will be much more detailed and appropriate than it would be if we went to Dictionary.com, for example, and looked up the words "social" and "resistance" in turn. If we did that, the definition cobbled together would be much vaguer. It would also not provide us with something even more interesting: the opportunity to relate our argument to the argument made by Author D. 


\section{Data and Statistics}

When you are examining the Occupy Wall Street page, you may collect data of your own. For instance, you could count insular comments and comments broader in scope, then compare the two numbers. The comparison will tell you something about the specific document you are examining.

However, while our data will be useful in a discussion of our specific evidence, it may not help as much when we go to connect our primary document to our broader subject matter. That is where other people's data and statistics will come in handy. Say Author E has made an exhaustive study of how American political activists use Twitter. The subject matter of his paper is not exactly the same as yours, but his statistics may be used to corroborate yours (if they seem to support what your own data and observations reveal), contrast yours (perhaps Twitter and Facebook operate in different enough ways that it will be instructive for you to examine the differences between the two sets of data), or contextualise yours (if the statistics are broad enough for

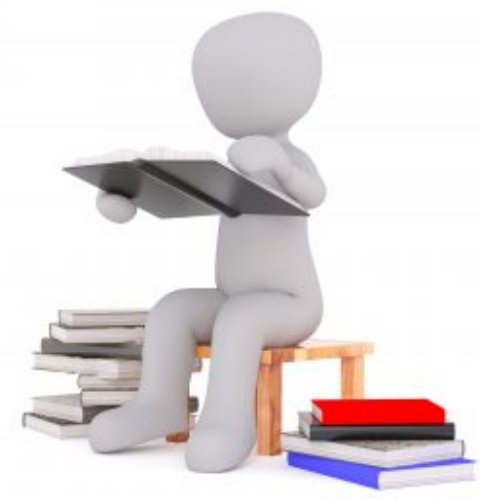

From Pixabay. your data to fit within them).

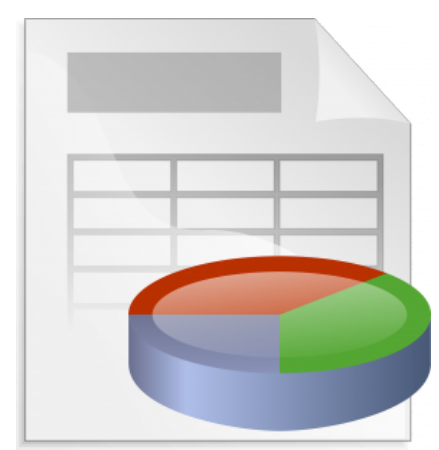

From Pixabay.

A statistic is not the same thing as an inarguable fact; data can be manipulated or presented in biased ways. It is therefore important not simply to present statistics and move on but instead carefully examine the works in which they appear. Where is Author E getting his data? Does he present it confidently or cautiously? Does he cite the statistics of others, or does he allow his statistics to stand alone? Always ask questions about the material you cite, and always be aware that this material is being presented by human beings, not machines. Like you, the authors on whom you are drawing are interpreting the material at hand, not simply announcing a series of facts. 


\section{"Factual" Material}

We are putting the word "factual" in quotation marks here because we need to be careful about what we treat as a fact in an analytical paper. Let's say you are reading Author F's expository paper on the origins of Occupy Wall Street. She is going to present a lot of factual material, including dates, names, and descriptions of events to which there were many witnesses. Yet Author F's paper will inevitably involve interpretation. Perhaps she goes into extreme detail about the movement but spares only a few sentences for the opposition to the movement. A casual reader might assume there was not much opposition instead of recognizing that Author F has simply left it out (which she may have done for any number of reasons).

Students sometimes ask why they must cite secondary sources containing factual material so well-known that it appears in hundreds of sources. One good reason is that while there are hundreds of sources that contain the information, all of them present it in subtly different ways. Our readers need to know which sources we are drawing on so they can evaluate our work in light of the quality of our sources. As well, we need to be able to decide, while reading a

source, what is fact and what is interpretation. It is thus a good idea to consult more than one source when we are looking for factual information.

It is also worth noting that citation demonstrates to the reader that we have not simply made up a piece of information. 


\section{Analysis}

Almost all of the types of sources mentioned above-corroborative, contrastive, contextualising, and containing definitions, data, statistics, or facts-will ultimately be analytical in nature. As we have discussed, no matter how you are using a source, you will need to take its interpretive elements into consideration. However, can a source be used primarily for its analysis?

Analytical material will certainly be useful to you, and you are encouraged to draw on it. Yet such material can cause problems when used in certain ways. The next section will go into more detail about how to incorporate other authors' analysis while still ensuring that your argument remains your own. 


\section{Engaging With Research}

Whether an analytical work is extremely specific or sweepingly broad, it will tend to constitute an interpretation of evidence leading to a conclusion: an argument. You are already familiar with this concept, as you have been working with it throughout the course. It is important to remember, as you work with sources, that their authors are writing arguments, not reporting inarguable fact. It is equally important to remember that these arguments belong to their authors. You may draw on them, but you must avoid adopting them in place of an argument of your own.

Research will help you explore various aspects of your thesis. What it will not do is provide you with an argument. When you draw on a source, you are doing so because it allows you some insight into your own unique argument; you are not adopting someone else's argument and "proving" it via your own data. Imagine Author G has come up with an argument about why social media is not an effective tool in protest movements. If we read this argument and decide that now our argument is also, "Social media is not an effective tool in protest movements," and we demonstrate it by presenting data that backs it up, all we are doing is adding to Author G's body of evidence and thus arguing his point for him.

Engaging with research requires us to analyze research material just as we do our primary document. Author $\mathrm{G}$ has put together an interesting argument, but he's used specific evidence and interpreted it in a specific way. Why has he chosen this approach? What assumptions lie behind his argument? Is that argument as simple as it seems on the surface? The close-reading skills you learned in the first half of this course are relevant here, as close reading your secondary sources will help you discover how they will be useful to you.
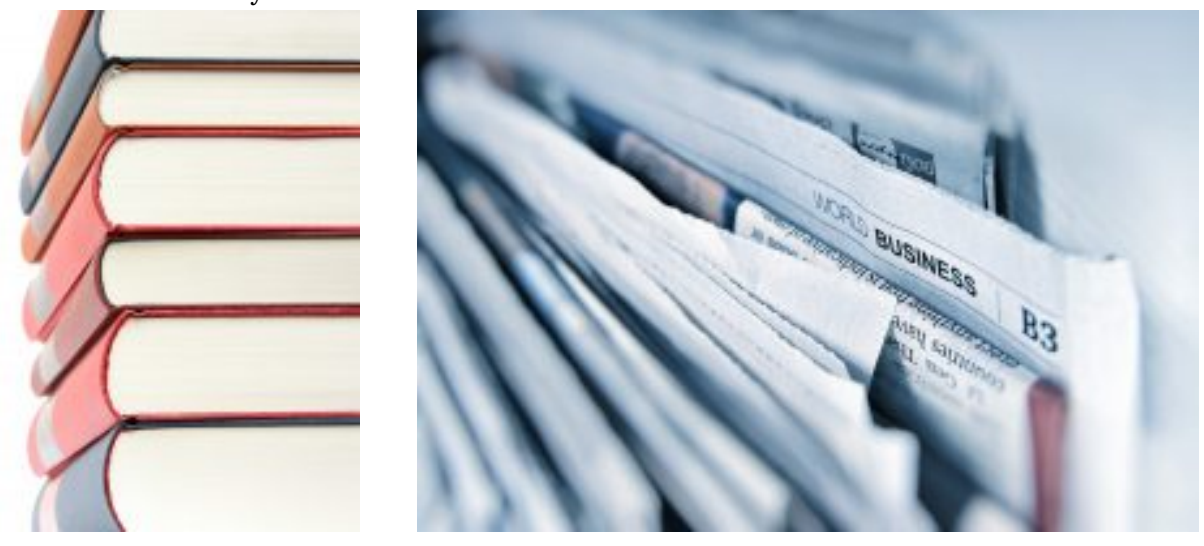

Once we do understand Author G's approach, we incorporate his work into our paper by treating it as what it is: an argument. If we quote or paraphrase Author G, we don't simply leave the cited material sitting in the middle of our paragraph and move on without comment. We use it. We comment on how one of Author G's ideas applies to our evidence. We remark on the discrepancies between his approach and ours. We can take one of his ideas further or in a different direction. We could disagree with one of his points, then explain how this disagreement strengthens our argument.

Secondary evidence is still evidence; its meaning and its significance to your argument remains unclear until you interpret it. 


\section{The Scholarly Concept}

One especially useful type of secondary source is a type that provides you with a scholarly concept. Let's spend a moment defining this term.

A scholarly concept is what you get when you take an author's idea or theoretical approach and apply it to your own primary material. Again, this is not the same thing as adopting someone else's argument and plugging your evidence into it. It is more like performing an experiment with the same tools used by another scientist, though in the process, you approach the tools themselves critically instead of taking them for granted.

An example may help clarify this definition:

Imagine Author H has written an article on the 2017 Women's March as a viral phenomenon. Using her knowledge of feminist theory in combination with her knowledge of the Internet as a communal space, she has examined the protest as both a physical and a virtual phenomenon, then unpacked the significance of her observations. Her article is not taking the same approach as yours, and the broad issues it examines are a bit different, but the combination of feminist theory and the exploration of the Internet as a community has provided us, potentially, with a scholarly concept: a theoretical approach we can extract from Author H's article and apply to our paper. We ask ourselves the question: "If I take this idea that Author $\mathrm{H}$ has had and look at my evidence in light of it, what will happen?" The results will probably not mimic Author H's exactly, and we don't want them to do so. We are using the scholarly concept to cast a certain type of light on our subject matter; we are not writing Author H's paper for her or allowing her to write ours.

Author H's paper is still an argument, and we are still going to interpret it as we go. We are not going to take it at face value; in fact, even as we are adopting Author H's scholarly concept, we may find that we disagree with some or all of her argument. Again, we are using Author H's material, not simply reproducing it.

The idea of the scholarly concept will come up again in later chapters. For now, practice thinking of research not as a source of facts or arguments you can borrow but as a source of ideas you can apply. 


\section{Questions to Ask}

When you are exploring the ways in which research might fit into your work, it is often useful to ask yourself a series of pointed questions. These questions will prompt you to think of research as more than something that needs to be plugged in at the last minute; they will encourage you to think in terms of the research improving your argument and making it more complex.

You can come up with your own list of questions, but here are some that may help you on your way:

1. What concepts am I discussing that may need to be defined? What might be some good (complex, specific) sources in which to find these definitions?

2. What aspects of my thesis might be strengthened via the use of data and statistics?

3. What aspects of my thesis might be strengthened via a focus on historical or factual information about the broader categories into which my primary example fits?

4. What aspects of my thesis might benefit from the introduction of alternative perspectives (arguments that seem to contradict mine, arguments regarding related but distinct subject matter, etc.)?

5. Where in my thesis would use of a scholarly concept be beneficial? 


\section{Application}

In terms of the three-storey thesis and outline we've been working with in this chapter, we can try answering these questions. The answers will give us at least a broad idea of the kinds of sources we might consider looking for when we research this paper. We can refine our answers as we progress through the writing of the paper. Just for instance, at the beginning of the research and development process, the terms that need to be defined will probably be fairly general ones. Later, as we become more knowledgeable about our subject matter, more specific terms can come into play.

1. What concepts am I discussing that may need to be defined? What might be some good (complex, specific) sources in which to find these definitions?

So far, terms of interest to us might be: "social media," "protest movement," "community," "insularity." Note that all these terms have dictionary definitions. We are, however, interested in using the terms more specifically. To define them in more detail, we can look for scholarly articles on related subjects: community and the Internet, the social aspects of social media, protest as a social force, community as inwardly focused. As we search, we may find better, more specific terms to replace or refine these general ones.

2. What aspects of my thesis might be strengthened via the use of data and statistics?

We are examining the content of the comments section, but we're also paying some attention to how it is structured, how many comments derive from each sub-community, etc. Perhaps finding comparable studies of other protest movements and/or other forms of social media will help us. We could also search for articles on social media that do not relate to protest or political change. A comparison between the behaviour of social activists online and, say, the behaviour of fans of the television series Game of Thrones might prove instructive. What would it mean if we found similar patterns? What would it mean if the patterns we found differed radically? Wider statistical studies can also be helpful, as they allow you to contextualize your own small study, examining how (and if) if fits into the wider pattern. Therefore, look for articles that takes statistics-based approaches both to comparable studies on specific documents and wider studies on larger patterns.

3. What aspects of my thesis might be strengthened via a focus on historical or factual information about the broader categories into which my primary example fits?

We are studying one Facebook post on the Occupy Wall St. Page. The post itself gives us a body of evidence with which to work, but it doesn't tell us much about Occupy Wall St. as a movement. We might do some reading on the movement. Examining the Occupy Wall St. web presence will help, but so will finding scholarly articles on the movement's development. While we may not use all the information we uncover, it will provide us with some context for our discussion.

We don't, however, need to stop there. We could read up on the Internet and protest movements, the way Facebook (as opposed to other forms of social media) tends to be used by protest movements (or, in comparison, by other groups), or the different ways in which official groups (such as governments) and counter-cultural groups (such as protest-based organizations) use social media. Again, we won't use all this information, and we'll have to resist the urge to repeat it rather than apply it, but understanding of context can be a great help in this kind of research paper.

4. What aspects of my thesis might benefit from the introduction of alternative perspectives (arguments that seem to contradict mine, arguments regarding related but distinct subject matter, etc.)?

Is it possible to see the insularity we have found in this comments section as less of a weakness than we think it is? We might search specifically for sources that treat community insularity as a strength. Perhaps we'll eventually refute these sources, or perhaps we'll be able to incorporate their perspectives into our thesis, producing something more complex and subtle than "insularity is here, and it's a problem."

5. Where in my thesis would use of a scholarly concept be beneficial?

We need to look for aspects of our approach that currently seem vague or lacking in focus. What elements of our 
thesis would benefit from the application of a specific theoretical concept? In this case, we might consider looking for articles on communities and how they work. The study of communities and communication between and within communities is a major scholarly area. Because our paper-when we drill down to its essence-is really about communities and communication, a specific article dealing with this subject may offer us a theoretical perspective that will allow us to apply relevant concepts to our body of evidence and see what happens. 


\section{Try This!}

\section{Activity}

Go through the questions again, but this time, apply them to your own thesis. What kinds of sources do you think you might look for? What keywords are beginning to seem important to you? Can you think of any potential scholarly approaches that might be useful to you? 


\section{Watch This!}

Now watch Video 9.3: Considering research's Place in the Essay in which we move step by step through these questions in relation to our paper on the Occupy Wall St. Facebook page.

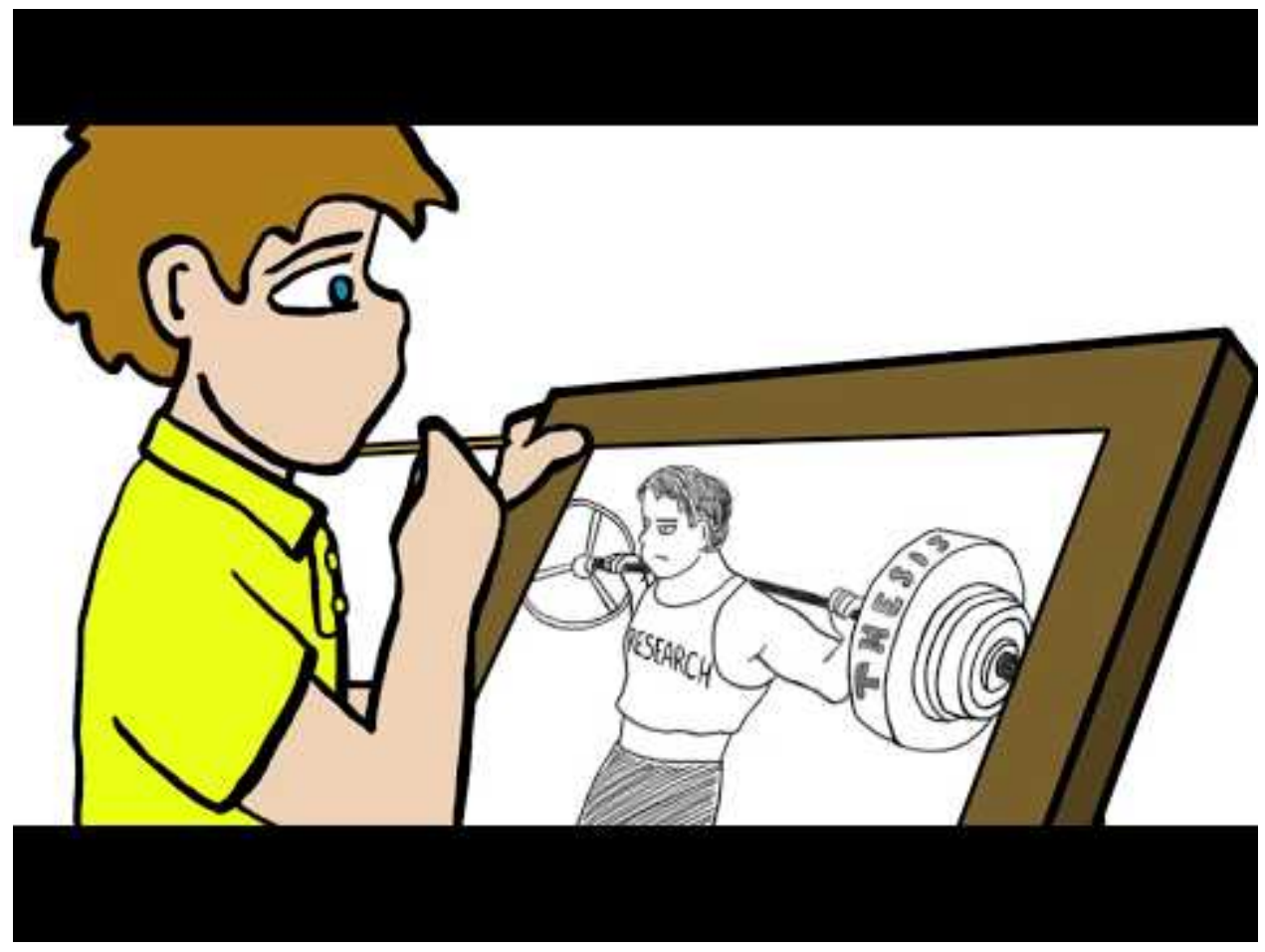

A YouTube element has been excluded from this version of the text. You can view it online here: https://pressbooks.library.ryerson.ca/writehere/?p=1061 


\section{Looking Ahead...}

In this chapter, we have taken Chapter 7's two-storey thesis and added a third storey, which we have used to create a working outline for our essay. In addition, we have started to to consider how we might incorporate research into our paper. Notice that we have not yet modified our thesis or our outline in view of our research; the placeholders remain. However, we can see how the modifications could eventually happen. In Chapter 10, we will be examining in more detail how research can be incorporated into the thesis and the essay's body. 


\section{CHAPTER IO: JOINING THE CONVERSATION: PRIMARY SOURCES, SECONDARY SOURCES, AND YOU}





\section{Chapter Overview}

\section{Learning Outcomes}

\section{In this chapter we will:}

- $\quad$ Identify some of the common errors made when citing sources and discuss ways to avoid them.

- $\quad$ Discuss and demonstrate how best to use primary and secondary sources to support our claims.

- Work toward developing an essay that uses a specific example to further a larger scholarly discourse.

- $\quad$ Review the thesis and outline we created in Chapter 9 and decide which primary and secondary evidence we will be citing and when. 


\section{Standing on the Shoulders of Giants: Using Your Essay to Look Forward}

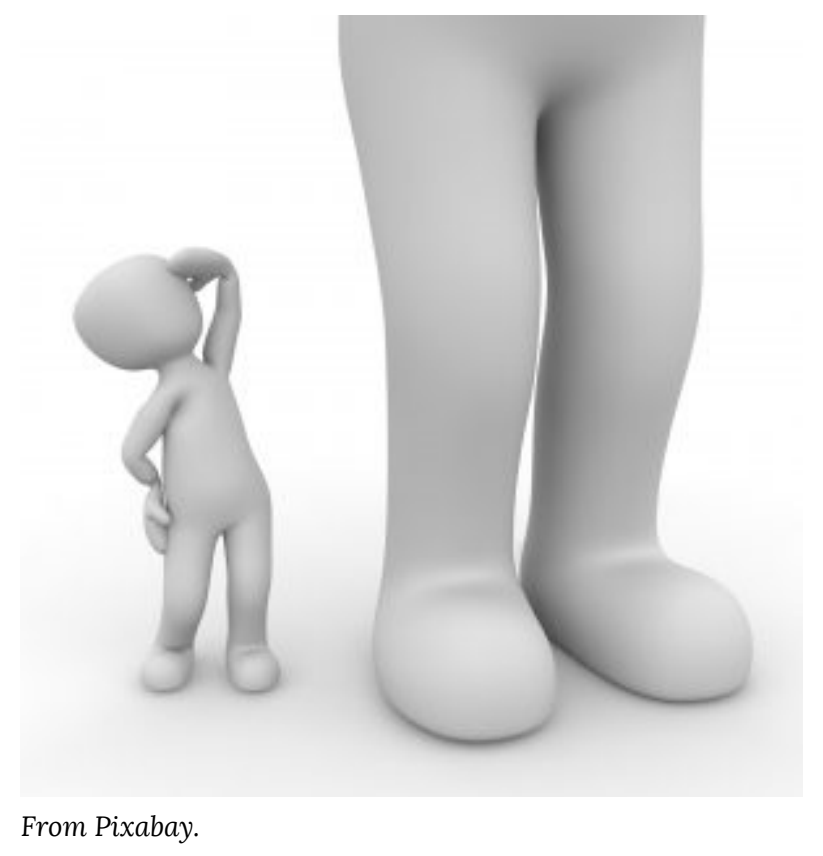

Reflecting on his own considerable and influential body of work, Isaac Newton wrote, "If I have seen further it is by standing on the shoulders of giants." When we reflect upon Newton's output in the fields of mathematics, astronomy, and physics, it rather quickly becomes apparent that Newton was himself a giant whose broad shoulders are forever crowded by thousands gazing into a distance he has made visible. As Newton's own self-assessment reveals, he became a giant not through some solitary moment of inspiration, but through joining and furthering the ongoing conversation.

Discourse-the respectful reception of other ideas and the reflective response to them-is the lifeblood of all scholarly disciplines, all universities and colleges, and all university and college courses-such as the ones in which you are currently enrolled. Your research essay, like all research essays, is a vital contribution to this discourse. Universities and colleges exist primarily as a space to foster the ideas that the works of others inspire in you, the responses to these works that you develop, and the dialogues between you and others as you consider complementary and contradictory responses.

One of the goals of this text is to prepare you to enter this conversation and make sure your contributions are taken seriously at this level. One of the key components of a meaningful essay at this level is the proper balance of your ideas, the examination of primary evidence, and the elevation of your investigation through the proper use of scholarly sources. You are using secondary sources to elevate and complicate your reading of your primary evidence, not replace it. Use secondary sources to support your claim. Your interpretive claim is always driving your analysis. Your interpretive claim determines how secondary sources are applied to your primary evidence and what inferences you derive from that application.

In creating your research paper you are performing two essential tasks: 
1. Selecting a primary source for closer examination

2. Selecting a particular scholarly discourse to which you would like to contribute meaningfully

You make these selections because discussion of both in the light of each other will result in an elevated understanding of the primary source and a useful extension of the scholarly discourse. You cannot join an ongoing discourse by waving vaguely and making generalizations. You can join an ongoing discourse by examining a specific example in detail and in the light of how it extends and further complicates the scholarly conversation. This is the hope we have when we select and analyze the example we have been working on in Chapters 7 and 9. 


\section{Finding Our Scholarly Conversation Partners: Primary and Secondary Sources}

Let's have a look at the three-storey thesis we developed in Chapter 9 so that we can identify the larger discussion we are having:

\section{Example}

Occupy Wall Street's Facebook group page showcases some flaws as users of the space have a difficult time breaking away from their own "villages" in order to link those global events to their local concerns. This is demonstrated by the comment field under the post "From \#Ferguson to \#Gaza \#BLM," wherein discussion of the event turns to users calling each other names like "idiots" and wondering aloud about the two topics are related (ex. The post "What the hell does BLM have to do with geopolitics in the Middle East?") rather than discussing the event promoted. Such interaction in this space demonstrates that while Facebook groups do provide a useful tool for distributing information and bringing large tribes together, that users often struggle to attach that awareness to action or viewpoints beyond local/personal concerns or interests; instead of users speaking to each other in an attempt to foster stronger global connections and consciousness, users often end up posting their own disconnected content and/or insulting content without the necessary conversation around the complex topics posted The Occupy Wall Street Facebook page's tendency to strengthen local connections while weakening links to larger social and political contexts acts as an indicator that despite the increased reach of an online community, insularity among its users is likely to affect its ability to influence governmental policy and provide a base for civilian power. Users who wish to turn the Internet into an effective tool designed to provide a counterpoint to corrupt, dictatorial, or simply misguided governments will need to address this insularity and attempt to ensure that the broad reach of the social-media platform does not replace the broadness in scope of the movement itself.

We have done well here to narrow our focus to a manageable primary example. "Facebook" would be much too wide a focus, and even "Occupy Wall Street's Facebook page" could get a little unwieldy. The primary source we are selecting for closer examination is a specific post on Occupy Wall Street's Facebook page-"From \#Ferguson to \#Gaza \#BLM"-and the subsequent dialogue it sparked.

Now we need to review the evidence we gleaned from this primary example and decide which pieces we think would best benefit our analysis. In particular, we want to use those examples that really inspire and support the claim of our second storey: "Such interaction in this space demonstrates that while Facebook groups do provide a useful tool for distributing information and bringing large tribes together, users often struggle to attach that awareness to action or viewpoints beyond local/personal concerns or interests; instead of users speaking to each other in an attempt to foster stronger global connections and consciousness, users often end up posting their own disconnected content without the necessary conversation around the complex topics posted." 


\section{Watch This!}

Let's watch Video 10.1 in which we review the source material and the information we have gathered, then rank and organize what material best supports our analysis and which material challenges and complicates it.

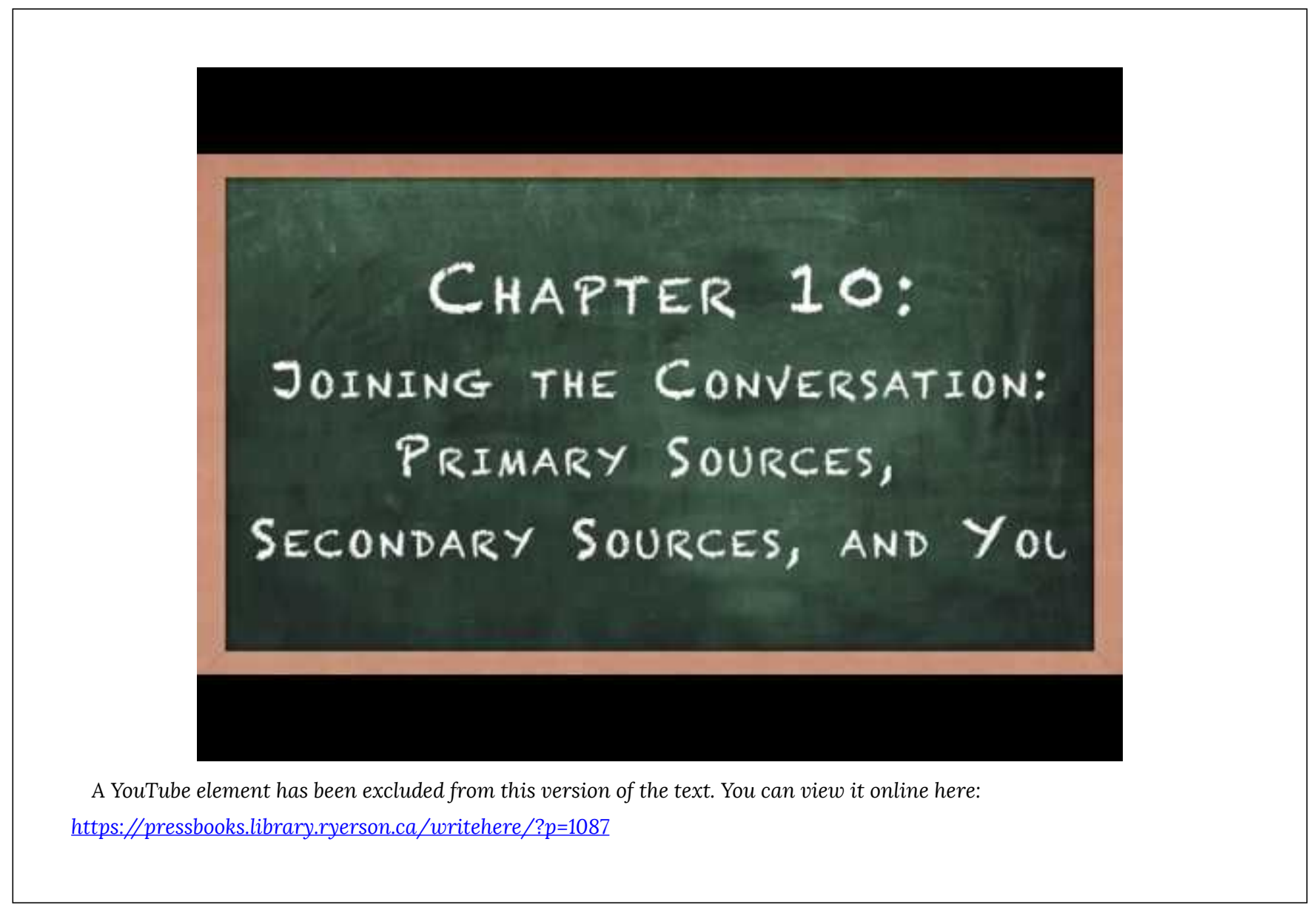




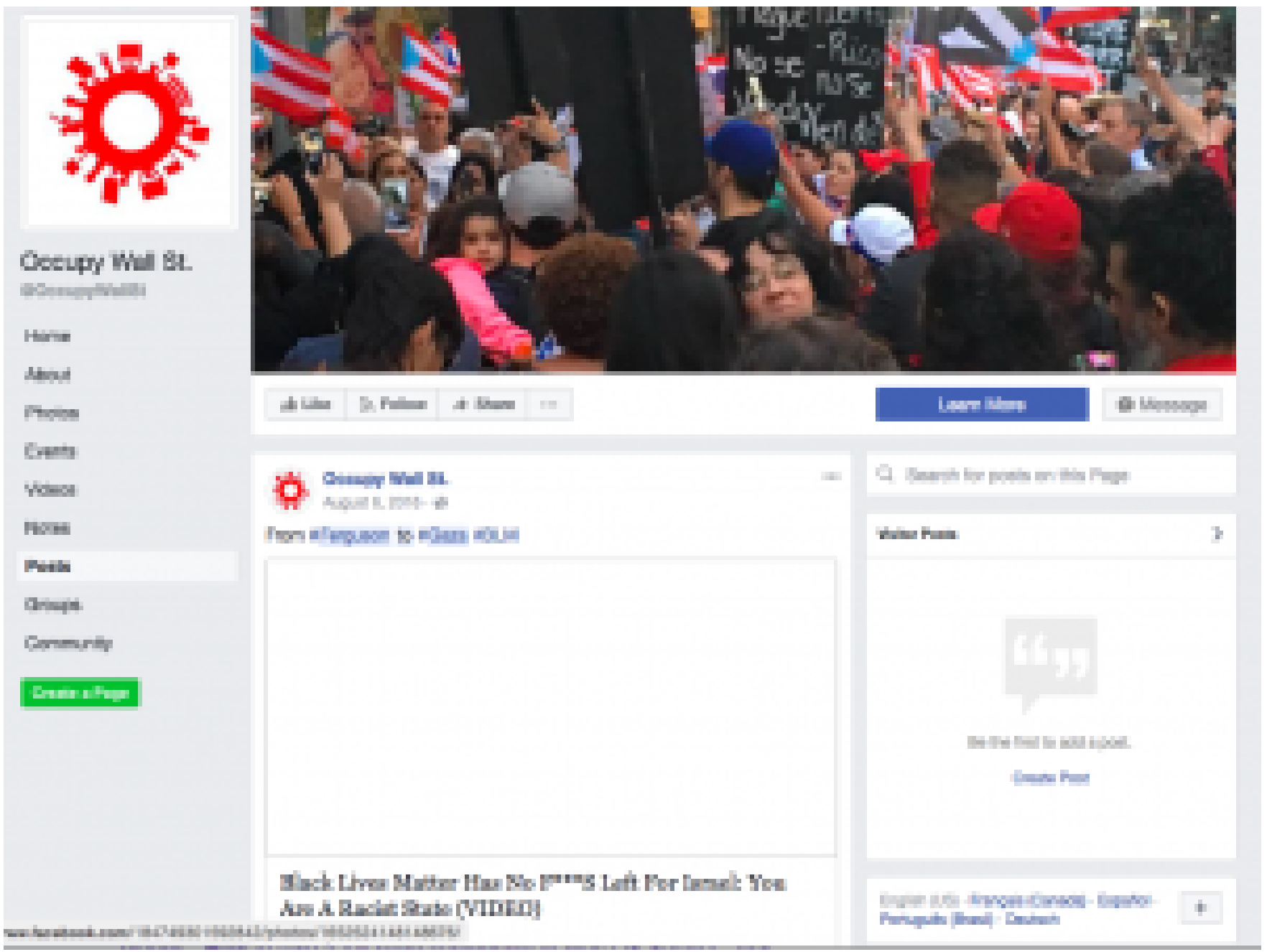




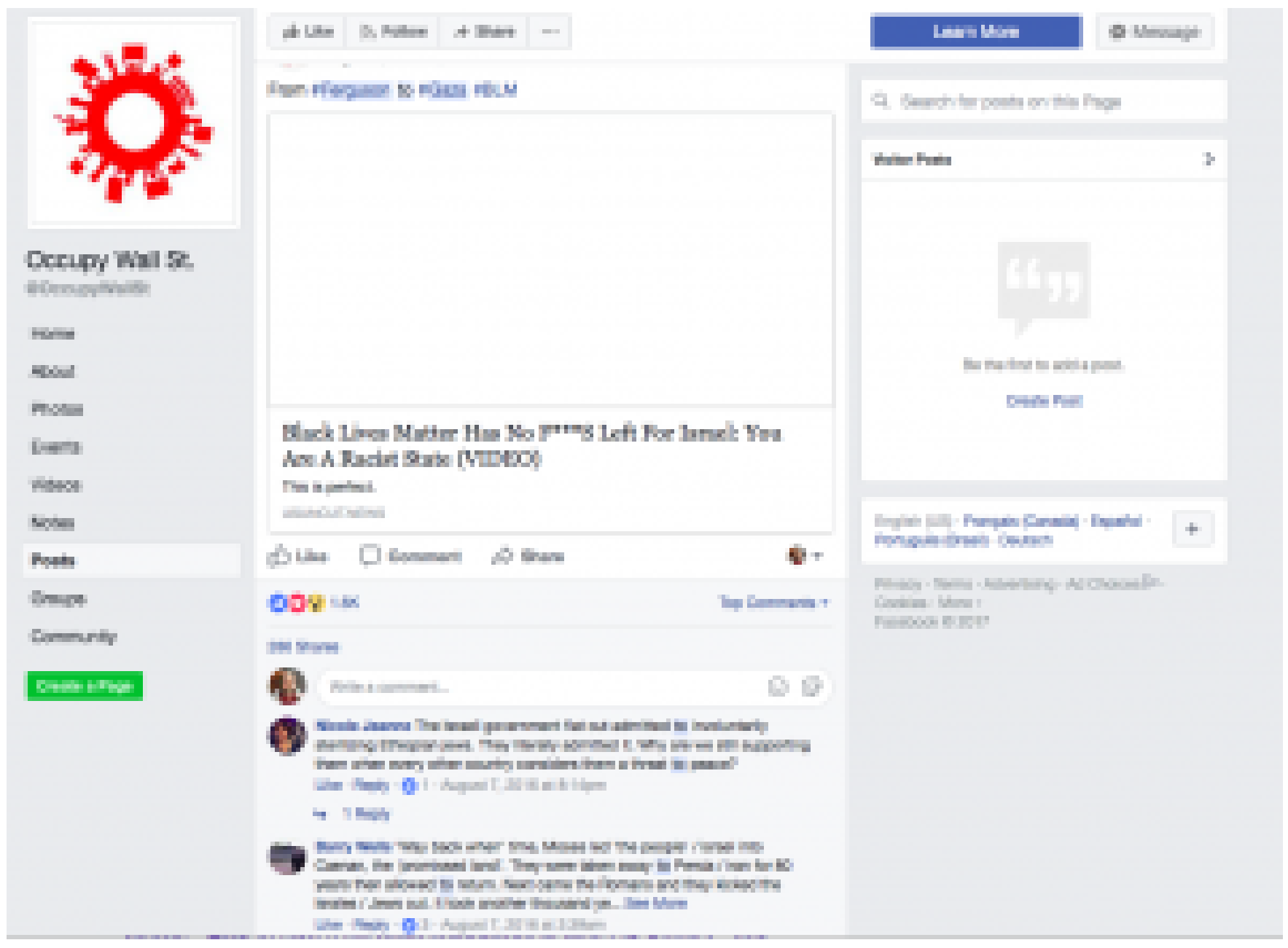




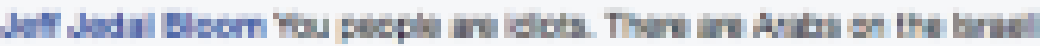

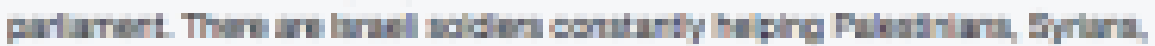

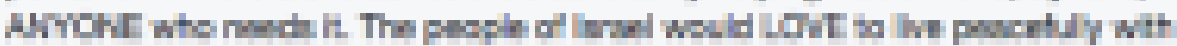

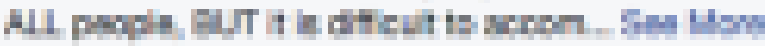

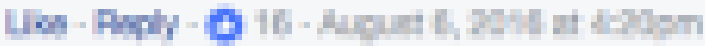

4 Mlebis

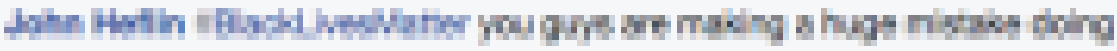

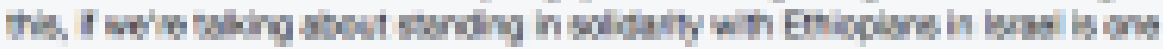

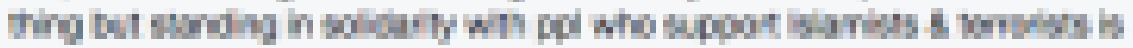
robut

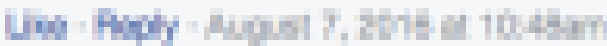

4 1Aas.

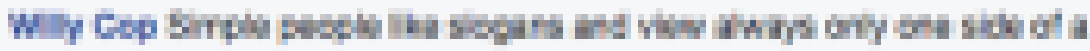

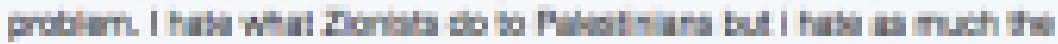

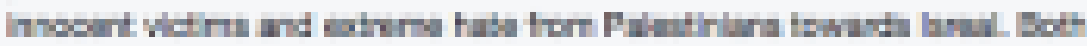

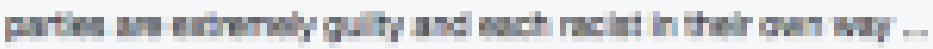

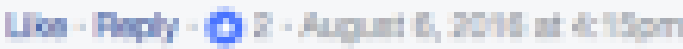

+ Heris

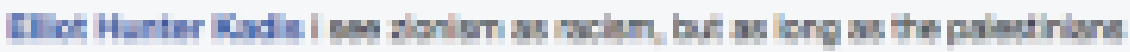

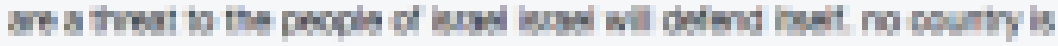

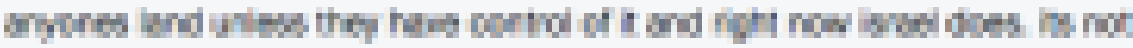

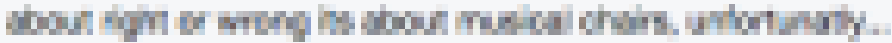

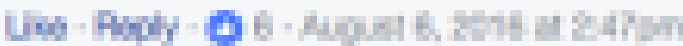

4 it Pestin

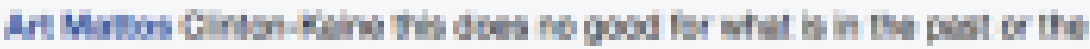

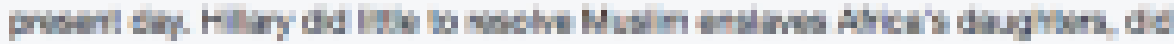

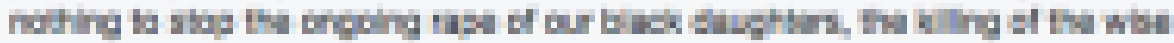

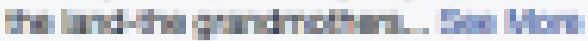

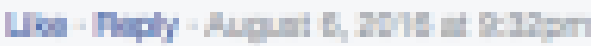

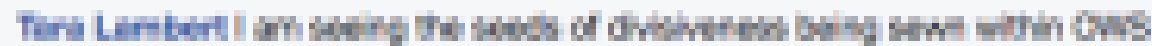

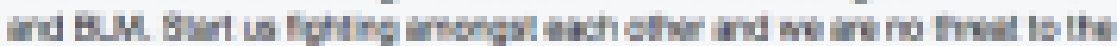

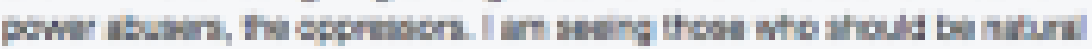

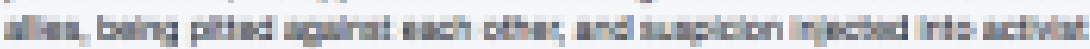

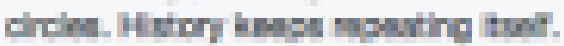

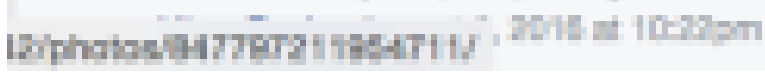




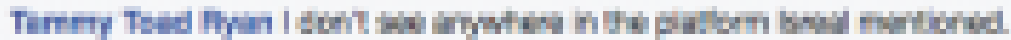

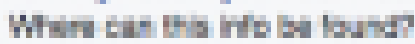

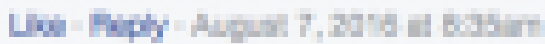

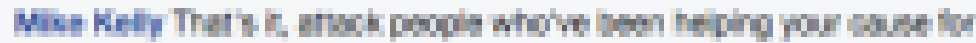
Mrinithy

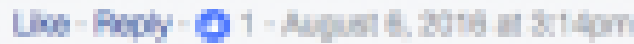

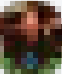

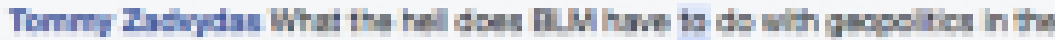
Mittin Funt

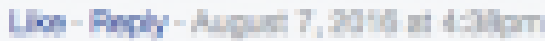

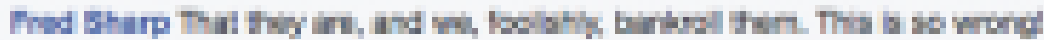

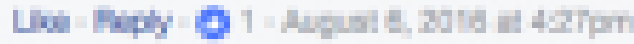

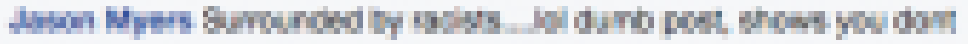

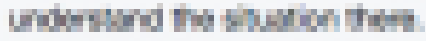

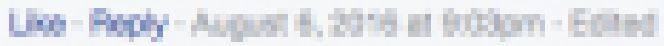

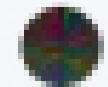

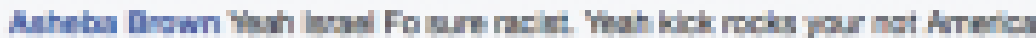

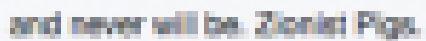

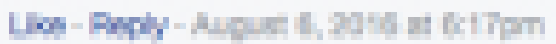

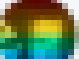

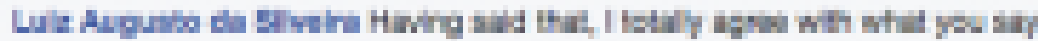

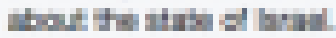

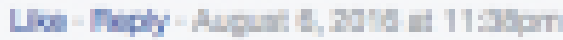

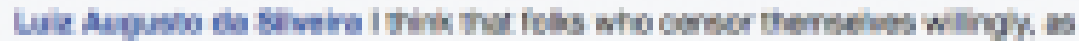

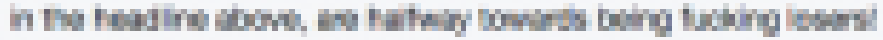

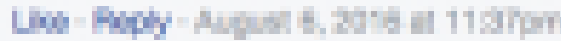

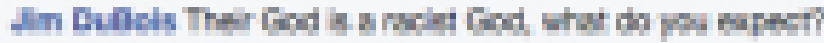

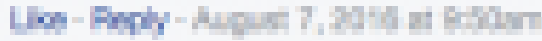

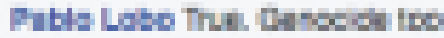

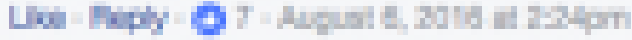

4 inting

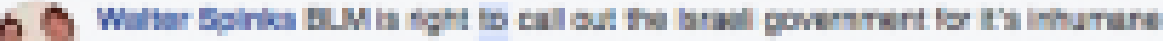

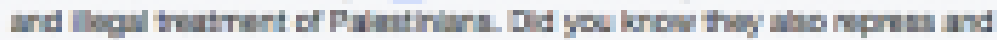

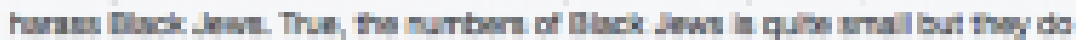

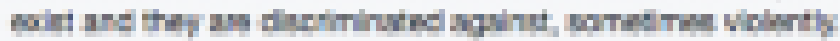

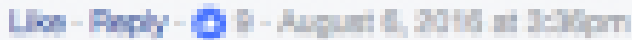

+ JHests 


\section{Scholarly Articles}

It is now essential that we find the scholarly articles needed to elevate our analysis of our primary evidence. As a reminder of how to do this, let's return to the hypothetical research question from Chapter 8 and review how we broke it down into searchable keywords and Boolean Concepts:

\section{Example}

Comics and graphic novels are important tools for teaching secondary school students Shakespearean drama. Their use of visual narratives bring enhanced meaning to the late-sixteenth- and early seventeenth-century English language and improve both reading comprehension and memory retention.

Concept 1: comics OR graphic novels OR manga

Concept 2: teaching OR study OR learning

Concept 3: secondary school OR high school

Concept 4: Shakespeare

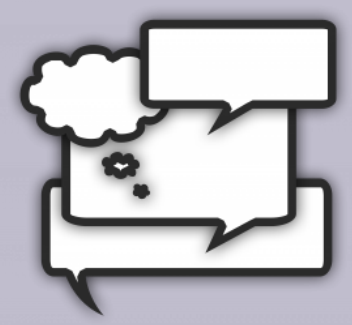

From Pixabay.

Concept 5: drama OR plays OR theatre OR theater

Concept 6: reading comprehension

Concept 7: memory retention

In this case, there are probably too many concepts broken out. You may want to reorganize your list and prioritize three or four concepts to search at the start. If you search for too many concepts, you may get no results. 


\section{Scholarly Articles}

Our current thesis is far larger and more complex than the previous example, so, for the purposes of clarity and manageability, let's first break each storey down individually:

\section{Example}

FIRST STOREY: Occupy Wall Street's Facebook group page showcases some flaws as users of the space have a difficult time breaking away from their own "villages" in order to link those global events to their local concerns. This is demonstrated by the comment field under the post "From \#Ferguson to \#Gaza \#BLM," wherein discussion of the event turns to users calling each other names like "idiots" and wondering aloud about the two topics are related (ex. The post "What the hell does BLM have to do with geopolitics in the Middle East?") rather than discussing the event promoted.

\section{Concept 1: Occupy Wall Street AND Facebook}

Concept 2: Facebook AND villages

Concept 3: Facebook AND local problems

Concept 4: Online Activism OR Social Movements

Concept 5: Online Activism AND Miscommunication

\section{Example}

SECOND STOREY: Such interaction in this space demonstrates that while Facebook groups do provide a useful tool for distributing information and bringing large tribes together, users often struggle to attach that awareness to action or viewpoints beyond local/personal concerns or interests; instead of users speaking to each other in an attempt to foster stronger global connections and consciousness, users often end up posting their own disconnected content without the necessary conversation around the complex topics posted.

\section{Concept 1: Facebook groups AND global connections}

Concept 2: Social Media AND Social Movements AND Debate

Concept 3: Social Media AND local AND global

Concept 4: Social Media AND Protest AND Organization 


\section{Example}

THIRD STOREY: The Occupy Wall Street Facebook page's tendency to strengthen local connections while weakening links to larger social and political contexts acts as an indicator that despite the increased reach of an online community, insularity among its users is likely to affect its ability to influence governmental policy and provide a base for civilian power. Users who wish to turn the Internet into an effective tool designed to provide a counterpoint to corrupt, dictatorial, or simply misguided governments will need to address this insularity and attempt to ensure that the broad reach of the social-media platform does not replace the broadness in scope of the movement itself.

Concept 1: Facebook OR Social Media AND Civilian Power

Concept 2: Facebook OR Social Media AND Protest

Concept 3: Occupy Wall Street AND Fail*

Concept 4: Social Media AND insularity AND online community

Concept 5: Social Media AND Social Activism AND 


\section{Scholarly Articles}

You'll notice that our concepts range from the specific to the vague. Such search terms may seem contradictory to all the advice we have been giving so far about focus and specificity. What is important to understand when looking for scholarly sources that support our primary example is that this search often goes in the opposite direction from focus and specificity. It is highly unlikely that we are going to find a scholarly source on the Occupy Wall Street Facebook post "\#ferguson2palestine: October 21 @ 7PM - JOIN US!" and such an article is not what we are looking for anyway, so it would not help us to plug the words from that post into a search engine when searching for scholarly articles. You will notice we use the asterisk truncation feature in our search "Occupy Wall Street AND Fail*." This will widen the net to find variations of fail like failing, failings, failure, and failures.

We are looking for sources that represent the larger discussion we are entering. We are looking to ways to join that larger discussion using our primary example. We are looking for articles that question whether social media is a facilitator of online communities or an incubator for insularity. So we will type these broader terms into various search engines with the goal of finding articles that deal with similar subjects-articles we can use to elevate the examination of our example. We will then use the specifics of the smaller social world of our chosen post to challenge the scholarly discussion we have discovered.

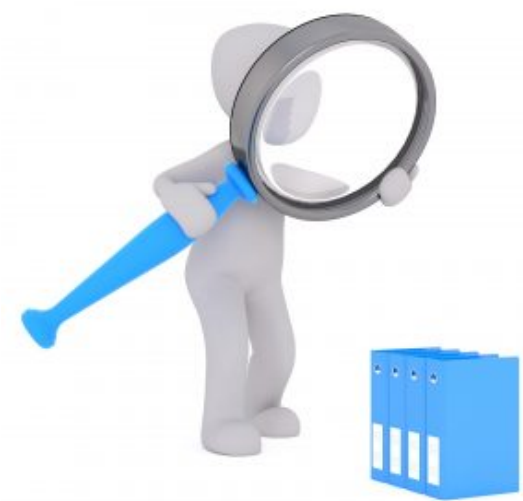

From Pixabay. 


\section{Watch This!}

Let's watch Video 10.2 and see what happens when we plug some of these concepts into different Boolean search engines.

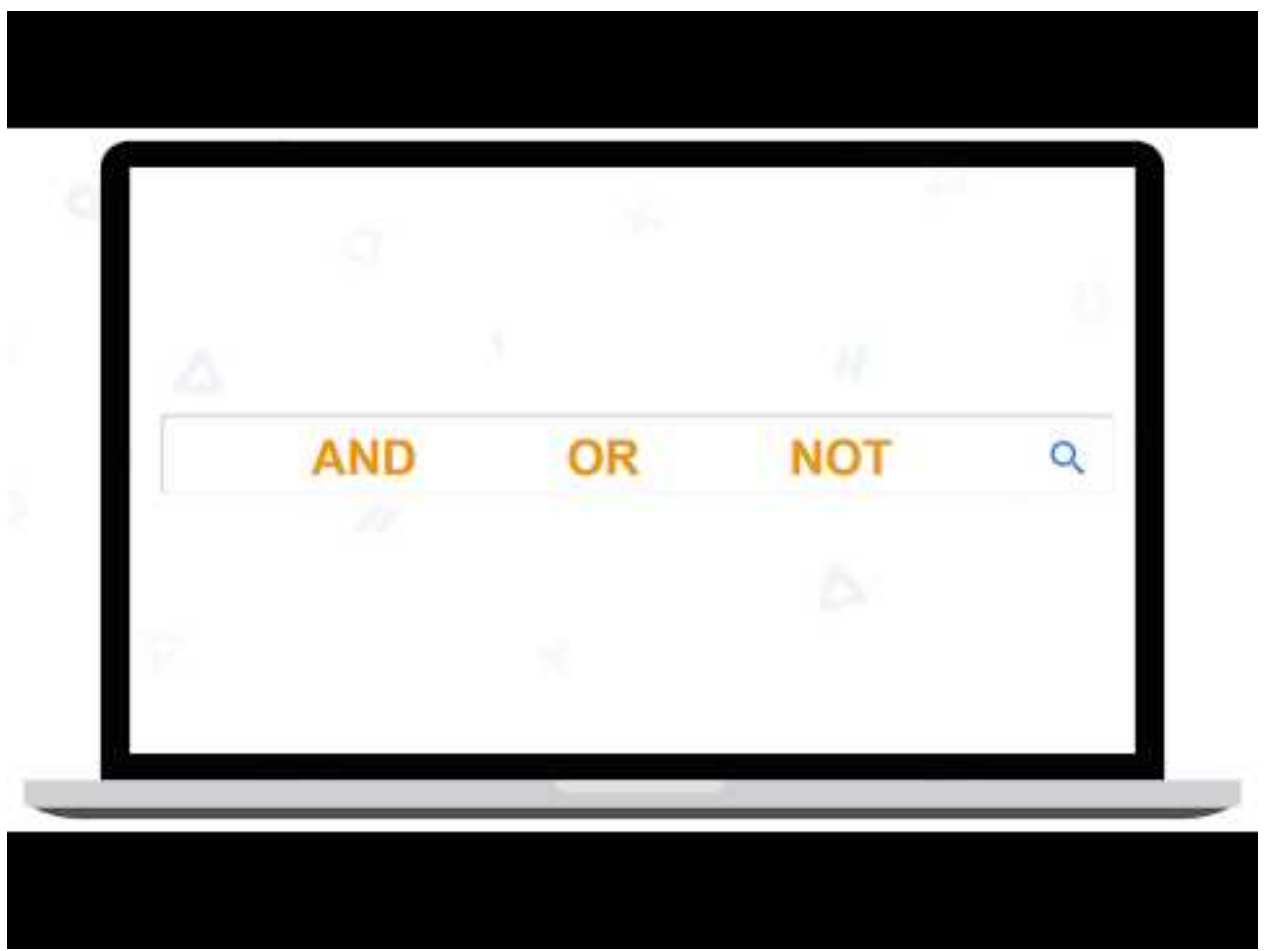

A YouTube element has been excluded from this version of the text. You can view it online here:

https://pressbooks.library.ryerson.ca/writehere/?p=1096

Article: "Productive Provocations: Vitriolic Media, Spaces of Protest and Agonistic Outrage in the 2011 England Riots"

Authors: Anthony McCosker (Swinburne University, Faculty of Life and Social Sciences) and Amelia Johns (Deakin University, Centre for Citizenship and Globalisation)

Abstract: The intense social upheaval that spread through a number of UK cities in the riots and protests of August, 2011, signalled the terrifying speed with which passionate disaffection can turn to uncontained violence. At stake in the dense and volatile debate that ensued, and in the acts of violence themselves, were contests over spaces as well as competing models of democracy, publics and citizenship, including the appropriate use of social media. Within these debates, almost universally, rational deliberative discourse and action is assumed to be the only route to legitimate "civil" society. So what is to be made of the violent physical contest over city squares, streets and property, as well as contests over acts of participation and 
demonstration played out online through the hundreds of eyewitness videos posted to sites like YouTube and the endless flow of often vitriolic words in blogs, comments spaces and social network sites? This paper uses a video posted to YouTube titled 'Clapham Junction Speaker (London Riots 2011)' to examine the passion and provocation that flowed beyond the city streets to enliven, intensify and sustain forms of protest and civic engagement. We argue that the aggressive and antagonistic tenor of the Speaker's twenty minute monologue, the bitter vitriol that flowed through the comments space, and even the act of posting it constitute significant elements of a generative, 'agonistic' public, to use Chantal Mouffe's term, that operates in multiple spaces and outside of the rationalising discourse demanded by mainstream media and government. This paper develops a richer understanding of these spaces of protest, and the concept of provocation central to these events.

You will notice that the article we have chosen does not focus on the exact subject of our representative example. This is fine. Applying the research and ideas of scholars to examine another topic is a long-standing scholarly practice. There are countless postcolonial or feminist or Freudian readings of Shakespeare's plays that use the claims and findings of academics to create new readings of different subjects. Just because you are standing on the shoulders of giants does not mean you have to look in the same direction. Creating new applications with the articles you find is a major part of joining the scholarly conversation. 


\section{Joining the Scholarly Conversation: Using Your Primary and Secondary Evidence}

So, we have our primary material and we have one scholarly secondary source. Of course, your essay will use several sources, but for the purposes of brevity, we'll use just this source in the examples to follow. First, here are a couple of problematic uses of primary and secondary sources.

We find that one of the best approaches for students preparing to write a research essay using primary and secondary evidence is to imagine taking part in a conversation-perhaps an introduction of two people you know very well but who do not know each other. In this conversation, you will have to take a leading role, but you are hoping that the people you are introducing will hit it off and begin conversing with each other as well. Two mistakes students make when facilitating this scholarly conversation are:

1. Dominating the conversation to the point that neither the primary or secondary sources contribute meaningfully.

2. Being a passive conduit and contributing very little in the hope that both sources will somehow carry the conversation all by themselves.
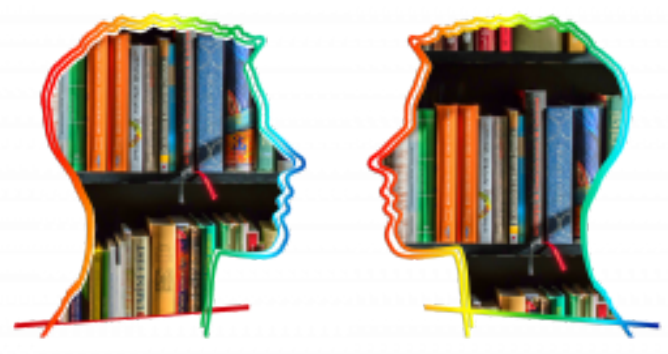

From Pixabay. 


\section{Dominating the Conversation}

Let's look at some examples of these mistakes and then examine ways to remedy them.

The first mistake involves acting like a domineering, interrupting, and inattentive conversation partner-the sort of person who finishes other people's sentences, most often in ways the interrupted person did not intend. This sort of mistake most often manifests itself in essays in which the student paraphrases the sources, making them say things they are not really saying for the sake of proving their own argument, or using minimal, even one-word citations and plugging them into their own argument out of context. In this way, the writer ignores what either source is saying because the primary concern is making the conversation arrive at the desired conclusion no matter what the cost. Here is an example of this sort of "bullying" of sources using our primary evidence and our secondary article:

\section{Example}

As McCosker and Johns confirm in "Productive Provocations: Vitriolic Media, Spaces of Protest and Agonistic Outrage in the 2011 England Riots," "aggressive, antagonistic behaviour" like the "unchecked flow of racial bigotry" and the "vitriolic expression and aggressive interaction" found in the comments section of the Occupy Wall Street Homepage demonstrate how such pages "simply give voice to and perpetuate forms of bigotry and incite hatred and further violence." As commenters call each other "idiots" and "terrorists" and "Zionist pigs," they demonstrate how "volatile debates erupting online" serve as "modes of incitement" for real world violence. When one commenter accuses another of having a "racist God," or when one calls another's religion a "fake story," they demonstrate the "angry, adversarial and provocative speech" that fosters only divisiveness and violence. The original message and intent of the Occupy Wall Street movement is lost in the "angry tenor of speech" dominating the comments section as people reply to each other's comments with "simple people like simple slogans" or "lol dumb post."

Here we see the author using McCosker and Johns's article as if it is about the Occupy Wall Street page, which it is not, and as if it agrees with the author's assessment of the primary evidence. This secondary source is misused to support what the author wants it to say about the subject. Also, the citations are short snippets used without context. Exactly what are McCosker and Johns referring to when they describe "aggressive antagonistic behaviour?" Exactly what are they referring to when they discuss "angry, adversarial and provocative speech?" And what is the context of each of the harsh phrases the author has lifted from the comments page? If you review McCosker and Johns's article, you'll see there are several times here where the author has clipped a citation to make it serve the desired argument. McCosker and Johns' point is a little more qualified when describing the "volatile debates erupting online." They write of the "dense and volatile debates erupting online," implying a more nuanced reading of online discussions than simply pointing at their potential for danger. The author needs to decide how to read the primary evidence then determine if McCosker and Johns' argument as it exists in their essay can support that reading. 


\section{Passive Conduit}

The second mistake occurs when the writer hopes that the sources will somehow speak to themselves and arrive at a meaningful conclusion without much help. In these sorts of conversations, the student has become a non-contributor, sitting passively as the sources speak at each other rather than speaking to each other in light of the conversation the student is trying to facilitate. This sort of non-conversation occurs in papers in which the student quotes large passages from one or several sources with minimal purpose or interaction. It is as if the student has said, "Source A, meet Source B," then departed quickly rather than get in the way of the magic that will hopefully happen as these two sources make a meaningful connection. Using once again our primary evidence and our secondary article, here's what happens when the student hopes the sources will speak to and for themselves:

\section{Example}

As McCosker and Johns claim in "Productive Provocations: Vitriolic Media, Spaces of Protest and Agonistic Outrage in the 2011 England Riots," it is the "lack of consensus, the evident irrationality and passionate individualism, as well as the intensity of emotion revolving around the continuous generation of provocation and (re)action that reveals the positive capacity of unmoderated comment spaces. That is, while not always dialogic in the strict sense of an ongoing conversation or consensus, the comment field as described here enables the emergence of 'a 'life politics' able to reach the various areas of personal life, creating a 'democracy of emotions' (Mouffe, 2005: 15)." This can be seen in the comments on the Occupy Wall Street Facebook page, when after a series of vitriolic comments and insults, contributor Tara Lambert is able to say, "I am seeing the seeds of divisiveness being sewn within OWS and BLM. Start us fighting amongst each other and we are no threat to the power abusers, the oppressors. I am seeing those who should be natural allies, being pitted against each other and suspicion injected into activist circles. History keeps repeating itself."

To borrow Tara Lambert's metaphor, I think we can see the "seeds" of the argument the author of this paragraph is trying to make, but the author relies far too much on large citations from the primary and scholarly sources. Neither source is being put to use and the author's intention is not clear. This author needs to inject purpose into this paragraph and use the evidence to support the claim. 


\section{Purposeful Conversation}

Now that we have looked at the mistakes made most often when trying to create this sort of conversation, let's use the same information and develop a more useful, more purposeful conversation. Remember to let these sources speak, but also remember that the purpose of this conversation is all yours. Secondary sources allow you to gain a richer, more informed, and complex vantage point on your primary material. However, you must avoid relying on secondary sources to act as your "answers." You are using secondary sources to elevate and complicate your reading of your primary material, not replace it. Use secondary sources to support your claim. Your interpretive claim is always driving your analysis. Your interpretive claim determines how secondary sources are applied to your representative example and what inferences you derive from that application. Here's an example of how we elevate our analysis of our primary evidence so that it becomes part of a larger scholarly discourse:

\section{Example}

While it is discouraging to read the comments section of the Occupy Wall Street Facebook page and see commenters calling each other "idiots," "losers," and even "Zionist Pigs," it may be beneficial to regard these debates and dialogues in the same light as McCosker and Johns regard similar online discourse in "Productive Provocations: Vitriolic Media, Spaces of Protest and Agonistic Outrage in the 2011 England Riots." McCosker and Johns claim "[t]he kinds of provocative, often vitriolic and antagonistic but massively multiple expression acts throughout the comment fields... enact agonistic forms of contest as an alternative model of citizenship, acts that incorporate forms of passion and conflict but are no less productive for it." While there are several instances on the Occupy Wall Street Page of people responding to posts with less-than-civil comments like "Grow up" or "lol dumb post"-as McCosker and Johns say of similarly vitriolic online discussions of the 2011 England Riots-these "modes of civic participation can be initiated in ways that might become part of legitimate public discourse, before the eruption of violent destruction in the form of riot and looting." Such debates may be the first step in the Internet functioning as a tool for individuals to confront their own insularity and deal with difference peacefully before moving toward unification through a common goal.

In this example, there is a fine balance between this author's intent and the sources used. Neither overwhelms the other. The author keeps an eye to both purpose and context here, using but never altering the meaning of the primary and secondary sources, to support and complicate a deeper reading of the Occupy Wall Street Facebook page. 


\section{Watch This!}

Now, watch Video 10.3 detailing how we move from being a domineering or a passive conversationalist to an informed contributor of a discourse we really want to join.

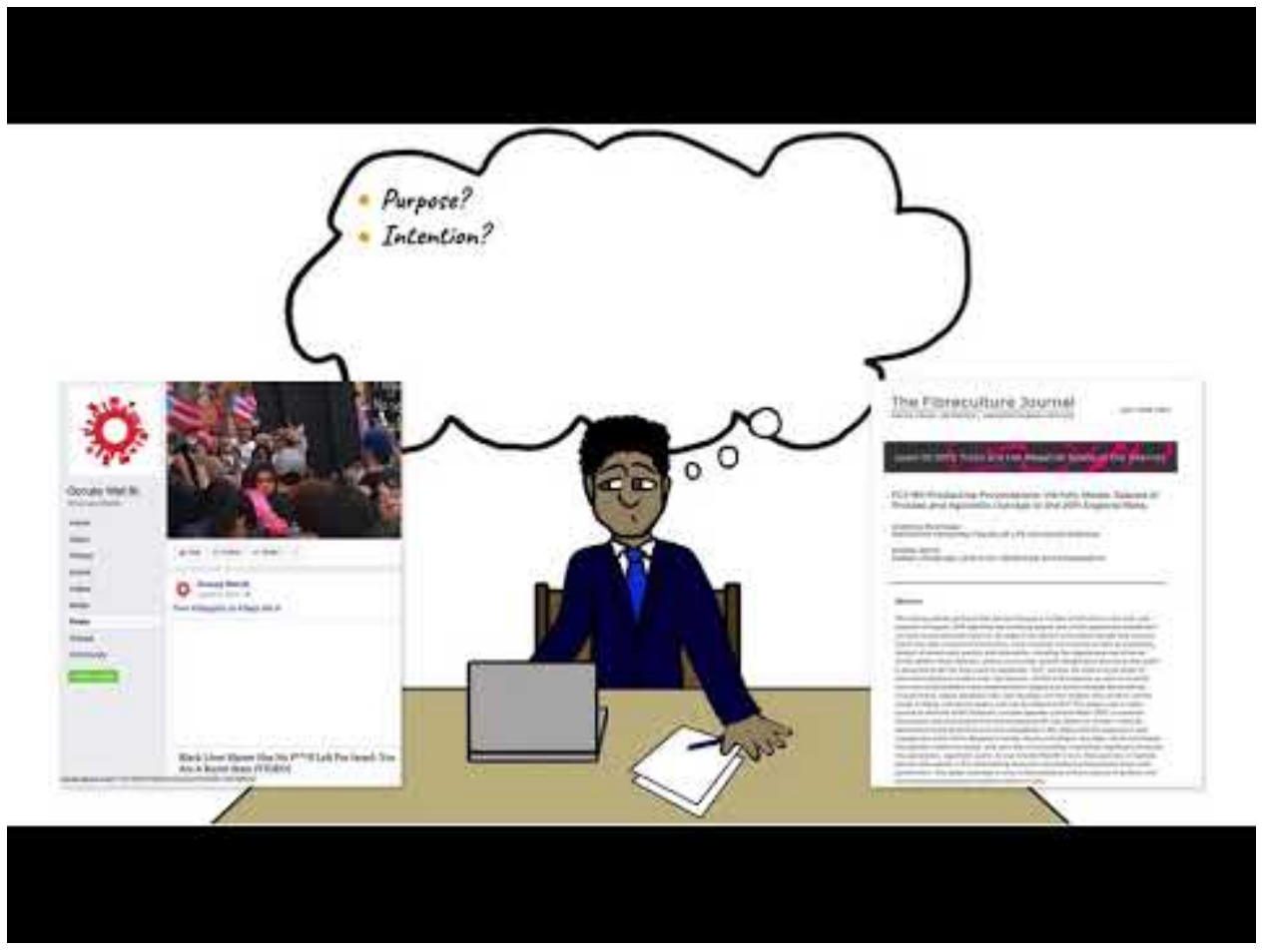

A YouTube element has been excluded from this version of the text. You can view it online here: https://pressbooks.library.ryerson.ca/writehere/? $p=1113$ 


\section{Your Turn!}

Select one of the paragraphs from your essay in which you examine some aspect of your primary evidence and employ at least one scholarly source and then ask yourself the following questions. For every no response, revisit what you have written, revisit the sources you have read, and revisit the notes you have taken, and then determine what you need to do to improve that aspect of your paragraph.

\section{Taking Measure}

Have you read and reread your primary and secondary sources so that you can write about them with confidence?

$\mathrm{Y} / \mathrm{N}$

Have you selected specific aspects of both the primary and secondary sources that will lead to a more elevated and interesting reading of the primary material?

$\mathrm{Y} / \mathrm{N}$

Have you selected specific aspects of both the primary and secondary sources that will enable you to produce a meaningful contribution to the ongoing scholarly conversation that is both an extension and a complication of the current discourse?

$\mathrm{Y} / \mathrm{N}$

Is this paragraph still very much part of your argument and analysis? Are you using primary and secondary sources to work toward the examination you proposed in your thesis?

$\mathrm{Y} / \mathrm{N}$

Do you clearly identify the author of each source as you use it?

$\mathrm{Y} / \mathrm{N}$

Does your use of the sources in your paragraph constitute a moving forward? Do you use your primary and secondary sources to produce something new?

$\mathrm{Y} / \mathrm{N}$

Do you end your paragraph on your own informed idea rather than a citation that "answers" your question? $\mathrm{Y} / \mathrm{N}$

Is the purpose of your paragraph clear and does your use of primary and secondary sources enable you to achieve that purpose?

$\mathrm{Y} / \mathrm{N}$

Do you avoid letting your claim overshadow your primary and secondary sources, and avoid using short snippets without context to "prove" your point?

$\mathrm{Y} / \mathrm{N}$ 
Do you avoid being a passive conversationalist or relying on large citations of both primary and secondary evidence to do your work for you?

$\mathrm{Y} / \mathrm{N}$

278 | Your Turn! 


\section{Setting the Stage: Getting the Primary and Secondary Sources into Your Introduction}

Now let's return to one of the last things we said in Chapter 9, which was a promise of what we planned to do in this chapter: "In Chapter 10, we will be examining in more detail how research can be incorporated into the thesis and the essay's body." Now that we have some experience developing purposeful paragraphs that balance our claims with the supporting evidence of both primary and secondary sources, let's return to each storey of our thesis and connect our ideas to specific aspects of our researched material.

Example

Occupy Wall Street's Facebook group page showcases some flaws as users of the space have a difficult time breaking away from their own "villages" in order to link those global events to their local concerns. This is demonstrated by the comment field under the post "From \#Ferguson to \#Gaza \#BLM," wherein discussion of the event turns to users calling each other names like "idiots" and wondering aloud about the two topics are related (ex. The post "What the hell does BLM have to do with geopolitics in the Middle East?") rather than discussing the event promoted in the original post. Such interaction in this space demonstrates that while Facebook groups do provide a useful tool for distributing information and bringing large tribes together, users often struggle to attach that awareness to action or viewpoints beyond local/personal concerns or interests. Instead of speaking to each other in an attempt to foster stronger global connections and consciousness, users often end up posting their own disconnected content and/or insulting content without the necessary conversation around the complex topics posted. The Occupy Wall Street Facebook page's tendency to strengthen local connections while weakening links to larger social and political contexts acts as an indicator that despite the increased reach of an online community, insularity among its users is likely to affect its ability to influence governmental policy and provide a base for civilian power. As Anthony McCosker and Amelia Johns note in "Productive Provocations: Vitriolic Media, Spaces of Protest and Agonistic Outrage in the 2011 England Riots,"while examining the online discourse around the violent protests in England in 2011, such online comments "remain almost primarily dissociated, impassioned expressions relaying a range of points of view without an internal dialogical order." Users who wish to turn the Internet into an effective tool designed to provide a counterpoint to corrupt, dictatorial, or simply misguided governments will need to address this insularity and attempt to ensure that the broad reach of the social-media platform does not replace the broadness in scope of the movement itself. As McCosker and Johns claim, properly attuned, such dialogues "can be conceptualised as acts of multiple initiations-of a space of protest, of a constitutive public, of passionate expression of the conditions of existence, of provocations for further exchange."

There are no hard and fast rules for incorporating scholarly support into your thesis. Some authors choose to begin by citing a scholarly source they will either examine or debate then follow the cited passage immediately with their particular thoughts or criticisms. There are many approaches that you will no doubt encounter as you gain experience and move through disciplines. When dealing with first-year writers, we prefer the approach of establishing your reading in the first and second storeys, then situating it within a larger discourse in the third storey. This ensures that your 
approach to your primary material is focused and comes from something you want to say about the text. Once you have established your approach, it is easier to situate it within a larger discourse without losing the specifics of the argument that make it your own. 


\section{Looking Ahead...}

Now that we have a good grasp on how to use primary and secondary material, we now must consider how to best organize our essay and how to cite our sources properly. The next chapters will look at how we build our argument using multiple sources and how we make sure we are always clear on whose sources we are using. Keep working on your essay and your entrance into the scholarly conversation. You're already there!

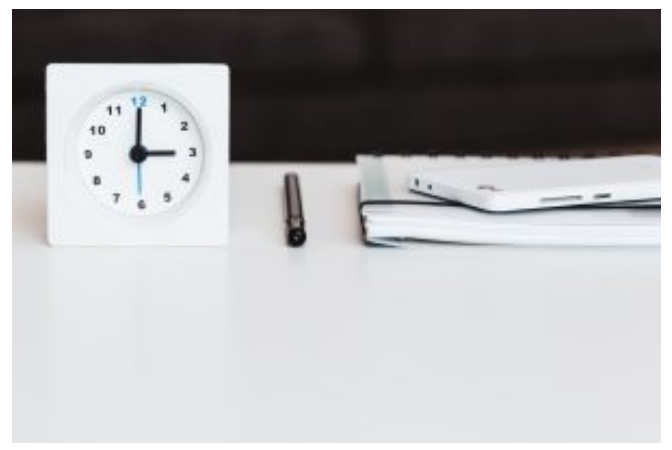

Photo by freestocks.org on Unsplash 



\section{CHAPTER II: EDITING AND EVOLVING THE THESIS AND OUTLINE}





\section{Chapter Overview}

\section{Learning Outcomes}

\section{In this chapter we will:}

- Determine the scholarly conversation that best defines and supports your approach to your subject.

- $\quad$ Decide what primary evidence you should analyze first and what scholarly support best develops your reading of the evidence.

- Use your primary and secondary sources effectively, never letting cited passages stand alone and showing how your sources support your argument.

- Develop transitions from one argument to another and from one scholarly source to another so that your ideas progress in a logical way. 


\section{Revisiting Body Paragraphs}

The last chapter focused on developing your essay's body with your research in mind. In developing your paragraphs you must consider what kind of research furthers the analysis of your primary evidence and facilitates your entry into the larger academic discourse represented by your primary example. The following self-evaluation will help you review and evaluate how well you integrated secondary sources into your body paragraphs.

\section{Taking Measure}

Answer "yes" or "no" to each question below. If you answer "yes," give yourself one point. If you answer "no," be sure to revisit your body paragraphs and rectify your problematic use and integration of your secondary source(s). Your final scores will be a mark out of five (four "yes" responses $=4 / 5$ ).

1. Did you let your sources speak without manipulating them into supporting your desired reading of the primary evidence?

$\mathrm{Y} / \mathrm{N}$

2. Did you let your sources speak without taking their argument out of context to prove your own conclusions?

$\mathrm{Y} / \mathrm{N}$

3. Did you actively direct the purpose of the scholarly conversation with sources by NOT citing large chunks of text in place of your own interpretation of the primary evidence?

$\mathrm{Y} / \mathrm{N}$

4. Did you discuss citations by contextualizing the author's arguments before trying to apply them to your reading of your primary evidence?

$\mathrm{Y} / \mathrm{N}$

5. Did you use secondary sources to advance and complicate your reading of the primary example AND not as a substitute for your own analysis and interpretation of the primary evidence?

$\mathrm{Y} / \mathrm{N}$ 


\section{Effectiveness of Your Sources}

Using your sources to elevate and complicate your reading of the primary example is an ongoing process. You will have to evaluate whether your original sources allow for the deep reading of your primary evidence that brings something new to the scholarly discussion of your larger topic. To do this, you will have to ask yourself some basic questions (while focusing on your third storey): what aspects of your topic/subject do your sources not address? What are the limitations of the arguments in your sources? Are there details in your sources that remain implicit that you need to draw out and clarify before applying to your reading? Given your sources' conclusions, what problems might arise when you apply them to your topic? In short, you will need to consider the limitations and shortcomings of your research. Keep in mind that the purpose of doing so is not to discredit your sources and omit them in favour of other sources, but instead to further develop your reading.

Let's look at the example from Chapter 10 of the thesis with the secondary sources included.

\section{Example}

Occupy Wall Street's Facebook page showcases some flaws as users of the space have a difficult time breaking away from their own "villages" in order to link those global events to their local concerns. This is demonstrated by the comment field under the post "From \#Ferguson to \#Gaza \#BLM," wherein discussion of the event turns to users calling each other names like "idiots" and wondering aloud about how the two topics are related (ex. The post "What the hell does BLM have to do with geopolitics in the Middle East?") rather than discussing the event promoted in the original post. Such interaction in this space demonstrates that while Facebook pages do provide a useful tool for distributing information and bringing large tribes together, users often struggle to attach that awareness to action or viewpoints beyond local/personal concerns or interests; instead of users speaking to each other in an attempt to foster stronger global connections and consciousness, users often end up posting their own disconnected content and/or insulting content without the necessary conversation around the complex topics posted. The Occupy Wall Street Facebook page's tendency to strengthen local connections while weakening links to larger social and political contexts acts as an indicator that despite the increased reach of an online community, insularity among its users is likely to affect its ability to influence governmental policy and provide a base for civilian power. As Anthony McCosker and Amelia Johns note in "Productive Provocations: Vitriolic Media, Spaces of Protest and Agonistic Outrage in the 2011 England Riots," while examining the online discourse around the violent protests in England in 2011, such online comments "remain almost primarily dissociated, impassioned expressions relaying a range of points of view without an internal dialogical order." Users who wish to turn the Internet into an effective tool designed to provide a counterpoint to corrupt, dictatorial, or simply misguided governments will need to address this insularity and attempt to ensure that the broad reach of the social-media platform does not replace the broadness in scope of the movement itself. As McCosker and Johns claim, properly attuned, such dialogues "can be conceptualised as acts of multiple initiations-of a space of protest, of a constitutive public, of passionate expression of the conditions of existence, of provocations for further exchange."

In considering our use in the thesis of McCosker and Johns' essay, we might start by backtracking to ask what the authors mean by "dialogical order"? Moreover, if online comments are mostly "dissociated, impassioned expressions" without a 
"dialogical order," then what about offline forms of political discourse? Are they more logical and less impassioned forms of expression with "an inherently dialogical order"? What might be the value of impassioned and seemingly disassociated speech?

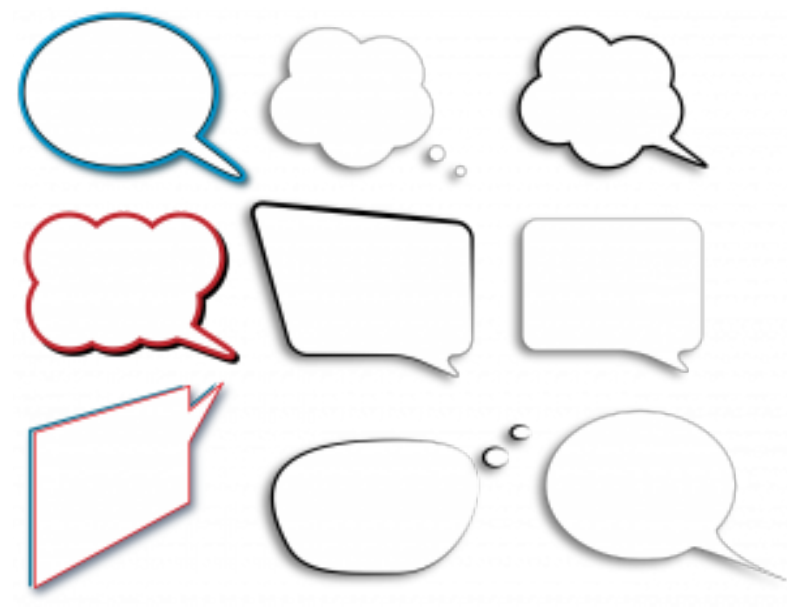

From Pixabay.
To begin, we can define dialogic[al] expressions as those in dialogue with other utterances or expressions. In other words, our communication is relational and contextual, as it depends on what was said before and what the speaker anticipates will be said in response. Linguist Mikhail Baktin theorizes that all language is by nature relational and dialogical. So if all expressions have a dialogic order, might we conclude then that all communication is successive/consecutive and logical? We cannot, because language is relational and contextual, but speakers respond also to their own particular, acknowledged or unacknowledged, personal or political contexts-not only to others' communication-so misunderstandings and impassioned reactions are common enough in any discursive community.

Communication is not tidy by nature and especially not in the "global village." We alluded to this idea in our thesis in the second

storey with reference to McLuhan's "tribes." For McLuhan, tribal communication (and ritualized practices) suggests a multi-sensory, impassioned engagement but also a potentially chaotic and unruly one. This is also true of "global tribes" in the "global village." So if all communication is potentially disorderly, and especially communication in online communities, then are Facebook pages useful political tools after all? We might still conclude they are indeed viable political tools; however, all communication is potentially complicated, sometimes confusing and certainly open to overheated exchanges. The internet is merely a reflection of the difficult and muddled reality that is human communication. But the question still remains, is the internet then a viable political tool?

Before we answer the above question, let's take inventory of what we have accomplished so far. We have teased out details and meanings in our secondary source that were at first implicit, such as the meaning of language having a "dialogical order." We concluded thoughtfully that while all language is dialogical, this does not prevent misunderstandings and seemingly unconnected responses in online communication. We complicated our understanding of the McCosker and Johns argument further, in its application to our thesis, when we noted that all communication is both inherently dialogical and non-dialogical, whether the communication happens online or offline, but that online communication is, as McLuhan suggested of tribal communication and by extension electronic communication, inherently susceptible to being incoherent and impassioned. These are ideas we will need to include in our revised thesis.

To answer our outstanding question though, we might seek out further research to help us conclude whether online communities, such as Facebook pages are useful political tools. Let us turn to the following open source: 


\section{Article}

\section{Article: "FCJ-194 From \#RaceFail to \#Ferguson: The Digital Intimacies of Race-Activist Hashtag Publics"}

Author: Nathan Rambukanna (Wilfred Laurier University)

Abstract: This paper explores the rough, emergent and partial public culture of race-activist hashtags through the discourses of \#RaceFail, a critical race quarrel that started in the sci-fi and fantasy blogosphere, and expanded from there into a broader, sustained discussion over social media; and \#Ferguson, a recent race-activist hashtag raising issues around censorship, filtering and 'gated discourse'. It ends with a discussion of how the frictions between the neoliberal desire to reduce hashtag publics to product publicity, and the activist desire to use hashtags to further public sphere awareness of political issues, is exemplified in the controversy over Facebook's 'algorithmic filtering' of \#Ferguson, and how, nevertheless, critical race hashtags are tapping into a developing tradition of vocal social media-supported dissent.

Having read the article, let's pull out some paragraphs that are crucial to our reading of our primary evidence and that we will work with, in conjunction with the McCosker and Johns article, to further develop our third storey, the political usefulness/viability of Facebook pages.

\section{Rambukanna writes:}

In fact, since the dawn of the Internet age, discussion of the democratic potential of Internet-mediated space has been one of the major top level conversations. Yet a lot of that discussion gets mired in an orthodox Habermasian take on what we should consider a democratic public sphere-that is, one where rational critical discourse on matters of societal importance (such as, most critically, the actions of the State) can take place; populated by citizens stepping out of their private roles as interested individuals and into a public space where they become participants in disinterested discussion and debate (Habermas, 1962).

While one can argue the merits of Habermas's public sphere, what of the other kinds of discussion and debate that are facilitated by networked technology? Taking its cue from critical public sphere theorists such as Nancy Fraser (1992) and Michael Warner (2002), this paper explores those other publics: more-or-less subaltern, moreor-less rational, more-or-less critical, and almost certainly partial, affective, interested and loud. The paper is interested in angry publics. It is interested in fringe publics. It's interested in the kinds of publics that do politics in a way that is rough and emergent, flawed and messy, and ones in which new forms of collective power are being forged on the fly, and in the shadow of loftier mainstream spheres. These are the publics born of frictions, in Anna Tsing's sense, 'the awkward, unequal, unstable and creative qualities of interconnection across difference' (2005: 4).

$\cdots$

The political role of communication media cannot, therefore, be to 'fix' a broken system of public sphere communication, but rather to 'un-fix' staid communication patterns, to re-figure the public conversation about important issues and topics (such as inequality, racism, sexism and abuses of power) with a view to cracking open stable systems of meaning-making, and working-as Peters reminds us we need to do (1999: 30)-to build better communication across and between cultural and subcultural spaces. We need to work with and through the 'productive friction[s] of global encounters' (Tsing, 2005: 3), to tap the unpredictable and raw energy that is concomitant with our increasing interconnection. 
As we did with the McCosker and Johns article, we will need clarify some details in the above source that are more or less implicit and that we will want to expand on before applying this secondary source to our thesis. For one, we need to ask, what is the nature of "a democratic public sphere"? How does it engage in political discourse? Moreover, if communication in these public spheres is indeed "broken," as Rambukanna suggests, then what is their political value? What can we hope to derive from online communities engaged in political discourses?

Rambukanna clearly states that "democratic public spheres," where online political communities engage in democratic discourses, are not places where people engage in "rational critical discourse" on socio-political issues. Moreover, such politicized individuals are also not "disinterested" in their political interactions or in "debates." In other words, they are "impassioned," to quote McCosker and Johns. In fact, for Ramabakunna, these individuals are "partial," (read: highly subjective, biased or narrow-minded) "affective," (read: emotional or impassioned) "interested," (read: engaged) "loud" (read: boisterous, vulgar and rowdy) and their political engagement style is "rough and emergent, flawed and messy." They are "angry" online political communities "born of friction," meaning they are disorderly, sometimes hostile and discordant online spaces where conflicting and divergent viewpoints are the norm.

Rambukanna's view of "public democratic spheres" is similar to McCosker and Johns' depiction of online communities. The authors would agree on the nature of the political discourse and communication that occurs online on sites like the Occupy Wall Street Facebook page. It is discontinuous-not dialogical-impassioned, "insular" or "partial" and often vulgar, even insulting. They accept this nature of communication as more or less normal-to be expected-for public spaces are not, as Ramabukanna argues, spaces where "interested" individuals participate in "rational critical discourse" or "disinterested discussion and debate" on political issues. The authors also concur that these flawed and volatile online spaces are still engaging in valuable discussions. Rambukanna acknowledges soberly that "public sphere communication" is "broken" and technology or "communication media" cannot solve or "fix" it, but it can "un-fix' staid communication patterns, to re-figure the public conversation about important issues and topics...cracking open stable systems of meaning-making." For Rambukanna, the only way to challenge systems of inequality is to work through the "friction" and diverging viewpoints and harness the passion of committed individuals to work for change. Here, his ideas are very much aligned with McCosker and Johns, who suggest that impassioned and "vitriolic" speech can be "productive" and addressed legitimately through public discourse before said speech escalates into violence.

To return to our thesis and the third storey, keeping in mind both McCosker and Johns' and Rambukanna's understanding of online communication, we might qualify our thesis as follows:

\section{Example three-storey thesis}

Occupy Wall Street's Facebook page showcases some flaws as users of the space have a difficult time breaking away from their own "villages" in order to link those global events to their local concerns. This is demonstrated by the comment field under the post "From \#Ferguson to \#Gaza \#BLM," wherein discussion of the event turns to users calling each other names like "idiots" and wondering aloud about the two topics are related (ex. The post "What the hell does BLM have to do with geopolitics in the Middle East?") rather than discussing the event promoted in the original post. Such interaction in this space demonstrates that while Facebook pages do provide a useful tool for distributing information and bringing large tribes together, users often struggle to attach that awareness to action or viewpoints beyond local/personal concerns or interests; instead of users speaking to each other in an attempt to foster stronger global connections and consciousness, users often end up posting their own disconnected content and/or insulting content without the necessary conversation around the 
complex topics posted. The Occupy Wall Street Facebook page's tendency to strengthen local connections while weakening links to larger social and political contexts acts as an indicator that despite the increased reach of an online community, insularity, hostility and discord among its users, which is typical of both on- and offline communication, could potentially affect its ability to influence governmental policy and provide a base for civilian power. As Anthony McCosker and Amelia Johns note in "Productive Provocations: Vitriolic Media, Spaces of Protest and Agonistic Outrage in the 2011 England Riots," while examining the online discourse around the violent protests in England in 2011, such online comments "remain almost primarily dissociated, impassioned expressions relaying a range of points of view without an internal dialogical order." Yet they are also confirmation that communication does not "naturally invite understanding, connection or societal harmony-despite a common [mis]conception that this is the case," as Nathan Rambukanna underscores in "FCJ-194 From \#RaceFail to \#Ferguson: The Digital Intimacies of Race-Activist Hashtag Publics". Users then who wish to turn the Internet into an effective tool designed to provide a counterpoint to corrupt, dictatorial, or simply misguided governments will need to address this insularity and attempt to ensure that the broad reach of the social-media platform does not replace the broadness in scope of the movement itself. They will also, as Rambukanna says, need to work "to build better communication," despite the inherent volatility and fractiousness of such communities and the diverging viewpoints expressed therein, if they wish to foster dialogue and connection leading to the creation of new political networks of change. As McCosker and Johns claim, properly attuned, such dialogues "can be conceptualised as acts of multiple initiations-of a space of protest, of a constitutive public, of passionate expression of the conditions of existence, of provocations for further exchange." 
Try This!

Activity

Conduct further research. Then modify thesis by including new research to replace or modify past research. 


\section{Starting a Conversation with Your Sources}

As promised in Chapter 10, we will now address how to incorporate multiple sources, and indeed we've already practiced this strategy in building our argument/developing our three-storey thesis.

Incorporating multiple sources and getting them into conversation is the practice of using your sources to lay down building blocks or a framework within which to read your topic, or an aspect of it, and eventually develop your own ideas about it. It is useful as a scaffold upon which to build your argument. While you may agree or disagree with one or the other source, the point here is to actively use them in dialogue with each other to draw out a point you want to make about your reading of the primary source. You might reference points of similarity between them and the significance of differences in their arguments, but always with intention to draw some conclusion from this interaction about your reading and understanding of your topic.

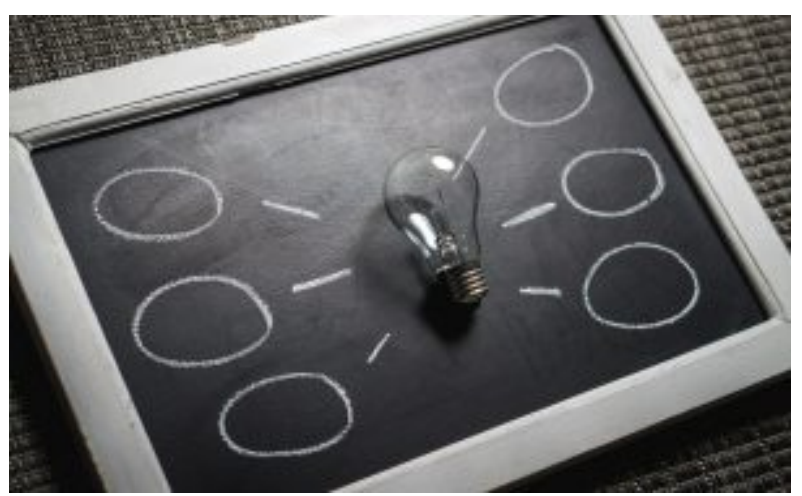

From Pexels. You might also consider how one source's ideas respond to and qualify the ideas or claims of your other source. Your role then becomes to clarify their positions and moderate the conversation with the intent of eventually coming to a new perspective or new insight. A word of caution: always be clear regarding what source you are using and whose ideas you are referencing. Also be clear about what ideas belong to your sources and what ideas are your own.

Let's look at an example. In Chapter 10, we already engaged in a conversation with McCosker and Johns' article. We will now use that source in conjunction with Rambukanna and get these two talking to each other.

Similar to McCosker and Johns in "Productive Provocations: Vitrolic Media, Spaces of Protest and Agonistic Outrage in the 2011 England Riots," Rambukanna examines online political spaces and the way they "do politics." He notes that interactions in these online communities are both difficult and challenging and yet possibly constructive in effecting political or social change. He argues that online communities are often "angry" public spaces where committed and impassioned citizens engage in political discourses that are "flawed and messy." Despite these challenging interactions, however, these communities have the potential to "crack[...] open stable systems of meaning-making." In other words, it is precisely their frustration and rage that can be harnessed and directed toward disrupting the status quo. Without constructive conflict, activism becomes too insular.

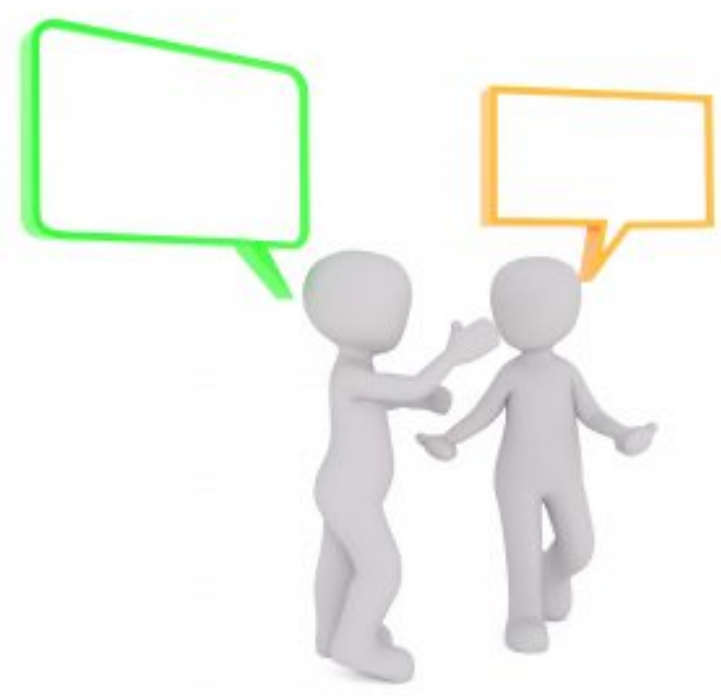

From Pixabay.

Furthermore, Rambukanna, illustrates via the race-activist \#RaceFail how participating in angry exchanges or "unfix[ing] staid communication patterns" leads to disrupting or changing social systems (in this case, actively increasing awareness of race issues in the SFF sphere, leading to publishers actively seeking authors of colour as well as to the publications of anthologies and conferences dedicated to race issues in sci-fi and fantasy). For the most part, McCosker and Johns would agree with Rambukanna, as they too argue that "excesses of emotion and acts of often aggressive provocation" are "paramount" in civic and political engagement. McCosker and Johns also make it clear that passion 
and provocation are in fact productive because they prevent the very "disaffection" or disillusionment that can lead to violence. Online communities are the public forums and outlets that give the disenfranchised a voice before their frustrations turn destructive. For McCosker and Johns, this is their civil function or utility. Yet neither Rambukanna nor McCosker and Johns address the very real and alternative possibility that an excess of online rage (and cyberbullying) might also lead to a total breakdown of communication, increased insularity or entrenched viewpoints and offline violence. Some restraint and sensibility are also necessary in public debates on online communication forums.

In short, in light of the above research, the heated and passionate exchanges on the Occupy Wall Street Facebook page, even those that seem off topic or hostile, have the potential to lead to political activism so long as these disruptive voices are judiciously addressed or engaged and made relevant so their seemingly unrelated or acrimonious comments lead to constructive change and not violence. While it may not be possible to reach consensus in democratic spaces and open forums, like the Occupy Wall Street page, marginal voices must have an outlet and cannot be ignored, if such public spaces are to be considered democratic spaces and function as political tools. 


\section{Watch This!}

Let's watch Video 11.1 in which we review how to get sources into conversation with each other (by referencing differences or similarities and considering how each might respond to the other's ideas) and offer a context in which to read our topic.

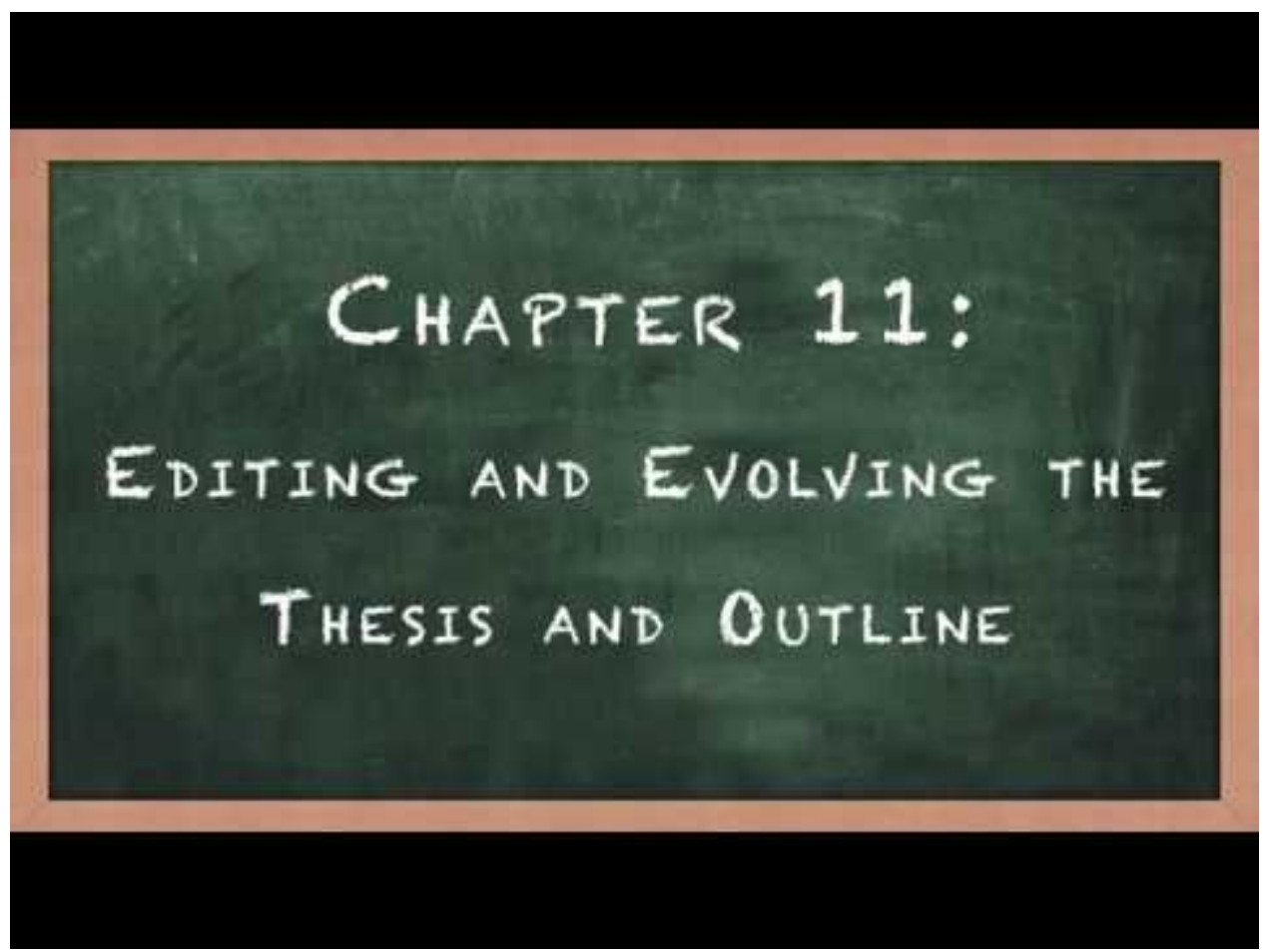

A YouTube element has been excluded from this version of the text. You can view it online here: https://pressbooks.library.ryerson.ca/writehere/?p=1250 


\section{Try This!}

\section{Activity}

Rewrite a paragraph or two from the draft of your final research paper (be sure it includes research), keeping in mind the principles discussed above. 


\section{Transitioning Between Ideas}

Just as it is important to introduce and transition into a quote or paraphrase, it is equally important to use transitions to connect ideas from one sentence to another or from one paragraph to another. Ideas in an essay relate to and build upon each other. Ideas in one sentence or paragraph develop and elaborate on the ideas that precede them. It is important to create a logical progression of ideas and arguments for readers and to be clear about how specific paragraphs connect to each other.

Transitional words or phrases link your ideas together and help you transition from one sentence to another or one paragraph to another and subsequently move from one idea and argument to another smoothly and logically. There are various types of transitions that will signal to your reader the direction of your ideas and paper. For instance, additive transitional words like "and," "also," "moreover," "furthermore," or "in addition to" all suggest that you are continuing with the same argument. However, words such as "however," "but," "yet," "nevertheless" or "on the contrary" suggest a counter argument or shift in your thinking. To conclude on a point, you might try transitional words like "in conclusion," "therefore," "hence," "consequently," and so forth. To emphasize a point, words like "in fact," "indeed," "to highlight," or "more importantly or significantly" work well.

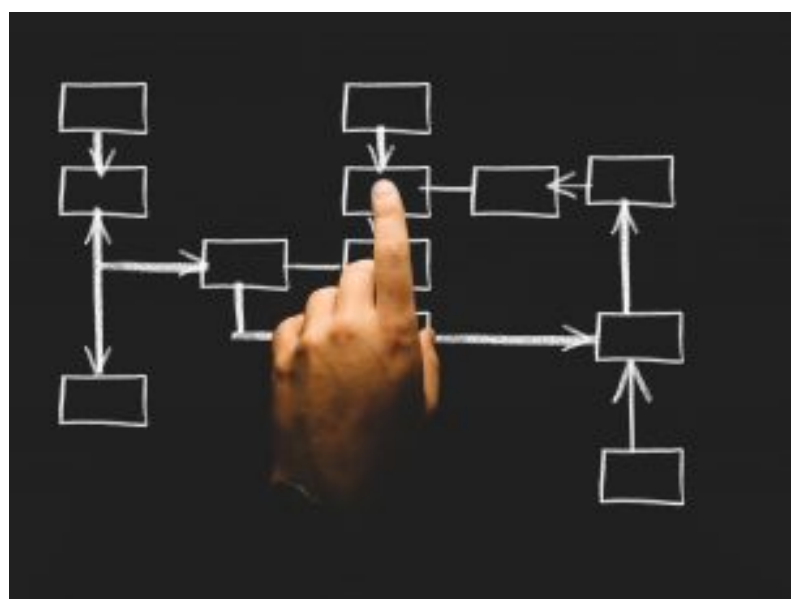

From Pexels.

In short, there are a number of ways to transition from one point to another and it is important that you use effective transitions to help you build and develop your ideas and arguments smoothly and in a way that is easy for your audience to follow.

Such transitional words appear in the above example when we put McCosker and Johns into conversation with Rambukanna. When showing commonality between their ideas, we used transitional expressions such as "like" or "they too," and when we showed difference between their arguments and our own, we used words like "yet" or "in contrast". To draw together their ideas and show how they applied to our argument, we used "in short." 


\section{Watch This!}

In this next Video 11.2, we'll review key transitional words and phrases that will help you transition and progress from one idea into another.

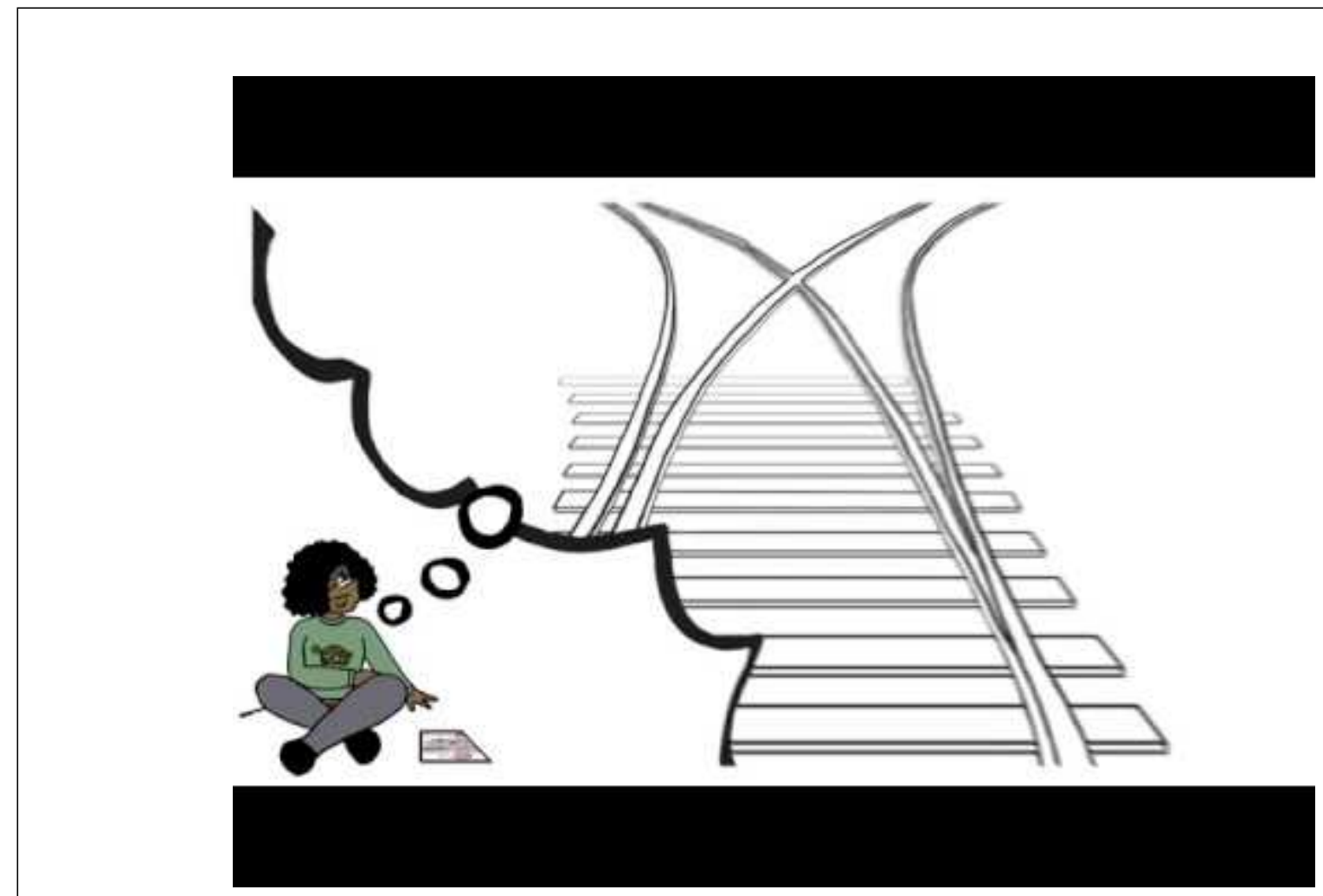

A YouTube element has been excluded from this version of the text. You can view it online here: https://pressbooks.library.ryerson.ca/writehere/? $p=1257$ 


\section{Try This!}

\section{Activity}

Using the draft of your final research paper, write a transition sentence for each paragraph to paragraph transition. Then choose two paragraphs and write a more comprehensive two sentence transition that links the two ideas in the paragraphs. 


\section{Thinking ahead...}

In this chapter you have considered what scholarly sources best suit your approach to your subject and enable you to develop your own arguments and evolve your thesis. Following your scholarly discussion of your topic, you will need to review your research and come to some conclusions about your subject. In short, you will need to write a conclusion and that is the focus of the following chapter.

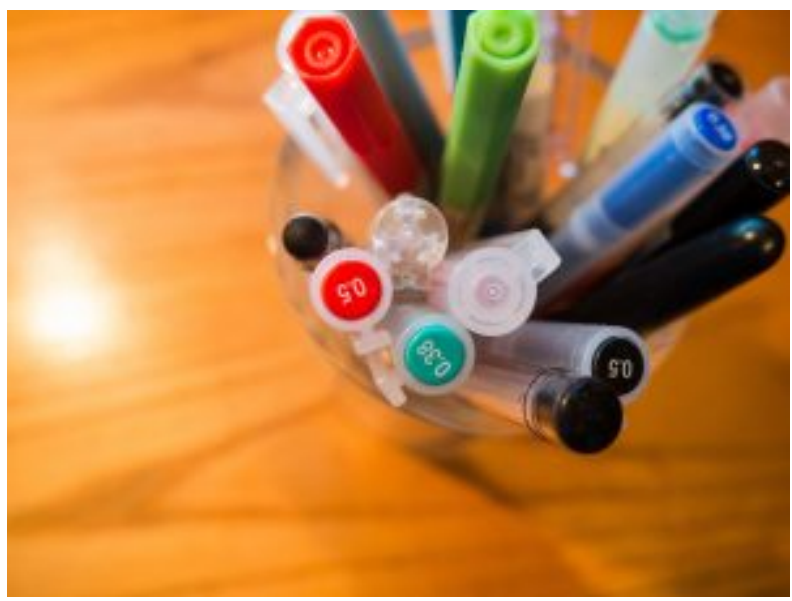

From Pixabay. 


\section{CHAPTER I2: WHAT HAVE I ACCOMPLISHED? CONCLUSION AND FINAL ASSESSMENT}





\section{Chapter Overview}

\section{Learning Outcomes}

\section{In this chapter we will:}

- $\quad$ Re-read and revise your entire essay.

- $\quad$ Self-evaluate your completed complex argument and essay.

- Write a concluding paragraph that reflects your complex argument.

- $\quad$ Re-read and revise your entire essay for the final time. 


\section{Revising Your Thesis and Body Paragraphs}

Before you begin revising your work, it would be useful to review both the three-storey thesis that you wrote as part of Chapter 9 and the paragraph-by-paragraph skeletal outline that you created as part of Chapter 11. It may even be useful to print these two documents and read them side-by-side so that you can compare the structure and content of what you had planned to argue with what you actually argued in your essay. This is not to say that your initial thesis and your outline need to be identical to what you wrote in your essay. Rather, they provide the broad outline of your thoughts and argumentative structure and will help you assess the strength of your argument during this revision stage.

Broadly, the most effective way to revise your essay is to make it unfamiliar to yourself. Because you know the argument you want to make, there is a danger that you will make assumptions and logical leaps within the work that an outside reader would not make. Therefore, you need to approach your essay as if someone else wrote it so that you can objectively evaluate its strengths and weakness. Some strategies to help you do this include:

- Printing your essay and reading it as a hard copy: Often when we read on our computer screens, even in a word processing program, we gloss over the text and do not read as carefully as we should. Moreover, reading on a computer provides an environment with many potential distractions. Print your essay and read it.

- Read with a pen in your hand: Taking notes and responding by hand in the margins on your own work will ensure that you are remaining an active reader of your own argument.

- Read your essay in a different room: This is similar to reading a hard copy of your work. Moving to a different writing environment will help defamiliarize the text and provide you with a new perspective on your own argument.

- Read your essay out loud: Reading your own work out loud is a great way to hear how your argument sounds. This will be helpful for understanding your whole essay and whether the paragraphs link together logically.This technique will also help you identify any awkward style or errors in grammar or punctuation. If you stumble over a sentence when you are reading it out loud, there is likely something in that sentence that needs to be fixed.

Now that you have taken steps to make your essay and argument seem

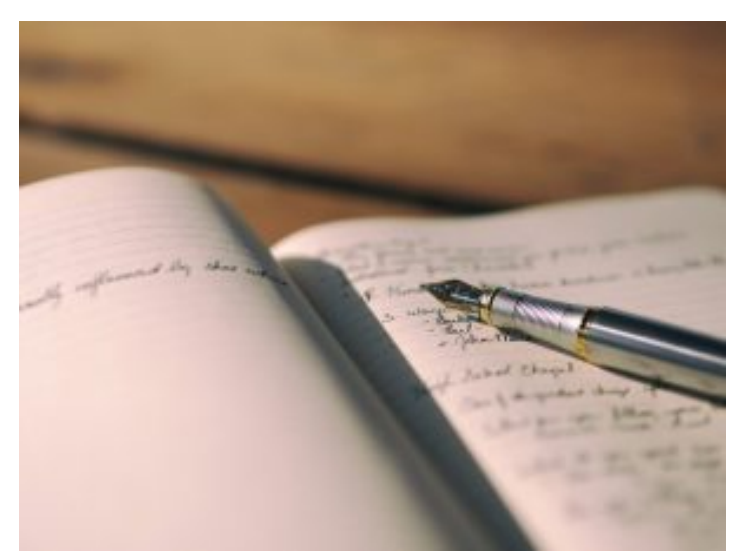

From Pixabay. less familiar, you need to set some specific goals for your revision. You have a lot to reconsider, so setting specific goals will help you revise your essay effectively. You need to reconsider the final version of your thesis that you have been complicating and reformulating during this process. And you need to reconsider your use of primary and secondary evidence, as well as your analysis of these elements. In this way, it is useful to edit in small, iterative waves with specific goals for each wave. It is very difficult, for example, to revise paragraph-to-paragraph transitions, grammar, thesis construction, and integration of research in a single pass. Instead, each of these concerns should be separated into its own wave and you should read your essay with that one specific concern in mind.

At this point, revising your essay means asking a number of questions of your own writing. By asking one specific question as you read your essay, you will stay focused in your revising process and strengthen your argument from many directions. You will be asking both large- and small-scale questions; some questions will address your writing at the word, sentence, and paragraph level, and some will concern your essay as a whole. Again, you cannot address all these issues at once, so give yourself a specific task with each reading of your essay. 


\section{Potential Questions to Ask}

\section{At the paragraph level:}

- Does each paragraph have a unique argument that complicates the overall thesis?

- Does the topic sentence reflect the argument being made in that paragraph?

- Does each paragraph have a distinct progression from beginning to the middle to the end?

- Does the paragraph go off on any tangents? Does it remained focused, from the first sentence to the last, on the argument within that paragraph?

- How long is each paragraph? Are some too short? Are some too long?

- Do any paragraphs repeat key parts of the argument?

- Does each paragraph connect logically to the next paragraph?

- What is the job of each paragraph? For example, one paragraph may be for analyzing a detail from your central example, while another will be incorporating scholarly research. Is it achieving its job?

- Is the analysis of the central example done effectively?

- Is the research integrated and activated effectively?

- Although the argument is being reformulated as new evidence is added, is the argument clear in each paragraph?

\section{At the sentence level:}

- Do the sentences make sense syntactically? (Did you stumble when you read them out loud?)

- Does each sentence add something new to the paragraph?

- Do any sentences repeat the same idea?

- Does each sentence connect to the next sentence?

- How long is each sentence? Are some too short? Are some too long?

- Are there any run-on sentences?

- Are there any sentence fragments?

\section{At the word level:}

- Are key terms defined with a scholarly definition?

- Are the verbs effective? Are the verbs precise and demonstrative?

- Are the pronouns used (I, you, we, us) effective and appropriate for the genre of writing?

- Is each word clear and logical?

- Are words repeated? If so, is the word being repeated central to the argument being made in that paragraph? Is it central to the argument being made throughout the essay? 


\section{At the the essay level:}

- Does the argument get stronger as evidence is added?

- Does the argument build logically?

- Is the argument clear at each stage of the essay?

- Is there missing research that might strengthen the argument?

5. Proofreading:

- Is every word spelled correctly, including author's names, cities and unique vocabulary?

- Are all words used correctly?

- Is each sentence correct grammatically?

- Is all punctuation used correctly?

- Are in-text citations used properly? 


\section{Try This!}

\section{Activity}

Print your essay and then pick one of the first four levels. Read your essay once with that level in mind and make your responses in the margins of your text. Don't be too afraid of deviating from your question if you see big errors, but try and remain as focused as you can answering one question fully with each reading of your essay. After having asked and answered these questions, return to your essay and make any adjustments to your essay that you feel you need to make. 


\section{Watch This!}

Video 12.1: Walking Through an Edit With a Specific Question, gives you an example of a student walking through a round of revision that focuses on just one question and marking up the text. Remember: you are going to read and revise your essay more than once by answering more than one question.

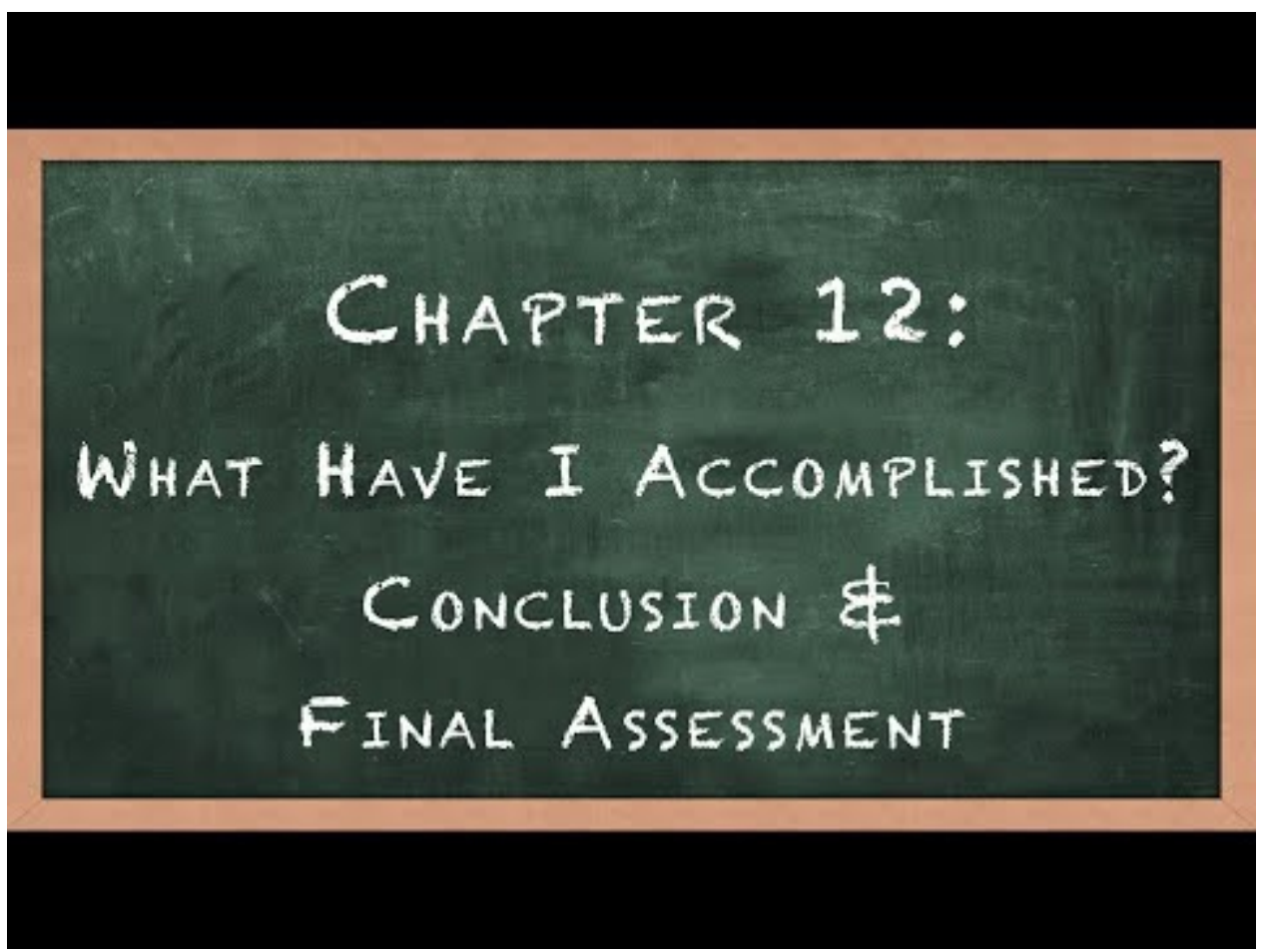

A YouTube element has been excluded from this version of the text. You can view it online here: https://pressbooks.library.ryerson.ca/writehere/?p=1143 


\section{Concluding Your Argument}

Now that you have gone through your essay and revised with specific questions in mind, you are ready to write the conclusion to your essay. Your conclusion should contain a full and complex version of your thesis that incorporates the analysis and details you have added to your introductory thesis. Everything you learned in Chapter 6 about concluding a close reading can be applied to concluding your own complex argument:

- The conclusion is not the "bottom bun" of your argument. The conclusion should be used as a space to take stock of your entire argument and let your readers exit your essay with all the components linked together compactly and logically.

- The conclusion is not a summary of your argument. Your reader has just read your essay. Like Chapter 6 tells us, readers are not goldfish-they do not need a reminder of your thesis.

- The conclusion is not a final proclamation about what is "right" or "wrong." The conclusion should be utilized as a final opportunity to place your argument within the scholarly discussion that has already taken place. This is the last chance for your readers to assess the total of your argument and consider the further implications of your analysis and argument.

Your conclusion is the accumulation of your analysis, your scholarly research, your complex argument, and your threestorey thesis all working together. In many ways, your conclusion is a response to the initial thesis you present in the introduction to your essay and, as such, you need not repeat it. Instead, your thesis will have grown more complicated and complex as you've added analysis and scholarly research, which should refine and sharpen your initial argument into one that is more complex.

A strong conclusion also acknowledges the scholarly discussions that your essay is participating in and places your final argument within that discussion by pushing your reader to consider further thoughts and arguments that might arise. This can be tricky, because conclusions, above all else, are for concluding. You do not want to introduce a new idea or facet into your argument in one sentence, and then end your essay. Instead, all components of your argument included in your essay deserve the time and space to be explored. In this way, resist introducing new evidence in your final paragraph or asking rhetorical questions. Instead, return to the third storey of your thesis and write your conclusion as though it is answering the question the third storey has posed. What elements discussed throughout your essay enable you to answer that question? What new piece of evidence needs to be added to best complete that answer?

When considering strategies for concluding your argument, remember that not all of these strategies are appropriate for every genre of academic discourse. For example, creating an anecdotal story that personalizes and illustrates some small portion of your argument might be appropriate in some humanities classes, but seem out of place in a lab report. If you have questions about appropriate strategies, ask your professors about their expectations. You can also look at the scholarly research you have been reading. How do these scholars conclude their arguments? What models can you follow from those writings?

Consider the language and strategies you used in your introduction. For example, if you use a quotation as the hook in your introduction, can you return to that quotation (or a similar quotation)? How has your argument built and changed since you introduced this quote?

With all this in mind, here are some strategies to consider using in your conclusion:

- Return to a quotation you've given earlier in the essay and re-analyze it as the context for your final argument. Using a quote from a scholar is likely the most effective, as it reminds your reader what scholarly conversations your essay is joining. Remember, however, that you should not simply put a quotation into your conclusion without 
analyzing specific words and phrases, just as you've done throughout the whole of your essay. Nor should you end your essay on a quotation. You want the last words of your essay to be your own.

- Describe a relevant image that illustrates some aspect of your final argument. For example, if your essay is making an argument about texting habits of male high school students, then describing a male high school student texting would be a relevant way of wrapping up your final argument.

- Give a statistic or fact that is relevant to your final argument. Again, this is a chance to place your argument within a scholarly discussion while lending it a scholarly quality.

- Create a call to arms. You can use the problem that you have raised in your third storey to argue that certain actions need to take place. Encourage your reader to take up that responsibility. Charles Justice uses this strategy effectively in his conclusion to "The Ultimate Communications App" -it might be useful to revisit that essay.

- Quickly and compactly explain your final argument. You don't need a fancy flourish at the end of your essay if you don't want; instead you can simply state your final argument, given all the analysis and scholarly research you've added to your initial thesis, and conclude your essay. 


\section{Try This!}

\section{Activity}

After you have revised your essay, write a concluding paragraph that uses one of the above strategies and contains your fully complex final argument. This may mean going back to your introduction and adjusting it so that the strategy in your conclusion matches the one used in the introduction. When you are finished, write a different version of your conclusion using a different strategy. Which one do you prefer? Which one does a better job of situating your argument in a scholarly discussion? Which one does a better job of providing a final argument for your essay? Which one is most appropriate to the genre of academic discourse in which you are participating? 


\section{Watch This!}

Watch Video 12.2: Walking Through an A-level Conclusion, as it walks through the conclusion to "Productive Provocations: Vitriolic Media, Spaces of Protest and Agonistic Outrage in the 2011 England Riots" by Anthony McCosker and Amelia Johns, which you looked at as part of Chapter 10, and explains what makes it such a strong conclusion. How does your conclusion compare?

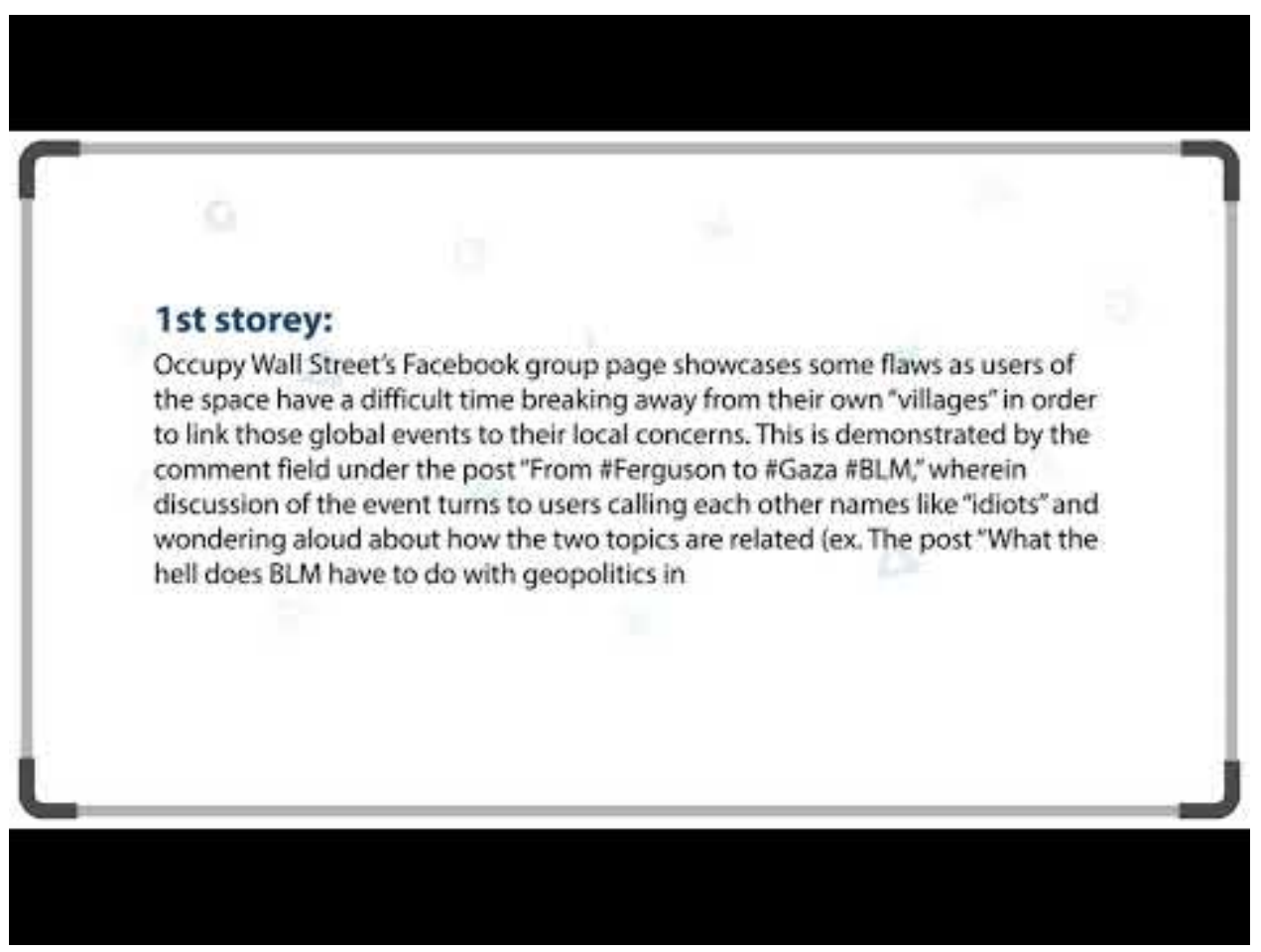

A YouTube element has been excluded from this version of the text. You can view it online here: https://pressbooks.library.ryerson.ca/writehere/?p=1150 


\section{Revising and Editing for the Last Time}

Congratulations! You are nearly done! Now that you written your entire essay, it is time to do some last revisions and proofreading before submitting it; you may wish to return to the beginning of this chapter and use the $5^{\text {th }}$-level questions to help you in these final stages. Complete your Works Cited or Reference page and check all your in-text citations; if you need further resources on how to do this correctly, see Chapter 8. You are going to do one last self evaluation and then some further revisions in response to that evaluation. Reread your essay and, once you've finished, complete the self-evaluation below, giving yourself 1 point for every Yes answer.

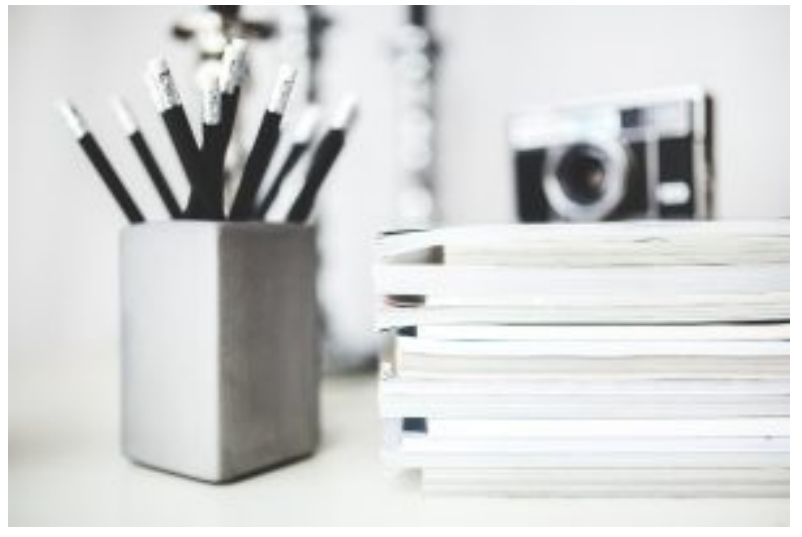

From Pexels. 


\section{Self-Evaluation}

\section{Taking Measure}

\section{Introduction}

Does your introduction contain a specific and illustrative strategy that introduces your thesis? $\mathrm{Y} / \mathrm{N}$

Does your introduction contain your two-storey thesis?

$\mathrm{Y} / \mathrm{N}$

Does your thesis point clearly to your central document?

$\mathrm{Y} / \mathrm{N}$

Does your thesis contain two specific pieces of evidence from your central document? $\mathrm{Y} / \mathrm{N}$

Does your thesis contain a complex argument that follows logically from those pieces of evidence? $\mathrm{Y} / \mathrm{N}$

Is every quotation and/or paraphrase cited correctly using correct in-text citation? $\mathrm{Y} / \mathrm{N}$

Have you read your introduction out loud and found no grammatical or syntactical errors? $\mathrm{Y} / \mathrm{N}$

\section{Body Paragraphs}

Do you have a topic sentence for each paragraph?

$\mathrm{Y} / \mathrm{N}$

Does that topic sentence build on the information or analysis given in the previous paragraph? $\mathrm{Y} / \mathrm{N}$

Does the content of the paragraph relate to the topic sentence? $\mathrm{Y} / \mathrm{N}$

Does the end of each paragraph transition into the following paragraph? $\mathrm{Y} / \mathrm{N}$

Is every quotation and/or paraphrase cited correctly using correct in-text citation? $\mathrm{Y} / \mathrm{N}$ 
Did you define all the key terms within your argument with a scholarly definition?

$\mathrm{Y} / \mathrm{N}$

Is each quotation introduced and contextualized?

$\mathrm{Y} / \mathrm{N}$

Is each quotation within each paragraph analyzed fully and actively?

$\mathrm{Y} / \mathrm{N}$

Is the analysis of the central document detailed and specific?

$\mathrm{Y} / \mathrm{N}$

Does the analysis of the central document arrive at evidence that supports your complex argument?

$\mathrm{Y} / \mathrm{N}$

Is each piece of scholarly research (quotation, statistic, definition) analyzed actively and fully?

$\mathrm{Y} / \mathrm{N}$

Does each piece of scholarly research refine your complex argument?

$\mathrm{Y} / \mathrm{N}$

Does at least one body paragraph clearly state your complex argument clearly and logically?

$\mathrm{Y} / \mathrm{N}$

Does your essay build logically to include your third storey?

$\mathrm{Y} / \mathrm{N}$

Do you dedicate at least one paragraph to explaining your third storey?

$\mathrm{Y} / \mathrm{N}$

Does your third storey include scholarly research?

$\mathrm{Y} / \mathrm{N}$

Does your third storey add something new to your second storey?

$\mathrm{Y} / \mathrm{N}$

Have you read your body paragraphs out loud and found no grammatical or syntactical errors? $\mathrm{Y} / \mathrm{N}$

\section{Conclusion}

Does your conclusion respond to the thesis in your introduction?

$\mathrm{Y} / \mathrm{N}$

Does your conclusion include an effective concluding strategy?

$\mathrm{Y} / \mathrm{N}$

Does your conclusion contain your final, complex argument? 
$\mathrm{Y} / \mathrm{N}$

Does your conclusion provide closure to your reader?

$\mathrm{Y} / \mathrm{N}$

Is every quotation and/or paraphrase cited correctly using correct in-text citation?

$\mathrm{Y} / \mathrm{N}$

Have you read your conclusion out loud and found no grammatical or stylistic errors?

$\mathrm{Y} / \mathrm{N}$

\section{Academic Style: Formatting/Works Cited/References}

Do you have a cover page, if it is appropriate?

$\mathrm{Y} / \mathrm{N}$

Have you titled your paper and included your personal information correctly?

$\mathrm{Y} / \mathrm{N}$

Have you double checked your machine-generated citations for errors?

$\mathrm{Y} / \mathrm{N}$

Have you used a consistent citation style?

$\mathrm{Y} / \mathrm{N}$

Have you cited every source that you referenced in your essay?

$\mathrm{Y} / \mathrm{N}$

Are your citations in alphabetical order?

$\mathrm{Y} / \mathrm{N}$ 


\section{Try This!}

\section{Activity}

Now that you've completed your self-evaluation, you have a better sense of what might be the last few places you need to revise in your essay. Return to the different levels of revision from the beginning of this chapter, answer the question for two levels and do two more revisions with those specific levels as your directives. Pay special attention now to your conclusion in your revisions. Does it follow from the previous logic in your essay? Does it in fact conclude your essay? Does it contain your final argument?

As you are responding to these questions, for your last revisions, bring your computer to a different room or print your essay and read it out loud to yourself. Every time that you find yourself stumbling, mark it in the margins of your essay and correct it once you are done reading the whole essay. Try not to correct it in the moment: interrupting yourself may disrupt your understanding of the logical flow of the article and it is useful to do at least one relatively uninterrupted, continuous reading of your work. 


\section{The Last Edit}

Your last revisions have polished your essay and you are nearly ready to submit it. Before you do, however, you must do one last edit for spelling, punctuation, and typographical errors. This level of editing should be the last thing you do. In earlier stages of revision, you are changing content and sentences, adding and deleting content and quotations-it doesn't make sense to focus on micro-issues like commas and spelling so much of the essay was still in flux. Correcting these types of errors is important not because professors take off of points, but because every time your reader comes across an error, it takes them out of your complex argument and interrupts the logical flow of your argument. In this way, punctuation, grammatical and spelling errors get in the way of understanding your complex argument, and your grade will be affected. This is also a good time to double check whether you've correctly spelled all the scholars' names that you reference and that you have double checked your in-text citations and your Works Cited/References to ensure you have all your sources and that they are cited correctly. Again, while this last edit may seem somewhat cosmetic, it ensures that your reader will have no reason to be distracted from your argument.

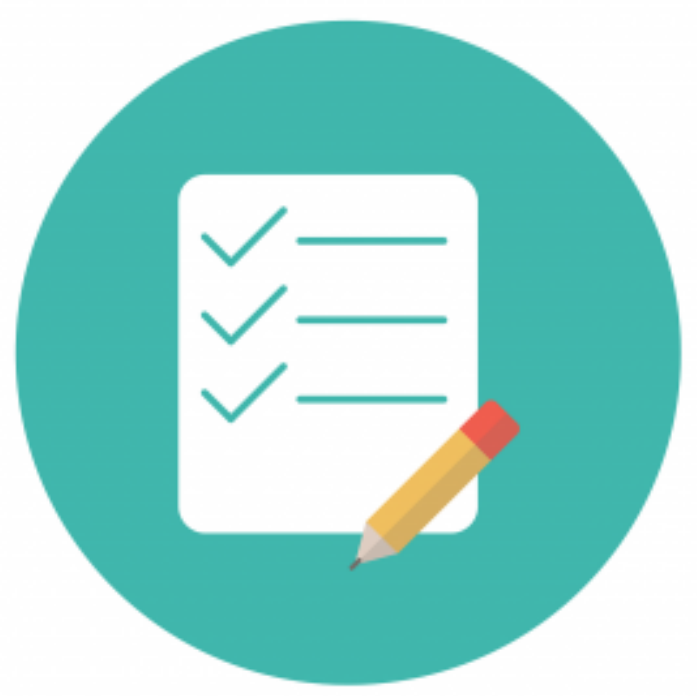

From Pixabay. 


\section{YOU'RE DONE!}

Once you've revised the digital version of your essay, print it. Do one last check: ensure that you have a title page if your citation style requires it; ensure that your name and the page number is on each page; ensure that you have your Works Cited /References at the end of your essay; lastly, make sure that you staple or paperclip it all together if submitting in hard copy.

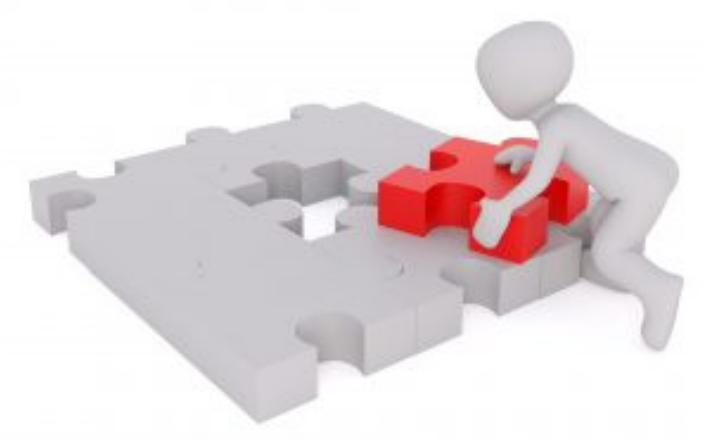

From Pixabay.

Congratulations! You are finished your essay and ready to submit! Before you submit your essay, spend just a few moments reflecting on your writing and the progress you've made. Think back to the first writing that you did for this course.

- In what ways do you think you've most improved?

- What do you think is the most important skill to have when writing academically?

- What do you think is the most important skill to have when reading academically?

- What skills are you most likely to carry into writing in your other courses?

- How much time did you spend writing? In what stage of writing did you spend your most time?

- How much time did you spend editing? In what stage of editing did you spend your most time?

- What would you like to improve about your writing going forward?

- What is the one thing you would recommend to a first-year university student about writing academically?

Once you've thought about these questions, make sure to take some time to relax and celebrate. You've worked incredibly hard and made a lot of improvements! What you've done is a major accomplishment and you should celebrate it as such! 



\section{CHAPTER I3: WORKS CITED}





\section{Chapter Overview}

\section{Learning Outcomes}

\section{In this chapter we will:}

- $\quad$ Explain why citing is necessary and how to do it.

- $\quad$ Describe two citation styles and provide examples for common types of sources.

- $\quad$ Suggest ways of keeping track of the sources and creating error-free bibliographies. 


\section{Introduction to Citations}

A citation is a reference to another person's work within the text of your essay. Before writing an academic essay you are expected to read what others have written on the topic, think about it, and construct an argument of your own. When you include a citation to another work within a paragraph of your own words and ideas, you prove to your audience that you have done some research before formulating your argument.

Citing other points of view on a topic positions your ideas within the scholarly conversation on a topic. When you are quoting numbers and statistics, citations provide a way for your readers to confirm that the information is factual and can be trusted. Whether you are asserting a unique take on a classic novel or developing an improved cooling valve for the International Space Station, citations give your audience confidence that you have done some exploring, you have done some thinking, and you know what you're talking about.

Citations provide just enough details to lead your reader to the sources you used, in a standardized format. Students are often required to include scholarly citations in their academic writing, but other types of writing can benefit from citations as well.

Researchers in the social sciences tend to cite scholarly articles and the APA (American Psychological Association) style was designed for referencing secondary sources.

Researchers in the humanities often cite a variety of source types, including archived personal letters or first-edition works, which suits the MLA (Modern Language Association) style.

Both of these citation styles are developed by committees and updated every few years to reflect changes in information sources, so make sure you consult the most current manual. 


\section{Scholarship is a Conversation}

Watch Video 13.1 to learn more about the importance of citations and references.

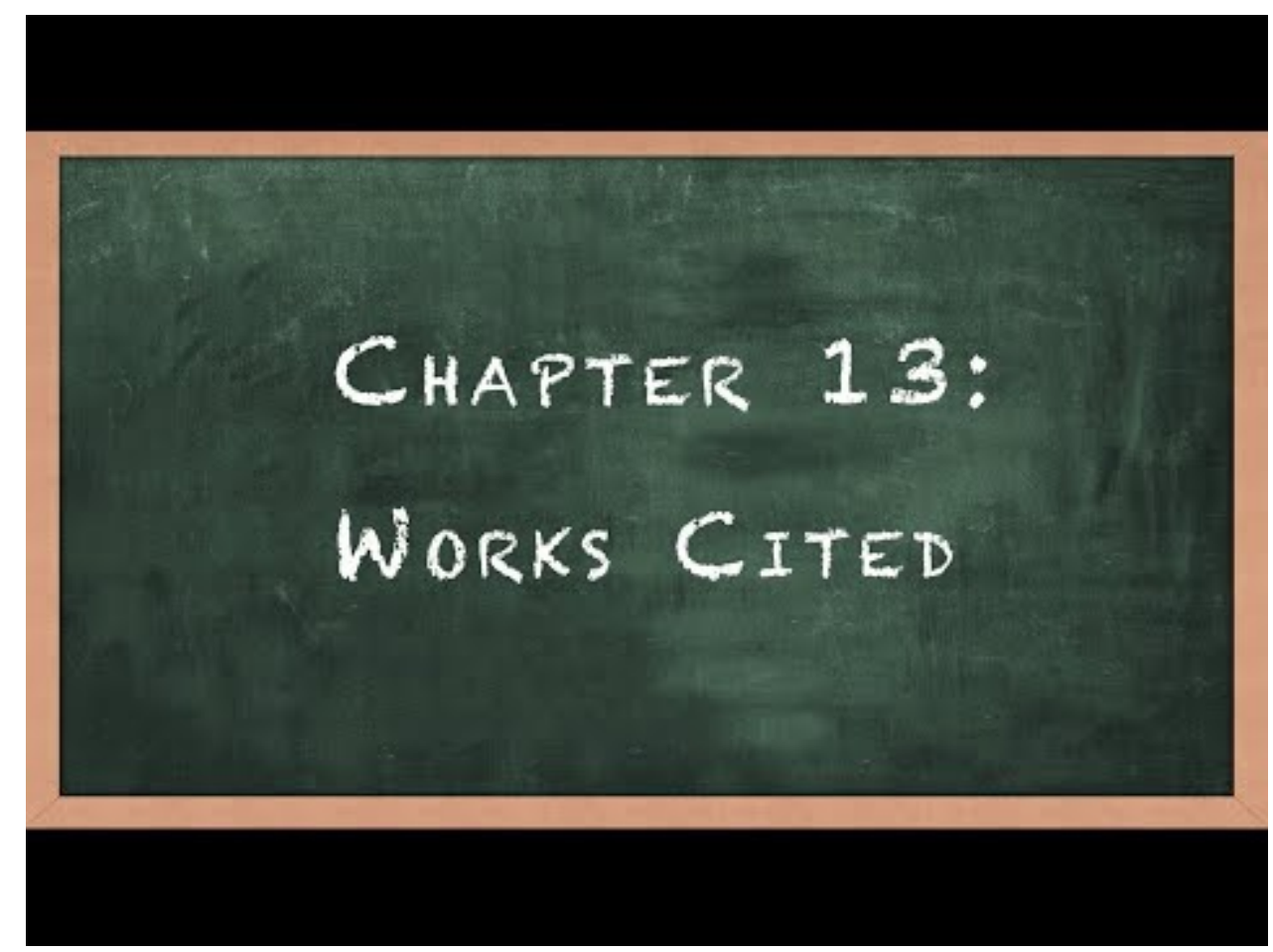

A YouTube element has been excluded from this version of the text. You can view it online here: https://pressbooks.library.ryerson.ca/writehere/? $p=1176$

Over time, as students and scholars write about a topic, the accumulation of writing becomes a scholarly conversation. With each writer, new insights and discoveries are documented over time, adding different perspectives and interpretations. In science, for example, the conversation has lead to improved technology and treatment for illness.

Referring to other essays, studies and reports and describing how they relate to your own work gives authority to your arguments. This is particularly important when people have different opinions about the topic you are addressing in your writing. Citing other researchers proves that you know what you are saying is relevant, since you're placing your words in the context of the existing literature. If the topic you are writing about is subjective in nature, your reader knows you've consulted other research and your opinions are based on some consideration of the scholarly conversation on that topic.

Citations help to demonstrate that your work is really your work. Informing readers where you found information helps to distinguish between existing sources and your original thoughts. By revealing your sources, you are proving that your work can be trusted. This is super important! Failing to cite can lead to a charge of plagiarism, which can result in a mark of zero on the assignment, or a failing grade in the course. Read the definition of plagiarism by Ryerson's Academic Integrity Office.

Many readers (such as the person marking your assignment!) want to know whose work inspired your ideas. Many 
readers want to follow the trail of evidence you've used to support the points you've made. Citations give enough information to make it possible for others to locate and read the sources for themselves.

In addition to written words, your research may lead you to social media posts, personal correspondence such as email messages, films, maps, graphs, web pages, photographs, television news reports, lectures, and audio recordings. Cite everything you use to learn about the topic and formulate your own arguments: the texts you read, the audio you hear, and the videos you watch. Keep track of all of the resources you use as you do research for your assignments.

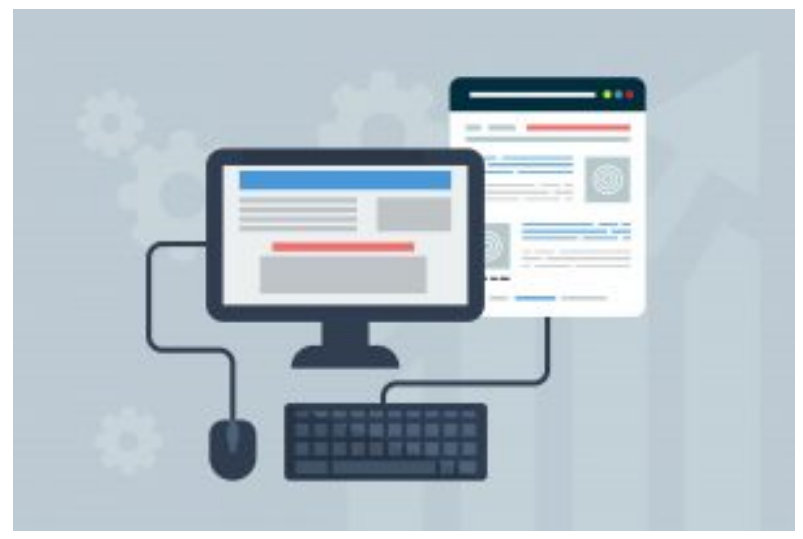

From Pixabay.

Quote something when it's memorable, the phrasing is evocative or a "classic". You might quote also for precision and accuracy, or when something is short.

Paraphrase to express the situation and ideas in your own words as they relate to your argument.

Summarize/synthesize to provide an overview of the ideas as they relate to your essay. Ideas must also be attributed, even when you are not pointing to a specific paragraph or page.

Scenario: Imagine yourself spending months traveling and doing research in your field of expertise. Your blog serves as a travel journal where you upload photographs, itineraries and short essays about your field work, as you gather evidence for a book.

Soon after, you read an article in a newspaper about traveling that includes some of the exact sentences you wrote on your blog, with one of your photographs. There is no mention of your name. While it is satisfying to know someone thought so well of your work, you expect them to acknowledge that the phrasing and photography was originally your work.

In the music industry, using another artist's words without giving them credit leads to a copyright infringement lawsuit. In an academic context, the charge of plagiarism can result in a mark of zero on the assignment, or a failing grade in the course. 


\section{Watch This!}

Plagiarism, how not to do it (2:50)

Pause and Reflect

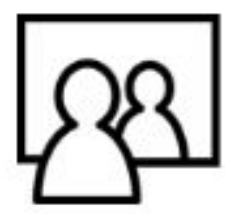

What are the consequences of a plagiarism charge for students at Ryerson? Activity

1. Check your course outline to verify whether you must submit to turnitin.com

2. Get help with writing assignments at an academic integrity workshop 


\section{What is Bibliographic Information?}

Bibliographic information refers to specific elements such as the author's name, the title of the thing (book, documentary, journal article) and the date it was created. Author + Title + Date are the most common pieces of information and they are often found on a book's title page and the back of the title page, also known as the verso. Often the date is found on the verso.

For example:

Indigenous Writes A Guide to First Nations, Métis \& Inuit Issues in Canada

Chelsea Vowel

Highwater

Press

Verso of title page

(C) 2015 Chelsea Vowel

APA reference for this book

Vowel, C. (2016). Indigenous writes: A guide to First nations, Métis, and Inuit issues in Canada. HighWater Press.

MLA reference for this book

Vowel, Chelsea. Indigenous Writes: A Guide to First Nations, Métis, and Inuit Issues in Canada. HighWater Press, 2016.

The exact bits of information you need depends on the type of resource being cited.

Bibliographic information for a journal article includes

- publication date

- a volume number, and sometimes an issue number.

- the title of the journal

- the title of the article

This screenshot shows bibliographic information for online journal article published in a journal called The American Sociologist 


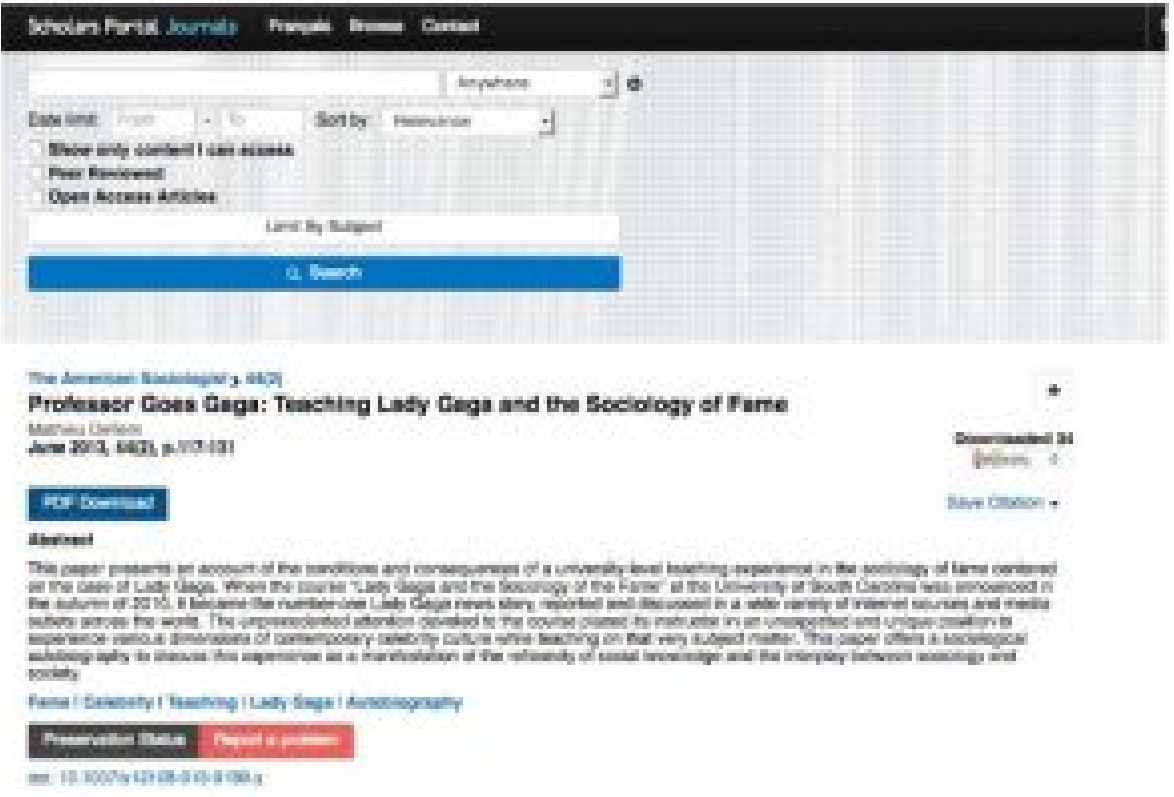

APA reference for this journal article

Deflem, M. (2013). Professor goes gaga: Teaching Lady Gaga and the sociology of fame. The American Sociologist, 44(2), 117-131. doi: 10.1007/s12108-013-9180-y

MLA reference for this journal article

Deflem, Mathieu. "Professor Goes Gaga: Teaching Lady Gaga and the Sociology of Fame." The American Sociologist, vol. 44, no.2, (2013), pp. 117-131. doi: 10.1007/s12108-013-9180-y

Bibliographic information for a chapter in a book includes 2 titles - the chapter title and the book title.

Chepter 6 - Indigenous Science: Proven, Practical and
Timeless

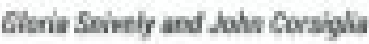

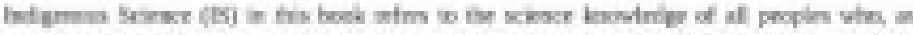

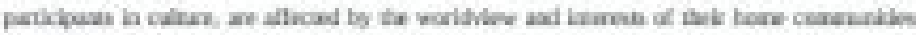

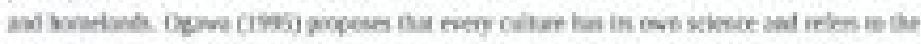

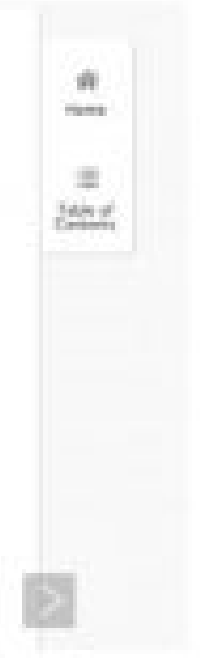

APA reference for this chapter in an online book

Snively, G., \& Corsiglia, J. (2016). Indigenous science: proven, practical and timeless. In G. Snively \& Wanosts'a7 Lorna Williams (Eds.), Knowing Home: Braiding Indigenous Science with Western Science, Book 1. Victoria: University of Victoria. 
https://pressbooks.bccampus.ca/knowinghome/chapter/chapter-6/

MLA reference for this chapter in an online book

Snively, Gloria and John Corsiglia. "Indigenous Science: Proven, Practical and Timeless." Knowing Home: Braiding Indigenous Science with Western Science, Book 1, edited by Gloria Snively and Wanosts'a7 Lorna Williams, University of Victoria, 2016.

pressbooks.bccampus.ca/knowinghome/chapter/chapter-6/

Bibliographic information for a resource on the web may include a URL or DOI - digital object identifier.

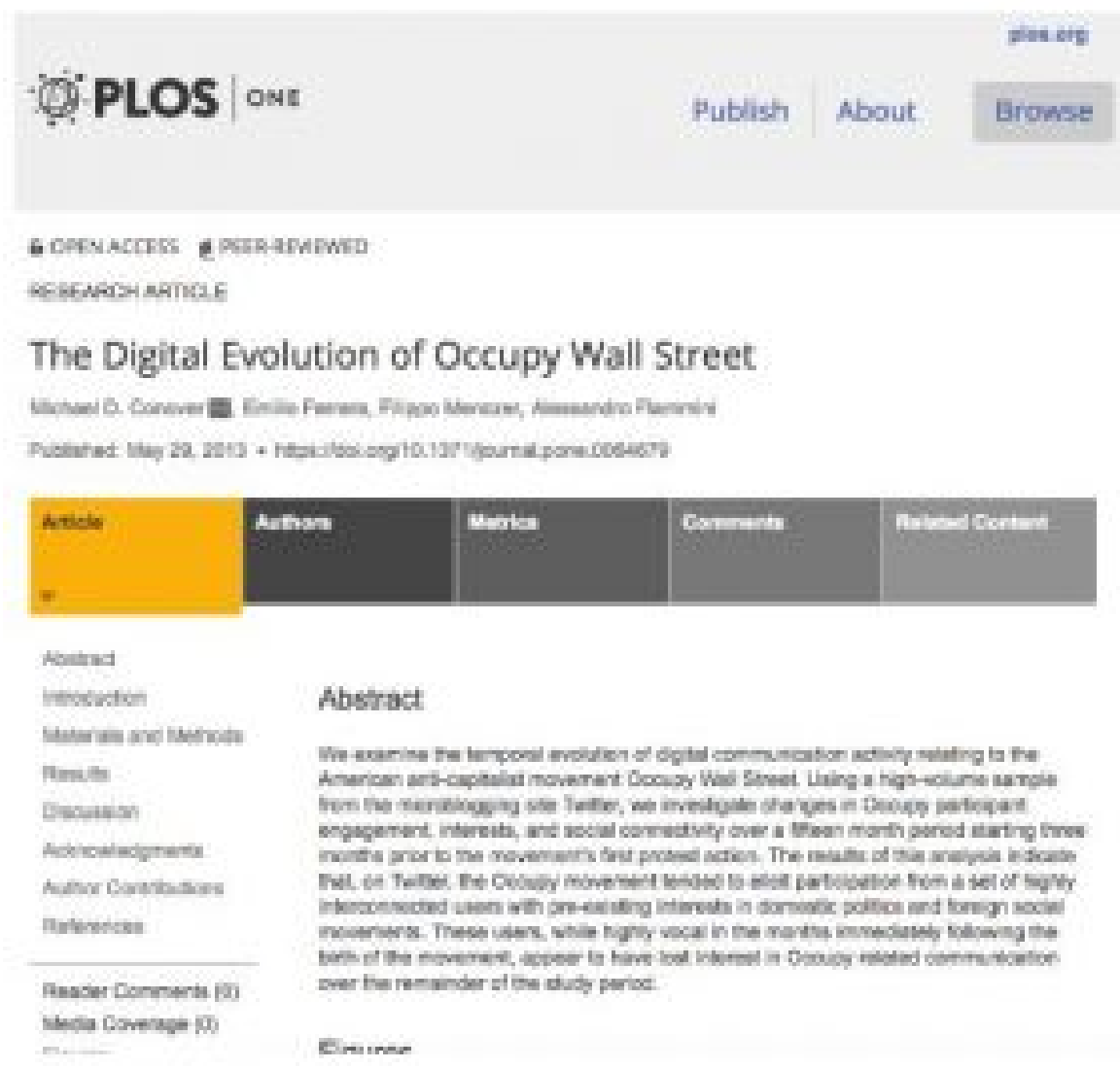

APA reference for this online resource

Conover, M. D., Ferrara, E., Menczer, F., \& Flammini, A. (2013). The digital evolution of Occupy Wall Street. PloS One, 8(5). doi:10.1371/journal.pone.0064679

MLA reference for this online resource

Conover, Michael D., et al. "The Digital Evolution of Occupy Wall Street." PloS One, vol. 8, no. 5, 2013. doi:10.1371/ journal.pone.0064679 


\section{Try This!}

\section{Activity}

Go to the website of the Digital Object Identifier Foundation and use the DOI in this citation to find the article online. 


\section{What is a Bibliography?}

A Bibliography is a list, in alphabetical order, of all the sources consulted for a piece of writing.

In most cases students are instructed to include a bibliography with only those sources actually cited within their paper.

In the APA citation style this is called a References page. View this Google doc to see a bibliography in a References list in APA style. Check out the bibliography in this sample paper in APA style on the OWL site.

In the MLA citation style a bibliography is referred to as a Works Cited page. View this Google doc to see the same bibliography in a Works Cited list in MLA style. Check out a sample MLA paper at OWL Purdue

Research tip!

Once you have found an relevant article or book that you can use in your research, look at the bibliography. It's full of potentially useful research that you can use.

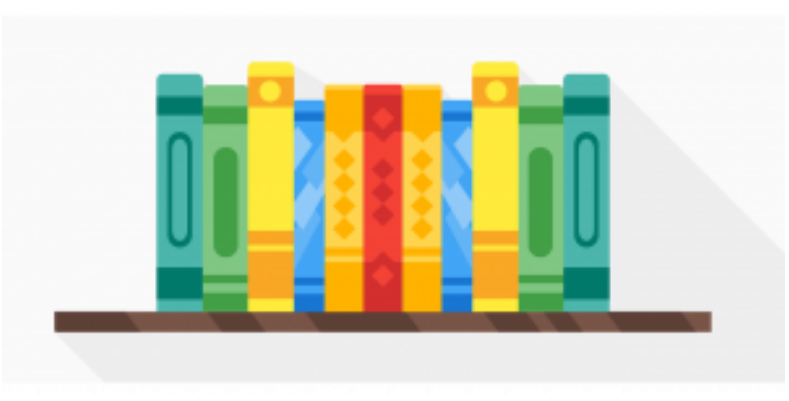

From Pixabay. 


\section{Citation Styles}

Citations are an important part of the scholarly conversation. The order of the bibliographic elements is prescribed by the citation style, which is a convention for the sequence of information and punctuation used. People write for different purposes and different audiences. Citation styles reflect these differences by specifying:

1. How to structure the elements (such as date and title) within a citation and

2. All of the details that should be included in the bibliography, which goes at the end of your essay

Citation styles force researchers to standardize the content and format of their citations and references. When the title and date are always found in the same place in every citation, research is a bit easier because the information is presented in a consistent way. Whether you are citing print books or YouTube videos, this protocol of scholarly conversation is an efficient way to discuss and share sources. 


\section{Citation Tip!}

Read the assignment instructions to determine which citation style you should use. If you are allowed to choose one for yourself, the most important thing to remember is: use one style per assignment and be consistent, do not mix and match styles within a paper.

\section{APA citation style}

The American Psychological Association style is used primarily in the social sciences, including economics, geography, journalism, criminology and law.

APA reference style is based on the following:

- Each reference begins with the author's last name followed by initial(s), and the list is in alphabetical order

- Capitalize only the first letter of the first word of a title and subtitle, the first word after a colon or a dash in the title, and proper nouns.

- The first line of each entry in your reference list should be left justified and remaining lines indented one-half inch from the left margin, which is called hanging indentation.

- Italicize titles of longer works such as books and journals, but not the titles of shorter works such as journal articles or essays in edited collections.

- Do not italicize, underline, or put quotes around the titles of shorter works.

- APA recommends providing a Digital Object Identifier (DOI), when it is available, as opposed to the URL. Always check with your instructor to confirm that you should include DOIs or URLs in your bibliography.

See the full list of instructions on citing with APA at the OWL Purdue Online Writing Lab.

\section{APA citation for a journal article}

Author surname, initial. (Date). Title of article. Title of journal, volume number (issue number), pages.

Brown, J., \& Duguid, P. (1996). The Social Life of Documents. First Monday, 1(1).

http://firstmonday.org/ojs/index.php/fm/article/view/466

\section{How to cite and reference with APA}

When summarizing the facts from another writer's piece of writing, an in-text citation is used to credit the original author. You can do this by including a short quotation from the original text within your work, or a paraphrase of the ideas, followed by the author and year of publication.

Despite the media's insistence that it is colourblind, Serena is most often portrayed as a symbol of black pride and heritage. (Schultz, 2005). 
Another option is to begin the sentence with a signal phrase that includes the author's last name followed by the date of publication in parentheses:

According to Schultz (2005), despite the media's insistence that it is colourblind, Serena is most often portrayed as a symbol of black pride and heritage.

When including a direct quote, add the page numbers.

According to Schultz (2005) "In the overwhelmingly white world of professional tennis, Serena Williams and her older sister Venus are frequently re-presented in the tradition of black pride and heritage" (p. 339).

Include the full reference of the journal article in the References:

Schultz, J. (2005). Reading the catsuit: Serena Williams and the production of Blackness at the 2002 US Open. Journal of Sport and Social Issues, 29(3), 338-357.

In this APA example of in-text citing, the author's name \& publication date is included as part of the sentence. The quote is followed by the page number in parentheses (including lowercase letter p. - which MLA does not include)

Ruffo (2015) said his poems were a natural and spontaneous response to being moved by Morrisseau's art, and focused on the paintings he admired most (p. 9).

Include the full reference in the bibliography at the end of your paper like this:

Ruffo, A. G. (2015). The Thunderbird poems. Harbour Publishing.

\section{APA reference examples}

Book

Vowel, C. (2016). Indigenous writes: A guide to First nations, Métis, and Inuit issues in Canada. HighWater Press. Chapter in a book

Fong, E. (2017). Residential segregation of visible minority groups in Toronto. In Roland Sintos Colomba and Gordon Pon (Eds.), Asian Canadian studies reader. Toronto: University of Toronto Press.

Scholarly journal article

Deflem, M. (2013). Professor goes gaga: Teaching Lady Gaga and the sociology of fame. The American Sociologist, 44(2), 117-131.

Government document online

Mackay, R., Phillips, K., \& Canada. Parliamentary Information and Research Service. (2016). The legal regulation

of marijuana in Canada and selected other countries. Library of Parliament. Retrieved from https://lop.parl.ca/ Content/LOP/ResearchPublications/2016-94-e.pdf

Lecture

Ehret, S. (18 January 2018). Introduction and Overview of the Canadian criminal justice system. CRM 100: Introduction to Canadian Criminal Justice [Lecture]. Ryerson University.

Film

Monkman, K. (Director) \& Lee A. (Producer). (2015). Sisters \& brothers [Film]. Canada: National Film Board.

Online magazine article

Cole, D. (2015). The Skin I'm in. Toronto Life, 49. https://torontolife.com/city/life/skin-im-ive-interrogatedpolice-50-times-im-black/

Tweet

@ladygaga. (12 Sept. 2017). In our documentary the \#chronicillness \#chronicpain I deal w/ is \#Fibromyalgia I wish to help raise awareness \& connect people who have it. [Tweet] https://twitter.com/ladygaga/status/ $\underline{907571825294675968}$ 
YouTube video

Stoehr, K. \& Eisen A. (2014). Research 101: Scholarship is a Conversation. [Video file]. Retrieved from: https://youtu.be/YGia3gNyHDM

Music

Beyoncé (2016). Formation. On Lemonade, Parkwood Entertainment. www.beyonce.com/album/lemonadevisual-album

Art

Pratt, C. (1965). Young girl with seashells [Oil on board]. Memorial University Art Gallery Permanent Collection, Corner Brook, NL. 


\section{MLA Citation Style}

The Modern Language Association style is used primarily in the humanities, including literature, visual arts, music and philosophy.

MLA reference style is based on the following principles:

- Always include these essential bits of information with specific punctuation and in this order

Author.

Title of source.

Title of container,

Other contributors,

Version,

Number,

Publisher,

Publication date,

Location.

- Chapters and journal articles are pieces of information contained within larger containers. The larger container holds the smaller sections. For example, a short story may be contained in an anthology. The short story is the source, and the anthology is the container. Information about both the specific chapter/article and the container are formatted in a specific way in MLA citations.

- Capitalize each word in the titles of journal articles, books, etc. Do not capitalize initial articles (the, an), prepositions, or conjunctions unless one is the first word of the title or subtitle.

- Italicize titles of containers and use quotation marks around titles of shorter works within them.

- The eighth edition recommends including URLs when you cite online sources. Always check with your instructor to confirm that you should include DOIs or URLs in your bibliography.

Detailed instructions about each element can be found on the OWL Purdue MLA site. 


\section{How to Cite and Reference with MLA}

When paraphrasing ideas or summarizing the facts in a piece of writing, parenthetical citation is used to credit the original author. You do this by including the author's last name and the page number(s) in parentheses at the end of the sentence:

The media is more interested in reporting on Serena's appearance than her spectacular athletic abilities (Schultz 338).

Another method is to include the author's name in the sentence with the page number(s) in parentheses at the end of the sentence.

Schultz argues that the media is more interested in writing about Serena's appearance than her spectacular athletic abilities (338).

Include the full reference of the journal article in the Works Cited list.

Schultz, Jaime. "Reading the catsuit: Serena Williams and the production of blackness at the 2002 US Open." Journal of Sport and Social Issues, 29(3), 2005, pp. 338-357.

In this MLA example of in-text citing, the author's name is used in the introductory phrase (a.k.a. signal phrase), the page number is in parentheses and follows the sentence:

According to Ruffo, his poems were meant to create a connection between the paintings and actual events in Morrisseau's life (9).

Include the full reference in the bibliography at the end of your paper like this:

Ruffo, Armand G. The Thunderbird Poems. Harbour Publishing, 2015.

\section{MLA Reference examples}

Book

Vowel, Chelsea. Indigenous Writes: A Guide to First Nations, Métis, and Inuit Issues in Canada. HighWater Press, 2016.

Chapter in a book

Fong, Eric. "Residential Segregation of Visible Minority Groups in Toronto." Asian Canadian studies reader, edited by Roland Sintos Colomba and Gordon Pon, University of Toronto Press, 2017.

Scholarly journal article

Deflem, Mathieu. "Professor Goes Gaga: Teaching Lady Gaga and the Sociology of Fame." The American Sociologist, vol. 44, no. 2, 2013, pp. 117-131.

government document available online

Mackay, Robin, Karin Phillips, and Canada. Parliamentary Information and Research Service. The Legal Regulation of Marijuana in Canada and Selected Other Countries. vol. 2016-94-E., Library of Parliament, 2016. lop.parl.ca/ Content/LOP/ResearchPublications/2016-94-e.pdf

Lecture

Ehret, Stephanie. "Introduction and overview of the Canadian criminal justice system" CRM 100: Introduction to Canadian criminal justice [lecture]. Ryerson University, 18 January 2018.

Online Video

Rose, Martine, director. Trawna Tuh Belvul. National Film Board of Canada, 1994. www.nfb.ca/film/ trawna_tuh_belvul/ 
Article in a magazine

Cole, Desmond. "The Skin I'm in." Toronto Life, vol. 49, 2015.

Tweet

@ladygaga. "In our documentary the \#chronicillness \#chronicpain I deal w/ is \#Fibromyalgia I wish to help raise awareness \& connect people who have it." Twitter, 12 Sept. 2017. twitter.com/ladygaga/status/907571825294675968 YouTube

Stoehr, Kali \& Eisen, Anna. "Research 101: Scholarship is a Conversation." Youtube, 2014. youtu.be/YGia3gNyHDM Music

Beyoncé. "Formation." Lemonade, Parkwood Entertainment, 2016, www.beyonce.com/album/lemonade-visualalbum/

Art

Pratt, Christopher. Young Girl with Seashells. 1965. Memorial University Art Gallery Permanent Collection, Corner Brook. 


\section{MLA Citation for the Same Article}

Author surname, firstname. "Title of Article." Title of Journal, Volume, Issue, Year, pages.

Brown, John Seely, \& Paul Duguid. “The Social Life of Documents." First Monday, 1.1 (1996).

http://firstmonday.org/ojs/index.php/fm/article/view/466

\section{Other citation styles}

Historians generally use the Chicago Manual of Style or its derivative, A Manual for Writers of Term Papers, Theses, and Dissertations which is commonly known as Turabian after the manual's author. Chicago is the standard style used for book publishing in North America, so books will generally use Chicago, even in the disciplines that use APA or MLA.

Recommended resource:

Citing for anthropologists, biologists, and other specialized disciplines at Simon Fraser University, BC

Why are there so many Different Citation Styles?

\section{Remember!}

At the university level, writing essays means entering an ongoing scholarly conversation. Throughout history scholars have addressed the subjects you are studying in your courses and have articulated similar concerns and ideas as the ones discussed in your classes. Engaging with existing scholarship and citing in your essay makes you part of the conversation. Congratulations! 


\section{Document Your Research As You Go! (or, How Not to Cry When Creating a Bibliography)}

Writing an essay begins with gathering evidence - reading, looking for themes and patterns, following leads to other texts, and taking notes. As you read the work of other scholars and think about your approach to the topic, make it a habit to keep track of where you found the ideas and themes that spark your interest. Always note the author, date, and title in your notes to ensure you can find that source again. Keeping careful track also reduces errors in your final bibliography, which is a key part of your essay. Details are important. Citations include names of people, titles, dates and volume numbers. Formatting styles including punctuation.

These details are easy to keep track of when you use a citation manager. Citation managers (a.k.a. reference managers) are software programs that allow you to save and organize your citations, and quickly create bibliographies for your assignments. Using a digital tool will save you so much time when referring back to your sources and writing your paper and preparing your bibliography.

Activity: Review the RULA information on citation managers and choose the one that best suits your working style Wikipedia has a detailed page comparing citation managers (some of which are free)

libguide 


\section{Summary}

Video 13.2

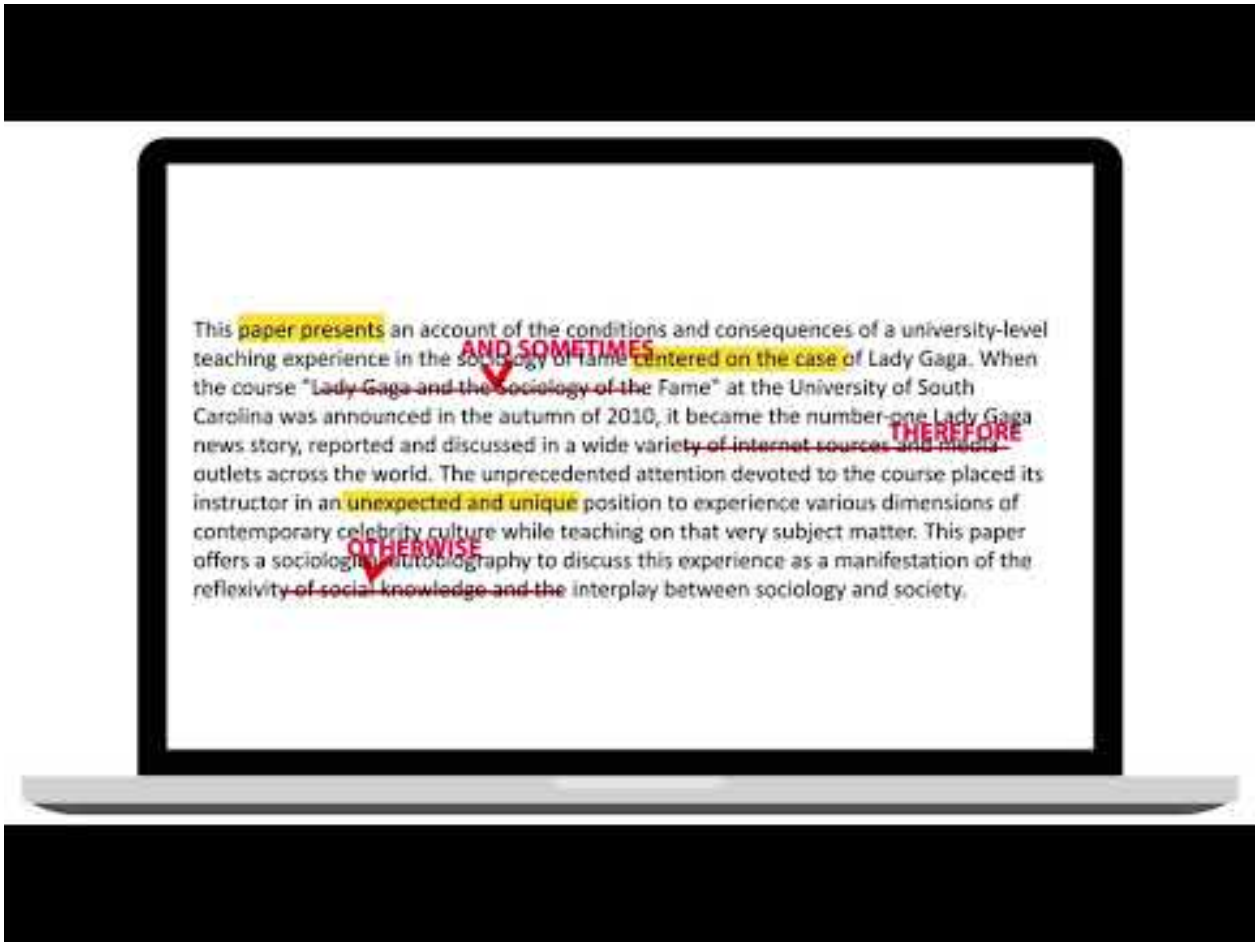

A YouTube element has been excluded from this version of the text. You can view it online here:

https://pressbooks.library.ryerson.ca/writehere/? $p=1207$

The rationale for citing carefully is to:

- Show you have read widely and creatively as per the expectations of the discipline

- Demonstrate you've learned from the work of people who studied the topic before you

- Give credit to your sources of information (definitions, other scholars' concepts, statistics) and avoid plagiarism

- Provide the details of your research path for others to follow so that they can find the materials and read/learn/ think for themselves

- Actively participate in the scholarly conversation. Go you! 


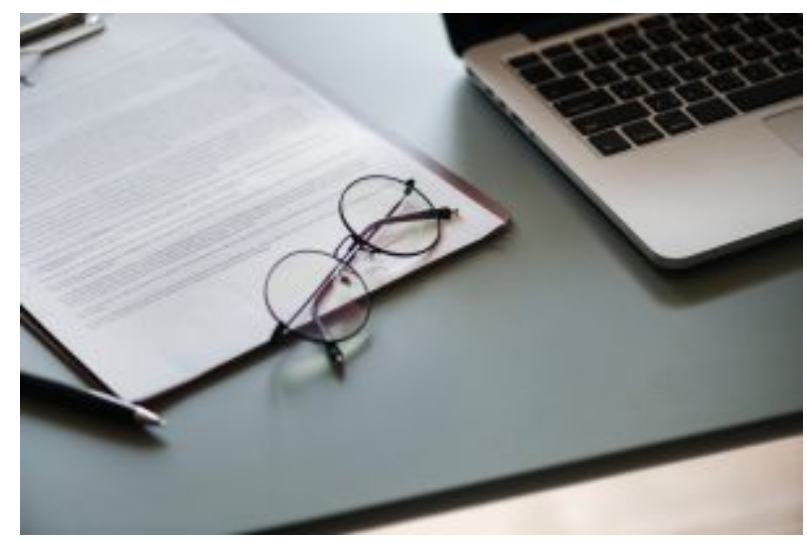

From Pixabay. 


\section{Try This!}

\section{Activity}

Spot the problems with these APA citations:

Anbarci, N., Arin, K. P., Okten, C., \& Zenker, C. (2017). Is roger federer more loss averse than serena williams? Applied Economics, 49(35), 3546-14.

Payette, J., \& Hirst, G. (1992). An intelligent computer-assistant for stylistic instruction. Computers and the Humanities, 26(2), 87.

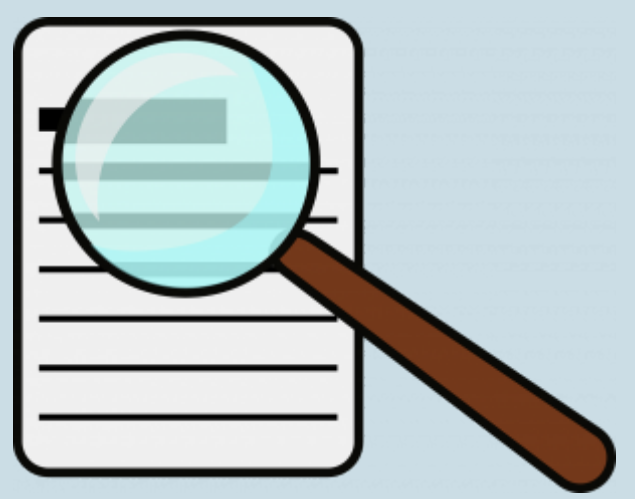

From Pixabay. 


\section{Answers to Try This!}

Answers:

Anbarci, N., Arin, K. P., Okten, C., \& Zenker, C. (2017). Is roger federer more loss averse than serena williams? Applied Economics, 49(35), 3546-14.

A: names not capitalized

Payette, J., \& Hirst, G. (1992). An intelligent computer-assistant for stylistic instruction. Computers and the Humanities, 26(2), 87.

A: journal title not italicized 


\section{Try This!}

\section{Activity}

Check out how easy it is to email citations to yourself. Do a search in RULA's Search Everything engine for your topic. Watch RULA's video tutorial on Keyword Search Strategies to optimize your results, then

1. Choose the folder icon "Save this item" beside the results you like

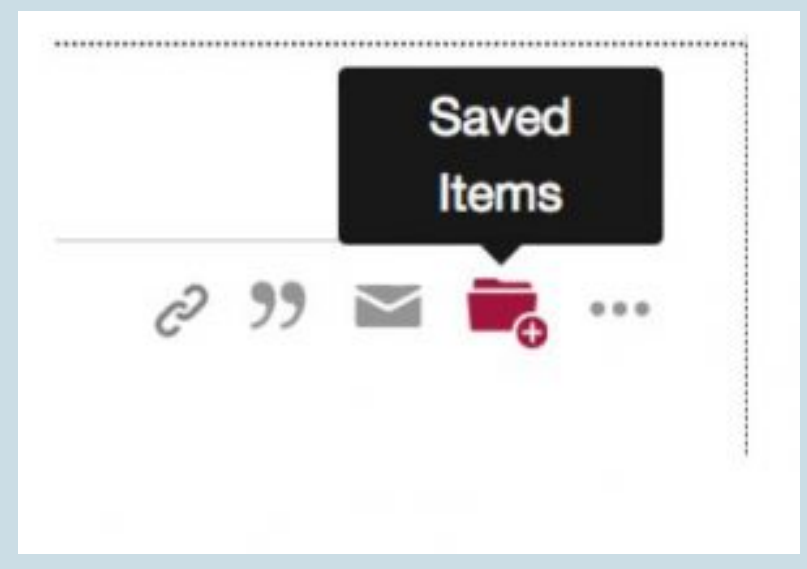

2. Open the (temporary) folder at the top right corner to see the sources you've chosen

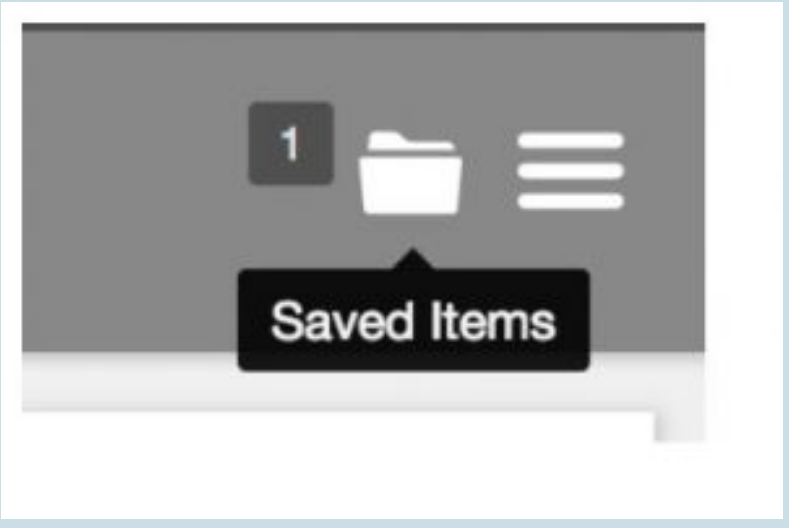

3. Select the citation style you want then email to yourself

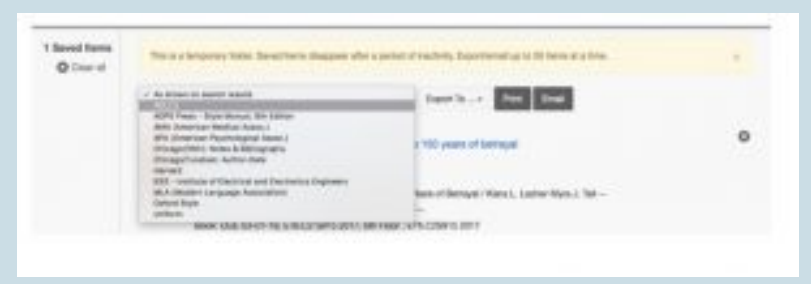


4. Warning! This is a temporary folder and will disappear when you close the browser tab or leave the session idle. It does not save your citations for later. 


\title{
Recommended Reading
}

\author{
APA Style Blog There's an Art to It \\ APA style blog: How to Cite Social Media in APA Style \\ MUN LibGuide Citing Art MLA Style \\ How to cite Statistics Canada products
}

Your Bibliography checklist

- The list starts on a new page and include the proper heading as per MLA or APA instructions.

- All entries are formatted using the same citation style.

- The second and subsequent lines of citations are indented to create a hanging indent.

- Proper nouns (names of people and names of places) are capitalized.

- List is in alphabetical order by author.

\section{Activity}

Compare the APA and MLA citations for the Encyclopedia of action research - choose "cite" 
FOR THE INSTRUCTOR 



\section{Chapter r: Time is on Your Side}

For the Instructor

Provide your students with a short article they can analyze and submit online for evaluation. Commit some class time to discussing the interesting and challenging words they found and how their initial observations and questions about these words can lead to an interrogative and focused thesis.

It would also be useful to assign your students the observational paragraph from the end of the chapter to take up in small groups during class time. This will allow for peer feedback and provide you with additional writing on which to give direct feedback.

\section{In class:}

1. Bring in an image and ask the students to analyze it using the skills detailed above. The image could be a piece of art or an advertisement. Have the students make multiple and miniscule observations and encourage them to develop the most outlandish, controversial claim they can make while making use of specifics from the image. All inferences and claims must be connected to some actual aspect of the image.

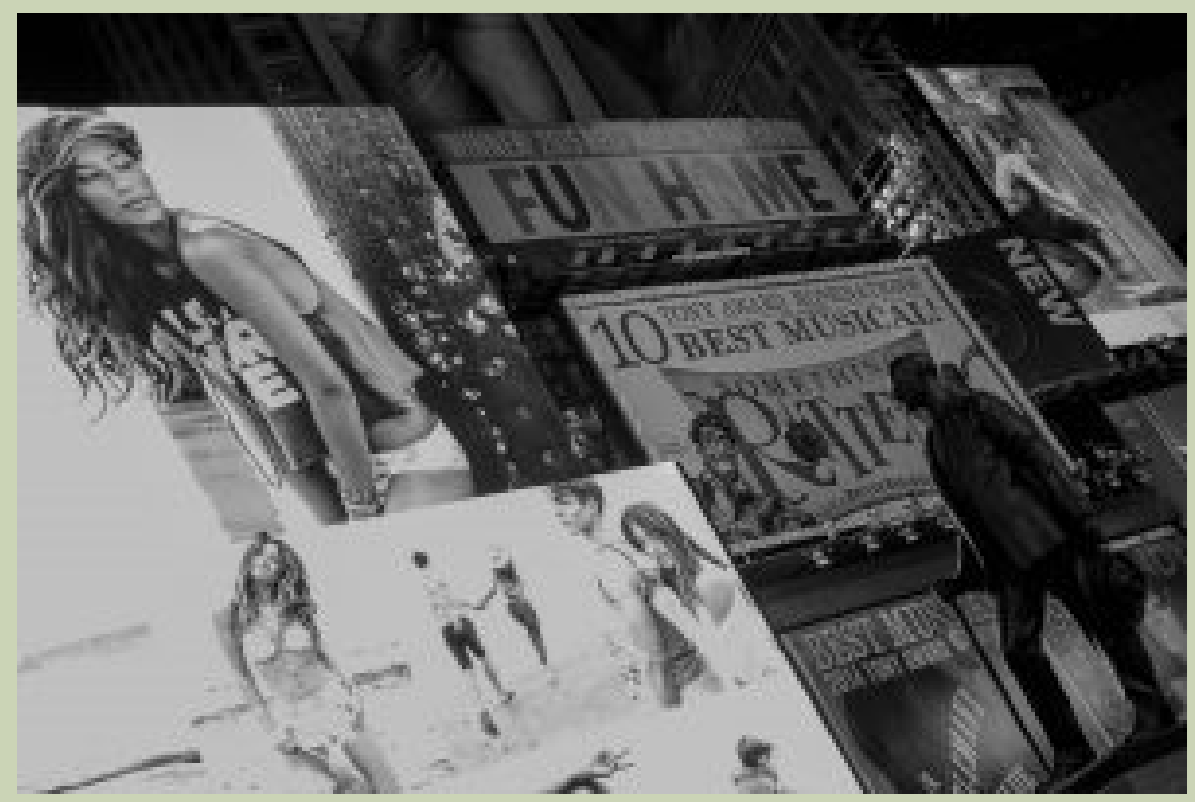

Advertising is hard to escape. Learning to analyze it is a useful skill. From Pixabay/CC0 1.0

2. Organize students into groups of 3-5 and have them analyze an unseen text you will provide them in class. Give the students time to compile information using the techniques detailed in this chapter. But rather than simply observing what is there, ask them develop an opening sentence indicative of a 
challenging, scholarly reading. Don't let students rely on phrases like "This text is about..." Encourage them to begin their examination into the motivations of the author. Require your students to consider why the author is writing, exactly what is at stake, and exactly how the author best conveys this message. Ask the students to produce a sentence following this format:

In "[Name of Article]," [Name of Author] uses citable textual evidence in order to feasible but controversial claim about what this text is really doing .

Have the students share and critique their answers.

- Which claim was the most controversial?

- Which claim promises the most interesting reading? 


\section{Chapter 2: Evidence}

\section{For the Instructor}

1. Provide your students with a short article they can analyze in an hour of class time. Organize students into groups of 4 or 5 and have each group work toward creating their two-storey opening. If possible, make special note of two openings that are contradictory but equally plausible. It is important to always reiterate to students that there are no "right" or "wrong" readings. Perhaps discuss ways to develop both of these contradictory readings into " $\mathrm{A}$ " level analytical papers.

2. Consider running a midterm workshop in class. Ask students to bring their blueprints to class. Pair them up in a peer-review exercise. Each student should evaluate the their partner's chosen focus in the first storey and then rate the interest and controversy of the claim in the second storey. 


\section{Chapter 3: The Full Three-Storey Thesis}

For the Instructor

1. This is a good time to introduce more lengthy scholarly articles or long-form articles from a well-respected popular publications. This will give the students more complex documents on which to practice the reading skills and techniques outlined in the first three chapters. Additionally, it will introduce the students to scholarly concepts that they can then use in their argumentative essay in the second half of the semester. In our own courses we use a 1969 interview of Marshall McLuhan in Playboy Magazine, which has been republished on the Next Nature Network blog.

2. If you plan to give students class time to prepare for the midterm, you can assign some of the early stages of close reading. Ask students to write a three-storey thesis statement in response to their chosen midterm article(s). They should bring their three-storey to class for peer assessment.

In class:

This week's class will likely be split into two components. In the first, if you have not done so already, have the students read the midterm articles, do a slow analysis of it (as outlined in Chapter 1) and build a two-storey thesis in response (Chapter 2). If you have already completed this in a previous week, have the students pair up and, using the short evaluation form embedded in this chapter, have them give each other a score for their thesis statements. Then have the students use this feedback to write a second draft of that two-storey thesis and, when finished, have their partner evaluate it again. Lastly, in line with the content of this chapter, have them add a third storey to their edited thesis and share with a partner. In particular, when evaluating the third storey, have the students look at their partner's thesis and answer whether their third storey addresses the questions from earlier in this chapter:

- Is the author arguing that something must be done? Why?

- Is the author offering a solution to a problem raised earlier in the text?

- Is the author warning of specific further consequences that will arise from a problem raised earlier in the text?

- What does the author want their reader to leave the text thinking and/or doing?

Before meeting in class, assign your students a more lengthy scholarly or well-respected popular article. In the second half of the class, break the students up into groups of 4 or 5 and give each of them a small portion of the text to read and analyze as experts. Ask the students, in groups, to read their excerpt and provide the key patterns, opposites, new words found within their passage (Chapter 1). After the group has done this, ask them to build a two-storey thesis in response to their excerpt. Once this has been completed, have each group present their observations and thesis statement to the class.

This activity will provide the opportunity for class discussion and a more theoretical lecture component to the class.After reading a scholarly article, students can begin talking about the complex ideas in the text and linking those ideas to the issues in their own lives that they are interested in writing about further. Ideally, this second component of class time will reiterate the close-reading and thes building skills established in the first three 
chapters of the text as well as introduce some topics and ideas that students can think and write about as part of the final essay in the second half of the semester. 


\section{Chapter 4: Getting From Your Thesis To Your Essay}

For the Instructor

As you have been working towards having the students prepare for their midterm close reading, it is best that you have them bring in a three-storey thesis to this class (as discussed in Chapter 3). It makes sense that they bring in a sample three-storey thesis statement in response to the midterm articles that you have assigned. This particular class is a very useful one for giving specific and direct one-on-one feedback on those thesis statements and giving the students activities that they can do on their own or in pairs will free you to look at student thesis statements and give specific feedback on their writing.

In class:

Have the students look at the thesis statements they wrote in response to the midterm articles and evaluate each other's work using the evaluation form earlier in this chapter. Have the students discuss their own thesis statements and give their partners suggestions and feedback. Again, while they work in pairs, you can circulate and give specific direct feedback on their writing.

After they have completed this, have them rewrite their thesis statements with a specific focus on the third storey. By the end of this activity they should have a full revised three-storey thesis statement. You could then have them meet with their partners again and share this new revised version, getting them to give each other feedback on this new version and respond to the edits that were made. Pausing to showcase exemplary student examples is a good way to model positive modes of writing and raise morale.

Lastly, have them take this new full thesis statement and expand it into an essay outline, as mapped out earlier in this chapter. It may be useful to walk them through an example, focusing on identifying the small components in their thesis statements that deserve their own paragraph(s). Again, this is an opportunity to circulate around the class and give further individual feedback. Once they have completed their essay outline, have them resume working in pairs and walk their partner through the logical process of their proposed argument without looking at their outline. Having the students explain their arguments anew will demonstrate how well they understand their own thesis and the author's argument. After this, have the partners evaluate each other's essay outlines and give feedback on the logical flow and cohesion of their partner's argument. 


\section{Chapter 5: Maintaining Focus and Purpose: The Body Paragraphs}

For the Instructor

When our students reach this stage of the writing process in our courses we like to dedicate a class to the InClass Midterm Essay Draft Exchange. We identify a "draft" as the close reading essay-in-process and we require each student to come to class with at least one typed double-spaced page of their essay. We ask that each student provide a complete introductory paragraph and at least one complete body paragraph. It is understood that this document is a draft, and while we ask our students to produce their best work, we let them know that their essays will still undergo several changes before they are ready to submit the final product.

We remind students that an introductory paragraph must contain a three-storey thesis in which they use the information gathered through analysis to establish a focus, stake a claim, and explain the purpose of the proposed essay. For the purposes of this assignment, we ask our students to underline the first storey, italicize the second storey, and bold the third storey. We have discovered that this is beneficial in both the writing and review processes. For the student writing the thesis, the different fonts make visible the connections between the storeys and, most importantly, make visible which storeys need to be lengthened or shortened. If a student's introduction is almost entirely underlined while containing only a few bolded words, it should be obvious to that student that too much time is being dedicated to textual material and not enough time is being committed to establishing the student's particular reading. Differentiating the storeys by font is also beneficial in the review process as students new to this way of writing can use the visual aid when assessing the parts of a three-storey thesis.

We put students in groups of three so each student gives and receives two sets of feedback. If time permits, we also like to have each group meet with the instructor for debriefing and additional feedback before they leave the class. We encourage students to write on each other's drafts and we also provide them with a feedback sheet with direct questions about various aspects of the draft:

\section{Introduction/Working Thesis}

1. Can you identify the writer's thesis?

1. What is the text-grounded focus identified in the first storey?

2. Does the second storey contain a controversial claim? If so, what is it?

3. Does the author explain the significance of his/her analysis in the third storey?

2. Does the thesis make a claim that is unique to the text the author is analyzing? Does the author 
use general language and terminology that could be applied to almost any essay? If applicable, please identify the generalizing terms or phrases and suggest more (text-)specific alternatives.

3. Is the thesis clear? Do you understand exactly the sort of reading the author is proposing? Do you have any suggestions to help the author establish his/her thesis?

\section{Body Paragraph(s)}

1. Does the paragraph have a topic sentence? What is the main point or claim of the paragraph?

2. Does the author use textual evidence and/or quotations? Too much? Not enough?

3. Does the paragraph contain a warrant? Does the author explain adequately how the evidence supports the claim?

We require each student to answer each question as thoroughly as possible, and we make it clear that simple yes/no answers are not acceptable. We typically make the In-Class Midterm Essay Draft Exchange an assignment worth $5 \%$ of the term grade, and this tends to incentivize maximum participation. This is one of our favourite classes of the term as students grow comfortable with sharing their work while they experience and enjoy the benefit of the in-class writing workshop. 


\section{Chapter 6: One Last Time Before You Go: The Conclusion and Final Review}

\section{For the Instructor}

To help students write their conclusions, have them review the evidence they gathered but did not include in the thesis or body paragraphs. They should try to identify a piece of evidence that pushes their claim to its ultimate extension. Have them begin drafting conclusions in which they cite and analyze that evidence.

To help students compose their final lines, ask them to consider what their focused, purposeful readings have revealed about the text. Then, ask them what still needs to be said before they leave their analysis of this article?

Have some fun with creating titles for their essays. Encourage students to consider titles that reflect the approach they are taking in their essays. According to your taste, encourage puns, or alliteration, or other forms of clever wordplay. Steer them away from "Midterm" or "Essay Number One" toward titles that invest a little of their personality into their essay. 


\section{Chapter 7: Making Your Own Argument}

For the Instructor

Part II of this textbook leads your students through the second half of the semester as they build their final essay. We have found it essential to stress that while the focus of the assignment shifts from analyzing someone else's argument to the students building their own arguments, the mechanics learned in Part I are the same as the mechanics in Part II. In our experience, students often repeat the assignment from Part I in their work for Part II and will need clarification and discussion in the shifts in purpose and scope that the assignment asks.

Just like the close reading in Part I, it would be useful for your students to come into class with some work already done. Create your essay prompts and give them to the students before they come to class this week. We've generated some sample prompts as part of the Introduction to Part II of this textbook if you would like some examples.

We recommend having your students come to class having read the chapter, chosen a prompt and having done a close reading of their prompt (which you could also check as homework). Additionally, if you have them think about, if not choose, what their central document will be, you could do some of the activities outlined in the chapter with their chosen central document.

\section{In Class}

As these are the first steps of the final project for the course, you will likely want to go over the assignment guidelines and the prompts with your class.

As well, we recommend doing a number of the activities that are done within this chapter in class with your students and their specific central documents. In particular, you may want to spend time reaffirming what a short, focused central document is and helping them find one and then write a paragraph explaining why they have chosen it. Once you do that, have them do a close reading of that document, stressing that their two pieces of evidence must be specific. The A-level example used here is useful as a guide but using your students' work as a model is also effective.

It would be ideal if your students could create a draft of the two-storey thesis and share it with a partner by the end of the class. This will also allow the students to begin thinking about and working on finding and using scholarly research in the coming weeks.

In our sections of the course, this is also the time when we plan to, within the next few weeks, take the students to the library to do some research with a professional librarian. As such, having the students complete a first draft of their two-storey thesis in class will allow them to answer some of the questions from the end of this chapter for themselves which will then make their research more focused and relevant. If you have time, have the students answer the questions in class to prepare to begin moving into undertaking scholarly research:

- What words or phrases in my thesis might need further scholarly definitions?

- What types of statistics might be useful to support my argument?

- What discipline am I writing within? Who are the experts within that discipline? 
- Are there other terms or words that might be useful search terms when looking for scholarly research about my argument? 


\section{Chapter 8: Gathering Research and Establishing Evidence}

\section{For the Instructor}

This would be a perfect time to contact your library to book a session with a librarian. This will give your students an opportunity visit your institution's library and learn about the research process. To prepare for the library visit, disseminate a library research assignment that helps students develop a research question or thesis statement and then create a research strategy using the library databases that will uncover two scholarly sources. Students should also be asked explain how they plan to use the two scholarly sources and cite them using an appropriate citation convention (MLA, APA, Chicago, etc.)

\section{For the Librarian}

The focus of instruction should be the hands-on activity of finding two scholarly articles. To achieve this, it is recommended that you adopt an online/flipped version of research instruction. Putting together an online resource to teach the basic research skills will give the students an opportunity to experiment with search practices in order to find relevant resources using library databases. They will utilize their critical checklist to identify scholarly sources.

In our practice, we developed this example libguide that serves as an online tutorial to be read before coming to the library. During the library visit, we suggest ten or fifteen minutes to quickly go over the online modules. We used the free online quiz game kahoots to review the material. The rest of the class was spent searching for two articles and both the librarian and instructor were available for consultation and assistance.. 


\section{Chapter 9: Towards the Well-Researched Paper}

\section{For the Instructor}

At this point in the course, your students should have chosen the subject matter of their research assignments and started to examine it closely. They should also have started their research. Some of the problems mentioned in the "Instructor" section of Ch. 7 may be more apparent by this point; students may, for instance, be treating the research assignment like a repeat of the close reading (choosing one article and analysing it). It's important to convince students that they can apply the concepts from Part I to the different type of evidence discussed in Part II.

We recommend that you require your students to read the chapter before class and bring to class the threestorey thesis and outline they should have been developing while working through the chapter.

\section{In Class:}

This is a good class in which to workshop the thesis statements and outlines the students have come up with. Students unable or unwilling to see the flaws in their own work will more easily see it in the work of their peers. Group work or class-wide discussion of samples from a few students will allow students to begin revising and refining their thesis statements in light of the evidence they have collected. It will also allow students to recognise thesis statements that lean towards vagueness or summary.

By the end of the class, students should have some idea of the future direction of their research and should have begun the process of refining and developing their thesis statements. 


\section{Chapter ro: Joining the Conversation: Primary Sources, Secondary Sources, and You}

For the Instructor

At this point in the writing process it is a good idea to once again dedicate a class to an essay draft exchange. Similar to the In-Class Midterm Essay Draft Exchange we detail in our "For the Instructor" section in Chapter 5, we identify a "draft" as the research essay-in-process and while we ask our students to put in a solid effort for this exercise, we remind them that among the many benefits of the In-Class Research Essay Draft Exchange is the receiving and implementing of feedback. It is important to remind students that their essays will undergo several changes before they are ready to submit the final product. In our introductory writing courses, we require each student to come to class with at least two typed double-spaced pages of their essay. We ask that each student provide a complete introductory paragraph and at least three complete body paragraphs. Once again, we ask our students to underline the first storey, italicize the second storey, and bold the third storey of the three-storey thesis.

As we did in the previous draft exchange, we put students in groups of three so each student gives and receives two sets of feedback. If time permits, we also like to have each group meet with the instructor for debriefing and additional feedback before they leave the class. We encourage students to write on each other's drafts and we also provide them with a feedback sheet with direct questions about various aspects of the draft:

\section{Introduction/Thesis Statement}

1. Can you identify the writer's thesis? Does the introduction do more than announce the topic? Paraphrase the thesis statement.

2. Does the thesis make a claim that is unique to the subject the author is analyzing? Does the author use general language and terminology that could be applied to almost any essay? If applicable, please identify the generalizing terms or phrases and suggest more (subject)specific alternatives.

3. Is the thesis clear? Do you understand exactly $t$ he sort of reading the author is proposing? Do you have any suggestions to help the author establish his/her thesis? 


\section{Paragraph Structure and Coherence}

1. Does the structure of the essay make sense? Does it flow logically?

2. Are there paragraphs that are repetitive? Is so, which ones?

3. Are there paragraphs that need to be separated and expanded because there is too much material? Which ones?

4. Are there topic sentences that need to be revised or transitions that need to be rewritten? Where? Be sure to share with your partner your editorial suggestions.

\section{The Central Document and Research}

Is the central document defined clearly in the introduction?

Does the author analyze a new aspect if the central document in every paragraph? What are these new aspects? Are these aspects supported through primary evidence?

Does the author stray from his/her analysis of the central document? Does $\mathrm{s} /$ he fall into the five paragraph essay form of touching on several examples? Are there places where $\mathrm{s} /$ he needs to get back on track?

Does the author apply secondary, scholarly sources when analyzing his/her central document? What works? What doesn't?

As before, we require each student to answer each question as thoroughly as possible, making it clear that simple yes/no answers are not acceptable, and we typically make the In-Class Research Essay Draft Exchange an assignment worth $5 \%$ of the term grade. As the topics for the research paper are so varied, this is an excellent learning opportunity or students to distinguish between introducing a topic and analyzing a topic. A student reader unfamiliar with a student writer's chosen central document is situated ideally to provide some useful feedback on what we have discovered to be one of the most challenging aspects of the first-year research paper. Is the author's central document clearly defined? Most importantly, is the author's analysis of the central document clear and constant? Does the author fall into a simple summary of the subject matter? We have found that this peer-to-peer exercise helps students recognize and eliminate those moments where they rely on passive relaying of facts and evidence. Explaining their particular reading to their peers, students simultaneously gain confidence in their arguments and recognize the importance of building their essays around their readings of the subject matter. 


\section{Chapter II: Editing and Evolving the Thesis and Outline}

\section{For the Instructor}

In class, have your students bring in one of the scholarly sources that they think they may use and have them read it again carefully, annotating their reading. This can be done with either a hard copy or an online version. If they are reading an online version, ensure that they are using the annotation settings on their PDF reader to makes notes as they go along.

At the end of the their reading ask them to identify:

3 definitions of key terms the author provides in the work.

3 statistics or number-based evidence the author uses.

2 key quotes that may be useful to their argument.

2 sources from the Bibliography or Works Cited that may also be useful to read.

Once they have completed that checklist, have them imagine where each piece of information might fit within their essay (i.e. where might this definition fit best? At what stage of my argument?). Remind them that they don't have to use all the information they found, but they should at least consider it.

Once they have a rough idea where the information might work, have them write a body paragraph incorporating in one of the pieces of research that adds to and clarifies their argument.

At any point during this process, it may be helpful to have the students share with each other in small groups or pairs. 


\section{Chapter I2: What Have I Accomplished? Conclusion and Final Assessment}

For the Instructor

It may be useful to pair the discussion of conclusions in this chapter with some readings containing strong conclusions. Give such readings to your students, either online or in-class in the weeks leading up to the final day of class. Pointing to one or two examples of what you consider an excellent

conclusion would be very helpful in demonstrating the skill for the students.

\section{In Class:}

It is very likely that this is your last day of class. Students will be submitting their papers and you may be doing Final Exam preparation, if your class has a final exam. It may be helpful to take time, as a class, to reflect on the progress the students have made throughout the semester and have them think more specifically about their writing and writing process. Beginning in pairs, ask them to answer the questions from earlier in this chapter (feeling free, of course, to add your own):

- In what ways do you think you've most improved?

- What do you think is the most important skill to have when writing academically?

- What do you think is the most important skill to have when reading academically?

- What skills are you most likely to carry into writing in your other courses?

- How much time did you spend writing? In what stage of writing did you spend your most time?

- How much time did you spend editing? In what stage of editing did you spend your most time?

- What would you like to work on with your writing going forward?

- What is the one thing you would recommend to a first year university student about writing academically?

While having the students answer these questions on their own and then again in class may seem on the surface a bit redundant, it is useful for students to hear what other students think and feel about their own writing and about academic writing in general. The goal of the in-class asking and answering of these questions is to build upon the solitary thinking the student does by asking those students to listen to and compare themselves to their peers. After giving time to have the students talk in pairs, come back and ask the questions again as a class and have the students share their own experiences in the larger group setting. 


\section{Chapter iz: Works Cited}

\section{For the Instructor}

Before class, prepare a set of citations in MLA and APA that have mistakes in them; also bring in the basic information for four or five articles that will need to be cited. Try to get a variety of sources (a webpage, a journal article etc)

In class have the students get into small groups and "correct" the mistaken citations. You could even make a small game of this, making the groups teams that are competing against each other.

After this, in the same groups, give them the basic information for the four or five articles and have them cite them correctly in MLA and then APA. Again, this could be done as a competition. 
The Control-F List, opens new window

The Ctrl-F is a tool meant to help you identify broad words so that you can choose more specific vocabulary in your revision process. When applying the Ctrl-F list to your thesis, the intent is not to say that you should never use words like "society" or "people," but rather to say that those words are so ambiguous and general that they retain very little value. Instead, you should say what you mean! Instead of "society" or "people," you mean "2017 first year university students in Canada." Hit "ctrl-f" and plug the following words into your essay to see how often you are using them. In particular, look back through your thesis, and essay as a whole, and ensure that you are replacing those broad terms with language that speaks more directly to the author's audience and the complex argument they are making.

\title{
Broad Terms
}

\author{
Internet \\ Technology \\ People \\ Society \\ Government \\ Communication \\ Today \\ Modern \\ Contemporary \\ Media
}

\section{Pronouns}

We

You

Us

\author{
Abstract Terms \\ Self \\ Identity \\ Reality \\ Knowledge \\ Information \\ Real/Fake/Authentic
}


True/False (self)

Social justice/change

\section{Phrases}

X "has changed"

$\mathrm{X}$ "is different"

\section{Listing}

Also

Then 